\title{
198
}



9, Linden $\mathscr{P}_{\text {ark, }}$

Tunbiidge Wells.

With the hind regards of the Author

H.R. Ripe

F. L.Beddard Sop F.R.S. 



EVOLUTION IN THE PAST 




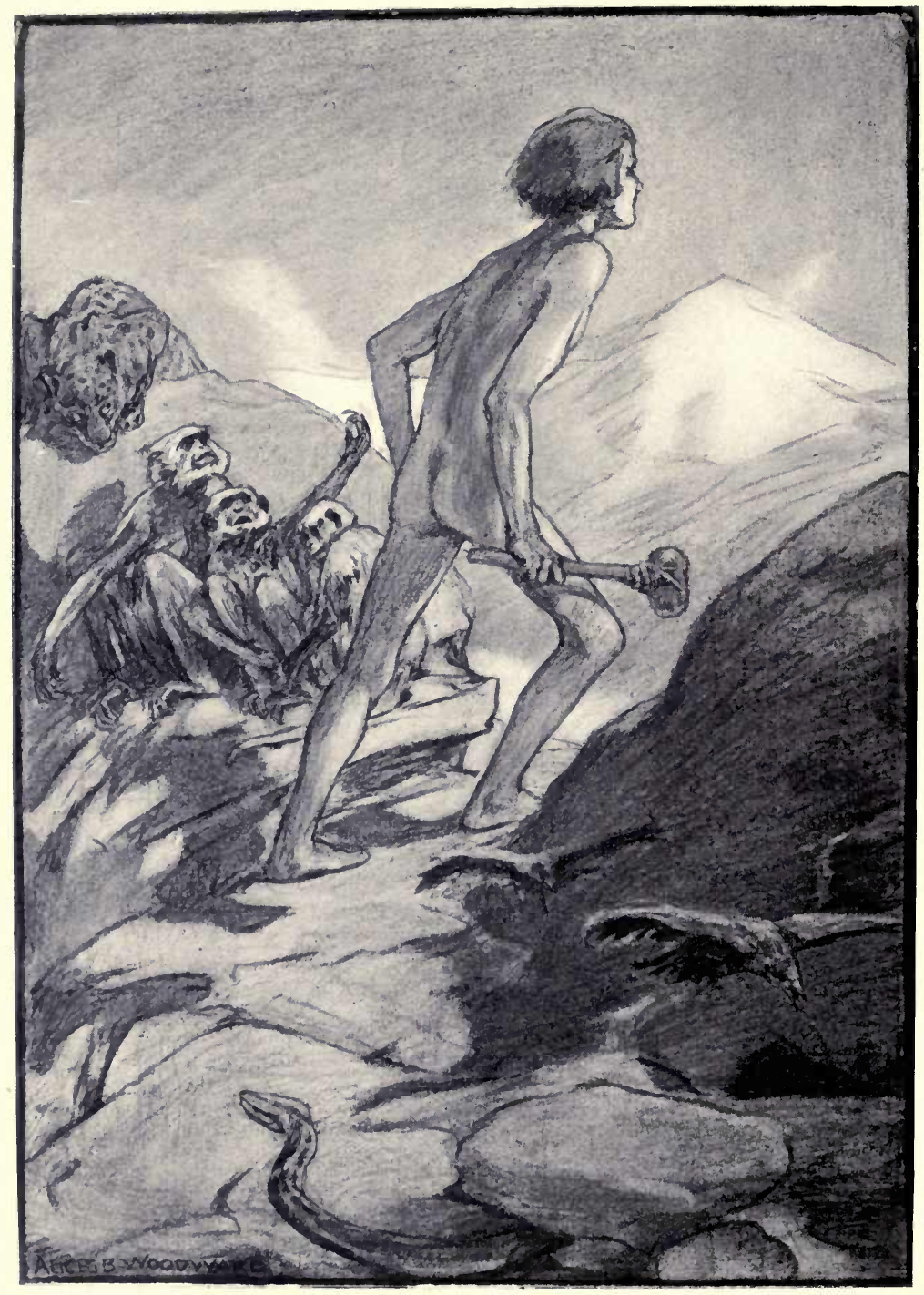

[To face Title-page 


\section{EVOLUTION IN THE PAST}

BY

HENRY R. KNIPE, F.L.S.

AUTHOR OF "NEBULA TO MAN"

WITH ILLUSTRATIONS

BY

ALICE B. WOODWARD AND ERNEST BUCKNALL

LONDON

HERBERT AND DANIEL

2 I MADDOX STREET

W.

I912 


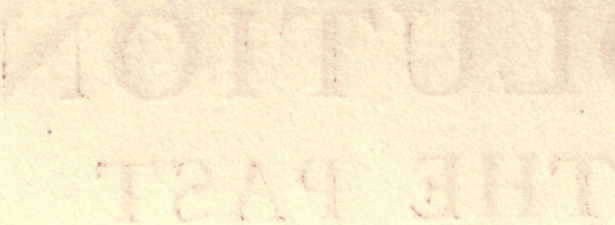




\section{PREFACE}

IN the following pages I have endeavoured to give in nontechnical language, and in some detail, an account of ancient life as now known and understood. The wider and increasing interest in the subject is, no doubt, in part owing to many recent discoveries of important fossil remains. The whole subject, however, became invested with a new interest as soon as it came to be recognised that all modern life has been evolved, step by step, from the life of the past.

The material for bringing ancient life into view is, it must be admitted, still sadly deficient. Much - and of the highest value-has been lost ; but, thanks to the labours of hosts of workers, much has been recovered. Thousands and thousands of extinct species of life-forms are now recorded; and had these not been described and classified, the student might well have been bewildered at their multiplicity.

Fortunately for him such works as Zittel's " Text Book of Palæontology," Nicholson and Lydekker's "Manual of Palæontology," and Arthur Smith Woodward's "Vertebrate Palæontology" have come to his rescue. These books represent a prodigious amount of difficult work conscientiously and ably performed; and they are indispensable to anyone who seeks to tell the story of life through past ages.

I would also acknowledge great assistance received from the various Catalogues and Guide Books dealing with fossil life, which have been issued by the Trustees of the British Museum. These valuable publications are especially helpful to an understanding and appreciation of the vast collections in the Natural History Museum. A full list of the principal 
works which I have consulted, and to which I desire to record my obligations, will be found in the Appendix.

I have sought to enliven these pages by introducing restorations of extinct forms of life. Of the fifty-six plate illustrations fifty-one were especially drawn for this book. The remaining five first appeared in my "Nebula to Man," published in I905.

I acknowledge with gratitude the valuable expert assistance which Miss Alice B. Woodward received at the British Museum (Natural History). Her pictures thus possess a real scientific value in addition to their artistic merit. Dr. Arthur Smith Woodward, F.R.S., Keeper of the Department of Geology, kindly advised on several of the drawings ; and I would especially mention his help in the restorations of early fishes and fish-like life. In regard to that subject I have also to thank Dr. Ramsay Traquair, F.R.S., whose skilful restorations I have been permitted to use. Dr. C. W. Andrews, F.R.s., rendered very great assistance. Indeed, nearly all the restorations of reptiles and mammals drawn by Miss Woodward were made under his able supervision. For this kind help I cannot speak too gratefully. In the restoration of the first known fossil bird (Archcopteryx) and the wingless Cretaceous sea-bird (Hesperornis) Miss Woodward had the highly qualified assistance of Mr. W. P. Pycraft. Dr. F. A. Bather, F.R.S., gave valuable advice on Crinoids, Dr. W. T. Calman on Eurypterus, Mr. G. C. Crick on Belemnites and other invertebrates, Mr. W. D. Lang on Sponges, and Mr. R. B. Newton on some of the shellfishes.

My friend Dr. Henry Woodward, F.R.S., and formerly keeper of the Department of Geology in the British Museum, not only gave advice on some of the restorations, but also kindly read and criticised my typescript. In my final revision I thus had the great advantage of his observations and suggestions.

H. R. KNIPE. 


\section{CONTENTS}

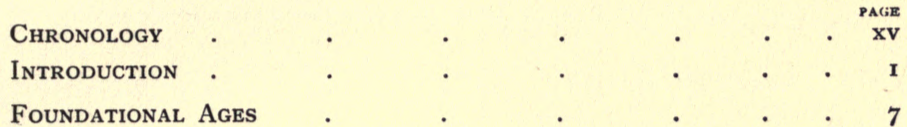

PALAOZOIC AGE

Cambrian Period

Ordovician Period

Silurian Period

Devonian Period

Carboniferous Period

Permian Period

MESOZOIC AGE

Triassic Period

Jurassic Period

Cretaceous Period

\section{CAINOZOIC AGE}

Eocene Period

Oligocene Period

Miocene Period

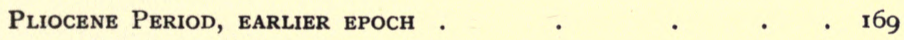

Pliocene Period, later epoch . $\quad . \quad$. $\quad$ i 82

QUATERNARY AGE

Pleistocene Period

Present Period

\section{APPENDIX}

Authorities Consulted . 


\section{ILLUSTRATIONS}

The plates marked with an asterisk appeared in "Nebula to Man.",

Frontispiece . . . . . Alice B. Woodrward

CAMBRIAN PERIOD

MARINe InVertebrate Life . . . Alice B. Woodward ${ }^{\text {Page }}$

ORDOVICIAN PERIOD

MARINe InVertebrate Life . . . Alice B. Woodward 22

SILURIAN PERIOD

Marine Invertebrate Life - . . Alice B. Woodward 34

OSTRACODERMS . . . . . . , , . 36

DEVONIAN PERIOD

Ostracoderms and Arthrodiran Fishes . Alice B. Woodward $3^{8}$

SHARKS AND GANOIDS . . . " , , . 40

CARBONIFEROUS PERIOD

Vegetation . $\quad$. $\quad$. $\quad$. Ernest Bucknall 50

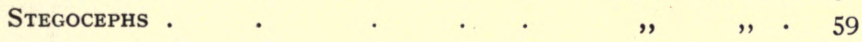

PERMIAN PERIOD

Pareiasaurus and Inostransevia - Alice B. Woodward $6 \mathbf{I}$

EDAPHOSAURUS . . . . . , , , .

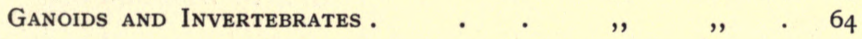

TRIASSIC PERIOD

Vegetation $\quad$ - $\quad$. $\quad$. Ernest Bucknall 70

ICHTHYOSAURS • . . . Alice B. Woodward 79

JURASSIC PERIOD

* Marine Invertebrate Life . . Alice B. Woodward 86

Vegetation $\quad$ - $\quad$. $\quad$. $\quad$. Ernest Bucknall 88 
Diplodocus

Alice B. Woodward go (i)

Stegosaurus

Scelidosaurus

,

, . 90 (ii)

Ceratosaurus

",

" . 92 (i)

METRIORHYNCHUS

Ernest Bucknall

Cryptoclidus and Pliosaurus

Alice B. Woodreard

Flying Lizards

ARChaEOPTERYX

$\begin{array}{llll}\text { " } & \text {, } & \text { • } & 94(\mathrm{ii}) \\ , & \quad, & \text {. } & 96(\mathrm{i}) \\ \text {, } & \quad, & \text {. } & 96(\mathrm{ii})\end{array}$

\section{CRETACEOUS PERIOD}

IGUANODON Alice B. Woodroard 98 (i)

* Polacanthus

Triceratops

* Pteranodon

* Marine Life

HESPERORNIS

\begin{tabular}{|c|c|c|}
\hline ," & , & - \\
\hline ," & ", & - \\
\hline ", & ," & - \\
\hline ", & ", & - \\
\hline ", & , & - \\
\hline
\end{tabular}

EOCENE PERIOD

Phenacodus

- Alice B. Woodward II9

HyRACOTHERIUM

CORYPHODON

MERITHERIUM

Palamastodon

* Arsinoitherium

\begin{tabular}{|c|c|c|}
\hline , & ", & \\
\hline ", & , & . \\
\hline "' & , & . \\
\hline ", & , & 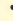 \\
\hline ", & ", & \\
\hline
\end{tabular}

OLIGOCENE PERIOD

Titanotherium

HYRACODON

Hyopotamus

Vegetation

Pliopithecus

Macharodus

Altecamelus

TETRABELODON

HipPaRIoN

Dinotherium

Cervus Sedgwicki

Megatherium
Alice B. Woodward 141

", . 142

, " . 144

Ernest Bucknall ${ }^{152}$

MIOCENE PERIOD

Alice B. Woodward 154

$\begin{array}{llll}", & , & . & 156 \\ ", & , & . & 158 \\ " & , & . & 160\end{array}$

PLIOCENE PERIOD

Alice B. Woodward 169

, , . $17 \mathbf{I}$

, , $\quad 183$

,, , . 185 
ILLUSTRATIONS xiii

\section{PLEISTOCENE PERIOD}

\begin{tabular}{|c|c|c|c|c|c|c|c|c|}
\hline Pithecanthropus & . & - & & . & Alice $B$. & Woodrvar & & $\begin{array}{l}\text { PAGE } \\
187\end{array}$ \\
\hline ELASMOTHERIUM & • & $\theta^{\circ}$ & & - & , & ,' & . & 189 \\
\hline МАммотн & - & • & $\bullet$ & - & , & , & - & I9I \\
\hline HOMO MOUSTERIENSIS & . & . & • & ? & , & ", & - & 196 \\
\hline HIPPIDIUM . & - & - & & - & , & ,", & . & $2 \mathrm{O}_{3}$ \\
\hline DAEDICURUS & - & - & $\cdot$ & - & , & ", & . & 204 \\
\hline MACRAUCHENIA & . & • & • & • & , & , & . & 206 \\
\hline DIPROTODON . & - & . & . & . & , & , & . & 208 \\
\hline
\end{tabular}

TEXT-FIGURES

Monobia (p. 9), Morula (p. 10), Blastosphere (p. 10), Gastrula (p. I I). 



\section{CHRONOLOGY OF THE EARTH}

B.C.

Collision between extinct heavenly bodies, and formation of the Nebula .

Concentrations in the Nebula, and emergence of the

Earth as a molten body

Long Ages of intense heat of the whole Earth

Surface of the Earth so far solidified as to support vast seas

Foundational Ages extending over $70,000,000$ years.

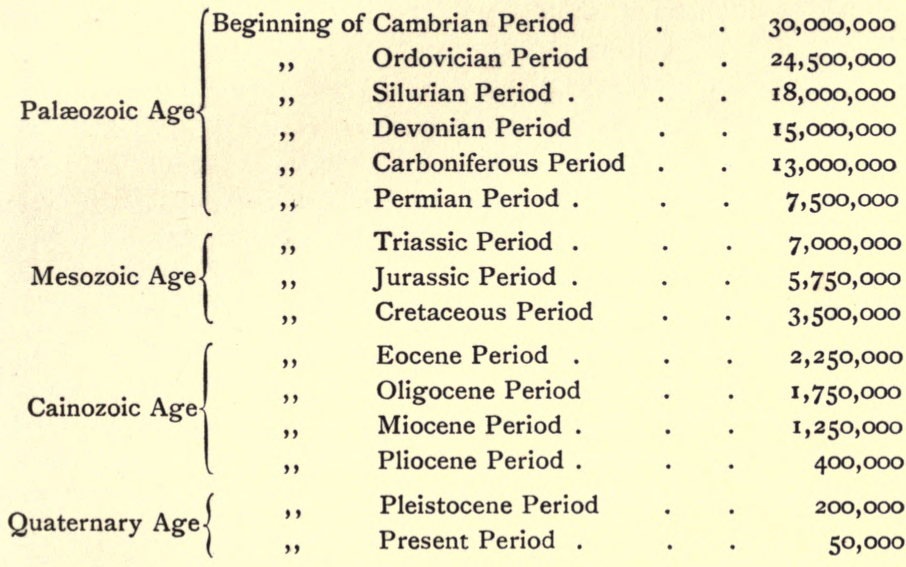

(The estimate of the relative durations of the Periods is founded on the thicknesses of the successive geological strata. All dates are conjectural, and the above duration must be regarded as a minimum.) 


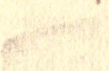

\section{4}




\section{EVOLUTION IN THE PAST}

\section{INTRODUCTION}

THE conditions under which life first became manifest on earth are quite unknown. All attempts to reproduce them have failed; and even if the conditions, or likely conditions, were ascertained, the mystery of life would not be solved. Indeed all phenomena present unfathomable problems, and man in pursuit of knowledge must needs limit the range of his researches. Wide fields, however, still are left him; and in his endeavour to trace the steps by which life, once initiated on earth, attained its present development, he has not been unrewarded.

No one supposes that life, when it first appeared on the globe, presented, as now, a series of graduated forms, ranging from specks of animated matter to human beings. It is felt that life-forms of simple type must have come first; and that these were followed in orderly sequence by organisms becoming less and less simple, until in time forms of high and of ever-increasing complexity appeared.

The doctrine of Evolution that the higher organisms have been evolved step by step from lower organisms is now generally accepted. The thought that life had developed in some such continuous and connected manner dawned on the mind of man centuries ago; and Aristotle, Lucretius, and other ancient writers gave vague expression to it. In recent times Goethe, Erasmus Darwin, and Lamarck all believed in Evolution, and enunciated clear ideas on the subject. They had, however, no convincing evidence to offer. This, as the result of long and patient observation, was supplied by 
Charles Darwin, and he will ever be remembered as having first placed the doctrine of Evolution on a sound basis.

The Evolution doctrine receives strong support from facts ascertained in the study of embryos. Organisms in their embryonic condition pass through stages in which they resemble the young of animals lower in the scale of life. A rabbit, for instance, in its immature condition passes through a stage in which it resembles a young reptile. Rudimentary organs also make a transitory appearance. Gill-clefts, for instance, appear in the embryonic history of all the higher animals. This takes the latter at least as far back as amphibians. And amphibians in their embryonic growth pass through stages in which they resemble fishes. These embryonic phases are only explainable on the hypothesis that, in the origination of higher animals, lower animals took a direct ancestral part.

The doctrine of Evolution is also supported by evidence brought to light from the geological strata. Innumerable fossils have been found testifying to successive developments undergone by life in the course of past ages. Evidence of this direct nature-incomplete though it is-is of the greatest help. The sequence of life thus revealed is quite in accordance with an evolutionary process - the lower forms preceding the higher. And remains of numerous animals are found combining features that became distributed in later forms. Phenacodus of the Eocene, for instance, was more or less closely related to deer, pigs, tapirs, horses, and carnivores. Then remains of toothed birds with long lizard-like tails have been exhumed (Archaopteryx), showing that early bird life retained some very remarkable affinities with reptiles. Pedigrees of particular animal forms have also been recovered. The ancestral history of elephants, for instance, would be a matter for speculation but for fossil evidence.

Existing life also makes important contributions. In the light of comparative anatomy creation is certainly more suggestive of an organic whole than of an assemblage of independently formed types. Small organisms are found that cannot be classed satisfactorily either as plants or as 
animals (e.g. Volvox). Plants are divided into Cryptogams and Phanerogams; but the latter retain characters pointing to their descent from the former ; and all recent study tends to bring the two groups very closely together. The various classes of Invertebrates present connecting links. Many forms, for instance, of very different outward appearancecrustaceans, spiders, scorpions, etc.-point to a remote common ancestry, the members of which must have resembled ringed worms. Then there are animals that cannot properly be classed either as vertebrates or invertebrates (e.g. Balanoglossus), and these show affinities with the fishlike Lancelet, the lowest vertebrate now in existence. Fishesespecially lung fishes-show affinities with amphibians; whilst amphibians are closely related to the lizard-like reptile known as Sphenodon. Birds retain several reptilian features in their anatomy-some peculiarly so (Opisthocomus cristatus, Palamedea cornuta). And the lowest forms of mammals (Monotremes) reveal in their ribs and other parts of their structure reptilian features not found in animals of higher grade.

Thanks to Charles Darwin, Russel Wallace, Huxley, Spencer, Haeckel, Weismann, Cope, and other hard workers in the fields of Biology, the doctrine that higher life-forms have been evolved from lower may now be said to have passed out of the region of controversy. It must, however, be admitted that many subsidiary problems of descent and inter-relationship remain as yet unsolved.

All forms of life, therefore, that now abound may be regarded as having come down, through inconceivably long vistas of time, from an ancestry of minute one-celled organisms, possessing a power to vary. At some very remote period this innate power became manifest in two distinct directions by the appearance of minute plants and minute animals. From these humble divergent forms, through innumerable variations in the past, the whole of existing plant and animal life has gradually obtained its present condition of development. The power to vary possessed by the earliest organisms must have been enormous. How they came to be thus endowed is beyond the reach of knowledge. 
Inter-struggle in localities of congestion, temperature, chemical action, and other forces of environment undoubtedly prompted the putting forth of variations, but they cannot have produced the power to vary.

The course of evolution is hard to realise. The difficulty, however, is lessened by bearing some facts in mind. The cell is the unit of life ; every organism of whatever degree begins its existence as a single minute cell; and all life-forms above the lowest are cells in combination. All organisms, therefore-from the highest to the lowest-are in a sense intimately related.

In the vast majority of cases the initial variations that led to new forms were probably extremely slight. Organisms remained much the same as their parents. Important changes, however, came to be chronicled when small variations of a useful kind had been accumulated and intensified through a series of generations. That, at least, is the view that Charles Darwin propounded; and it has been accepted by most evolutionists.

From researches-chiefly botanical-pursued in recent years by Hugo de Vries and W. Bateson, it has been claimed that variations not infrequently are of a pronounced character. It is also claimed-on somewhat fragile evidence-that that is the usual method whereby new species appear. For such substantial changes suddenly effected the name of "mutations," also of "explosions" (Depéret), has been given. There is certainly evidence that developments of this character take place; and the fact was admitted by Charles Darwin, and other evolutionists of the time. It was, however-and still is-urged that such phenomena very seldom occur; and that they are in fact sports and monstrosities that cannot be perpetuated in wild Nature. Nor has this view been proved to be incorrect, although Mendel's discoveries show that in domesticated Nature, mutations, repressed in one generation, reappear in another.

Although not quite in line with a portion of Darwinism, the Mutation Theory, of course, does not affect the general doctrine of Evolution. Should it ever be established-and it 
is as yet far from that-Evolution would be proved a somewhat less tardy process than Darwin supposed.

Whatever be the rate at which Evolution proceeds, it is quite clear that all structural changes, except of the most trivial description, have sooner or later to submit to a severe test. To this testing process Darwin gave the name of Natural Selection. "Survival of the Fittest "- suggested by Herbert Spencer-has the same meaning.

That Natural Selection applies and must always have applied to all forms of life was first recognised by Darwin and Wallace. More organisms may be said to desire to live on earth and to multiply than can be accommodated ; and which shall survive must be determined by a principle of selection. In the inevitable struggle, all those forms which become the better adapted to meet the difficulties and dangers that surround them are the more likely to survive and leave posterity. The fittest, in short, are selected by Nature for preservation, and all advantageous variations in development receive encouragement. In this way forms of life are slowly reconstructed, reshaped, and recoloured; and in course of time they become so changed as to present a very different appearance from that of their remote ancestors. Natural Selection, therefore, in a sense, may be said to originate species.

This selective system-involving as it does a real progressdoes not imply that organisms of inferior rank necessarily cease to prosper as forms of higher rank are evolved. Organisms low down in the scale have proved well able to contend with their conditions, whilst many superior forms have failed, and disappeared without leaving descendants. Small shrimp-like creatures that lived in Cambrian seas are still represented by unmodified forms generically known as Nebalia. Those little creatures, therefore, are seen in their watery haunts to-day, reflected, as it were, from a remote past. Certain lampshells also give us living pictures of times long gone (Lingula). Moreover, minute one-celled organisms are still through sea and land in their millions, and billions, and myriads of them are probably not very different from the forms in being when the world was young. Whilst humble life-forms have thus continued their annals, 
stegocephs, dinosaurs, plesiosaurs, toxodonts, amblypods, and other animals of high organisation have come and gone.

The following pages are mainly occupied with an attempt to give a sketch of life, founded on discoveries made in the geological strata. The record is certainly defective, but there is the consolation of knowing that we are face to face with facts. 


\section{FOUNDATIONAL AGES}

AcCoRDING to the Nebular Hypothesis the solar system was evolved from a vast gaseous mist or nebula. This rarefied and intensely heated matter was the outcome, it is supposed, of a collision between extinct suns or other once-luminous bodies. In course of time, owing to loss of heat by radiation, concentrations took place in various parts of the vapour. And the Earth and other planets gradually emerged as molten bodies moving round a great central concentrationthe forming sun.

As the result of radiation our planet in time became so far deprived of heat as to gain a superficial crust or covering. The heat of the crust, however, must for long have continued so intense as to be beyond the reach of any rainfall from the primitive atmosphere.

Owing to continued fall in temperature the crust must have increased in solidness. And a time came when the lower levels of the cooled and crumpled surface became the restingplaces of long-pent-up rains, no longer repulsed by an excessive heat. The Earth had its sea and land.

The heat of both elements was for a long time probably too intense for life, as man understands it, to become manifest ; but to what point temperature had fallen when the first forms of life appeared, is quite unknown. In this connection, however, it is a matter of interest that plants have been discovered living in thermal springs of a temperature of I $70^{\circ} \mathrm{Fahr}$, and in heat of $260^{\circ} \mathrm{Fahr}$. some spores have been found to retain vitality.

Of the earliest life-forms nothing, of course, is known. They probably originated in the shallow waters of the primeval seas; and may well have been excessively minute. Indeed 
if similar forms are now in existence no microscope, however powerful, would be likely to reveal them. Food must have consisted of simple chemical compounds; and there is no reason to think that the organisms disclosed any characteristics, stamping them either as plants or animals. They may. rather be thought of as a highly generalised stock from which plants and animals were in course of time to be evolved. The condition of things was Utopian;-peace abounded and equality.

Very long times may have elapsed before this primitive condition of things became varied by the emergence of definite life-forms. Probably the earliest organisms of distinct character were minute one-celled plants, possessing no defined root, stem, or leaf. Here was the foundation laid of the Kingdom of Plants.

In course of time another divergence from the vague primeval stock took place; and minute animals, one-celled and shapeless, made their appearance. These probably moved about the shallows without the aid of any definite locomotive appliances, and subsisted chiefly on their vegetal cousins. The foundation of the Kingdom of Animals was laid ; but Utopia was gone.

From the primitive plant-stock, it may be supposed, minute one-celled growths of a mixed algæ and fungus description in course of time made their appearance. Whilst the minute animals doubtless became varied chiefly by more active forms aided in locomotion by tiny thread-like outshoots of the cell.

All plants and animals, no doubt, for long consisted merely of one-celled organisms. Food could be taken in, and waste expelled at any part of the surface; and multiplication was effected by the cell splitting in two, and each portion becoming a complete self-sufficing cell. Such forms of life, indeed, still exist in great abundance.

Life on earth could clearly make no great advance towards its destined future so long as all organisms remained in a unicellular condition. It may be assumed, therefore, that in course of time cases occurred in which the two portions of the dividing cell did not become completely separated from one another. And these two-celled forms, by continued multi- 
plication and the holding together of successive generations, led to the formation of cell colonies or confederations. The foundation of co-operation was thus laid. But although the principle of union was in evidence, there is no reason to suppose that any cells, excepting as regards free individual locomotion, underwent any important change. Each cell probably continued self-sufficing and carried on life much as before. Loose confederations of this character are still in existence (e.g. Monobia confluens).

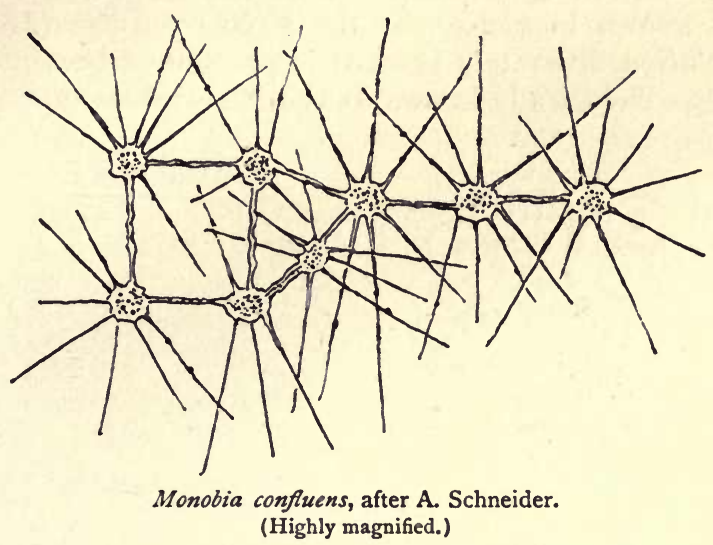

In course of time some of the colonies no doubt underwent various changes of form, and some of them came to present a ball-shaped appearance. But whatever their outward aspect they must all have had to face the population question. Cells were multiplying fast, and difficulties must have arisen from want of organisation among the more or less independent units. Resort, no doubt, was made to various expedients. In the case of some colonies the problem was doubtless solved by secession of cells from the union and the founding of new colonies. If this had been the only way open, further progress in life would have been indefinitely postponed, if not actually imperilled. In the case of some of the ball-shaped colonies, however, it may be assumed that the cells continued to hold together; and the power to vary was put to higher tests. 
From this point the development of animal life can be more closely followed than that of plant life. Each cell having to support itself, the cells in a ball-shaped colony must have striven to occupy and retain a surface position so as to be in contact with the outer world. As cell multiplication increased, the struggle for outside accommodation must have become: intense, and the cells whose fate it was to lie inside must have perished and polluted the colony unless an improved economy could be effected.

Then came the great effort to deal with this congested condition, known in biology as the Mulberry stage (Morula). The solution ultimately reached is probably represented by the stage biologically known as the Blatosphere or Bud-like:

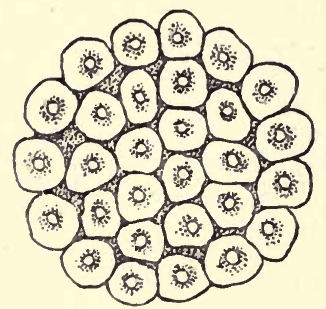

Morula Stage.

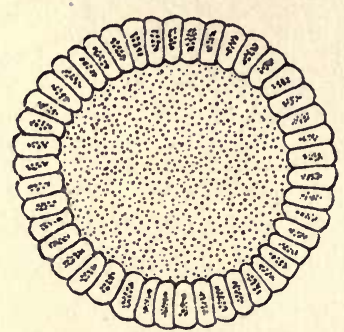

Blastophere (in section).

(Highly magnified.)

stage. Taking this as a guide, the inner cells, by some unknown process, were forced up to the surface, and the vacated interior became filled with water. The colony had. now become a small ball-shaped mass overspread with a. single layer of cells.

To what extent this outward-forcing process could be carried cannot be determined. But rapid cell-multiplication, no doubt, brought difficulties; and in some of the colonies. a solution was found of higher character than mere outward. expansion. Not only a physical but a psychical change was impending. The individual cells or units of the colony had: not as yet shown a disposition to a truly united life. There was no division of labour ; and " each cell for itself " was, soto speak, the motto of the colony. A new modus vivendi of a most startling description was now to be evolved. The 
theory of it was nothing less than the gradual breaking up of individual self-sufficiency, and forcing the cells to work more or less with one another for the common weal of the colony as a whole. In other words, particular functions were to be assigned to particular cells ; labour was to be divided;
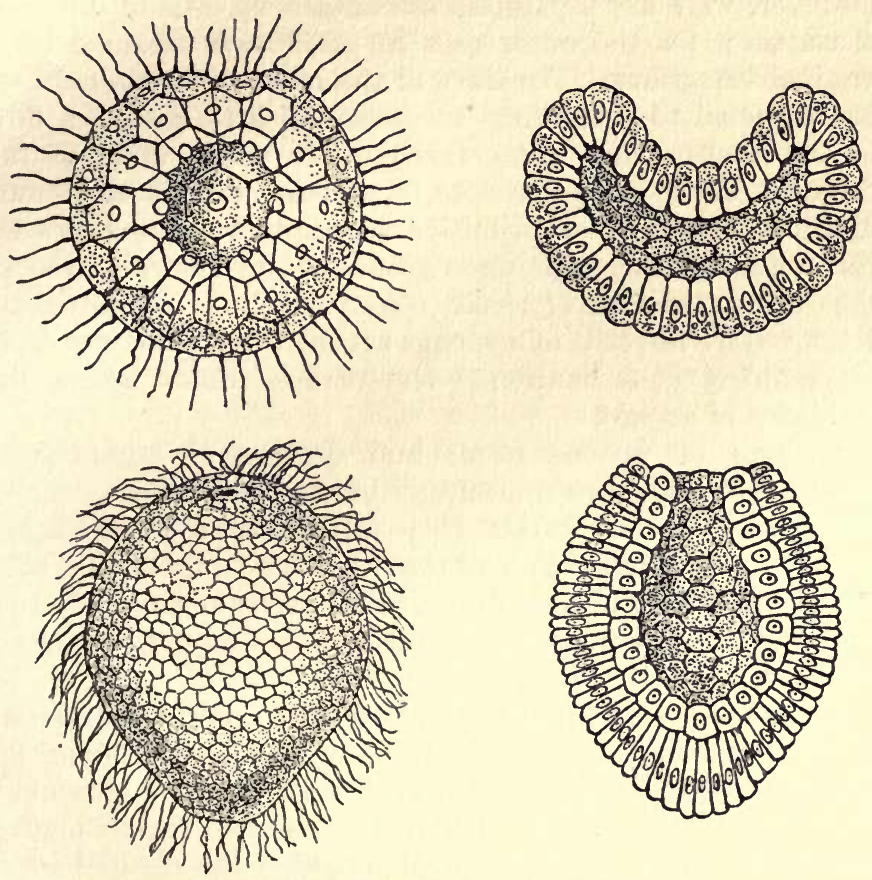

Gastrula Stage (highly magnified).

The figures to the right are in section.

egoism (for a time) was to make way for altruism;-an interesting datum in primitive ethics.

The first attempt to this higher life was probably made amongst colonies from which, in course of time, Sponges were evolved. At one point in the colony certain cells gradually lost their versatile powers and were more or less drawn into the interior. As the result of continued indrawal, a tube or cavity was formed, and the colony thus came to 
consist of an outer and inner layer of cells (Gastrula stage). Some division of labour was impending and in time became evident. The outer cells gradually took up as their duties matters of protection, reproduction, and arranging lines of communication with the interior. These several labours, however, were not separately discharged by cells of different character; for the outer cells in great part retained their original versatility. The duty of the inner cells was more or less confined to promoting, by means of little lashes, a flow of the food-bearing water through the whole body of the colony. There was, therefore, a certain amount of labourdivision, although of primitive description. As, however, there was no thorough differentiation and co-ordination of the cells, the transformed colony lacked individuality. Even to-day the cells of a sponge are far from being in a state of complete co-ordination. The porous edifice is not the residence of an ego.

Sponges of various forms and degrees of organisation must have made their appearance before the Cambrian times. Very early in their career they settled down to sedentary lives ; and it is not supposed that they led to the appearance of any life-forms of higher grade. This line of animal evolution - savouring somewhat of the vegetable-was not, therefore, momentous.

Sprung from the same stock as sponges, and for a time, no doubt, retaining close affinities with them, other organisms slowly appeared. These transformed colonies gradually developed into hydras, jellyfishes, corals, sea-anemones, and allied forms. These animals enjoyed the distinction of possessing a mouth, opening into a cavity in which digestion was carried on. This cavity had also duties to discharge relating to circulation. Nerves-unknown to Sponges-were in a primitive stage of evolution; and certain cells became transformed for stinging purposes. The various cells were, no doubt, so far co-ordinated as to constitute an individuality. Altruism, therefore, had resulted in a bigger ego.

The animals never gained the distinction of possessing either heads or hearts. Becoming more or less sedentary in habit, they developed roundness of structure - the best 
symmetry with which quiescent life can confront conditions. Their stings were probably the organs that first raised, in an acute form, the puzzling problem of pain.

From the primeval colonies which, on separate lines of evolution, had given rise to sponges, and to stinging animals, another line was struck destined to lead to far more important results. This departure was evidenced by creatures which, in those remote times, are best classed under the comprehensive appellation of Worms. As the result more or less of boring into the mud and sands of the shallows, the bodies of these animals became elongated and two-sided. And although most forms, no doubt, were of a plump and stumpy aspect, they presented a very different appearance from the sedentary and rounded stinging animals. As regards, however, internal organisation, some of them were probably not greatly in advance of the latter. In course of time several internal changes were effected. The channel used at one end as a mouth became a complete thoroughfare through the length of the body; whilst the original stomach-like chamber was rendered more complex by the formation of a second enclosed space (colum). In this new apartment some of the labours of the old cavity were carried on, and other functions were also undertaken. Division of labour-a cardinal feature of progress-was therefore carried farther.

Some of these more advanced worms were probably expert swimmers; but at one period certain of them adopted sedentary habits. In course of time their descendants became so sedate that the lower part of the body became fixed in the ground. Brought to this condition, they developed outwardly a five-sided and more or less radial symmetry. These animals formed the parent-stock of the spiny-skinned creatures (Echinoderms); and a certain amount of free existence was in course of time recovered. Cystids, sea-lilies, sea-urchins, starfishes, brittle-stars, and sea-cucumbers were the outcome of this line of Evolution.

Meanwhile other of the worms pursued another evolutionary course. A well-marked head was developed, a thick muscular surface was formed on the under-part of the body, and the scattered nerves underwent a considerable amount of concen- 
tration. These animals, it is supposed, gave rise to primitive molluscs ; and in course of time sea-snails, mussels, nautiluses, and allied forms made their appearance. These, however, were the only fruits on this branch of evolution.

Certain of the worms, however, developed more in accordance with primitive promise. The nerves became concentrated in the head region; a brain was gradually formed, and real intelligence dawned in animal life. In some forms-long sensitive to light only-eyes were slowly evolved. And these animals were probably the first inhabitants of earth to see anything of their surroundings.

In course of time some of the worms, in correspondence with internal modifications, became ringed or segmented (Annelids); and lateral outgrowths were developed for plodding about the shallows. In ringed worms of marine habits, worm-life reached its highest level of development. The head, it would seem, is a more ancient institution than the heart, for worms never developed what can be called " a seat" for their affections.

Ringed worms played a great part in Evolution, for it was from their ranks that important divergences took place. One line of evolution led to brachiopods or lampshells, and polyzoans ; another to an arthropod stock, which in course of time branched out into a variety of forms (trilobites, kingcrabs, shrimps, scorpions, etc.). The pioneers of the several departures were, no doubt, very small animals of their kind.

How far life advanced in the course of the Foundational Ages cannot be definitely ascertained. But from scanty preCambrian remains, and from the known life of the Cambrian, it may be inferred that invertebrates were represented in all main departments before that Period commenced. Fishes must certainly have had remote ancestors in pre-Cambrian seas, but the ancestral forms are quite unknown. For a long time they probably bore close resemblance to the unsegmented worms well on the road to the evolution of the spiny-skinned animals (Echinoderms).

In the absence of reliable evidence until much later times it is difficult to speak of the progress of vegetation in the Foundational Ages. But on its humbler plane it no doubt 
pursued an evolution similar in character to that of primeval animals. One-celled self-sufficing little plants multiplied by splitting into two. Then in some cases the portions of a divided cell remained more or less in connection, and aggregates of self-sufficing cells were formed. Then came the spirit of altruism : cells lost their versatility, and passed into various combinations severally charged with distinct and special duties for the benefit of the plant colony as a whole. And under this higher system, roots, stems, and leaves were gradually evolved.

Long before the Cambrian times, the minute one-celled growths of mixed fungus and algæ description, had given rise, no doubt, on two separate lines of evolution, to funguses and algæ. From the fungus line it is not supposed that any plants were derived of higher type than funguses. That excursion, therefore, from the primitive fold was not more productive in its way than the Sponge line of evolution in the animal world.

The minute algæ had a momentous part to play. In course of time some of them developed into seaweeds of various kinds ; others, spreading to fresh water, gave rise in time to land-plants. Some of these in the Foundational Ages may well have reached an organisation not far short of that of liverworts. Indeed, from some such stock, some small growths with mixed affinities to ferns, "horsetails," and club-mosses may already have arisen.

But whatever were the levels reached by Evolution, there is no doubt that life, first manifested on Earth as mere specks of animated matter, made great advances in the course of the long-lasting Foundational Ages. The Cambrian world, therefore, meets us, not as a sudden creation, but as the outcome of millions of years of ceaseless evolution. 


\section{PALAOZOIC AGE}

\section{CAMBRIAN PERIOD}

THE seas in Cambrian times, no doubt, spread far more extensively than now; but probably only the shallows and moderate depths were as yet the haunts of marine life.

Tiny one-celled plants and animals must have abounded in the waters. As to this, however, it is not likely that proof, except of a meagre description, will ever be forthcoming. PROTOzOANS The evidence as to seaweeds is extremely doubtful; but remains of some minute one-celled animals, that had for purposes of protection secreted particles of hard substance, have been brought to light. Some of these microscopic creatures were foraminifers or "aperture-bearers"-the name having reference to perforations in the body-covering, affording outlet for fine threads used in locomotion, and as food-collectors (Cristellaria). Others - sphere-shaped creatures-with minute flinty skeletons were probably radiolarians (Spharoidea).

SPONGES Sponges were in the seas, and in some variety. Certain transformed cells, it is clear, had long been at work in the flabby objects for the purpose of providing hard internal supports. Flinty material had been collected, and worked up into needles or spicules from the various centres of secretion. These structures, according to the canal system of the sponge, took various shapes. Originally they developed, no doubt, as tiny rods; but, in course of time, by throwing out crossrays, they became four-rayed and six-rayed. Sponges, thus fortified, were certainly living in the Cambrian (Protospongia, Archaoscyphia). Two well-known existing groups of Sponges were, therefore, already in being (Hexactinellids, Tetracti- 
nellids). The work, however, had not ended in spicule-making. In some cases the spicules were artistically joined together, forming a beautifully outlined framework. The builders were, therefore, artists as well as artisans.

Jelly-fishes have left impressions of their flimsy shapes (Medusites). Corals were in the waters, and were widely coRALs distributed (Archceocyathus); but no reef-builders had yet made their appearance. Some forms, however, allied to corals were living in more or less large colonies (Cladophora). The CLADOPHORA majority of these communities were rooted to the ground on a stem, and the zooids or individuals were borne on one side (only) of numerous branches and branchlets (Bryograptus). Other colonies enjoyed a somewhat free existence, and floated about attached by threads to seaweeds (Dictyonema). The zooid-communities of our own time, known as "sea-firs" (Sertularians), retain close affinities with these ancient colonies.

Little bud-shaped animals, rooted in the sea-floor, were cystiDs numerous. The box or cista which contained their vitals was protected by tiny plates rudely arranged, and rendered prickly by a deposit of lime. These little creatures-known as cystids-were not, as a rule, provided with arms (Protocystis, Stromacystis), and were therefore short of the facilities for obtaining food which later cystids generally possessed. Cystids, no doubt, dated far back into the Foundational Ages; for a few closely allied but more highly organised forms, known as crinoids or "sea-lilies," were living in SEA-LILIES Cambrian seas (Palceocrinus). The "spiny-skinned" stock was also represented on another line of evolution. Star- STARFISHES fishes were a fruit of this departure (Palesterina). For long periods during the Foundational Ages starfishes were probably -like their cousins the cystids and " sea-lilies "-fixed to the ground; but by a gradual wasting away of their stalks emancipation was in course of time obtained. The arms or rays of the Cambrian starfishes do not appear to have been so sharply defined as in later forms; and the animals, no doubt, had other peculiar features. So far as is known no animals in Cambrian seas had become so far developed as to be describable as sea-urchins (echinoids); but sea-cucumbers (holothurians) were probably in existence (Eldonia). 
worms Worms, no doubt, were abundant; but there is little evidence of their existence beyond the marks of their trails and burrowings.

LAMPSHELIS Among the most flourishing animals were the brachiopods or lampshells. These creatures were enclosed in two-valved shells, more or less lamp-like in outline. Some of them lived almost buried in the sand (Lingula), and their line has lasted till now. The majority, no doubt, passed their lives clinging to rocks by means of a muscular stalk protruded through the shell-valves. Brachiopods may have been the first animals to possess the semblance of a heart. At some period in their career their heads-except the mouth-certainly disappeared. In a rock-clinging existence, an improved circulation, it may be supposed, was a greater boon than a head-piece.

The shells of the brachiopods were in different stages of evolution. In the simplest forms the valves were not furnished with a hinge (Paterina, Obolella). Neither was there a special opening for the protrusion of the stalk; and for its outlet, therefore, the valves must always have been gaped to a certain extent. Other brachiopods were more securely ensconced, as there was a special aperture through which the stalk was protruded (Discinolepis, Kutorgina). The shellvalves, moreover, of these animals could be opened and closed with far greater precision owing to the presence of a hinge, regulated by teeth and sockets. This mechanical contrivance - the earliest known piece of machinery in Nature-enabled the animals to offer a very firm resistance to would-be intruders.

BIVALVED The rocks were also the abiding-places of some forms of MOLLUSCs bivalved molluscs-primitive mussels and arkshells (Modioloides, Glyptarca). Here also were hard-clinging univalves,

UNIVALVED MOLLUSCS

CEPHALOPODS shelled like modern limpets (Scenella). Other gastropods, some in ramshorn shells, some in shells of periwinkle shape, crawled about the shallows (Raphistoma, Holopea). Freeswimming forms glided through the waters, but their shells were not of the pattern of any "winged" snails now living (Hyolithes). Cephalopods related to the Nautilus were also on the scene. Their shells, however, in being either straight or but slightly curved, were very different from the tightly 

Jelly fishes

Hyolithes (Swimming

Hymeno-

Lampshells (Obolella)

Orthoceras (Paradox-
ides)
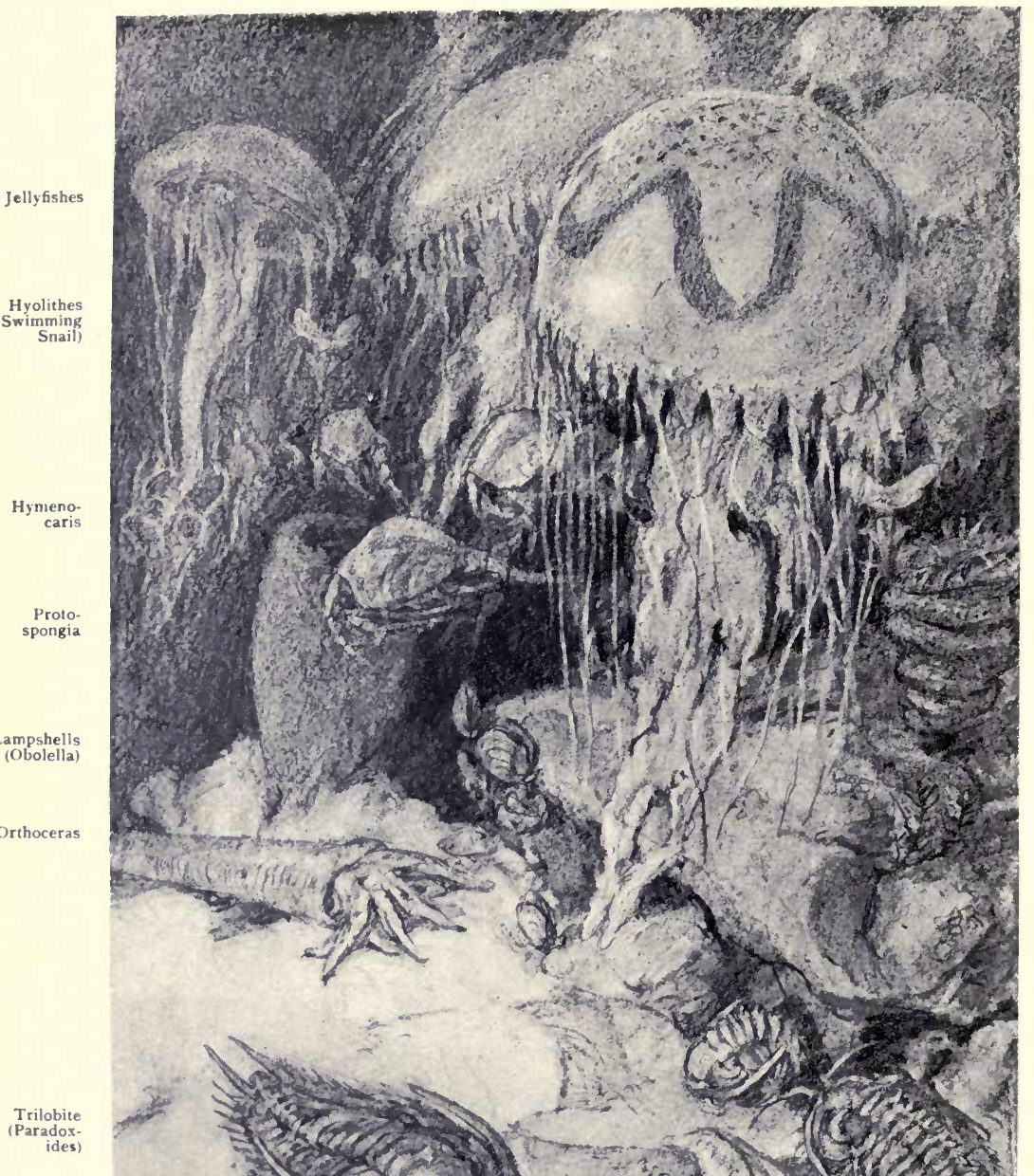

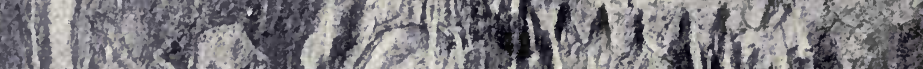

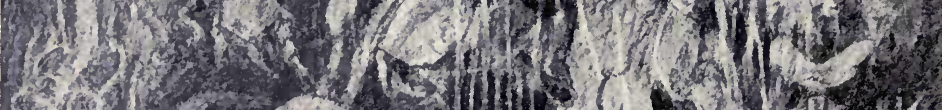

\section{a. 101}
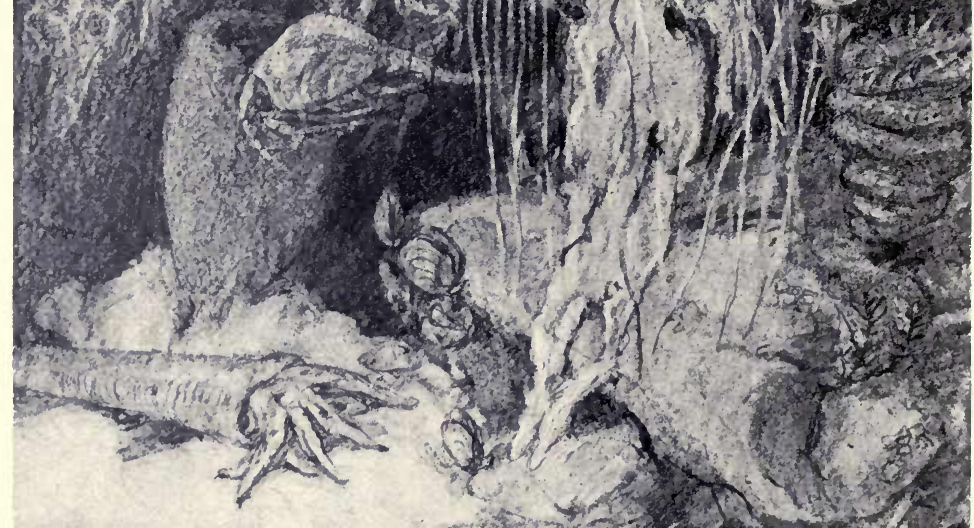

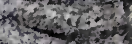
ffing $3 x^{4}+2 x+5$

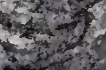

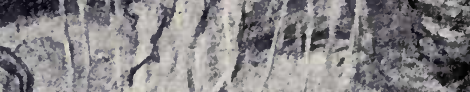

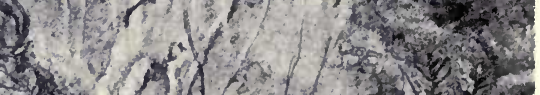
xis $x_{2}+2,10$

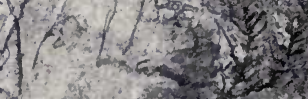

Bryograp-

Coral

cyathus)

tus

Trilobite (Olenellus)

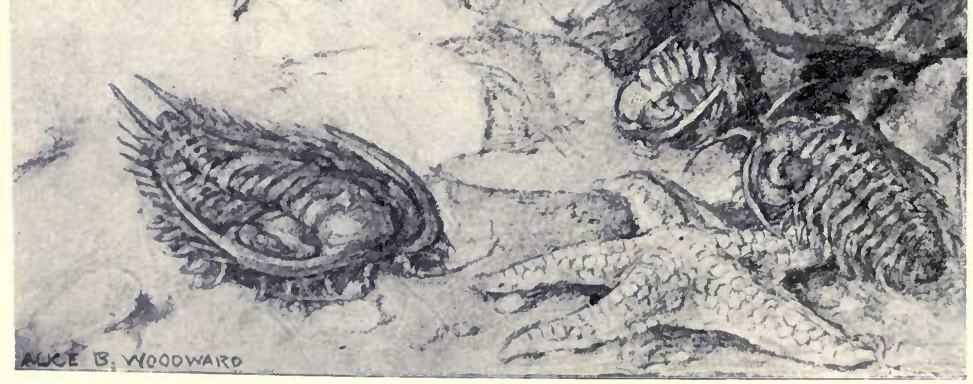


coiled encasements of their now living relations (Orthoceras, Cyrtoceras).

Exceedingly numerous and widespread were trilobites- TRILOBITES crusted animals with the body-covering segmented, and thrice-ridged from head to tail. They lived more or less in large companies in muddy waters, and were apparently the first animals to live gregariously. They varied greatly in size; the smallest being but as grains of sand; whilst the biggest were broad-shouldered, and measured as much as eighteen inches in length (Olenellus, Paradoxides). Some were endowed with eyesight; but many, having taken to a life beneath the mud, had become blind. A few forms appear to have been able to roll themselves up in woodlice fashion.

Small kindred forms were well shielded on the anterior PRIMrTIVE part of the body, and possessed spike-like tails (Aglaspis). In development they appear to have been intermediate between trilobites and king-crabs, and gave promise, therefore, of a new group of animals. Some small scorpion-like forms (Eurypterids) were also in the waters (Redlichia, SEAStrabops).

Species of ostracods were to be seen (Primitia, Entomidella), and primitive barnacles. Small phyllopods were also abroad, resembling the modern Apus-a relation of water-fleas.

Yet other crustaceans were long-tailed and shrimp-like in appearance, with the fore part of the body enclosed in a bent hood-like carapace (Hymenocaris). These little creatures had, no doubt, descended from the same stock as the phyllopods; and they were probably ancestral forms of the higher crustaceans of later times. Of animals now living the small shrimplike Nebalia retains the closest affinities with them, and may, therefore, be regarded as one of the "old blood " of marine society. Some allied forms had pod-shaped carapaces; and have, therefore, been termed pod-shrimps (Caryocaris).

Marine invertebrate life was, therefore, well represented in the Cambrian; but, in spite of a never-ceasing Evolution, the times were not exciting. Animals for the most part lived either buried in the mud, or rooted to the ground, or clinging in close-drawn shells to briny rocks. Such as indulged in locomotion moved about in most cases very slowly.

\section{SCORPIONS}

OSTRACODS BARNACLES PHYLIOPODS SHRIMP-LIKE FORMS 
Hearts were scarcely formed. In many groups there were no separate sexes. Brains were rare, and headless life abounded. Indeed, so far as evidence goes, the little shrimp-like forms and the winged snails alone relieved the prevailing inertia.

LAND LIFE The rocks tell nothing of life on land, and, so far as is known, it breathed as yet only in the waters. But there can be little doubt that a humble land-vegetation was in process of development. Some forms of algæ from salt and fresh waters may well have crept over the land, and even found their way to far up-country scenes. Indeed, funguses, liverworts, and even club-mosses and "horsetails" of primitive character, may have flourished far and wide; for, to judge by the plants of subsequent Periods, many steps must have been taken before the close of the Cambrian in the evolution of a land-vegetation. Possibly the land air was still unfit for animal breathing; but the carbon-absorptions of plant-life were slowly rendering it less choking and oppressive.

Long gone though be the Cambrian world, its scenery is not wholly past recall. There can have been nothing peculiar in the appearance of the sea; for, however much its inhabitants have changed, the general aspect of its waters must have been the same as now. Nor can the landscapes have been very different from scenes still to be found in many regions of the Earth;-vast ranges of mountains, active volcanoes, wide rivers rushing along laden with sediments; and hill-sides, valleys, and plains scantily clothed with a flowerless vegetation.

The air, no doubt, was excessively humid; and thick mists must have been frequent over land and sea. As regards life it was a world of silence; for the stillness was broken only by tempests, volcanic eruptions, and other disquietudes. of inanimate Nature. 


\section{PALAOZOIC AGE}

\section{ORDOVICIAN PERIOD}

LIFE in Ordovician times exhibited many developments, but none of a sensational character. Remains have been found of seaweeds in part lime-hardened, as is the case with Coralline seaweeds of our own time (Solenopora, Rhabdoporella), and giant forms of Laminaria were also in existence.

Sponges were extending their range (Protospongia fenestrata, etc.), and were larger, as a rule, and more graceful than their Cambrian ancestors. Corals, simple (Streptelasma) and compound (Columnaria, Cyathophyllum), were numerous, and apparently possessed but trifling differences from some corals now living. The creatures, as a rule, appear to have been in thick-walled, non-porous cups; and in the compound forms there was, therefore, an absence of that free circulation which characterised many colonies of later times. No reefs, it would seem, had yet been formed. A few colonies-apparently Alcyonarians-were now to be seen (Heliolites, Syringopora). These probably were forerunners of blue corals (Helipora), "sea-fans" (Gorgoniide), and Organ-pipe coral (Tubipora).

Colonies related to corals and of "sea-fir" type were GRAPTOhere much as those of the Cambrian. New colonies, howLITES ever, known as Graptolites, now come into view. These, no doubt, were related to the older colonies (Cladophora), but had become distinguishable by several modifications. The branching framework of the colony was somewhat stronger, and able to bear a double-rowed population. Various shapes were also developed so as to afford the tiny individuals greater facilities for obtaining food. Fixed existence -characteristic of the earlier colonies-had also ceased. 
Some drifted about on pieces of seaweed (Phillograptus, Didymograptus); others having developed a disc to act as a float-and looking like attenuated brittle-stars-had become free of adventitious support (Dichograptus). Such colonies, however, were no doubt more or less at the mercy of the currents; for it is not likely that the zooids had developed a central navigating authority. The colony had freedom, but was without any organised ability to regulate it.

Graptolites attained an extraordinary development during this Period. They seem to have been collected often in large companies, and to have thriven best in muddy waters. Widespread also was their range; for traces of them have been found in Europe, America (North and South), and Australia.

CystiDs The little bud-like cystids showed some progress over their Cambrian ancestors. The plates of the body-covering were more symmetrically arranged; and the animals could better withstand the pressure of sea-currents (Echinosphara, Cryptocrinus). Many of them were now provided with small "arms," and enjoyed, therefore, greater facilities for obtaining food. This was no small gain for animals rooted to the ground, and incapable, therefore, of pursuing prey. No stems, at least of any note, had as yet been developed; and the round little creatures-seldom bigger than walnuts-must have had a squat and dumpy appearance beside their near relations, the "sea-lilies."

SEA-IILIES Crinoids, or "sea-lilies"-scarce in the Cambrian-were variously developed, and easily first among the beauties of the sea. Some, indeed, had their "arms" bare and feebly developed, but they were by no means devoid of grace. The arms of many, however, were long, finely formed, and edged with feathery out-shoots (Glyptocrinus, etc.). Utility, of course, was the object, and beauty had come by the way. Long arms gave good reach for food, and feathery appendages were useful for sweeping the supplies down to the mouth, and also for aiding respiration. A few forms had undergone changes which, no doubt, greatly added to their enjoyment of life (Ichthyocrinida). With all 


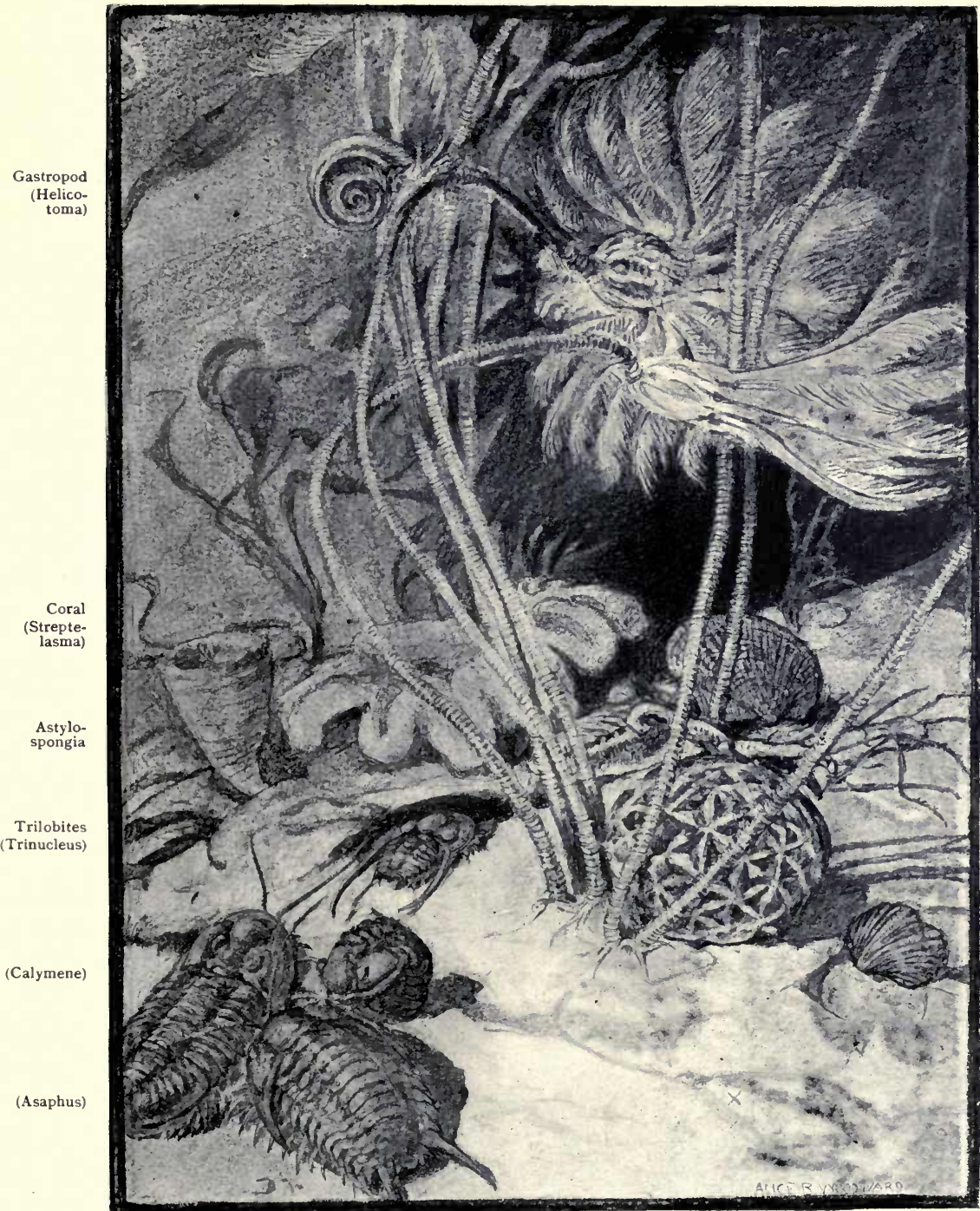

Crinoids

(Glypto-

crinus)

Polyzoan

Pterinaea

Graptolite

(Dicho-

graptus)

Cystid

(Echinos-

phaera)

Lampshell

(Platys-

trophia) 


\section{$\therefore$}


crinoids save these, the mouth of the animal was not exposed to view, but concealed under a disc of little plates stretching across the top of the cup. By this arrangement food brought down by the arms was conveyed to the mouth through small tubes or passages under the disc. In the case of these particular crinoids the mouth was brought into view by displacement of the discal plates, and the tubes were superseded by surface channels. The animal could thus take in food more freely, and of larger size; and in course of time muzzled crinoids all passed away.

Starfishes, owing to reduced discs, and more sharply defined arms, were now moving about more freely (Palaaster). But their numerous little tube-feet were not so well protected as those of later forms. Brittle-stars attested new developments. Some of these creatures possessed far more flexible rays than the starfishes (Protaster)-owing, no doubt, to the digestive system having become centralised in the disc, and not extending, as with starfishes, into the rays. Echinoids or sea-urchins-unknown in the Cambrian-were certainly now abroad. These Ordovicians-harbingers of a multitudinous and widespread race-were about the size of cherries; and their bristling body-coverings were more economically constructed than those of any later urchins (Bothriocidaris).

Here and there in chalky tubes, cemented to the rocks, certain worms (Ortonia) swelled the ranks of stationary lifealready considerable.

Among the shelly hosts cemented existence was also noticeable,-some very small lampshells having developed the less laborious method of clinging to rocks (Crania). The vast majority of lampshells, however, retained their mobility-such as it was-unimpaired. Many of these recalled the forms that lived and died on Cambrian coasts. Those, however, in hinge-worked shells had greatly increased; and in some cases their shells were strengthened with ribs (Platystrophia, etc.). Their less inventive brethren nevertheless were still numerous. Certain of the more advanced forms had also developed a lime framework for the "arms," so that the food-bearing water near the mouth could be better kept in motion (Atrypa, Rhynchonella). In later times

STARFISHES

BRITTLE-

STARS

SEA-URCHINS

WORMS

LAMPSHELIS 
this modification brought great rewards in the lampshell competitions for survival.

BIVALVED

Bivalved molluscs do not seem to have greatly increased : MOLLUSCS nor were they very widely distributed. There was, however, a little more variety in their ranks, for some were now in view with flaps to their shells (Pterineida), as with the wing-shells of our own time (Avicula). This development, no doubt, provided the hinge with an extra strong basis; and the hinge question was as important in molluscan as in lampshell life. Many forms were doubtless still living in old-fashioned shells without hinges; and in the case of some others the hinge was only imperfectly developed. But a few forms-forerunners of which had appeared in the Cambrian-had shell-hinges which were of superior mechanism to those of the most progressive lampshells (Ctenodonta). Such animals, therefore, were well equipped against burglarious starfishes, and other shell-intruders in the shallows.

UNIVALVED Winged snails had less weight to carry than of old, for MOLLUSCS their shells were now of much thinner texture (Cornularia).

New species of crawling snails were also in the seas; but there is no reason to suppose that they had undergone any very important modifications of internal anatomy. Some of them now possessed on the upper part of the foot a hard growth (operculum), which served as a trap-door to the shell as the animal lay coiled up within (Maclurea). Hospitality was more rigorously denied. The more expansive forms with well-raised towers to their shells (Cyclonema) were notably on the increase. Others (Helicotoma), to judge by their shells, had had their flanks considerably flattened, and had probably become more athletic.

SCAPHOPODS Scaphopods or "tooth-shells" were in existence at this time (Dentalium)-spending their lives more or less embedded in the mud and sand. They added nothing, therefore, to the gaiety-little enough-of marine life.

chitons Other animals-equally stolid-were ancestors of the "armour-shells" or chitons of our own time; and, save for their shell-plates not being so firmly secured to the margin of the mantle, they seem to have differed but little from the forms now living (Priscochiton). 
Some very small animals, distantly related to lampshells- POLYZOANs and more highly connected, therefore, than the coral-related graptolites-were now in evidence. Whether any of them lived in solitary state is unknown, but many colonies were certainly in existence. Some of these extended themselves over stones, shells, and other marine objects; others had taken root, and branched out in plant-like form, and resembled the "seat-mats" and so-called "lace-coral" of our own time. They certainly had a longer future before them than Graptolites, for there is no doubt that the polyzoans of to-day are their descendants, whilst Graptolite annals soon came to a close. Polyzoans differed in character, for in some colonies the zooids lived in round-mouthed and well-opened tubes (Cyclostomata); whilst in other colonies-probably an offshoot-the tube orifice was more or less protected (Cryptostomata). There were, therefore, two developments competing for Natural Selection; and what the result would be, time alone could show.

Descendants of the Cambrian nautiloids in straight and CEPHALOPODS slightly curved shells were numerous in Ordovician times. In North American waters some forms attained enormous dimensions, possessing shells a foot in diameter in front, and twelve feet in length (Endoceras). Such giants, suggestive in appearance of drifted tree-trunks, doubtless took terrible toll of various forms of marine life. Owing to their ponderous encasements they probably remained more or less stationary, throwing out their tentacles when prey came within reach. It is clear, however, that in this Period modifications were in progress towards rendering the shells of nautiloids more portable. Some forms were now appearing in shells partly coiled in the uninhabited portions; and the whole structure thus assumed the outline of a pastoral staff (Lituites). The shells of a few others were more or less completely coiled; and had, therefore, an outward resemblance to the shell of the existing Nautilus (Trocholites). These modifications were destined to revolutionise this class of life; but as yet an immense majority of the animals lived in shells of old fashion.

Trilobites were making great progress; and, during this TRILOBITES Period, attained their climax. Some Cambrian genera had 
passed away ; but many new genera had appeared. The new forms, with few exceptions, were endowed with eyesight, and were more broadly developed in the region of the tail (Asaphus, Trinucleus, Ceraurus, etc.). The power to roll up in woodlice fashion was also more common (Calymmene); but this mode of meeting dangers was not suggestive of a grand future.

POD-SHRIMPS

Numerous "pod-shrimps" were disporting in the waters, and of larger size than their Cambrian ancestors (Ceratiocaris).

osTRACODS Ostracods, some dwelling in rock-pools, others careering in large companies about the deep, were in a vigorous condition. In fact, their shells were never so varied at any other time (Beyrichia, Bairdia, etc.). They were mostly minute animals, but some monsters-nearly an inch in length-were among them (Leperditiida). In some cases-in the style of lampshells and bivalved molluscs-hinges were developed on the tiny shell; and in some shells there was a small perforation through which the antennæ could be thrust without disturbing the valves (Cypridina).

BARNACLES Attached to rocks, shells, and seaweeds, barnacles exhibited their peculiar structure in various stages of development. These animals had early departed from strict crustaceans, and were fast becoming an isolated group, leading lives similar to those of rock-clinging molluscs. Some were protected by loosely-arranged shelly plates (Lepidocoleus); whilst others were more or less completely encased in plates closely set and overlapping (Turrilepas). None of these barnacles possessed stalks for clinging to their resting-places. They may, indeed, have been capable of locomotion, but probably they did not much indulge in this exercise. Others had stalks of a rude, primitive kind (Polliceps); and in a few forms this organ was well developed (Scalpellum).

SEA-

There is no sign of small crustaceans with affinities to SCORPIONS trilobites and king-crabs, such as had appeared in the Cambrian. But the small scorpion-like animals (Eurypterids) were on the increase (Echinognathus, etc.). Sea-scorpions, so-called, did not, however, make their presence greatly felt in Ordovician times. Their descendants, as will be seen, 
became important animals not only in the sea, but in fresh water also.

Marine life, it will be noted, was for the most part strong in defence; and various animals of active and aggressive habits-of which nothing is known-may well have been in the seas. Fish-like forms were possibly coming to the fore, but there is no satisfactory evidence as to this. If-as is likely-they were already in existence, they were probably backboneless and soft-bodied, and had, therefore, no enduring " wrack" to leave behind.

On land, primitive " horsetails" (Protannularia) and club- VEGETATION mosses (Protostigma) were extending their range. Other verdant forms bearing mostly wedge-shaped leaves seem to have been combinations of these, and to have held, moreover, affinities with ferns (Sphenophyllum). Insects were certainly about the scenes (Protocimex). These creatures were well-winged, and appear to have been a species of the bug order (Hemiptera). Their presence leads one to suppose that various insects of lower grade, especially wingless forms, were already in existence. Many of them by this time may have quite forsaken the waters, where their ancestorsprobably minute crustaceans-had long dwelt and prospered.

INSECTS 


\section{PALÆOZOIC AGE}

\section{SILURIAN PERIOD}

VEGETATION SILURIAN life attested a well-sustained progress. Vegetation was becoming more diversified; club-mosses had greatly increased in variety (Berwynia, Sagenaria): and some plants had now become so far evolved as to be distinguishable as ferns (Sphenopteridium). All Silurian plants, it would seem, reproduced by means of spores-a somewhat circuitous and extravagant process for the end in view. The seed-bearersmore straightforward and less prodigal in posterity matterswere yet to come.

SPONGES The advance in marine life was necessarily attended by the falling out of many old forms and types. Increased competition, and other changes in environment, though conducive to progress, were bound to bring sectional reverses.

Sponges with simple rod-like needles-so prevalent at the present time-are first known in Silurian seas (Monaxida). The flinty supports may in some cases have been worked up into a framework, but probably they were more often scattered about the porous "flesh." A rigid framework must have interfered with a free development of canals; and the sponges that eschewed it developed, no doubt, highly improved canal systems, and so became enabled to confront more varied conditions. Some forms, in course of time, entirely discarded needles. This was a hazardous proceeding, for many animals - no longer afraid of a prickly receptiontook to preying on them. In long after-times this innocuous condition also led to their use as bath-sponges.

CORALS Solitary corals in thick-walled cups were numerous ( $\mathrm{Z} a \mathrm{ph}$ rentis, etc.); but what may be called reef-building was now in evidence. Certain forms, presenting in the mass a honey- 
comb appearance, were conspicuous in this activity (Favosites). The body-cups, although of thick texture, were perforated ; and a community of life was, therefore, to a certain extent established. Other colonies, presenting a chain-like appearance, were also much to the fore (Halysites); but individualism on these reefs was more or less rigidly maintained. The two schools of compound corals-communicative and close-walled-were, therefore, represented.

Graptolites were now on the wane. The more populous double-rowed colonies seem to have died out in the early part of the Period. The colonies with single rows of individuals continued somewhat longer. But though their wants were fewer, they were having a hard struggle for existence; and by the close of the Period they became practically extinct.

Changes had taken place in the ranks of the cystids. The progressive Ordovician families-characterised by a more symmetrical arrangement of the box-plates, and by the development of "arms" -were still in existence: and the families which had shown progress only by developing " arms" were still living, but in diminished numbers. The more primitive Cambrian family, without " arms," and with irregularly arranged plates, had apparently died out (Aristocystida). Stems were but little, if at all, developed by early cystids, but in the Silurian Period some well-stemmed forms were to be seen. These more dignified creatures had also other advantages. Their facilities for collecting food were increased -as in the case of some crinoids-by the development of feathery appendages on the somewhat diminutive arms: and they also possessed improved channels for conveying food to the mouth (Lepadocrinus).

Cystids seem to have been fairly prosperous during the Silurian ; but there were signs of decline. They were, in fact, slowly failing in their competition with crinoids or "sealilies," and had, indeed, by this time, been far surpassed by the latter alike in number and variety.

Crinoids were spreading in the seas with all the luxuriance of tropical jungles; and many large-cupped, graceful forms were now to be seen (Periechocrinus). Those with mouths rendered more free for the reception of food by the removal

SEA-LILIES 
of the covering disc were in a small minority in the previous Period (Ichthyocrinida). During the Silurian such forms were more in evidence. Among crinoids with covered mouths some highly speculative developments for dealing with the force of currents were taking place. In certain forms the arms were joined together by means of numerous branches resulting in a sort of network enclosure (Crotalocrinus). In a few other forms each branching arm was compacted into a fan-shaped petal (Petalocrinus). These experiments were not very successful, for wicker-crowned and petalled crinoids did not appear in any subsequent Period. Other forms had come out as sanitary reformers. The sanitary arrangements of many crinoids were doubtless far from perfect, as the waste products in passing away were liable to mix with the food supplies. To ensure against this, some forms had evolved long tubes calculated to carry the waste clear of the arms (Mastigocrinus, Botryocrinus).

Various modifications had been undergone in other cases, resulting in a freer play of the " arms," greater flexibility of the stem, increased strength of the cup or body-covering, and the out-growth of small clinging tentacles as means of support. Indeed, crinoids seem to have attained their greatest development in this Period; but they all differed as yet, in several structural details, from crinoids now living.

BLASTOIDS

Some related animals known as Blastoids were now on the scene. So far as is known they were confined at this time to North American waters. The most remarkable feature about these "bud-like" creatures was the presence beneath the body-covering of certain tubes, known as hydrospires. Currents of water, it is supposed, passed through the tubes, and respiration was thereby carried on. This was, undoubtedly, a less simple respiratory system than that of breathing by pores, as was the general rule with crinoids; and it may have yielded a greater thrill of life. Some of the animals (Troostocrinus) had the system more fully developed than others (Codaster). And various experiments were, no doubt, being made, for the creatures were as yet but tyros in the maze of competitive life.

STARFISHES Old-fashioned Cambrian forms of starfishes with ill-defined 
central discs were still in being. Certain forms were now more in line with those of to-day in having a thorough protection for their tube-feet (Lepidaster). Some of the brittle-stars had undergone a similar modification (Lapworthura). The latter animals were now well distinct from the starfishes; and by coiling round crinoids and other acrobatic feats they doubtless displayed their superior agility.

Various forms of sea-urchins were groping about amongst the seaweeds, or lurking in rock-hollows. They all differed from the known Ordovician forms (which had become extinct) in having tests with more numerous vertical platerows. In fact the plate-rows were more numerous than those on the body-coverings of any urchins now living. The tests of some were of a quite primitive character, the plates being thin and irregularly arranged (Echinocystis). In a few cases the under-part of the test was not perforated, and the lower tube-feet had to be protruded between the plates (Palcodiscus). The tests, no doubt, were highly flexible; and a very slight misfortune would have cracked them across had they been otherwise. Urchins thus encased, however, were not the best clad of the time; for certain forms were abroad in tests of stout, rigidly attached, and well-perforated plates (Palaëchinus). These animals were about the size of greengages, and were more or less covered with short bristles. They possessed, moreover-unlike their humble brethren-a well-developed jaw apparatus, capable of gnawing into the shells of molluscs. They were certainly the "fittest" urchins in the seas, and proved fit enough, indeed, to continue their line through the next two Periods.

The Ordovician worms, that had betaken themselves to extremely sedentary habits in chalky tubes cemented to rocks, had by no means entered on a fatal course. In spite of aggressive sea-urchins, and other intruders on their privacy, numerous descendants were living in this Period. Indeed, the line has been perpetuated until the present time (Serpulites).

Brachiopods or lampshells were in a state of vigour they had never experienced before, and were never to know again. Not only on the coasts of Europe, Asia, and North and

LAMPSHELLS

BRITTLE-

STARS

SEA-URCHINS

WORMS 
South America, but on Australian scenes they made a grand display. The shells were wonderfully varied in shape, pattern, and structural detail ; and there were differences also in the texture and the material of their composition.

The species with hinged shells had now far outstripped the "unhinged" (Pentamerus). Forms were arising that had developed spines on the shell-a new means of clinging to resting-places (Chonetes). The "arms" of some had now become so greatly developed that the shells in order to lodge them had assumed the shape of a butterfly with outstretched wings (Spirifer). And there were many other displays of originality in this plastic group. The animals, in short, were at the height of their glory: but a great sifting-out process was not far distant.

POLYZOANS Whilst the graptolite colonies were declining, conditions seem also to have been unfavourable to the colonies of higher grade, known as polyzoans. The older-fashioned open-mouthed colonies still kept the lead, but they had now lost their great superiority in numbers over the colonies with zooid-tubes of greater complexity.

BIVALVED

MOLLUSCS

UNIVALVED

MOLLUSCS
Bivalved molluscan life still remained in a primitive illdefined condition; but there were signs of progress. Some animals were appearing in a state of development between mussels and pearl-oysters (Myalina). Other forms were more in line with modern wing-shells than were their Ordovician forerunners (Pteria). A few new forms were appearing in exceptionally pretty shells, shaped like a cockle's, and with radiating ribs broken up into small knobs by cross furrows (Cardiola). These creatures seem to have been more nearly related to arks than to cockles : but their family was not destined to a very long career. With better prospects were certain other new forms, in shells of scallop pattern (Aviculopecten).

Sea-snails did not exhibit much notable development. Members of some families persisting from the Cambrian had their sanitary arrangements in an improved condition. The waste substance had been promiscuously discharged, and must often have polluted the water coming to the gills. It was now carried through a deep notch or slit in the shell, and 
kept clear of the breathing water (Pleurotomariida, Bellerophontida).

The only new forms of importance possessed long turreted shells with well-defined spires (Macrochilina, Loxonema). The Melaniida of our own day may be descendants of these sea-snails. If such be the case the family, in course of time, must have migrated from the sea; for its members now live in fresh water only.

Scaphopods or "tooth-shells" had undergone some slight SCAPHOPODS structural changes. They were, however, wellnigh sufficiently modified for perpetuation through the ages; for presentday scaphopods differ but little from them (Dentalium). In spite of excessively sluggish habits they have managedunlike some molluscs-to retain their heads. Hearts never seem to have been a scaphopod property.

Nautiloids in more or less straight shells were still abundant. CEPHALOPODS There were also new species of these old-fashioned forms ; the shells having undergone modifications in the chamberpartitions, or in the position of the tube which connected up the various chambers. Huge animals with excessively ponderous shells, such as had appeared in Ordovician times, had apparently died out. Life no doubt had proved unequal to the burdens which gluttony had entailed. Straightshelled nautiloids of considerable size were, however, still conspicuous in marine life (Orthoceras annulatum, etc.).

Some peculiar forms were now appearing boxed up in egglike shells with a T-shaped aperture. Through this contracted opening the " arms," no doubt, could be thrust ; but the rest of the animal must have been held close prisoner (Gomphoceras). This seclusion doubtless had a protective value; but in the end the drawbacks proved greater than the advantages. Nautiloids, however, thus sequestered, were in evidence during the two succeeding Periods.

The forms with coiled shells were making a decided advance in numbers. Those in shells of the transitional pastoral-staff pattern were certainly on the wane : but there were many new species in shells more or less of nautilus-shape (Hercoceras, Trochoceras, Ptenoceras). The coiled-shell forms were destined in time to supplant those in shells of older 
fashion; and the latter seem already to have been on the decline.

TRILOBITES Trilobites continued in considerable force, and were widely distributed. The blind forms were still languishing, and reverses had been sustained by several old families gifted with eyesight. In some genera important changes were taking place in regard to the eyes. In certain cases these organs had been shifted to new positions; and some forms bore their eyes elevated on stalks. There was apparently more need for vigilance than in times of yore.

Many of the trilobites had undergone variations in the shape of their head and tail armour (Phacops, Spharexochus, etc.); and the power to roll up in wood-louse fashion was still more in evidence. Many of the modifications seem to have been the result of a mere exuberance of energy : at any rate their precise use and value cannot be determined. Fantastic forms were now to be seen. Some of these had swollen uncheeked heads, covered with pimple-like excrescences (Staurocephalus). In some species the cheek armour had been modified into spines, suggestive of rigid fins; and the tail armour had followed suit (Deiphon). Several forms were appearing with long spiky tails, enabling an animal thrown on its back to rectify its position (Dalmanites limulurus, etc.). Trilobites, however, though still able to adapt and re-adapt themselves to the pressure of conditions, were coming to the end of their resources; and during this Period their decline commenced.

KING-CRABS Several species of small animals with head-shields and spike-like tails, and holding affinities with trilobites and king-crabs were now on the scene. Animals with these double affinities had appeared as early as the Cambrian Period (Aglaspis). The Silurian forms were certainly more in line with king-crabs. They retained, however, a marked trilobite character, as the segments of the middle body or thorax were not fused together: the second shield of the king-crab was, therefore, undeveloped (Hemiaspis limuloides, Woodw., Neolimulus falcatus, Woodw.). King-crabs, in short, were as yet but half made.

SEA- Sea-scorpions-of small account in Ordovician timesSCORPIONS were now giving promise of their coming importance. As 


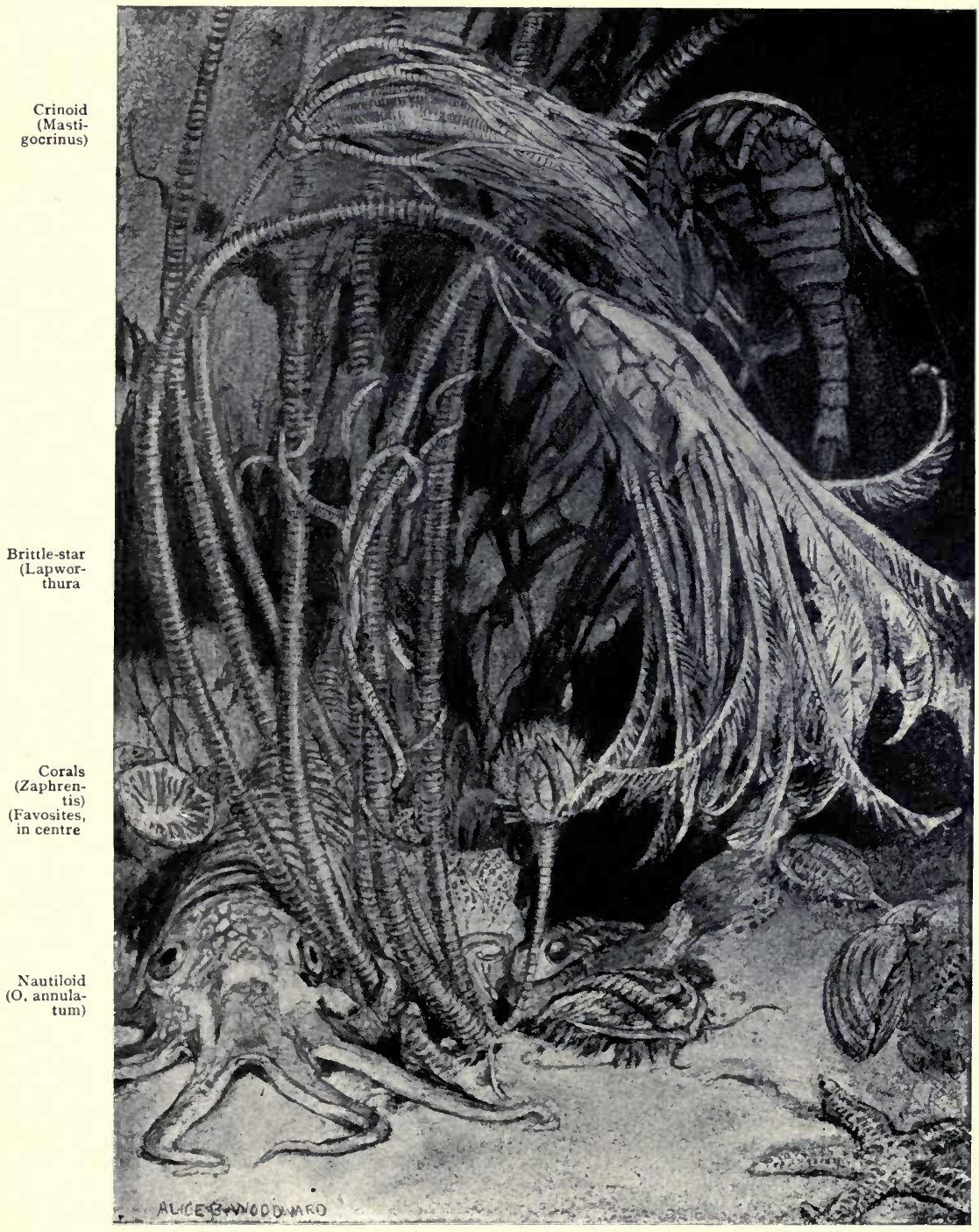

Sea-

scorpion

(Euryp-

terus)

Crinoid

(Perie-

chocrinus)

Cystid (in centre) (Lepidocrinus)

Dalmanites

Lampshells (Pentamerus) Trilobites (in centre) (Sphaerexochus) (Phacops) 

regards habits they had parted company; one section consisting of more or less active swimmers ; the other of forms, capable indeed of swimming, but more or less addicted to prowling about the sea-floor. To judge from their greater size, and variety, the active swimmers were the more prosperous. The last pair of limbs or appendages, in their case, had been modified into powerful paddles, and the tail was somewhat short, and in some instances plate-like (Eurypterus, Pterygotus). In the prowling forms the hind-limbs were greatly elongated and single-clawed, and the tail was long and slender (Stylonurus). Sea-scorpions brought forth monsters in later times; but the largest known Silurian form scarcely attained two feet in length.

Animals intimately connected with sea-scorpions, and scoRPIONS probably an off-shoot of them, were now coming into view (Palcophonus). These creatures seem to have closely resembled the scorpions of our own time; excepting that the limbs terminated not with double but single claws. They certainly possessed venomous stings; but it is doubtful if they resembled living scorpions in being land-dwellers. They may well, however, have paid occasional visits to the leafy scenes, where an increasing insect-population must have presented an attraction.

Ostracods seem to have had a set-back after their great osTRACoDs burst of prosperity in the previous Period. Small crustacean life, however, was now being enriched by the appearance of amphipods, popularly known as "beach fleas" and "sand- AMPHIPODS hoppers" (Necrogammarus).

Through the greater part of the Silurian there is no satisfactory evidence of any animals other than invertebrates; but towards the close of the Period there is little doubt that animals with at least rudimentary backbones had emerged from invertebrate ranks.

The great majority of these representatives of higher OSTRAColife, although fish-like in appearance, were much of the grade DERMS of hags and lampreys-animals not regarded as true fishes, Some, measuring about seven inches in length, had flattened heads, big in comparison with the body, and were somewhat skate-like in shape. Their skins, like the skins of sharks, 
were covered with little tubercles or prickles of a dentine substance. There was a fin on the back, and a forked tail fin, but apparently there were no paired fins as in the case of all true fishes (Thelodus). In some species the skin-prickles stood out like little spines (Lanarkia).

Other forms, similarly finned, were spindle-shaped like most living fishes. The tubercles on the body had been fused into well-defined scales; but those of the head had not undergone the process. These creatures, unlike the flat-headed forms, possessed on the under-part of the body a row of spiny scutes (Birkenia). Other allied forms had a few rod-like structures at the back of the head, and were liberally supplied with scutes along the ventral region; but they do not appear to have had the other parts of the body protected (Lasanius).

Yet other odd-looking little forms had the head and the anterior part of the body encased in shields consisting of small shelly plates. The rest of the body-to judge from more complete remains found in the next Period-was protected by enamelled or ganoid scales (Cyathaspis, Palaaspis, Pteraspis). A few forms were shielded in the region of the head only. But this armour, less in quantity, was of better quality, for it contained a certain amount of bony material (Tremataspis, Cephalaspis). The appearance of bone is notable: for bonemaking cells were rare in those days. "Backbones" at best were as yet only of a gristly, cartilaginous substance.

These various fish-like forms-known as Ostracodermswere probably of somewhat inactive habits, and seldom rose much above the sea-floor. They did not, therefore, greatly disturb the prevailing quiescence.

SHARKS True fishes were also in Silurian seas. Certain small finspines have been discovered, resembling in character the spines that protect the dorsal fins of Port Jackson sharks (Onchus). If these creatures fed on molluscs, their tables were amply spread. There is also evidence of small sharks of another kind (Climatius); and small sharks, there is little doubt, were the first true fishes that ever swam the seas. These small Silurian forms may have been derived from creatures much of the type of the prickly-skinned, unshielded ostracoderms (Thelodus). The shielded ostracoderms held 


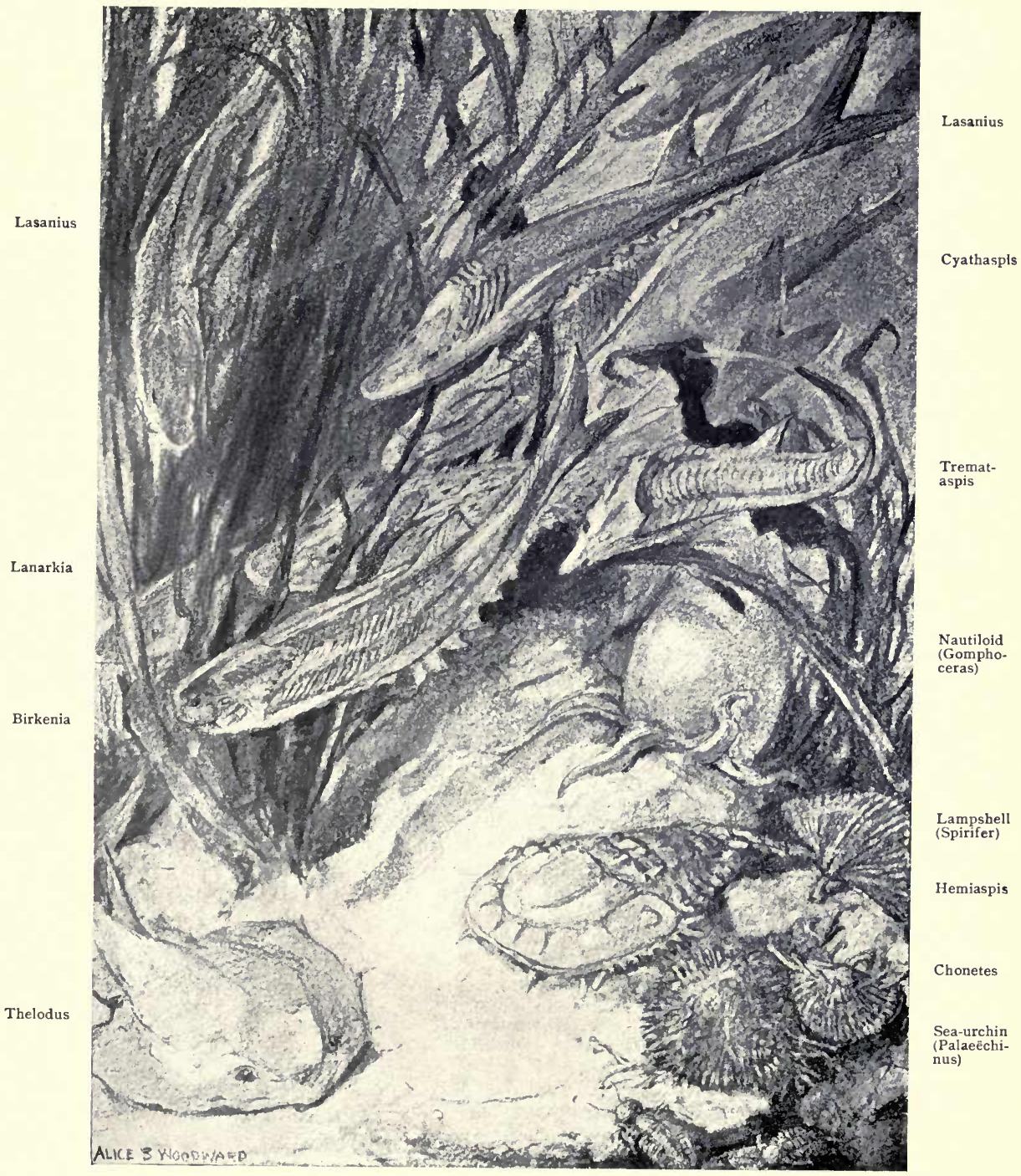

Staurocephalus

SILURIAN MARINE LIFE

Deiphon

[To face page 36 

strong affinities with trilobites and half-made king-crabs; and it is not likely that any of their descendants ever figured as true fishes.

The appearance of fishes attested the rise of a new power in the sea; and, as after-events proved, it was not to be a marine power only, but had wonderful destinies beyond its native element.

Long had the waters embraced sponges, corals, sea-lilies, molluscs, and creatures in crusty armour variously wrought; and now they nursed a life higher and more resourceful than any of these. Different indeed was the land with its humble verdant growths, and populated by animals of no higher grade than insects. 


\section{PALÆOZOIC AGE}

\section{DEVONIAN PERIOD}

FIsH-LIFE now abounded not only with strange types, old and new, but also with a variety of species less quaint and problematical.

OSTRACO- Sluggish flat-headed creatures in skins dotted with dentine DERMS were here much as those of the Silurian (Thelodus); and new and apparently related forms were also in being. In the case of the latter the scattered dentine had been collected and fused into plates and scales; and a protection resembling cuirass and chain armour had resulted (Drepanaspida).

Shielded forms of the same character as those of the previous Period were now in great force; and, as a rule, of larger size. Those, for instance, with bony head-shields attained in some cases a length of two feet; - twice the length of the finest of their Silurian ancestors (Cephalaspida).

There were also some forms-rarely more than a few inches long-with only remote likeness to Silurian types (Pterichthys, etc.). They were fully armed with bony plates and scales; and the eyes were well brought forward as on a human face. The mouth appears to have been of a primitive kind, without bony jaws. The most remarkable feature of these little curiosities was the possession of jointed breast fins or paddles. These plated appendages were probably used for crawling as well as for swimming and balancing purposes.

None of these shielded fish-like organisms-whatever may have been the possibilities of unknown earlier and less specialised forms-represented a progressive movement. Indeed their total disappearance was not far distant; for at the close of the Period they all became extinct.

Some small vertebrates, long-tailed, and with large mouths 


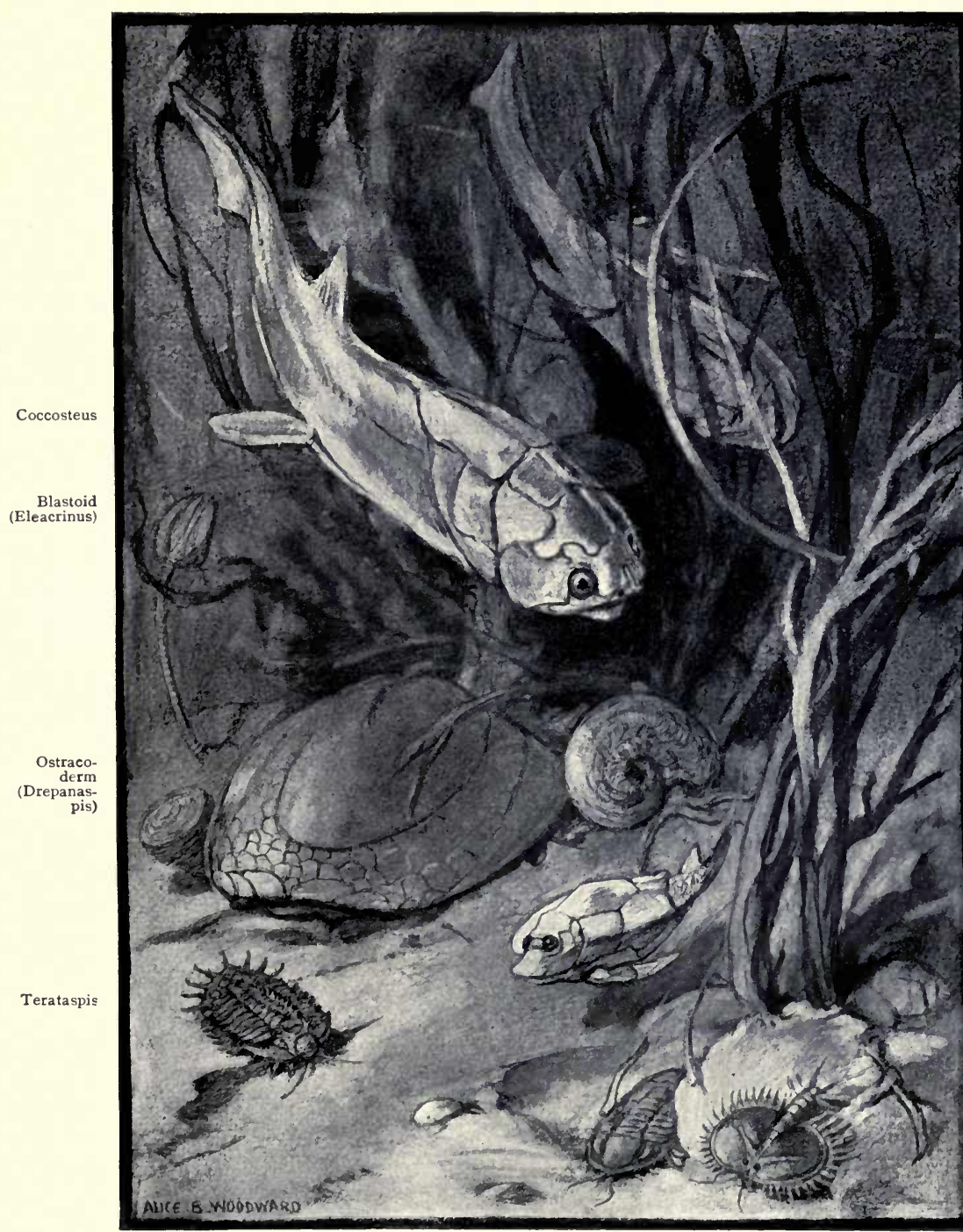

Coccosteus

Ammonoid

(Gephyro-

ceras)

Pterichthys

Proëtus

DEVONIAN PERIOD
Pephricaris

[To face page $3^{8}$ 

bristling with tentacles, were also swimming about. These cycLostocreatures were not true fishes; for they had no paired fins; MATA nor were their mouths surrounded with any hard material constituting jaws. The largest of them, so far as is known, did not exceed two inches in length : and their bodies seem to have been unprotected by any plates or scales (Palaospondylus). In anatomical respects they resembled lampreys; but they were more highly developed than those animals. Possibly they represented that line of life before it entered on a path of degeneracy.

Other and much larger forms were partially armoured, ARTHROand were provided with toothed jaws, and also, at least on DIRANS the hinder part of the body, with paired fins (Coccosteus). These true fishes were peculiar in being able to raise and depress the head without moving the body-hence their name the "joint-necked" (Arthrodirans). The nature of their teeth suggests a relationship with lung-fishes. They had, however, become too far specialised to be of any service in the work of Evolution. They represented, in short, an unsuccessful divergence, as did the armoured semi-fishes; and they experienced a like fate at the close of the Period, or soon after. In North America some of the later forms measured fully twenty feet in length (Dinicthys Herzeri). These nodding giants were quite without teeth, and the jaws had been transformed into a sort of nipper and nutcracker apparatus.

These various vertebrates, therefore, were, so to speak, in the shade. Indeed, the lamprey-like organism was the only bright spot among them. But fish-life, though destined to come to naught in some of its developments, had made great advances in other directions. This state of affairs is brought out in bold relief in the geological record: but there is a remarkable lack of evidence as to the intervening stages of the progress.

Shark-like fishes, in some evidence in Silurian times, were SHARKS now represented by several species. The biggest forms varied in length from two to five feet (Cladoselache). As regards skull and jaws they resembled the cow-sharks (Notidanida) of our own time, but in other respects they were 
of primitive character. The "backbone"-composed of cartilage-was unjointed; but, not being stoutly developed, it retained a fair amount of flexibility. The paired fins seem to have been capable only of an up-and-down flapping movement; and these, though useful as balancers, can have been but of little service for guiding purposes, or for assisting in onward locomotion. Their character gives support to the theory that fins originated as mere folds of flesh, strengthened by outgrowths from the internal skeleton; and that in time the folds became divided up into distinct flippers, which gradually developed increased functional powers. The tail, however, is the great organ of propulsion; and these fishes were not devoid of strength in that quarter.

More advanced in development were certain small sharks, forerunners of which had appeared in the Silurian (Climatius, Mesacanthus). The fins of these fishes, both vertical and paired, were well developed; and, excepting the tail-fin, were fore-guarded by spines. Some of these little creatures were as much as a foot in length, and no doubt were the élite of shark-life at this time.

CHIM ERAS Other shark-like forms, to judge by their teeth, were developing in the direction of chimæras (Ptyctodus). But the goal to which they were tending was as yet a long way off.

GANOIDS Other fishes of more engaging aspect were moving about in bony scales enamelled with a glistening substance (ganoin). This shining habiliment was doubtless the result of modifications of small tooth-like plates such as were formed in the skin of early shark-like forms : but how the transformation was effected is quite unknown.

CROSSOP-

Most of the ganoids-as these fishes are called-possessed TERYGIANS somewhat stiff, paddle-like fins; and as the appendages were bordered with thread-like structures, their owners are known as "fringe-finned" ganoids (Crossopterygii). The median fins-useful in keeping a fish straight on its course-had not supports equal to the number of the rays, as is the case with modern fishes. And the tail was not of the type best adapted for swift straight-ahead swimming. All these features tend to show that these ganoids cannot have been accomplished swimmers, at least according to modern ideas. 


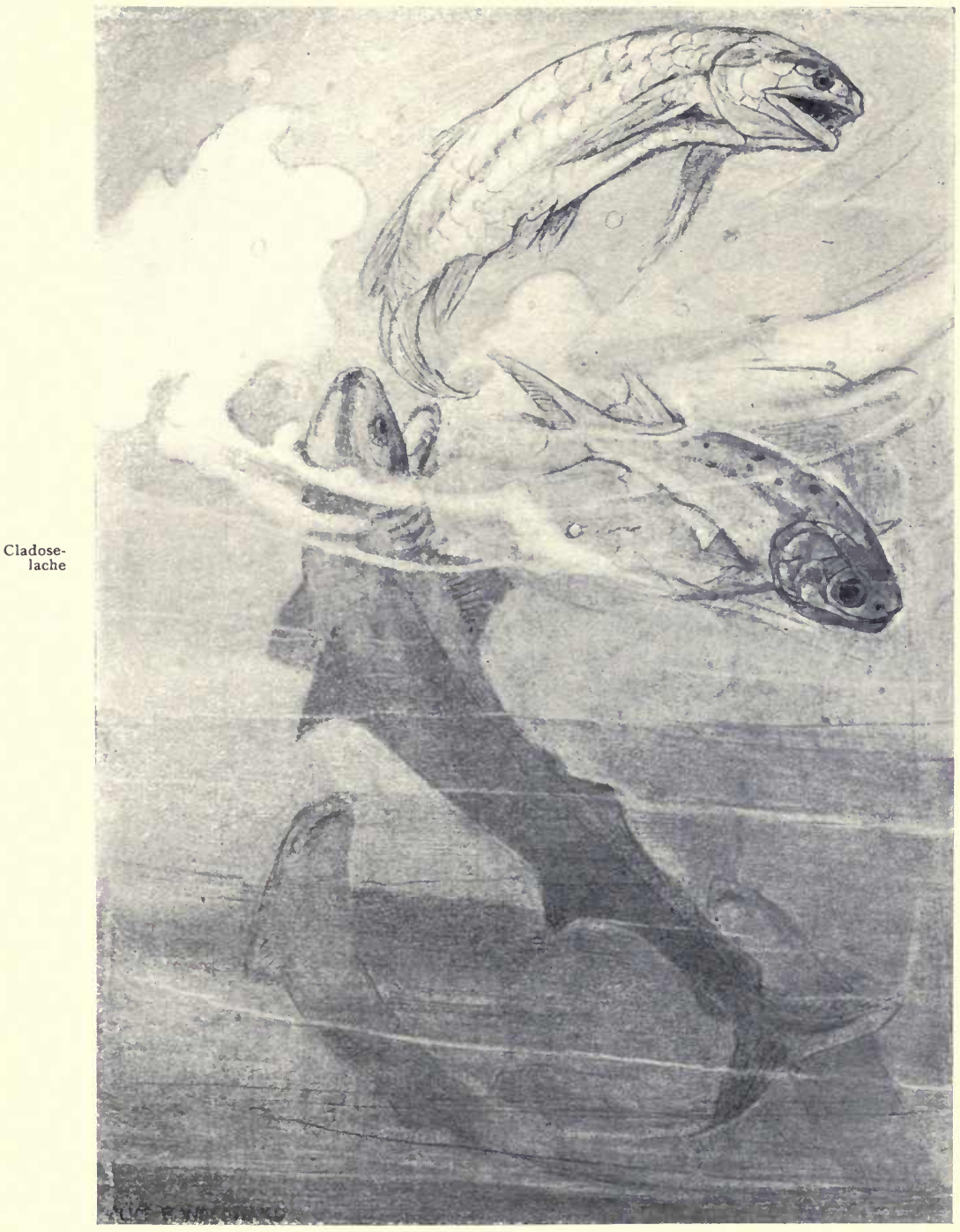

Holopty-

chius 

Probably their habits were not much more active than those of their contemporaries, the Ostracoderms; and their time was spent more or less in proximity to the shore (Osteleopis, etc.).

Some of these ganoids possessed teeth of a complicated pattern, brought about by an infolding of the surface enamel (Tristichopterus). In certain forms this infolding was of an extremely intricate nature (Holoptychius); and the teeth resembled those of certain amphibians of later times. Notable also is the fact that fishes with true backbones were at least in promise ; the gristly spinal column in some cases having undergone a certain amount of ossification (Tristichopterus).

Other ganoids, known as the "ray-finned" (Actinopterygii) were better equipped for swimming purposes, as the paired fins were light and flexible. Their tails, however, were of the same character as those of their fringe-finned relations, nor were the median fins more efficiently supported. No ossification was as yet perceptible in the spinal column; and there was nothing remarkable in the structure of the teeth. These undoubtedly more active fishes were apparently at the commencement of their career ; and they were the "coming" fishes. As yet they were few in number compared with the fringe-finned ganoids; and of no variety (Cheirolepis).

Other fishes, probably derived from the "fringe-finned" ganoids, seem to have been forerunners of the lung-fishes or double-breathers of our own time (Dipnoans). Many of them, no doubt, were denizens of the sea; but some certainly haunted lakes and rivers. The latter forms, indeed, may have been true double-breathers; i.e. with the air-bladder so modified as to serve as a breathing apparatus supplementary to the gills. A modification of this kind may have been rendered necessary by the animals being left high and dry at certain seasons of the year (Phaneropleuron, Dipterus).

No Devonian fishes had tails of the type that now prevails. In the vast majority of living fishes the tail-fin radiates from the stump-end of the spinal column. The fin, therefore, is in a sense free of the backbone (homocercal tail). In the case of all Devonian fishes the spinal column extended to the extremity of the animal, and its tapered end was bordered

ACTINOP-

TERYGIANS 
on either side with fin rays. In some cases the spine was continued to its end in a straight line, as with lampreys. (diphycercal tail); in other cases the end was bent upwards. as in the case of sharks and sturgeons (heterocercal tail). Lampreys, sharks, and sturgeons, therefore, are of antique fashion as regards the tail,-to say nothing of other features.

In the Devonian Period, fish-life, it will be admitted, was. fairly launched on several lines of evolution : and it must have been a great factor in the balance of power in the seas.

SEA-

Among invertebrates, sea-scorpions were widely distributed.

sCORPIONS To judge by some greatly lengthened and enlarged forms, they were exceedingly prosperous in certain districts. How far they were indebted to fish diet for their robust development is not clear. Some of the monsters, belonging to the better swimmers of the fraternity, measured nearly six feet in length (Pterygotus anglicus). The less active swimmers, with fewer facilities, it may be supposed, for self-aggrandisement, continued of more or less modest proportions.

TRILOBITES The decline of trilobites, which had set in during the preceding Period, continued, and in most regions with some rapidity. Old families were dying out, or becoming seriously impoverished; and no new families were arising to fill the vacancies. Desperate efforts were being made in somequarters to keep pace with the times; and the body armour was assuming florid and fantastic characters (Terataspis grandis, etc.). But it was all to no purpose. There was no, true energy behind it : and one is reminded of the wildness of Gothic architecture as it passed to its decline. The soundest family on the scene appears to have been one dating from the Ordovician Period, consisting of small creatures with welldeveloped heads, and clad in armour of simple character (Proëtus). This family was as yet far from extinction.

SHRIMP-LIKE Pod-shrimps-at no time chosen vessels for the evolution FORMS of crustaceans of higher type-were now declining. Some oddities, more or less closely related to them, were here and there exhibiting themselves in round shields edged with spikes. (Pephricaris horripilata). Notwithstanding their horrific aspect, they seem, one and all, to have disappeared after a. brief career. Far more important were other small forms. 
(Palcopalamon),-forerunners, probably, of great developments in crustacean life.

Devonian ostracods have left no record of much importance. OSTRACODS The little creatures, with notches in their shells, through which they could thrust their antennæ, were certainly prosperous (Entomis, etc.). Less fortunate were those that could only protrude the appendages by gaping the shellvalves.

A few isopods are first met with in this Period. This not Isopods very respectable group of crustaceans comprises sea-slaters, louse-crabs, gribbles, woodlice, and pill-bugs. In Devonian times, however, these isopod potentialities were concentrated within the narrow bounds of a few indefinite creatures (Prearcturus, Amphipeltis).

Molluscan life was becoming more prominent than of old. Its numerous species for the most part greatly differed from modern molluscs, but there were some clear signs of modifications in the direction of existing forms.

Among cephalopods there is no evidence, it is true, of cuttle-fishes and squids which now represent so largely this leading class of molluscs; but great movements were in progress.

The Nautiloids apparently were not so flourishing as in former times. Old-fashioned forms with more or less straight shells had become impoverished by the loss of some genera; and seem now to have been surpassed in numbers by those in coiled shells of the nautilus type.

The most notable cephalopods of the time were certain Ammonords molluscs, closely allied to the nautilus-like creatures, and known as Ammonoids. Their shells, as a rule, somewhat resembled a ram's horn in shape; and the Order for that reason has been named after the Egyptian god Ammon, generally represented as a man with a ram's head.

Some of the ammonoids of this Period had shells much of the shape of those of the straight-shelled nautiloids (Bactrites). The ram's horn name, therefore, is not strictly applicable in their case ; but as in certain internal features of the shell they differed from nautiloids, and resembled typical ammonoids, they are classed with the latter. They were probably 
survivals of some ancient forms, that had initiated the Ammonoid Order.

All other ammonoids may be divided broadly into two groups,-Goniatites and Ammonites. The Goniatites were the earlier forms. Their shells were of no great variety, and were generally of plain outward appearance. The partitionpatterns-not, as a rule, externally visible-were in most cases of extremely simple character. The Ammonite patterns attained a wonderful degree of complexity.

Many of the Devonian goniatites-ammonites had not yet appeared-were probably active swimmers (Gastrocampyli, Microcampyli). There is no doubt, however, that crawling habits were in course of adoption. In some forms (Clymenida) the partition-patterns were characterised by a slight elaboration. And this, no doubt, had resulted from strains on the shell caused by crawling becoming more or less habitual.

Goniatites became very numerous in the course of the Period, and increased in genera (Gephyroceras, Tornoceras, Anarcestes, etc.): but their shells continued of plain outward appearance, being either smooth on the surface, or marked only with delicate streaks.

UNIVALVED

Gastropods for the most part were of the same character MOLLUSCS as those of the preceding Period. A few of these snail-forms, however, had apparently developed a lung-chamber, and become capable of breathing out of water (Hercynella). The humble land-population was in prospect, therefore, of obtaining more recruits.

BIVALVED Bivalved molluscs exhibited considerable development. MOLLUSCS Primitive oyster forms, belonging to the family of which the saddle-oysters of our own day are members, were now abroad (Limanornia). Other forms appear to have been well on the way to becoming horse-mussels (Modiola); and burrowers of the "razor-shell" type were also on the scene (Palcosolen). Some forms had moved up from salt to brackish and fresh water. Certain of the emigrants bore a close resemblance to river-mussels (Archanadon).

POLYZOANS Polyzoan colonies, though suffering vast losses owing to the rapidly increasing molluscs, and, possibly, fishes, 
were now represented by various old and new forms. The colonies with open-mouthed zooids still seemed to be keeping ahead (Cyclostomata); and one family, which had first appeared in the preceding Period, and was notable for the large size of its zooids, became exceedingly prosperous (Fistuliporida). Among the "hidden-mouthed "-the later developed colonies - several new families were becoming established ; but an old family of Ordovician date, whose members resembled the "lace coral " of our own times, was dominant in this division (Fenestellida).

Lampshells were now declining; but they were by no means LAMPSHELLS descending rapidly from their zenith. Those in old-fashioned shells, without hinges, were certainly facing the turn of events with ever-weakening forces; and some old families had become fossil. But some forms of later development in hinged shells well maintained their position. Those, for instance, in shells of butterfly outline, were now in great force, and widely distributed (Spirifer). And the pressure of conditions was elsewhere eliciting responses, resulting in important modifications. Some brachiopods, for instance, now had their " arms" gathered up within the shell in simple loops. This new fashion, it may be supposed, brought some advantages relating to breathing and feeding; for its followers made great progress, and atoned in part for reverses incurred by brachiopods in other divisions of the Order (Terebratella).

Sea-urchins were no longer to be seen in such primitive SEA-URCHINS tests as protected many of the Silurian forms. All the animals were now in fairly strong body-coverings, and possessed, moreover, well-developed jaws. The descendants of the rigidly encased Silurian animals probably held the lead (Palaëchinus). In other forms the tests were made up of stout plates, but, as these overlapped, the old feature of flexibility-no longer urgent-was still retained (Lepidocentrus). All the tests still notably differed from those of existing urchins, owing to an excessive number of vertical plate-rows. Modifications, however, were in progress in the direction of economy, and also of greater efficiency.

Brittle-stars were giving distinct signs of progress. In BRITTLEaddition to those with extremely flexible arms, some forms

STARS 
were now appearing with the arms strengthened on all sides with small plates as is the rule with modern forms (Euophiurea). This development, no doubt, deprived the limbs of some flexibility; but it considerably improved the ambulatory powers of the animals.

STARFISHES Starfishes of Cambrian form were still in the seas; but were now in a failing condition, and before the close of the Period they became extinct (Palceasterina). Other forms, of later evolution, but with archaic features-notably in the construction of the arm-grooves-continued in some force (Palcaster). Several of the new Devonian forms seem to have been closely related to starfishes of our own time; but their sensitive skins were probably not so well protected (Astropecten, Echinasterella).

BLASTOIDS Blastoids, confined, so far as is known, during the preceding Period to the " new" world, had now discovered the "old," and were in some force in European waters. The peculiar breathing apparatus, for which these bud-like animals were remarkable, had undergone some modifications (Pentremitida, Eleacrinus). The tubes or hydrospires had been brought into closer co-operation, resulting, no doubt, in easier breathing and a consequent saving of energy.

SEA-LILIES Crinoids or "sea-lilies" seem to have been scarcely so prosperous as in the Silurian seas, but they still greatly outnumbered all other members of the "spiny-skinned" fraternity.

The sanitary reformers do not appear to have been making great progress. But in some localities they were fairly numerous; and certain forms had the long tube on an exaggerated scale (Eucalyptocrinus). The apparatus was probably efficient in working, but it may have required more protection against hostile attack than crinoids were able to supply.

There is no doubt that in the Devonian Period crinoids were being seriously affected by their foes; among which fishes, no doubt, were to be numbered. To meet dangers and difficulties, a few forms were appearing in which the cup or body-covering was protected by movable spines, resembling those of sea-urchins (Arthrocantha). As this device never came 
much into vogue, either in this Period or afterwards, its advantages must have been more apparent than real.

Cystids were fast dying out. However illustrious in the CYSTIDS past as the stock from which "sea-lilies" and blastoids had come, their glory had now quite departed. They were destined, however, to linger on for a time, but with an everdiminishing horizon.

On coral reefs the colonies of honey-comb appearance coRALS (Favosites) were still conspicuous; and new colonies-also with zooids of the more social kind-were becoming important as reef-builders (Phillipsastraa). The less social chaincoral colonies, prominent on Silurian reefs, had now become extinct (Halysites).

Calcareous sponges, that is, sponges with needles or spicules SPONGES formed of carbonate of lime, now come into view for the first time. They continued very few in number during the Period as compared with sponges with flinty skeletons, and their needles were smaller and less varied than those of the latter. Calcareous sponges never discarded needles, and consequently have always enjoyed some immunity from spongeeating animals.

The land population was not of much higher character than in Silurian times; but there were some notable appearances. Myriapods, with resemblance to certain millepedes MYRIAPODS of our own day, and descended from annelid sea-worms, were now abroad (Archidesmus, Kampecaris). Large-winged insects, allied to may-flies, were flitting about (Lithentomum); INSECTS and rough music was to be heard; for some of the number had wings adapted for emitting a scraping noise (Xenoneura).

Doubtless there were many other forms of insects of which no evidence has been discovered. For insect-life during this Period must have been stimulated into a varied evolution by the development of plant-life; and may indeed have rendered reciprocal services.

Vegetation retained many old features, but some important VEGETATION developments were in evidence. Certain climbing growths of ancient origin, and combining affinities with club-mosses, " horsetails," and ferns, were prominent, but were not developing sufficient stem-strength to stand alone (Spheno- 
phyllum). More stalwart were the growths of less wide relationships, and represented by existing club-mosses. The latter, possessing an outward appearance to mosses, are in many cases not larger than those plants. Even in tropical regions they are at best but shrubs and bushes. Very different was the condition of their ancestors. As early as the Devonian Period many growths of this type were big, branching trees, towering far above most of the other vegetation (Lepidodendron, Bothrodendron).

Occasionally rivalling them in height other forms with reedlike stems, ringed at intervals with leaves (generally of lanceolate shape), adorned the scenes (Calamodadus, Archaocalamites). These growths, known as calamites, attained great importance, whilst the plant world still was young; but they have long since dwindled, and to-day are represented only by the humble "horsetail" (Equisetum).

FERNS Ferns were increasing in variety ; and some forms (Asterochlana) apparently were forerunners of certain tropical species of our own time (Marattiacea).

CYCAD-FERNS In addition to ferns and other spore-producing growths, there were several fern-like plants which through frondmodifications had passed or were in process of passing from a spore-bearing to a seed-bearing stage (Alethopteris, Megalopteris). As the growths were in a condition of development between ferns and cycads, they are known as cycad-ferns (Cycadofilices). Their appearance in plant-life was a notable event, for it indicated a safer and more economical method of reproduction than had hitherto prevailed. A spore is in an ill-nourished condition when it leaves its parent, and, being without an embryo, it cannot give rise forthwith to a plant resembling the parent-form. Owing to their starved condition, and as the production of an embryo is a roundabout and hazardous process, spores are produced in enormous quantities. In the case of seed-bearers such profusion is unnecessary, as the principle of parental care is much more pronounced. Seeds are fertilised and well-nourished before leaving the parent, and are in a condition to give rise forthwith to growths resembling their parents. Fern-cycads, therefore, testified to a safer and more economical method of 
reproduction; and, moreover, their greater parental care exhibited a notable development in plant ethics.

Before the close of the Period plants known as Cordaites cordartes attested further progress in the evolution of seed-bearers. These more advanced growths - of remote ferny originexhibited strong affinities both with cycads and conifers, and were of higher order than any other known plants that adorned Devonian landscapes. No growths now exist that bear much resemblance to them. Their slender stemscomposed largely of pith-rose in some cases several feet in height. At the top-and there only-branches were thrown out, bearing long and narrow leaves; and here and there amid the foliage small catkin inflorescences were in display. These modest blooms, so far as is known, were the first flowers that appeared in Nature. 


\section{PALAEOZOIC AGE}

\section{CARBONIFEROUS PERIOD}

THE vegetation of the "Coal-bearing" Period was similar in character to that of the Devonian, but it attained an extraordinary luxuriance, and species multiplied greatly.

CLUB-MOSSES Branching club-mosses of pine-like appearance abounded; and in some cases rose to heights of one hundred feet and more (Lepidodendron). Some small members of the varied throng seem to have been of a present-day genus (Selaginellites). Certain of these (Miadesma) and a few of the larger growths (Lepidocarpon) had so far advanced beyond the spore-producing stage as to bring forth what may be termed sIGILIARIA seeds. Other club-mosses were spiky-leaved branchless trees with stout trunks, scarred with seal-like impressions, HORSETAILs left by shed foliage (Sigillaria). "Horsetails" with reedy stems, bark-covered and fortified in part with well-developed CORDAITES wood, were now to be seen over sixty feet in height (Calamites). Cordaites or cycad-conifers of many species were in evidence; and, so far as is known, continued the only CYCAD-FERNS growths with any floral pretensions. Seed-bearing cycadferns greatly extended their range, and new forms vied with the old (Alethopteris, Lyginodendron, Lagenostoma, Aneimites). Ferns of the same type as a now living group of tropical FERNS ferns (Marattiacea) were in great abundance-some of them attaining tree-like proportions (Psaronius); and oldfashioned climbing growths of mixed affinities still kept a place in the forests (Sphenophyllum).

COAL In swampy stretches of land, notably in England, France, Germany, and in North America, this varied vegetation underwent a series of remarkable vicissitudes. Trees, shrubs, 
至离

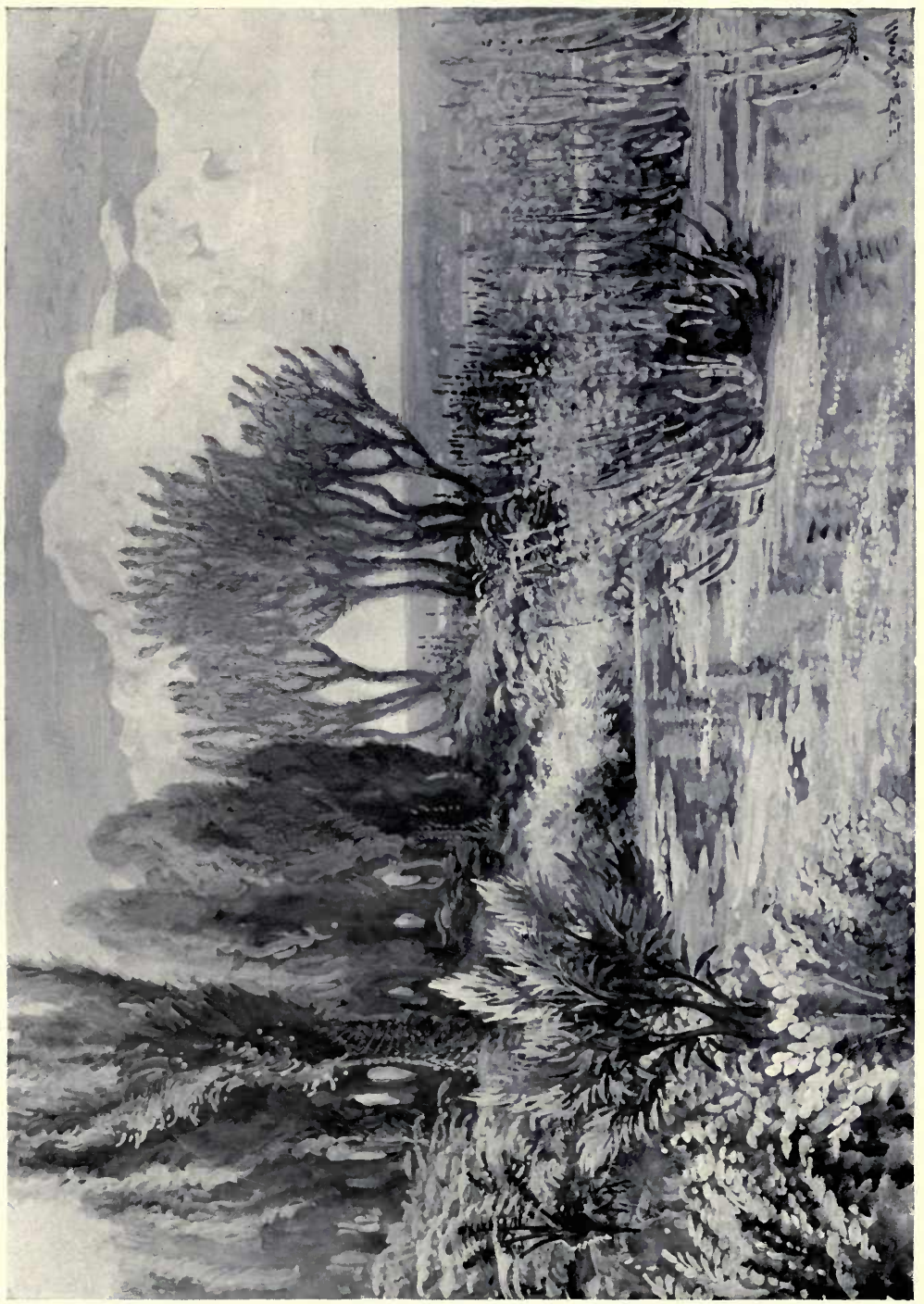

웅

$\Xi$

ษ

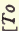

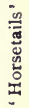

을

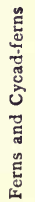

丞

نั 
and smaller growths in their generations flourished and died; and from their accumulated remains, deep and extensive peat-bogs were formed.

In course of time, owing to land oscillations, these peatbog areas-formed mainly in large deltas and estuariesgradually sank below the water-level, and became covered with muddy deposits.

Coal was therefore in promise; but the peaty material had to be submitted to tremendous pressure from above, and to undergo various chemical changes, before attaining that condition. This was to be the work of Time.

As subsidence continued, an ever-increasing pressure resulted from the accumulations of clay, sand, and other earthy material deposited by rivers on the buried peat. In some cases these muddy deposits were of enormous thickness, indicating subsidence of very long duration.

After the downward movement had ceased, river-borne deposits must have gone on accumulating, until they appeared well above the surface of the waters. Whilst in some regions the reappearance of land was doubtless accelerated by earth movements resulting in actual upheavals.

Vegetation, no doubt, quickly spread over the new land : and in course of time dense brakes and forests held the ground beneath which the earlier sylvan wealth lay buried and compressed.

Owing to a repetition of land oscillations the peat-bogs, formed on these scenes of renewed verdure, experienced in their turn the same fate as those of earlier formation. The marshy areas sank below the water-level, and were gradually overspread with mud and sand. Thus the material for a second bed of coal, separated from the first by riverborne deposits, and itself buried in like manner, became stored in the strata.

In some regions these up-and-down movements continued for an inconceivably long time, resulting in the entombment of a series of peat-accumulations. The intervals in the process, no doubt, varied greatly, for the layers of coal and the intervening muddy deposits are of divers degrees of thickness. 
Finally, it must be supposed, the waters in these great peat regions acquired a lasting predominance; and the series of black seams in the strata was brought to an end.

INSECTS Carboniferous brakes and forests must have swarmed with insects, winged and wingless. Primitive cockroaches (Progonoblattina, etc.), locusts, and grasshoppers appear to have been especially numerous (Palcacridida). May-flies flitted about (Palingenia, Homaloneura); and forerunners of dragonflies were also on the wing (Protodonates). Some allied forms were enormous creatures, with bodies a foot and a half in length (Meganeura). Other of the insects apparently were wingless, and were probably spring-tails of primitive description (Dasypeltus). Early forms of stick and leaf insects were also in the woods (Protophasmida); and some relations of present-day snake-flies (Miamia). Most of the insects, however, although comparable with living forms, were more intermixed in their relationships than is the case in modern insect-life. They were all probably either predaceous in habit or suctorial, subsisting chiefly on juices of plants. Environment was not yet favourable for the evolution of flower-lovers and gatherers of honey.

MYRIAPODS Millepedes - first known in the Devonian - were now scoRpIoNs represented by many species. Certain scorpions by this time had developed lungs, and taken to living more or less SPIDERS on land (Eoscorpius). Various ancestral types of spiders were now abroad (Anthracomartida). Some specialised forms. (Geralinura, Eophrynus) resembled the predaceous scorpionspiders of our own time (Pedipalpi); and true spiders were

AIRbeginning to appear (Protolycosa, Palasanea). Land life was BREATHING also diversified by certain snails that had completely lost GASTROPODS touch with their briny relations (Dendropupa).

Marine life was in a condition of vigorous development. SPONGES Sponges with simple rod-like needles and improved canalsystems became much more prominent (Monactinellids) : and the older known forms, rigid with artistically arranged needles, were flourishing in quiet waters (Tetractinellids, Hexactinellids). Some new sponges now appeared with needles more numerously rayed than any earlier forms. The supports for the "fleshy" organism were irregularly dis- 
tributed, and apparently did not greatly redound to the welfare of their possessors (Hexactinellids); for sponges with needles so elaborately developed had no representatives in any later Period.

"Honey-comb" corals of the kind that built up Silurian corals and Devonian reefs were now declining (Favosites), but some closely allied forms (Michelinia) were in great force in some regions-notably in a sea that then extended over Belgium. New colonies were also appearing with zooids enclosed in porous body-walls; and by means of connecting-tubes a greater community of life was established than what had hitherto obtained (Palcacis). These more communicative corals were possibly ancestral forms of one of the great reefbuilding families of the present time (Poritide).

Cystids, long on the wane, were now on the verge of cystids extinction.

Although abundant and diversified in some North American SEA-LILIES waters crinoids appear on the whole to have been still declining. The sanitary reformers, it is true, continued well represented (Actinocrinus, Platycrinus, Batocrinus); but the elongated waste-tube was by no means becoming general. Many crinoids, without any notable safeguard against food-pollution, continued fairly prosperous; and some of these exhibited remarkable robustness in the ventral region (Hydreionocrinus).

A large number of crinoids were now in evidence with clinging tentacles developed on the stem (Woodocrinus). Probably the stem-roots were wasting away, and the outgrowths arose as helps to meet initial difficulties attending emancipation. A few forms indeed-at least in the adult state-seem to have gained a complete freedom to move from place to place (Agassizocrinus). This was an advance to modernism : for locomotion is enjoyed by the majority of crinoids now living. The family, whose members had the mouth exposed in the manner in vogue at the present time, had increased in genera ; but as regards numbers and distribution it continued insignificant (Ichthyocrinida).

Fossils occasionally contribute to decorative art: and Carboniferous crinoids, like Devonian corals, have been immortalised in beautifully patterned marble. 
Blastoids during this Period reached their climax, and some very graceful forms appeared (Orophocrinus). Their culmination, however, was not marked by any wonderful display; and they descended from their humble zenith with some rapidity. By the close of the Period they seem one and all to have collapsed; and their annals, therefore, were comparatively short. Possibly the somewhat complicated breathing apparatus, which they had developed, proved unworkable owing to changes in surrounding conditions.

STARFISHES

Very little evidence has come down of Carboniferous starAND BRITTLE- fishes and brittle-stars; but as their Devonian ancestors

STARS were not far short in development of modern forms, their evolutions can only have been of a trifling character.

SEA-URCHINS Rigid-tested sea-urchins of Silurian origin were still in some force (Palaëchinus). At this time, however, they were being superseded by some closely related forms in bodycoverings with the plates constituted in more modern manner (Melonites). Urchins in flexible tests were still numerous, but flexibility had been considerably reduced in some cases (Archaocidaris). Rigidity, it is clear, had long been the pass-word through the ranks. So far as is known the platerows on all tests, flexible and inflexible, continued excessive in number compared with what ultimately became the rule.

SEA-

Holothurians or sea-cucumbers, in skins embedded with CUCUMBERs minute wheels, anchors, and other limy products, were certainly now in being (Archistrum). Their precise line of descent is obscure, but there is no doubt that they and seaurchins and all other of prickly group had descended from a remote common ancestry. Their nearest relations in Carboniferous waters were probably the fast-vanishing cystids.

LAMPSHELLS The decline of lampshells does not seem to have been arrested; but these persistent animals made a good display in many parts of the world. Some forms, moreover, of record size now made their appearance. The most successful at this time were those clinging to resting-places in shells provided with long spines (Productide). Clingers of this kind had appeared as early as the Silurian, but neither in that nor in the succeeding Period were they much favoured by fortune. Their prosperity, therefore, was long in coming; 
and when it came, the pent-up energy expressed itself not only in vast numbers, but in some colossal forms. The champion of the Period dwelt in a shell measuring nearly a foot across ( $P$. giganteus). Brachiopods in butterfly-shells were alsa numerous, and flourished on European, North American, and Asiatic coasts (Spirifer).

Lampshell-life, therefore, although long past its prime, and robbed of much of its old variety, was by no means going to pieces.

No notable developments appear to have taken place among polyzoans. Open-mouthed colonies were still in force on the sea-floor at various depths; but they had been surpassed in number by the later-developed communities in which the zooids lived in cups partially protected at the orifice.

Marine snail-life exhibited some changes: but many old genera, dating as far back as the Cambrian, still held on their way. A few new forms were now to be seen in shells with loosely coiled tubes, rising in spiral fashion (Vermetus). This development of the edifice, though peculiar, was not unsuccessful, for some marine snails-of extremely passive character-are still in tenements of this design.

Early types of scallops, wing-shells, ark-shells, and mussels, BIVALVED and various double-shelled molluscs in intermediate con- MoLLUSCS ditions of development were more fully and widely represented. The emigrants to brackish and fresh waters were also on the increase.

Among the creatures combining pearl-oyster and mussel affinities some very large forms were in evidence (Aviculopinna); and oysters were appearing with which the edible oyster of our own time retains more or less close relationship (O. nobillisima).

Among new forms were animals of the date-shell type (Lithophagus); and primitive file-shells were also to be seen (Lima). Other forms were appearing with the edges of the mantle modified into tubes or siphons for conducting water to the gills (Allorisma). These siphons could be withdrawn completely within the shell-valves, and were probably developed in connection with burrowing habits. 
Changes were going on in Cephalopod life. Several old NAUTILOIDS genera had now disappeared; but some nautiloids of long descent, in shells more or less straight, were still in evidence. These old-fashioned creatures, however, were being rapidly superseded by nautiloids of later development, and shelled more in the manner of the living nautilus.

But the greatest vigour of cephalopod life was moving AMMONoIDS on the lines disclosed by ammonoids of the last Period. The transitional rod-like forms had now quite disappeared (Bactrites); and the field was held by a variety of the coiled forms known as Goniatites. The shells of these animals remained for the most part with smooth surfaces, but in a few cases were ornamented with knobs or tubercles (Gastrioceras).

Efforts to render the shell more portable for crawling purposes-observable in some goniatites of the preceding Period-were unrelaxed : and the shell, in consequence of the continued strain, was developing somewhat complicated patterns beneath the surface (Pronorites, etc.).

TRILOBITES No change of conditions favourable to trilobites occurred. Only one small family-and that dating from Ordovician times-now represented that ancient and once flourishing Order (Proëtida). The most prominent of its members were small forms, slightly modified from their ancestors, chiefly in regard to the tail (Phillipsia). Surely no beings other than trilobites ever underwent so many head and tail changes in the course of their career. Their lateral appendages, curiously enough, always remained of primitive character.

SEA- Neither were the sea-scorpions enjoying much better scORPIONS fortune. Apparently those strange creatures-giant forms of which had appeared in the preceding Period-were now represented only by small animals. Some of these, preferring fresh-water life, were frequenting streams and pools in the forests.

Sea-scorpions seem to have died out in North American waters during this Period; but in Europe their extinction took place somewhat later.

SHRIMPS Pod-shrimps were still declining; and long before the close of the Period they became extinct. Prawns, lobsters, and 
crabs were still to come; but their advent was foreshadowed by various forms more or less resembling opossum-shrimps (Anthrapalamon, etc.). Other animals, slightly carapaced, bore a close resemblance to mantis-shrimps (Necroscylla); some (Praanaspides, Woodward), wholly without carapace, resembled the mountain-shrimps now dwelling in rock-pools of Tasmania (Anaspides).

Time had brought many changes among creatures above the rank of invertebrates. The flat-headed, prickly skinned little fishes, and several other Devonian types, allied probably to sharks, had now died out. All the quaintly armoured semi-fishes had also become extinct; and a like fate had overtaken the armoured fishes with jointed necks (Avthrodiva). There seems, indeed, to have been a process of disarmament in operation; and fishes, instead of being provided with heavy protection for the skin, were to have their gristly internal framework strengthened, and their swimming powers improved.

Shark-like fishes were very numerous and widespread. SHARKS Some of these (Acanthodes) were small creatures, less than a foot in length, and belonged to a family first in view in Devonian seas. These newer forms were probably quicker in guiding movements, owing to the enlargement of the breast-fins. Numerous blunt crushing teeth have also been found, which belonged probably to sharks more or less resembling the mollusc-eating Port Jackson sharks of our own day (Cochliodus). There were also fishes that appear to have been diverging from sharks in the direction of rays or skates (Tamiobatis): and a species of the family (Raiida) SKATES seems already to have been in existence (Petalodus). In addition to these there were some strange-looking forms that appear to have been intermediate in development between sharks and dipnoans or lung-fishes (Pleuracanthus).

Lung-fishes were more fully represented: but the new DIPNOANS forms, except in being as a rule of larger size, differed but little from their Devonian ancestors (Ctenodus).

Numerous modifications were going on in the ranks of CROSSOPTthe ganoids. Among the fringe-finned forms characterised, ERYGIAN among other things, by paddle-like fins, none of the known GANOIDS 
Devonian genera had survived: and the outlook was not very promising. In certain localities, however, some fishes of this type measured from five to ten feet in length, and were giants compared with earlier forms (Megalicthys, Rhizodus). Others were more advanced in anatomy. An improvement had been effected in the bony structure of the skull ; and the tail was assuming a modern character. The backbone was still of a gristly substance; but certain ossifications were going on within the body (Ccelacanthus). Fishes of this well-equipped family held their own for a long time.

The fringe-finned ganoids, however, were fast losing importance in consequence of the rapid on-coming of their ACTINOP- " ray-finned" brethren. These more flexibly finned fishes TERYGIAN - sparsely represented in the Devonian-were now becomGANOIDS ing numerous and varied. Some were long, herring-like forms (Palaoniscida); others had deep and more or less. compressed bodies (Eurynotus, Cheirodus). In their case, and indeed in the case of nearly all the ganoids, the end part of the spinal column was upturned, and extended to the extremity of the tail. The tail, therefore, was not of the: type best adapted for fleet swimming. Improvements in this and other respects were in store.

AMPHIBIANS Fishes, progressing though they were, had ceased to be in the van of vertebrate life. A momentous evolution, originating no doubt in much earlier times, was now clearly revealed by certain vertebrates possessing ability to breathe by lungs, at least in the adult state, and to crawl about on land. Amphibians, in short, had been evolved; and various creatures resembling in form lizards, newts, and salamanders were now on the scene.

(STEGOCEPHS) All these pioneers of higher life are known as stegocephs, as their skulls and cheeks were well " roofed" over with continuous bony plates. Very little is known about the early Carboniferous forms; but towards the close of the Period the animals were in evidence on several lines of evolution. Some, of salamander shape, did not measure more than two or three inches in length. These were triangular-headed, large-eyed little creatures, weak in the limbs, and with 



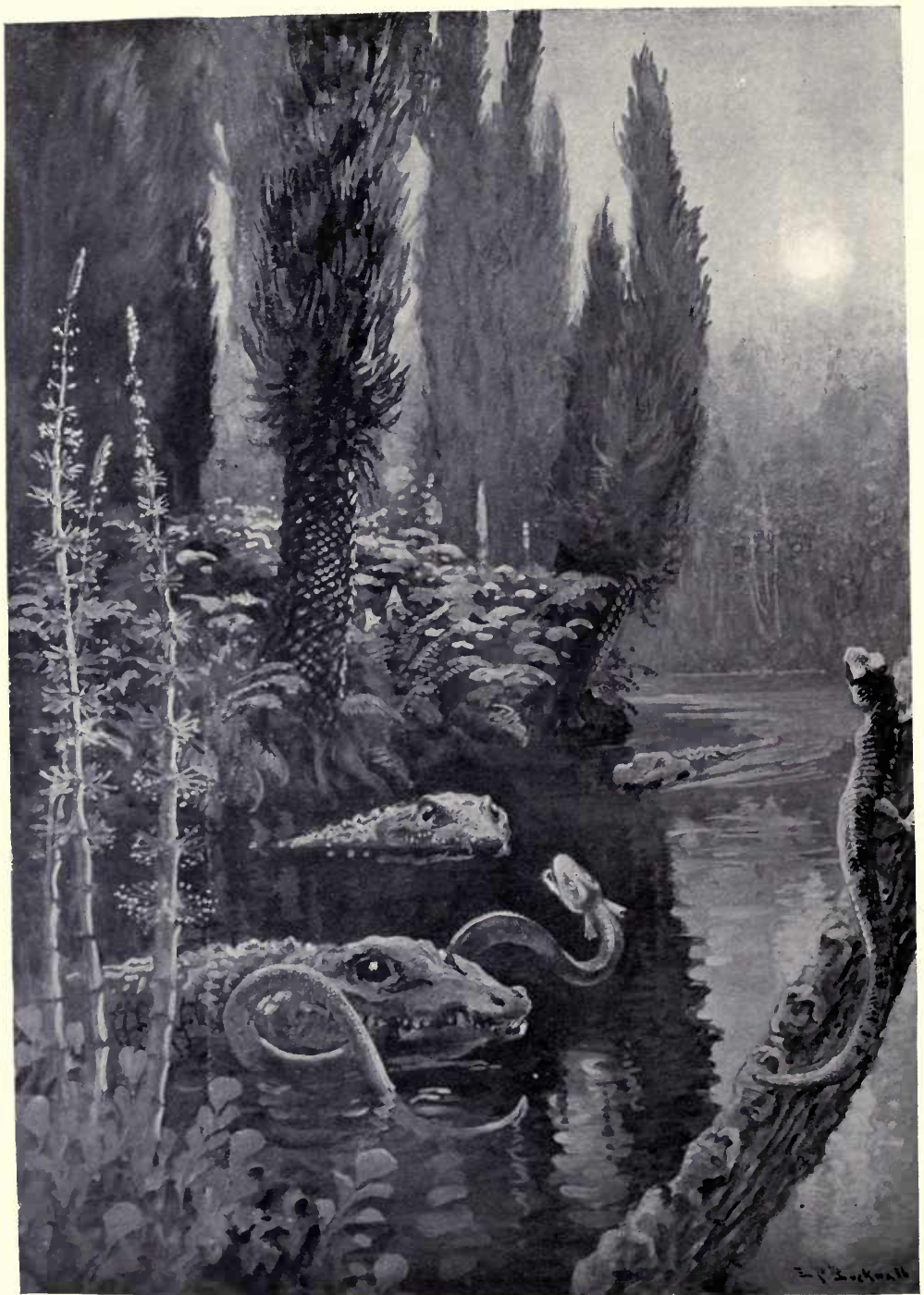

Kerater- 
"backbones" incompletely ossified. The under-part of the body was well covered with scales, affording protection in creeping over hard ground (Branchiosaurus). Others, in some cases four times the length, with elongated heads, tapering snouts, and long tails, possessed fairly stout hindlimbs, and the string of gelatinous tissue (notochord) running through the length of the body was enclosed in bony cylinders (Keraterpeton, Lepterpeton). In more advanced stegocephs, the vertebral column was well ossified, and had undergone divisional processes in order to render it more flexible (Dendrerpeton). These were strong-limbed little creatures, and probably penetrated far into the sylvan solitudes. Besides these, some large amphibians were abroad with skulls a foot and more in length, and with jointed backbones completely ossified (Loxomma, Anthracosaurus). Their teeth were remarkable, as numerous folds of the coating enamel invaded the dentine or inner substance of the teeth in a labyrinthine manner. These animals, known as labyrinthodonts, appear to have been the most formidable members of the new life; and in the absence of serious competition they doubtless fared sumptuously in their watery and riverside haunts.

Then there were other forms-about a yard in lengththat had lost their limbs (Dolichosoma); and must have somewhat resembled the limbless amphibians of our own time (Apoda). They probably preyed on the fishes and smaller stegocephs : and may occasionally have found themselves between the labyrinthine teeth of the lords of the rivers and marshes.

That the stegocephs were evolved from fishes there can be little doubt. Even at the present time amphibians retain many affinities with fishes, and Carboniferous amphibians held closer relationship with the fishes of their time. Their nearest relatives appear to have been the fringe-finned ganoids (Crossopterygians). These they resembled in several anatomical respects, notably in the structure of the skull, and in the hard plates round the eyes; whilst the labyrinthodonts - the most important amphibians-possessed teeth much as those of some of the fringe-finned ganoids. The 
earlier forms have come down to us less their limbs, but from footprints left in the strata it is clear that the limbs of some of them terminated with what may be called fingers and toes. Most of the later Carboniferous amphibians certainly possessed well-developed digits. The breathing difficulty had, no doubt, been overcome more or less in the same manner as with the lung-fishes. The animals in their youth, it may well be supposed, breathed through gills, for even in present-day amphibians lung-breathing is seldom developed until the adult state is reached.

The Carboniferous strata, therefore, are not only remarkable for their coal supplies, but also for the evidence they yield of a well-developed and varied life of higher rank than fishes. 



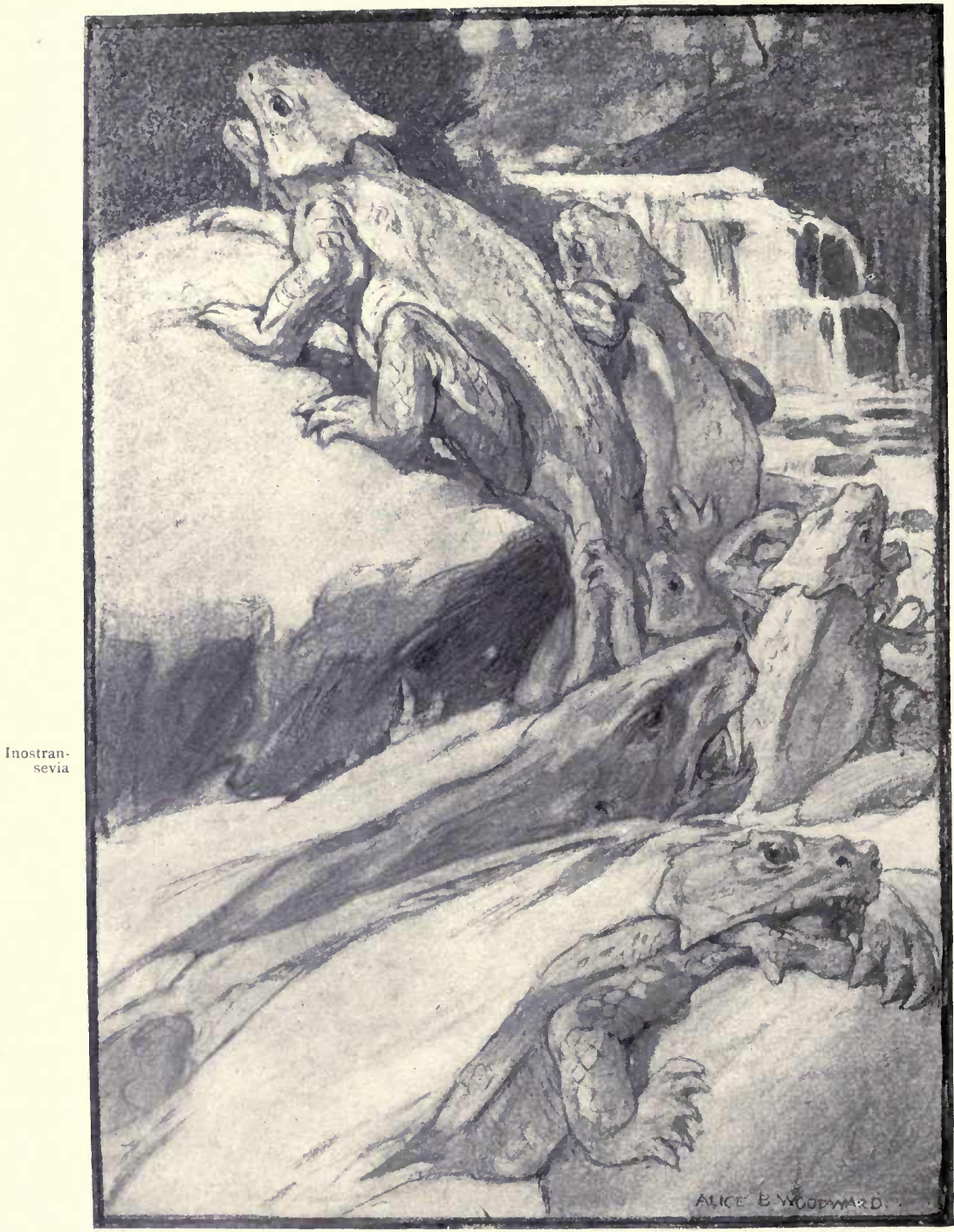

Pareia-

saurns

PERMIAN REPTILES

To face page $6 \mathrm{t}$ 


\section{PALÆOZOIC AGE}

\section{PERMIAN PERIOD}

MANY new species of stegocephs were now to be seen AMPHIBIANS swimming the rivers, and crawling the marshes. Some were (STEGOCEPHS) becoming of decidedly crocodilian aspect; but, so far as is known, they presented no essential differences from the types of the preceding Period. Forms, however, much larger than those of Carboniferous date were certainly abroad, especially among those with teeth of " labyrinthine " structure (Labyrinthodonts). Some of these animals attained a length of nine feet (Cricotus); whilst others with broad skulls of two feet in length must have been of colossal proportions (Eryops). These monsters were inhabitants of North American swamps and rivers. The largest European stegoceph-a creature of crocodilian appearance-was hardly as big as a monitor lizard (Archegosaurus).

Some stegocephs with teeth of simpler construction possessed what are known as abdominal ribs, i.e. transverse fibres of ventral tissue faced with a bony substance (Petrobates). A protective development of this description is characteristic of many reptiles.

But whatever may have been the reptilian tendencies REPTILES disclosed by some amphibians, a distinct divergence from the ranks of the latter had taken place, for primitive reptiles were now on the scene.

Most of these new leaders of life differed notably from the " roofed-head" amphibians owing to cranial modifications. Their skulls were not of the blocky type, but had been hollowed out in parts, and made lighter and more refined. These modifications had, no doubt, been accompanied by other important changes, mental as well as physical. 
The respiratory system, owing to lack of evidence, cannot be determined. Probably the animals did not breathe in infancy by means of gills, as did the amphibians, but were throughout life lung-breathers.

Some of these Permian reptiles scarcely attained a foot in length (Palceohatteria); but remains of more important animals quite five feet long have been found in England and Germany (Proterosaurus). These various animals must have looked very much like lizards, and crocodiles, in spite of anatomical differences. So far as can be ascertained the lizard-like Sphenodon of New Zealand has not much departed from them in structure. Indeed, that now-vanishing creature may almost be looked upon as an unmodified descendant of the founders of all the reptile race.

(THERO-

Towards the close of the Period reptile-life became diversiMORPHS) fied by various forms with marked resemblances to mammals, not only in tooth, but also in bodily structure. These advanced creatures have received the name of Theromorphs, or " beastshaped." Some in possessing well "roofed" skulls kept up a connection with the stegocephs (Pareiasaurus). These heavily skulled forms were probably of gregarious habits, and spent a good deal of their time in the waters, subsisting chiefly on aquatic plants. Many of them were big animals, some forms attaining a length of several feet. No doubt they were somewhat clumsy pedestrians when out on landexcursions; but they could when locomoting keep the stomach clear of the ground. This was an achievement of which a reptile might well be proud. They appear to have been prosperous animals. Their range was certainly extensive, for remains of them are found in regions so far apart as South Africa and Northern Russia.

Their peace, it is to be feared, was occasionally disturbed in some regions by certain big reptiles, likewise " beastshaped," but of a flesh-eating disposition. These theromorphs had skulls of the newer type, and their teeth were decidedly more of a mammal than reptile character. Some of these ferocious creatures-additional and important remains of which have been recently discovered in Russia (Professor Amalitzky, of Warsaw)-had tiger-like tusks 



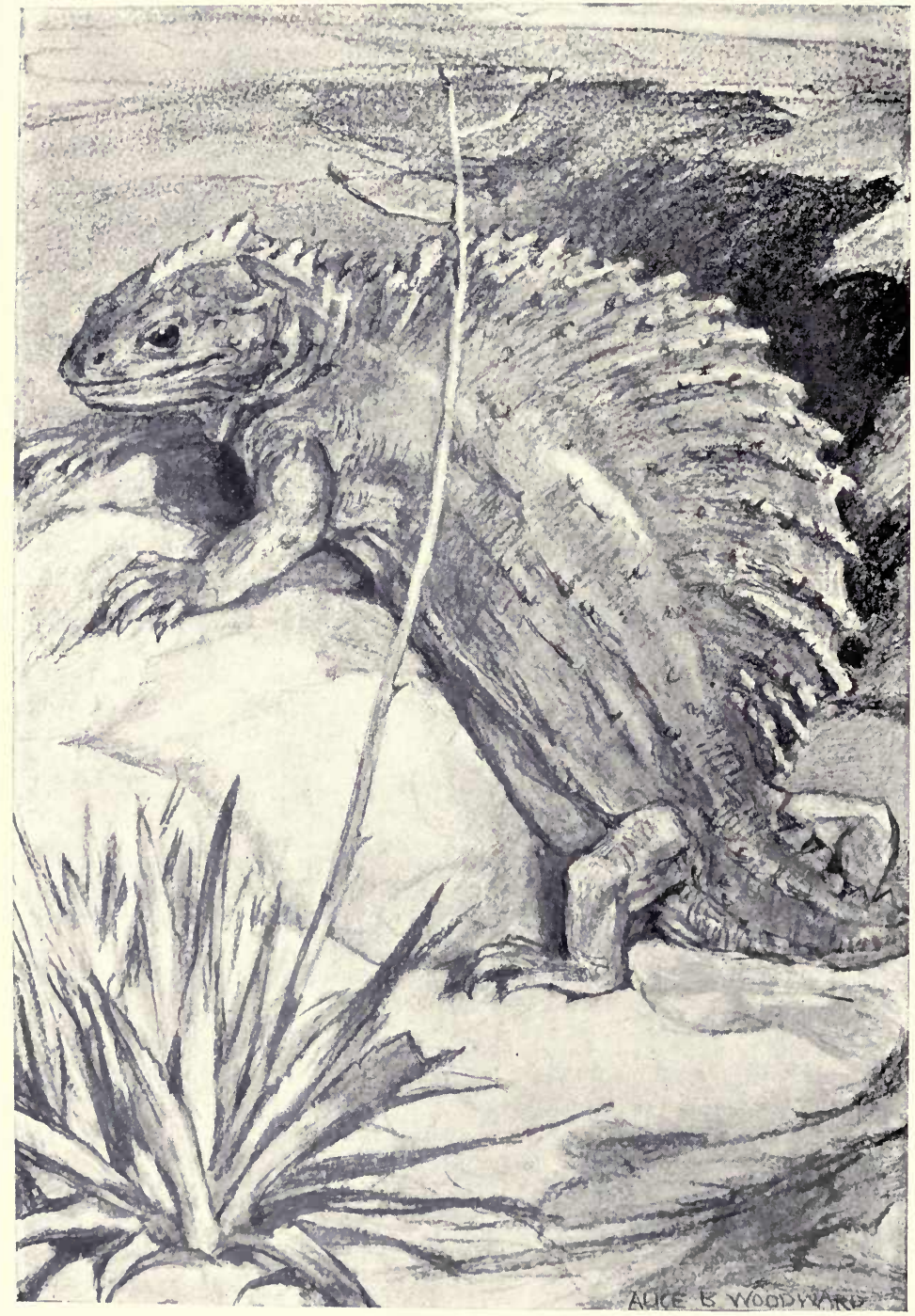

EDASOPHAURUS

A Permian crested reptile, about the size of a large sheep

[To face page 63 
(Inostransevia). As they were probably good swimmers, and not indifferent pedestrians, the vegetarian reptiles must at times have had their locomotive powers severely taxed.

Some of the tusked reptiles, living in South Africa, resembled lions in the shape of the skull (Dicynodon). Apparently of the same race were certain tuskless and toothless forms (Oudenodon). These, it is thought, belonged to the gentler sex.

Other " beast-shaped " reptiles were remarkable for crests, (PELYCOsupported by spines rising vertically from the backbone SAURIANS) (Pelycosaurians). The crest was probably susceptible of being raised or depressed; and was only at its highest elevation in times of excitement. In some cases the spines were branched, and the raised crest must have had a broad and hood-like aspect (Edaphosaurus).

The animals varied greatly in dimension, some (Edaphosaurus) being the size of sheep, whilst others (Theropleura) were as long as full-grown tigers. They all possessed strong and well-clawed limbs; and could, no doubt, keep the body clear of the ground when walking. Their haunts, it is supposed, were along the banks of rivers and estuaries. Occasionally they may have taken to the water; but they were not well adapted to aquatic life.

The broad-crested forms, to judge by their teeth, subsisted chiefly on molluscs and vegetables. Most of the other forms were of fierce carnivorous habits (Dimetrodon, etc.); and, no doubt, waylaid small amphibians and reptiles incautiously coming to land. At times they certainly became engaged in serious hostilities ; for many spine-supports have been found marked with ugly wounds.

Some members of the crested group lived in Europe; but the animals were in far greater force and variety on North American scenes. Even there, however, their career was of no great length; and at the close of the Period they seem to have become extinct on both continents.

In late Permian times several forms of "beast-shaped" (THERIOreptiles-sub-classed as Theriodonts or "beast-toothed "- DONTS) exhibited marked resemblances to mammals in tooth and 
skull, and in some cases as regards the limbs (Cynognathus, Tritylodon, Theriodesmus).

(CHELONIANS) Other reptiles appear to have been developing on tortoise lines, and were protected on the anterior part of the back by several bony plates (Diadectes, Cacops). In some of the smaller forms the plates seem to have covered the whole back; and, moreover, to have curved down on either side, affording the animals an almost box-like protection (Otocceus, Conodectes). These creatures, it is clear, were intent on a quiet life. The world was becoming troublous and strifeful ; and a walled existence afforded some escape from surrounding evils.

By the evolution of amphibians, fishes had lost the leadership of life, and the rise of reptiles placed them still farther from the van. In spite, however, of their humiliation, their evolution was proceeding with some rapidity. Fish-life, in fact, had never lagged; indeed, so far as evidence goes, it had come on with leaps and bounds from the time of its first appearance. But in spite of rapid development, fishes, at the close of the Carboniferous Period, had not undergone much ossification of the internal gristly skeleton, and so fell far short of the great majority of living fishes. Bony substance they certainly possessed, but this was more in the hard scales than in the internal framework.

ACTINop- It is in this Period that a glimpse is gained of some flexibly TERYGIAN finned ganoids with internal skeletons that had in great part GANoIDS become ossified (Acentrophorus). This improvement had probably been effected at the expense of the hard scaly covering. These fishes, moreover, had their median fins more adequately supported than was the case with their forerunners; and the tail was losing its old unsymmetrical (heterocercal) character. The upper lobe, hitherto much elongated by the invasion of the spine, was becoming spineless; and the short lower lobe was lengthening. The two lobes were thus becoming symmetrical, and the end of the "backbone" was being modified so as to provide them with a common base. In other words, the tail was becoming of the homocercal type, such as characterises the vast majority of fishes now living. 


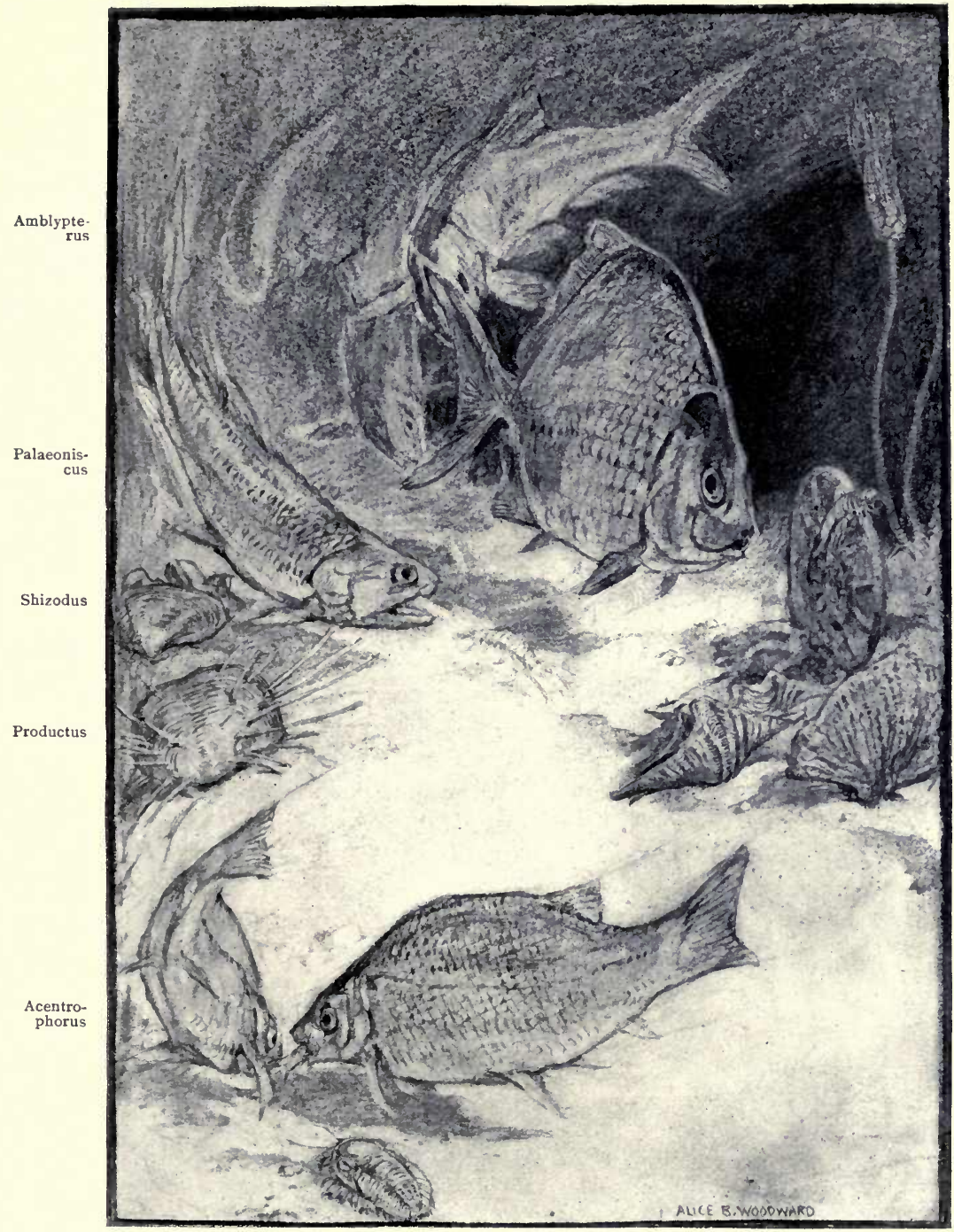

Crinoid

(Cyathocri-

nus)

Platysomus

Ammonoid

(Xenodi-

scus)

Lampshell

(Spirifer)

Polyzoan

(Fenestella)

Phislipsia

PERMIAN MARINE LIFE

To face page 64 

These fishes were doubtless the most highly developed of Permian forms, and were the forerunners of great developments in fish-life. As yet they were small in size, and insignificant in number.

Meanwhile the other flexibly finned ganoids, with more gristly skeletons, harder scales, and old-fashioned tails, were greatly on the increase, being represented by old and new genera (Platysomus, Palconiscus, Amblypterus).

The fringe-finned ganoids were still losing ground. But CROssopif, as seems likely, their Order had been more or less bound TERYGIAN up with the evolution of amphibians, they were not sinking GaNoIDs into obscurity with dishonour.

Many old genera of fishes of the lung-breathing type had now DIPNOANS disappeared; and only two or three new genera made their appearance (Conchopoma, Sagenodus). This division of fishlife had certainly lost importance, in spite of its doublebreathing abilities.

Nor do the sharks seem to have been enjoying much SHARKs prosperity. Possibly such as subsisted on finny life had been handicapped by the increased speed and wariness of their prey. Some forms, however, that had appeared in the Devonian, and had descendants with better-developed breastfins in the Carboniferous, were now represented by species still better off in that respect (Acanthodes). But it cannot be said that sharks were holding any remarkable sway in the seas. They were, no doubt, the best brained of all the fishes; and sharks, indeed, enjoy this pre-eminence at the present time.

The marine invertebrate life, so far as it is known, presents few distinctive features from that of the last Period. There is certainly not much progress to report in its fortunes. Indeed, for the most part, it seems to have been in a greatly depressed condition. The plight of some of its Orders is intelligible enough, for signs of decay had long been in evidence: but other groups that had been more or less prosperous, and are known, moreover, to have fared well in later Periods, seem for the time to have been wellnigh in extremis. Not only do they appear to have diminished in PROTOzoANs, numbers, but to have been reduced also in size. Even the ETC. 
minute foraminifera were smaller than many of their ancestors in Carboniferous seas. Sponges were very poorly represented. In coral-life reef-building was almost brought to a standstill. Starfishes and brittle-stars seem to have been quite under a cloud. Cystids, long languishing, died out early in the Period. Great havoc had been wrought in sealily ranks. All the sanitary reformers apparently had been wiped out : and crinoidal fortunes seem to have been in the keeping of an old family that had struggled on from Ordovician times (Cyathocrinida). But it was not all a catalogue SEA-URCHINS of woe. Sea-urchins of Devonian type, both flexible and inflexible, had indeed been nearly exterminated; but " rude forefathers" of some modern urchin-families were just beginning to appear. These were enclosed in rigid tests, with vertical plate-rows reduced to the number that now Polyzoans obtains (Hemicidaris, Cidaris). Polyzoan colonies were in great force. Those of the open-mouthed type had recovered their ascendency; but the rival group was well in evidence LAMPSHELls (Fenestella). Brachiopods or lampshells, though reduced in variety, made a good display, especially in Asiatic waters. Species with anchor-spines continued most prominent; but no giants were now in their ranks (Productida). Other forms in " butterfly" shells-also much in evidence in Carboniferous seas-were abundant (Spirifer); and several other lampshells of remote lineage were still clinging to the rocks.

BIVALVED There is no great progress to report among bivalved MOLLUSCS molluscs; but they attested their character as a rising group by new forms of ark-shells (Schizodus); and by the evolution also of some small forms (Bakewellia), founders of a presentunIVALVED day family of pearl-oysters (Pernida). Univalves exhibited MoLluscs little or no progress. The most prominent at this time were creatures in bell-shaped shells of Silurian pattern (BelNAUTILOIDS lerophon). Apparently all species of nautiloids in slightly curved shells had died out; and those in straight shells were represented by only one genus that had persisted from the Cambrian (Orthoceras). Several genera, however, in shells more or less resembling the coiled shells of the living nautilus, were about the seas (Stenopoceras, Pselioceras); and the long competition between the " uncoiled " and the "coiled" 
was thus terminated by the decided predominance of the latter.

Ammonoids-the most recently developed cephalopods AMmoNoIDS -were exhibiting all the adaptability of young life. Goniatites were disappearing, or at least, by an increased portability of the shell, were being transformed into ammonites. This is evidenced by the twisted and complicated patterns which were now being wrought beneath the shell-surface (Medlicottia, Xenodiscus). Outward ornamentation of the shell was also becoming a feature.

Trilobites-so widespread and varied in the past-were TRILOBITES now represented by only one or two species that soon became extinct (Phillipsia). Sea-scorpions were also but feebly SEArepresented (E. remipes); and likewise vanished in the scoRPIONS course of the Period. To redress the balance some very small creatures, developing apparently in the direction of lobsters CRUSTACEANS and crabs, were now beginning to appear (Hemitrochischus).

Marine invertebrate life may not, of course, have suffered so greatly as the geological record leads one to surmise; and discoveries may yet be made which will point to its having been in a much less impoverished condition. There is, however, good reason to suppose that in some regions, especially in the southern hemisphere, Permian life for the most part laboured under exceptional difficulties. At the commencement of the Period, and more or less until its close, severe glacial conditions prevailed over vast areas, that had for long enjoyed mild and equable climate; and the results to life must have been disastrous.

Vegetation, without doubt, was greatly affected; and vEGETATION some growths, long accustomed to humid and relaxing airs, having lost their pristine powers of ready adaptation, were in a parlous state. The progress, however, of growths of newer type and of more elasticity was, it would seem, expedited.

Calamites or "horsetails" certainly suffered; and the branching tree-like club-mosses, and their pillar-like allies dwindled almost to extinction (Lepidodendra, Sigillaria). The endeavour of certain Carboniferous lycopods to steal a 
march on other club-mosses by producing seeds instead of spores had resulted in complete failure; and no ambitious speculations in reproduction were again attempted.

Several new genera of ferns were superseding those of earlier times. In the southern hemisphere and also in northern Russia some hardy species with simple leaves variously shaped became abundant (Glossopteris). In northern Russia certain ferns by stem and leaf-stalk modifications exhibited important advances in development, indicating a greater division of labour (Zalesskya, Thamnopteris). Cycadferns continued numerous, but were now yielding to forms not far short of being true cycads (Pterophyllum, Sphenozamites). Meanwhile the old flower-bearing cordaites were fast succumbing.

CONIFERS The most notable Permian growths were of true conifer character. Primitive conifers-derived from plants of the Cordaite type (Cordaitales) -were probably, at least in sparse numbers, in Carboniferous woodlands; but the stability of the line was not well established until late in the Permian. Period. Many well-developed forms then adorned the landscapes: and although they differed in some respects from living conifers, they can be brought more or less into line with them. Some were closely allied to cypresses and araucarias (Walchia, Ullmania); some to spruces and Sequoia firs (Voltzia, Schizolepis); and some to yew, and gingko or maidenhair trees (Baiera, G. primigenia). These various growths, however, brought no bright colours in their train; and vegetation remained of a dull, monotonous hue. Nor were there as yet any birds, or even butterflies, to relieve. the sombrous scenes.

This brings us to the close of what is known as the Palæozoic Age. This Age with its six Periods must have lasted many millions of years; and was probably more than thrice as long as all the time that has elapsed since its close.

Progress, if slow, was sure. Plant-life, consisting in the Cambrian probably of algæ, funguses, lichens, liverworts, and other humble spore-producing growths, underwent in time various modifications, resulting in ferns, "horsetails," and club-mosses. Then came seed-bearing cycad-ferns and 
cycad-conifers; and finally shrubs and trees comparable with cycads and conifers of our own time.

Invertebrate life at the close of the Cambrian was certainly well represented in its existing main divisions; and during succeeding Periods of the Age great developments went on within its varied ranks.

There were also some notable examples of what seems to be the fate of all forms of life on earth. Cystids and blastoids rose, declined, and became extinct. Lampshells reached a grand zenith, and then entered on a downward path. Trilobites, after attaining vast variety of form and world-wide distribution, slowly declined, and utterly passed away. And sea-scorpions experienced, on a smaller stage, a like cycle of fortune.

From invertebrate ranks fishes gradually emerged, and, after a rigorous Natural Selection, some forms with greatly improved swimming powers, and with stronger internal framework, came into evidence. In course of time amphibians - evolved from certain of the fishes-made their appearance, and branched out into several types. And finally from amphibian ranks reptiles came forth, and took up the leadership.

In spite, therefore, of retrogressions and destructions, of waste and suffering, the main movement in Life was distinctly onward. Nor were signs wanting at the close of the Permian of coming great developments. 


\section{MESOZOIC AGE}

\section{TRIASSIC PERIOD}

VEGETATION TRIASSIC landscapes bore witness to great conquests made by the newer vegetation. Various growths more or less allied to araucarias, spruces, Sequoia firs, yews, cypresses, and maidenhair trees extended far and wide, and abounded with species. Club-mosses and "horsetails" struggled on with but scant success. Among the latter were some scarcely distinguishable from the modern degraded forms (Equisetum). Pillar-like sigillariæ-rampant in Carboniferous forests-had almost disappeared: and the old-fashioned, wedge-leaved climbing growths of mixed affinities had quite died out (Sphenophyllum).

FERNS Ferns, however, although of ancient standing, continued to spread with the vigour and resource of earlier days. Many Carboniferous genera flourished as of old; and new forms of like character (Eusporangiates) - some closely related to the existing "Adder's Tongue" (Chiropteris)-were also unrolling their fronds in the tangled undergrowth. Other débutants exhibited improvements in spore-case construction, and produced their spores in a more specialised and complex manner than did the older forms. These more advanced ferns were undoubtedly forerunners of the now prevailing type (Leptosporangiates). Towards the close of the Period some (Acrostichites princeps) but little distinguishable from " Royal ferns" (Osmunda regalis) were luxuriating in marshy lands, and adorning the banks of lakes and streams. Others appear to have been precursors of the Polypods-the dominant fern family of our own time (Cladiophlebia). 


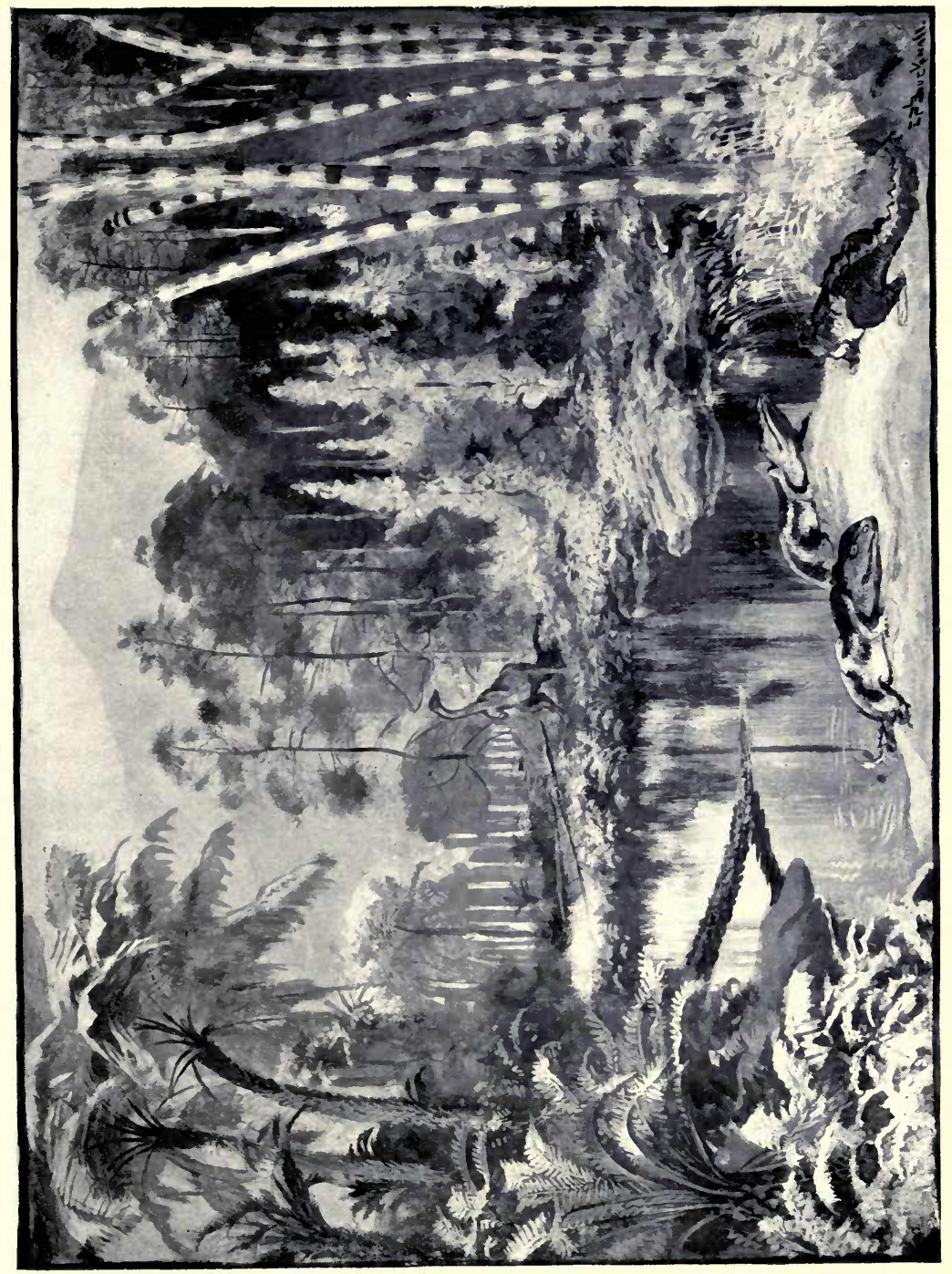

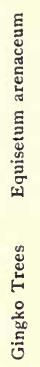

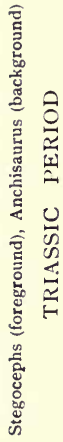

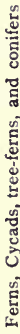



The flower-bearing cordaites had failed in their compe- CORDAITES tition with other seed-producing plants, and had become extinct; whilst cycad-ferns had been entirely superseded CYCAD-FERNS by offshoot forms describable as true cycads. The latter as a rule were short-stemmed plants, but some bore their feathery crowns on stems ten feet in height.

Cycads, moreover, were in evidence on various paths of cyCADS development. Some seem to have been on the lines of the modern Zamia (Zamites); others on the lines of the Australian Cycas. The most remarkable of all are not now represented in the plant world (Bennettitea); and they were of much higher organisation than any cycads now living. Fair-sized starlike flowers, possibly of greenish hue, stood out among the foliage ; and the fruit resembled in structure that of angiosperms - the most highly developed of living plants. The seeds, therefore, being enclosed or "vesselled" in an ovary, were much better protected and cared for than the " naked" seeds of conifers. Apparently these highly developed cycads held the leadership in the leafy world : and the greater care they took of their seeds marked an advance in what may be called the morality of plant-life.

How far insects were assisting in the development of INSECTS vegetation it is impossible to say. Doubtless these little creatures were increasing in variety, and changing their tastes and habits from time to time. Various kinds of beetles were certainly now in existence (Carabida, Buprestida, etc.); but bees and butterflies, so far as is known, were yet to come; as were also the various flowering plants to which they are specially helpful in the matter of fertilisation.

It will be necessary to return to Triassic lands. Meanwhile our glance must be directed to the submerged masses.

Invertebrate life-no longer in a pitiable conditionattested the sweet uses of adversity. Sponges with lime sponges spicules-first known in the Devonian-were flourishing in various shapes and sizes (Eudea, etc.). They seem to have been especially prosperous in central Europe, a large portion of which was at this time under water. 
CoRALs Many old forms of corals had passed away; or, if they can be said to have survived, it was only in modified descendants. One family (Poritide), which came in view in sparse numbers in the Carboniferous Period, was now markedly in the ascendant. The success of these corals was probably due to their possessing perforated body-walls, and their enjoying, therefore, a greater community of life. At the present day their descendants are in great evidence on the Australian barrier-reef.

Many colonies were also in existence composed of corals in solid body-walls : and descendants of some of these less socialistic communities are still living (Stephanoconia).

SEA-LILIES Crinoids, or "sea-lilies," were slowly recovering from Permian afflictions; but their convalescence was no prelude to a renewal of whilom vigour. They were certainly more modern in structure. This may be gathered from the manner in which the "arms" were attached to the cup; and from the fact that the exposed mouth-rare in earlier times-had become general (Encrinida, Pentacrinida).

SEA-URCHINS The lead in "spiny-skinned" life was in this Period being taken by sea-urchins. With most of these the bodycovering had been consolidated into twenty vertical rows of plates-the regulation number at the present day. A few reactionary forms with more than twenty plate-rows appeared occasionally in later times; but sea-urchins in tests of that character practically made their last appearance in this Period.

Polyzoans Among Polyzoans, the colonies with zooids in openmouthed tubes had entirely eclipsed those in which the zooid-tubes were " hidden-mouthed." Indeed there is little or no evidence that the latter colonies were even in existence. There is, however, reason to think that they were undergoing important improvements, the installation of which was involving them in temporary difficulties.

LAMPSHELLS Brachiopods were still on the downward path. More families had become fossil: but some of long standing and noted for well-beaked shells, were exhibiting no little vigour (Rhynchonellida, Terebratulida).

Bivalved molluscs retained, in great part, a mixed and 
archaic character, but fresh threads, so to speak, were BIVALVED coming out of the tangle. Some forms in the last Age had molluscs been developing in the direction of mussels; and freshwater and sea mussels of modern type were now in being (Unio, Mytilus). New forms of ark-shells were also in view ; some of which are still represented in the mollusc world (Limopsida). Oysters somewhat of the "thorny" kind were also on the scene (Plicatula); and cockles, which had more or less given sign in the last Age, were now rid of old partnerships, and established as a distinct family (Cardiid $\infty$ ). Among the bivalves with long, retractile siphons, new forms were to be seen (Corbula). These appear to have been of the type of the "gaper" molluscs of our own time (Myada), with "feet" too large for their shells.

Gastropods fell far short of the bivalved molluscs in point UNIVALVED of number : and it was a very long time before they equalled, Molluscs and finally surpassed them. The mental superiority of snails to bivalves may not have been so great then as now.

The most noteworthy fact in the Triassic annals of gastropods was an elaboration of the breathing system in certain species. Most of the marine snails then living probably breathed entirely through the skin, as do some of the fraternity at the present time. Some forms possessed gills as additional means of respiration; and it was in the case of certain of the gilled snails that notable changes had taken place. Aerated water had, of course, to be carried to the fold in the mantle where the gills were located; and this had hitherto been done through the agency of modified edges of the mantle. Under the new arrangement the work was being done in a more cleanly and efficient manner by means of a well-defined tube or siphon (Cerithiida).

In spite of the multiplications and deployments of bivalves, and the on-coming of univalves, cephalopods continued the leading molluscs. Their adaptive powers were certainly great, and they were probably the "intellectuals" of the mollusc world. How far their mental development was accelerated by the habit of walking more or less on the head cannot be determined. 
NAUTILOIDS Some old-fashioned, straight-shelled forms were still in existence (Orthoceras); but their protracted annals were now about to close. Coiled nautiloids held an easy dominance; and some old species that had been slowly developinginto the condition of the living Nautilus had now almost reached the goal.

AMmonoIDS The greatest activity in development was among the Ammonoid cephalopods. The Goniatites had wellnigh disappeared, or been transformed; and practically all Triassic. members of the Order may be described as Ammonites. The creatures, as a rule, had their shells in a far more portable. condition, as shown by the complicated sub-surface patterns. These twisted markings had assumed ornate characters, and resembled in many cases small foliage delicately indented (Phyllocampyli). In addition to this concealed beauty, many shells, owing to modifications on the edge of the mantle or body-skin, were highly decorated on the exterior (Pachycampyli).

Conditions were extremely favourable to ammonites for the greater part of the Period. They abounded in an immense variety of forms, their shells differing not only in sub-surface tracery, and outward ornamentation, but also in shape and strength.

Their range was world-wide, and they certainly attained. their climax in this Period, but before its close some signs. of breakdown became evident.

BELEMNITES Just as these signs were appearing, Cephalopod-life was. recuperated by the rise of creatures not greatly differing from squids and cuttle-fishes. They are generally spoken of as belemnites-a name derived from the dart-like appearance of their shells (Belemnitida). The shell, in being straight and tapering, exhibited a notable difference from the ammonite shell. It had, moreover, by a reverted extension of the mantle or body-skin, become internal.

Triassic belemnites were few in number, and small in size-the largest not being more than a few inches in length. As a rule they were provided, like cuttle-fishes, with ink-sacs, for clouding the water and confusing foes.

The origin of the animals is lost in obscurity. Their nearest 
relatives in Triassic seas were probably the straight-shelled nautiloids, rapidly passing away (Orthoceras).

The Permian promise-if promise it was-of the appear- CRUSTACEANS ance of crabs was not fulfilled. Crustaceans, however, were now in view with much nearer resemblance to prawns and lobsters than were the "pod-shrimps" and opossum-shrimps of earlier times (Pemphix).

King-crabs - called crabs by courtesy-were now in exist- KING-CRABS ence with a second shield developed. These animals appear to have been identical in structure with the modern Kingcrab (Limulus). The half-formed creatures, with front-shields only, seem by this time to have died out.

Triassic King-crabs were diminutive creatures; but the departure of their ancestors from the doomed and afterwards overthrown trilobite ranks had ensured survival.

Fish-life, different though its aspect from that of modern times, was making headway.

Sharks, after serious reverses in Permian seas, were now SHARKS abroad in new genera, and in great abundance (Hybodus, Acrodus, Strophodus). And less predaceous fishes were enjoying prosperity, not only in spite of old foes, but in the face of new dangers which will be noted presently.

The old "fringe-finned" ganoids with paddle-like fins GaNoIDs were still waning (Crossopterygii). This Order had apparently played its part-and a great one-in giving rise to primitive amphibians.

Among the more flexibly finned ganoids (Actinopterygii) old and new genera were now to be seen. The most notable absentees were certain deep-bodied forms such as had flourished in Carboniferous and Permian seas (Eurynotus, Platysomus). Among new forms may be mentioned some gristly skeletoned fishes with hard enamelled scales (Catopterus, Dictyopyge), and akin to some fishes of Permian times (Palconiscus, etc.). They, however, showed advance in development over their forerunners in having the dorsal and anal fins more effectively supported. Their tails, moreover, were of less antique character, in being to a certain extent free of the spinal column. In some closely allied pike-shaped forms an ossification of the spine was well in progress; 
but these did not exhibit in other respects notable advance over their Permian predecessors (Belonorhynchus, Saurichthys).

The most interesting ganoids were some highly developed forms, a few forerunners of which had appeared in the preceding Period (Acentrophorus). These possessed vertebral columns well ossified, dorsal and anal fins adequately supported, and tails that were assuming modern character. In short, they possessed all the features of progress evident in fish life; whilst no other fishes possessed them in entirety.

Fishes of this type-so rare in the Permian-were now varied and numerous (Semionotus, Lepidotus). They were for the most part of strange aspect, and not closely comparable with living fishes. Some very small forms bore a resemblance to herrings (Pholidophorus). Other forms (Caturus) in some respects strongly resembled the bowfins of our own time (Amia).

At the close of the Period these various members of welladvanced fish-life became fairly abundant; but their less highly developed relations-suggestive of bottles too old to hold much of the new wine-continued predominant.

Curious old forms, intermediate in development between sharks and lung-fishes (famous in Carboniferous and not insignificant in Permian seas), had now become practically DIPNOANs extinct (Pleuracanthus). Among dipnoans a few forms had now reached a point at which they differed very little from the Australian "mud-fish" of to-day (Ceratodus). In Triassic times "double-breathers" were abandoning salt water for brackish and fresh. And in this Period they practically made their last appearance as marine fishes.

AMPHibians The lizard-like Stegocephs were now represented by a variety of forms (Capitosaurus, Trematosaurus). Large-eyed monsters, too, were among them, with skulls of more than a yard in length (Mastodonsaurus). Those with teeth of elaborate structure, and named Labyrinthodonts, had greatly increased. Indeed practically all Triassic stegocephs, it would seem, belonged to that group. They were more highly developed than their Permian predecessors, as their back- 
bones were well-jointed and ossified : and their tooth-enamel was infolded in a still more complex or labyrinthine manner.

Although hard pressed by reptiles they were able to keep up a good front for the greater part of the Period. Towards its close they dwindled into utter insignificance; and the heroic days of amphibians came to an end.

Among reptiles remarkable developments were taking REPTILES place. The creatures, however, were still in what is termed a generalised condition; that is to say, it was as yet uncertain what particular forms of animals their descendants by successive modifications might become. They stood, in short, at the parting of the ways. New forms, not greatly differing from the Sphenodon semi-lizard type of earlier times, were appearing (Telerpeton, Hyperodapedon); and they ranged from western Europe far into Asia. Other forms -remains of which have been found in Europe and North America-seem to have been developing in the direction of long-snouted crocodiles (Belodon). At the same time they possessed features in common with dinosaurs-the " terrible lizards" that were just beginning to appear. Certain small forms-not much more than two feet in length-seem to have been committed to a more or less crocodilian development (Aëtosaurus).

The well-crested reptiles no more graced the scene (Edaphosaurus, Dimetrodon, etc.). But descendants of certain " beast-shaped" Permian reptiles, with vegetarian tastes, were in great force (Pareiasaurus). By going about in large companies, these animals no doubt enjoyed greater security, but the flesh-eaters were also represented by numerous descendants, deeply imbued with family traditions (Inotransevia, Dicynodon, etc.). Possibly in response to this, some small "beast-shaped" vegetarians were now to be seen with heads grown fearsome with bony excrescences (Elginia mirabilis).

In addition to these various reptiles, some allied but quite DINOSAURS distinguishable forms known as Dinosaurs, or "terrible lizards," were now in existence. Their range was already extensive, for remains of them have been found in Europe, 
South Africa, India, and North America. These strange creatures had well-developed hind-limbs ; whilst their " arms" were comparatively short. The latter, no doubt, were chiefly used for seizing and holding prey ; and locomotion was effected, somewhat in kangaroo fashion, on the hindlimbs only. Facility for agile and speedy movement was certainly afforded by the hollowness of the limb-bones (Zanclodon, Euscelosaurus, Epicampodon). The animals varied a good deal in size: some remarkable forms, with bird-like skulls, must have stood between five and six feet in height (Anchisaurus).

The precise line of dinosaurian descent is unknown. All the Triassic forms seem to have been carnivorous; and they haunted, no doubt, lake-banks and riversides; and victimised the tender and neglected offspring of amphibians and also of fellow-reptiles.

Dinosaurs, so far as is known, were the first bipeds to appear on earth-the first creatures to stand and move about in a fairly erect position. They come, in fact, within Plato's special definition of a man-“" a biped without feathers." Dinosaurs, therefore, were not dreamt of in his philosophy.

PLESIO- Other reptiles, now first in view and known as plesioSAURIANS saurians, betrayed no inclination to bipedalism; and when on land must have moved about in a somewhat laboured manner. They were undoubtedly good swimmers, and when afloat must have had an appearance such as swans, deprived of feathers and suffering from stiff necks, would present. They had probably descended from some forms that had been more or less permanent land-dwellers. Possibly their remote ancestors were some land-frequenting stegocephs of Carboniferous times. Terrestrial life, it would seem, had lost its charm; and these Triassic descendants were experimenting in water, and possibly becoming experts in fishing. Many of them were of small size; but here and there creatures were to be seen varying in length from four to six feet (Lariosaurus, Nothosaurus).

Plesiosaurians were much more developed in the next Period: and it is interesting to note that these Triassic 



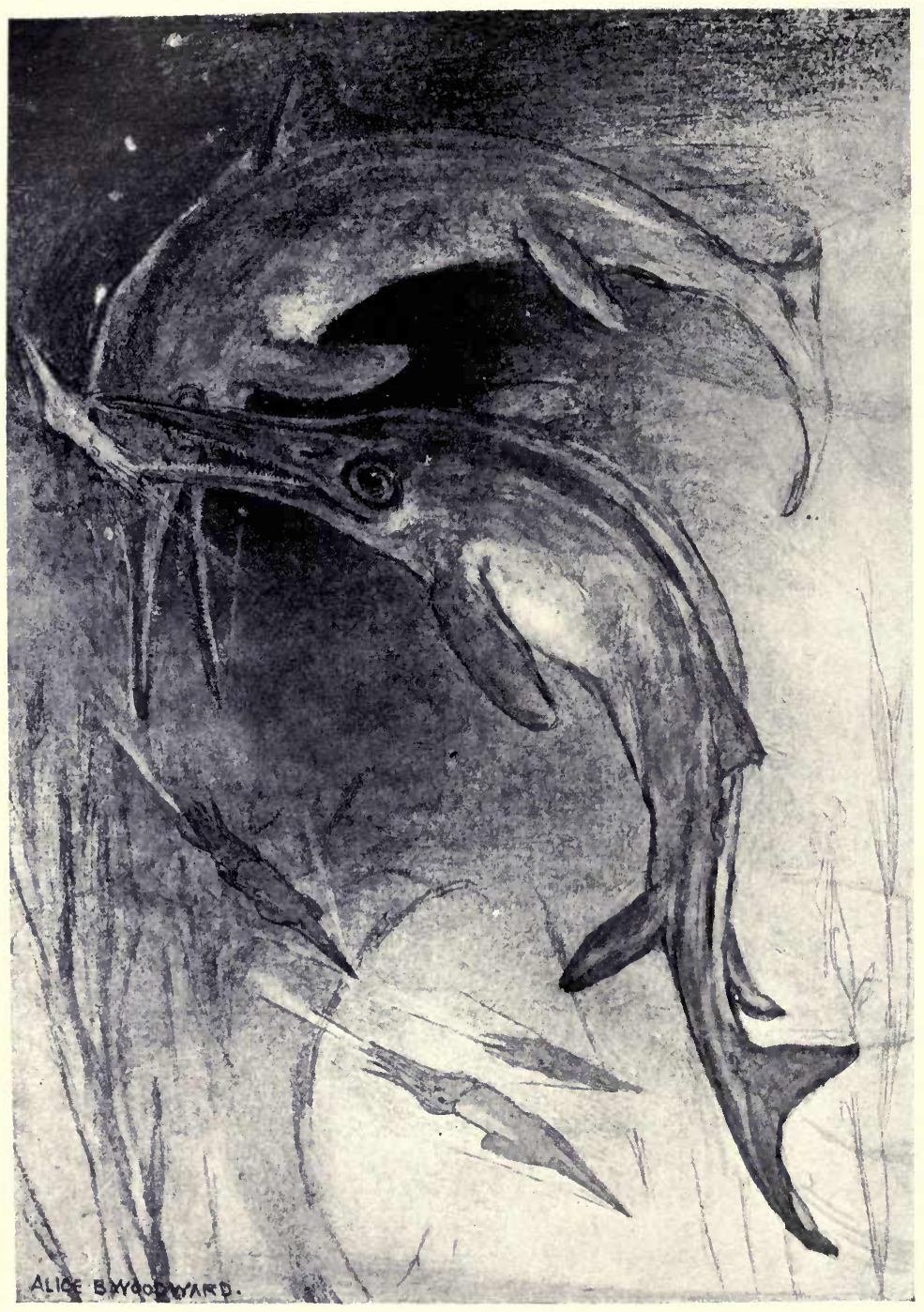


creatures probably still spent a good portion of their time on land. This may be inferred from the limbs not having acquired that complete paddle structure which characterised the later forms.

Other reptiles known as ichthyosaurs or "fish-lizards" ICHTHYo-also probably descended from land-haunting ancestorshad certainly gone steps further from terrestrial life, and had become whale-like in shape (Mixosaurus). They were shortnecked, long-jawed creatures, with sharp, conical teeth. The tail in its lower lobe was possessed to its extremity by a sharp down-curvature of the spine-a curvature reverse in direction to that in the old-fashioned fish-tail. This novel construction, no doubt, facilitated the ascent of the animal when seeking the surface for fresh supplies of air ; but it cannot have been so efficient for that purpose as the tail with horizontal lobes such as whales possess. All four limbs to outward appearance were fins or paddles; but fingers and toes, although undergoing modifications, were still defined within.

The largest of the Triassic forms did not exceed a yard in length. They were doubtless consumers of fishes; but they developed a great partiality for belemnites. These they must have found highly nutritious, as will be seen later.

Forerunners of tortoises had appeared in the Permian chelonians Period; and this Order of reptiles was now represented by animals not far short in development of modern forms. The ancestral sluggishness had been confirmed; and an unearned increment of armour-wealth had resulted. There seem to have been both " hidden-necked " (Cryptodira) and " side-necked" (Pleurodira) animals as at the present day-some that could telescope the neck and envelop the head in the box-like armour (Chelyzoon), and some that could only shelter the head by bringing it round under the side-edge of the upper shield (Proganochelys, Pleurosternum).

Triassic chelonians probably spent placid, uneventful lives in the swamps and rivers, and never ventured out to sea. They doubtless had foes among the less lethargic reptiles; but they were fairly safe within their bony walls. 
With primitive lizards, crocodiles, dinosaurs, plesiosaurs, " fish-lizards," and tortoises on the scene, there was, it must be admitted, a wonderful display of reptile life. But these creatures, although highly and variously developed, were not-at least in the latter part of the Period-the highest life-forms on earth : for at that time Mammals were certainly in being.

MAMmaLs It is not possible to picture the appearance of these prototheres or " first beasts" as they are named; for there is nothing to recall them save some jaws and teeth, and a few bones, found in Europe and North America (Dromatherium, Micronodon, Microlestes). They do not appear to have been larger animals than rats and mice. Some of them were probably constituted like the Australian ant-eater (Echidna), laid eggs, and nourished their young with milky juice oozing from the breast; whilst others probably brought forth young of minute size, and carried them about in pouches after the manner of marsupials.

These primitive creatures must have been in frequent danger from carnivorous reptiles; but they doubtless surpassed reptiles in some important respects. Reptiles, as a rule, are sluggish animals; their brain power is of humble calibre; and their morality, as judged by the little or no care they exhibit for their offspring, is equally low-pitched. And it is probable that the Triassic reptiles had similar shortcomings. On the other hand, these primitive mammals were probably nimble and active little creatures, with a relatively high intelligence, and keenly solicitous for the welfare of their young. These attainments were bound to tell in time, unless creation rested simply on brute force.

" Whence," one may naturally ask, "were these types of higher life evolved ?" There is little or no doubt they were evolved from reptiles, probably from some very small " beastshaped " forms (Theromorphs); and from such of those as had teeth of a more or less mammalian pattern (Theriodonts). At least no other descent so probable as this can be given.

The appearance of mammals was indeed an event of the highest significance. Nature after successive stages from marine invertebrates to fishes, amphibians, and reptiles, 
had embarked on a course destined to result in a wonderful development of life. Here, too, was Morality in active evolution, breaking like sunbeams through clouds. Animals had appeared, parts of whose bodies were designed, not for their own convenience and welfare, but for the use and benefit of their offspring. Altruism had passed to a higher stage ; and many virtues, hitherto obscured or undeveloped, were coming forth as lights in the world. 


\section{MESOZOIC AGE}

\section{JURASSIC PERIOD}

SPONGES THE annals of marine invertebrate life, if humble, were not uneventful. Sponges were in great force. Some six-rayed forms now had their needles arranged into a highly complex network (Craticularia); and among the four-rayed some thick-walled, cylinder-shaped forms of modern type were making their appearance (Cylindrophyma).

CORALS Corals do not seem to have made much headway during the early part of the Period; but in the course of its long years, reef-building corals-both perforate and non-perforate -became more abundant than ever. In central Europe, a very large part of which was submerged, they seem to have spread far and wide over the sea-floor.

Some new non-perforate forms were in the seas with cups divided up with numerous partitions in the manner of a fungus-cap (Fungida). These and other families, first known in this Period, have persisted until the present time (Stylophorida, Turbinolida).

SEA-LILIES Crinoids or "Sea-lilies," after a somewhat chequered career ever since the close of the Silurian, were now reviving. Modernised forms, such as had appeared in the Trias, seem by this time to have practically superseded all the older-fashioned types. No trace has been found of sanitary reformers, conspicuous in earlier times with cumbrous waste-pipes.

Some of the fixed sea-lilies, hitherto confined to the shallows, were at this time spreading out into comparatively deep waters (Eugeniacrinus). Forms free and stemless-at least in the adult state-were certainly on the increase (Antedon, etc.). At the same time there were stemless crinoids which apparently had no desire for a free life. 
Although they had lost their stems, they held fast to the sea-floor by means of a small outgrowth at the base of the cup (Cotylederma). Crinoids of this character are still living in the Caribbean Sea (Holopus).

Many of the Jurassic starfishes seem to have been in- STARFISHES distinguishable from species now living (Asterias, Astropecten, Luidia). Some new forms were appearing in which the central disc was being extended into the spaces between the arms; and the animals presented a five-sided cushion appearance (Goniaster). These, no doubt, were ancestors of the so-called "cushion-stars" of our own day. Some other forms had exceeded the numeral characteristic of the Order -and indeed of all "spiny-skinned" animals-by developing more than five arms (Solaster). Starfishes of this heretical description have continued until the present day, and are represented by "sun-stars" of many genera.

Brittle-stars had undergone some trivial modifications; BRITTLEand certain of the creatures were apparently identical in structure with brittle-stars now living (Ophioglypha).

Although "sea-lilies" were reviving, and starfishes and SEA-URCHINS brittle-stars were assuming modern aspect, sea-urchins continued predominant among the "spiny-skinned" invertebrates.

The most notable feature of Jurassic sea-urchin life was the appearance of many forms no longer characterised by globular tests. Numbers were now in existence in flattened and four-sided body-coverings (Clypeus, Echinobrissus); and the mouth was being brought forward from its old central position on the under-part of the test. These modifications of the test point, no doubt, to changes of habit on the part of the animals. In locomotion, for instance, the test would necessarily become exposed to special resistance from the surrounding medium, and tend, therefore, to lose its globeshaped symmetry. This would markedly be the case where boring and crevice-haunting habits were being adopted. And there can be little doubt that many Jurassic sea-urchins spent less sedentary, open-water lives than their ancestors, and also indeed than most of their contemporary brethren.

A few new forms, reviving an old fashion, were now 
appearing in thin and flexible body-coverings (Pelanechinus, Keeping). Successors of these in the next Period (Echinothuria, S. P. Woodward) closely resembled some sea-urchins now living (Calveria).

POLYZOANS The annals of polyzoans have not been very well preserved in the rocks; but there is evidence that some of the communities had undergone important modifications. Vast numbers of colonies with individuals in open-mouthed tubes were living in the seas ; and were very similar to their forerunners. The rival colonies, however, exhibited a great improvement. In these communities the orifice of the zooidtube, instead of being provided as formerly with a small shaft, was furnished with a movable lid. The zooid, therefore, could at will keep the entrance to the tube open or shut (Chilostomata), and so possessed more control over its destinies. In some forms the lid improvement had only been partially effected.

The " open-mouthed" colonies, however, in spite of their more primitive tubes, were far more prominent than their rivals. There is little doubt indeed that the latter had undergone great trials in the course of their reconstruction.

LAMPSHELlS Brachiopods continued to decline, but several old families maintained a stubborn front against " the slings and arrows" of fortune. This was notably the case with well-beaked brachiopods-much in evidence also in the Trias. Brachiopods in "butterfly" shells-with an ancestry running back to Silurian times-were still in existence (Spiriferina); but they had little enough oil, so to speak, left in their lamps; and before the close of the Period their feeble lights all flickered away.

BIVALVED Bivalves were manifesting their adaptive powers in many MOLLUSCS new developments.

Oysters of various forms were now in being; and in some regions they were gathered together in beds in the manner of modern oysters (Ostrea, Exogyra). Many of them were enclosed in shells curiously twisted by the growth of big beaks, developed, it may be supposed, in connection with fixation purposes (Gryphaa). Thorny oysters, vaguely looming for some time past, seem now to have reached a state 
generically identical with that of their living brethren (Spondylus). Other forms appear to have been what are now known as "edible" oysters. They were probably relished, at this time, mainly by whelks and starfishes.

Pearl-oysters were here, with their beady products (Meleagrina). Clams also were to be seen; but they did not much resemble modern forms (Diceras). File-shells, of which forerunners had appeared as early as the Carboniferous Period, were now abroad of much larger size (Plagiostoma). "Ship-worms" - molluscs so-called from their affection for boring into floating timber-had also appeared (Teredo); and doubtless gratified their tastes on flotsam tree-trunks from the forests. Other bivalves were forerunners of Venusshells, and tellens; and if their shelly coverings were as gaily painted as those of their living descendants, their collecting-grounds must have mirrored as flower-beds submerged (Venus, Tellina).

Gastropods still differed in many respects from living forms. It is interesting to note that those provided with a siphon apparatus had clearly derived health and strength from the contrivance. Such marine snails were vastly more numerous than in the Trias; and among them were forms recognisable as cowries, pelican-foot, and scorpion shells (Cypraa, Aporrhais, Harpagodes).

Ammonites continued predominant among cephalopods, AMMONITES and indeed among all marine invertebrates. Some Triassic families were still represented; but most of them had either been suppressed or transformed. Evidence of breakdown, visible in a slight degree at the close of the Trias, was now more marked. The adaptive powers, however, of the animals were still far from being exhausted; as evidenced by the various modifications to meet increasing difficulties.

Most of the Jurassic forms possessed shells well strengthened with ribs. These bands of support were of various designs, suggestive of rings (Lytoceras), straps (Aspidoceras), loops (Stephanoceras), and wavelets (AEgoceras). In not a few cases the shell was further strengthened by the presence of a keel, which must also have brought advantages in the matter of stability (Cardioceras, Harpoceras, etc.). 
Many ammonites, nearer the end of their resources, were crawling about in shells with dwarfed body-chambers (Cosmoceras, etc.); whilst some forms were beginning to uncoil, seeking salvation, it would seem, by a reversion to the more or less straight shell of far-back ancestors (Scaphites, Ancyloceras). This retrogressive movement became a prominent feature with ammonites, when their decline had fairly set in. In spite, however, of their trials and adversities, ammonites made a grand display in Jurassic seas.

BELEMNITES Belemnites, meanwhile, although handicapped by being the much-coveted food of many fishes and sea-reptiles, were coming on with a flood tide. They continued for the most part of small size; but a few forms were now abroad fully a yard in length ( $B$. giganteus). Their ranks were certainly presenting a less archaic character; as some forms differed but little from common squids or calamaries (Loligo vulgaris).

NAUTILUS The old straight-shelled nautiloids had by this time been wellnigh weeded out: and the group, which comprised them, was represented almost entirely by forms more or less identical with the living nautilus. Nautiluses, although developed on more lasting lines than Ammonites, were nevertheless quite unimportant cephalopods in Jurassic seas.

Crustaceans, by readjustments in points of their structure that had been more or less vetoed by Nature, were moving SHRIMPS with the times. Well-developed shrimps and prawns were numerous (Penceus, Eger); and small creatures, fairly LOBSTERS describable as lobsters, were adding distinction to the crusted fraternity (Eryon, Mecochirus, etc.). Animals of the same family (Eryonida) as some of these now wander in a sightless condition in abysmal ocean depths.

CRABS Crabs, by a series of modifications from early shrimp life, had now become distinguishable from their long-tailed forerunners. For the time being, however, they were insignificant, alike in number and variety (Palcinachus, Prosopon).

BARNACLES Barnacles for the most part pursued an undemonstrative career : but certain forms were setting their houses in order by reducing their shell-plates, and arranging such as remained in a more regular manner (Archaolepas).

Up to this Period fishes had been rapidly increasing in 


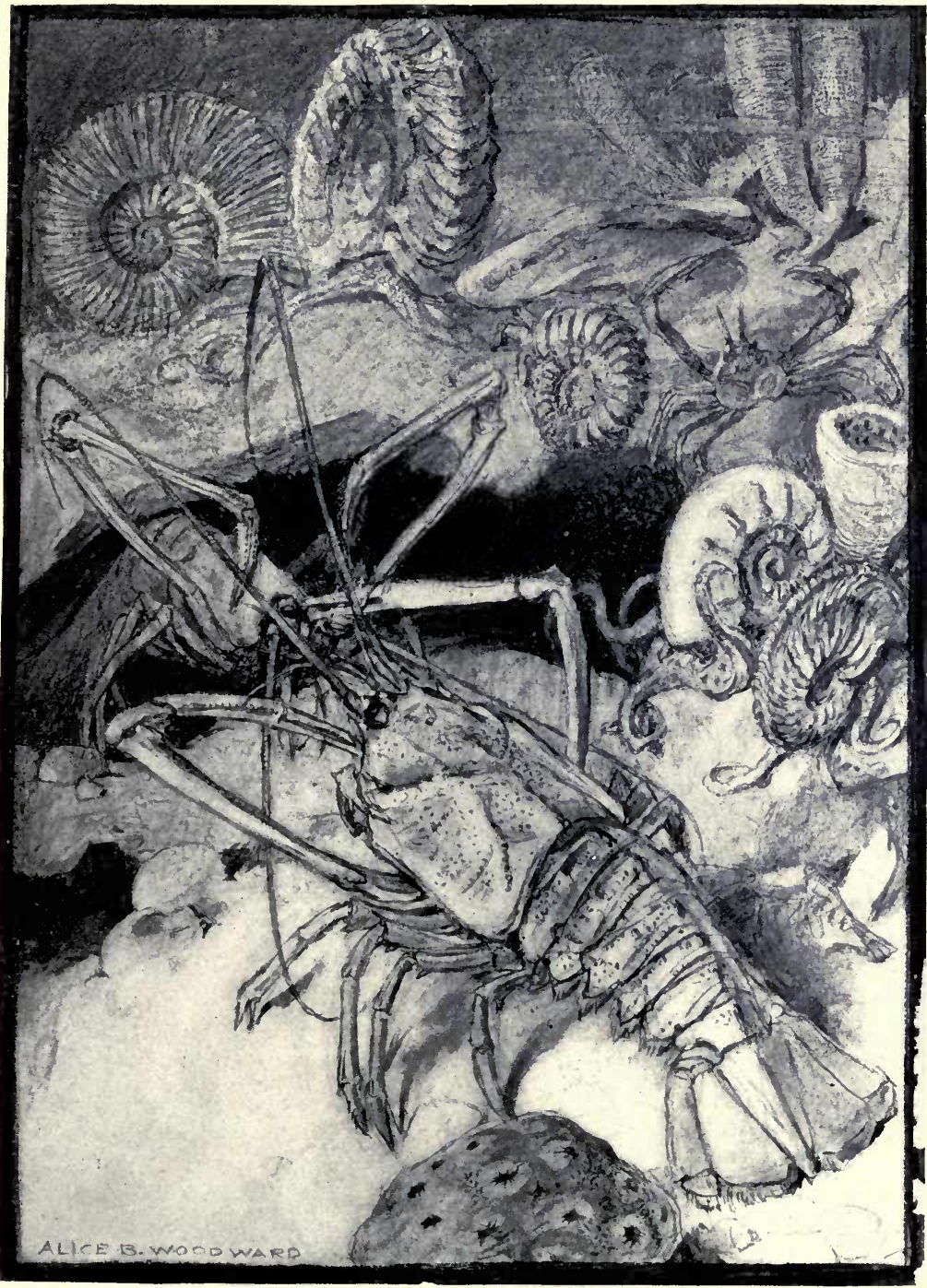

Sponges

(Cylindro-

phyma)

Crab

(Palaeina-

chus)

Mechochirus

Eryon

JURASSIC PERIOD

[To face page 86

Aspidoceras

Cardioceras 

variety: but with the exception of sharks, skates, lungfishes, and forms resembling bow-fins, and herrings, fish-life was not comparable with its present-day representatives. Nor in the Jurassic can many comparisons be drawn. Of fish-life in very deep seas nothing, it may be mentioned, is known. It is not unlikely, indeed, that as yet fishes lived only in shallow and moderately deep waters.

Sharks flourished in old and new forms. In addition sHARKS to those allied to Port Jackson sharks of our own time, ancestors of "comb-toothed" sharks were now roaming about (Notidanus); and sharp-toothed dog-fishes were also in the seas (Scyliide). Angel-sharks, so called from their large wing-like fins, had also appeared (Squatina): and certain sharks now possessed stout "backbones" rendered flexible by a system of joints (Palceospinax). Skates or rays -first known in Carboniferous seas-were now well developed (Rhinobatus, Belemnobatis) ; and Chimæras-foreshadowed in Devonian times-were represented by various species.

This was rather a formidable array of fishes that, for the most part, lived and fattened on their gentler brethren. Still, many of the latter were doubtless swifter and more agile swimmers than their foes. They had also, no doubt, an additional-if unappreciated-preservative in being more prolific.

The fringe-finned ganoids (Crossopterygii) still declined. GANoIDs An old family, however, somewhat prominent in the Car- (CROsSOPboniferous, and consisting of fishes notable for internal TERYGIANS) ossifications, and certain tail-reforms, kept up an imposing appearance (Colacanthida, Undina).

The key to a highly developed and greatly varied fish- (ACTINOPlife had long been held by the flexibly finned ganoids TERYGIANS) (Actinopterygii); and their ranks, therefore, excite the keenest interest.

Some members of this Order, it must be admitted, remained stationary in development. They still possessed hard, bony scales, and had made little or no progress as regards internal ossification. Their tails, moreover, continued of old type, terminating with the up-curved end of the spinal column (Chondrosteus, Gyrosteus). Some descen- 
dants of these fishes never advanced to structure of higher character; and the gristly skeletoned sturgeon, with his bony armour, and old-fashioned tail, may be regarded as their living representative.

Flexibly finned ganoids with tails of modern type were now far more numerous than their primitively tailed brethren.

Prominent among these more accomplished swimmers were some deep-bodied fishes (Dapedius), belonging to a family of late Permian origin (Stylodontida), and some of spindle shape (Lepidotus), members of a family first known in the Trias (Semionotide). But although modernism was evident in their tail-structure, their bony scales were of remarkable thickness, and their internal skeletons had undergone but little ossification.

Other forms were thinner scaled, and well ossified internally (Caturus furcatus, etc.). Some of these were salmonshaped (Hypsocormus); others resembled the bony pike (Aspidorhynchus). The most remarkable of all were spratlike forms with backbones completely ossified (Leptolepis TELEOSTEANS sprattiformis). Ganoids-protected typically by hard and enamelled bony scales, and possessing a more or less gristly internal skeleton-had now definitely given rise to a new group of fishes. True bony fishes, in short, were now in the seas (Teleosteans).

VEGETATION Fine forests adorned the land, but, so far as is known, the leafy wealth was much the same in character as that of the Trias. Conifers, cycads, and ferns still held the field; and in some regions araucarias and allied forms attained grand proportions. Cycads were extraordinarily abundant, and extended over vast territories in all parts of the world. Indeed at no future time were they so widespread, and so varied in species-a startling contrast with their present circumscribed limits, and impoverished condition. "Horsetails" showed no sign of recovering their lost importance. They certainly stood out here and there like giant forms of old ; but for the most part they were of very humble proportions. Their old associates the club-mosses appear to have collapsed to the size of shrubs and bushes. And the pillar- 


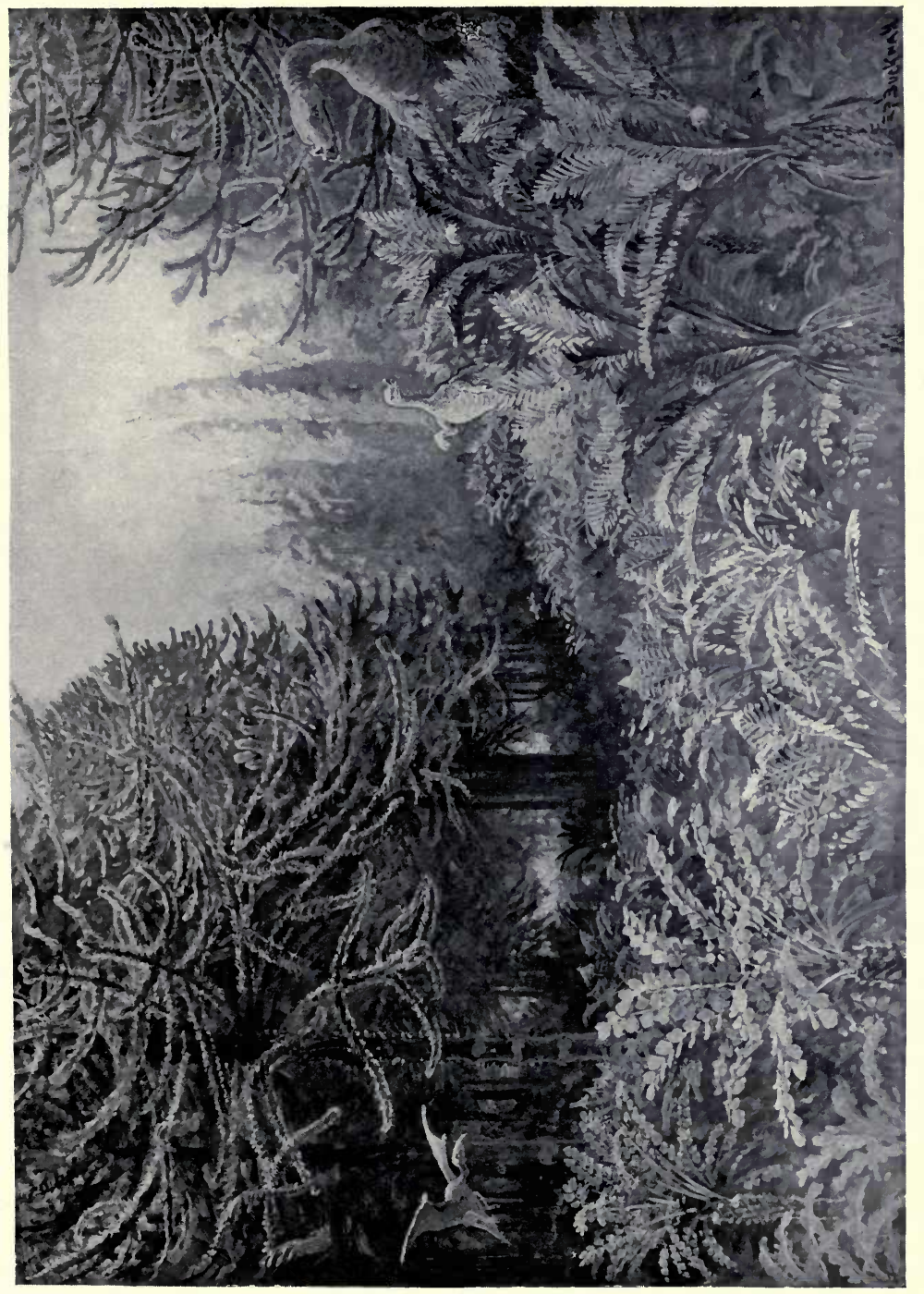

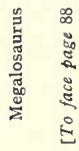

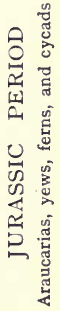

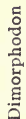



like sigillariæ had wholly succumbed. In some regions gingko or maidenhair trees-conifers with fern affinities-were in a condition of great luxuriance; but the cycads with vesselled seeds (Bennettitea) continued, so far as is known, the most highly organised forms in plant-life. Ferns also were in great profusion, and those of newer type were greatly extending their range (Leptosporangiates). Among these, Male ferns (Aspidium), Bracken (Pteris) and Hart's Tongue (Scolopendrium) had now appeared; and the family to which Royal Ferns belong-still retaining some special features of ferns of the older type-attained its zenith (Osmundacea).

Although it is not known that any angiosperms-the most highly organised of plants now living - had as yet appeared, it is highly probable that grasses and other simple growths with "vesselled" seeds were amid the vegetation. It is thought by many that angiosperms had for some time been in course of development in far northerly regions, where climate had not compelled migrations southward. Genial conditions were certainly prevailing in this Period on lands well within the arctic circle, for cycads were flourishing in Spitzbergen. The far north, therefore, may well have had some surprises in store.

Insects-especially wood-eating beetles-were abundant. INSECTS May-flies of many species flitted about; and dragon-flies, more or less developed in Carboniferous times, had now become differentiated into a distinct family (Odonata). There were also many kinds of insects unknown in earlier times-mosquitoes (Culicida), gnats (Chironomida), ants (Formicide), crickets (Gryllus), earwigs (Baseopsis), and termites (Termitida). The busy bee was also now abroad (Apiaria).

About the marshes, lakes, and rivers no amphibians of AMPHIBIANS giant size were now to be seen; and this class of life seems to have been represented only by small newts and salamanders of primitive type (Hylaobatrachus). Amphibians, owing to the wonderful developments of reptile-life, were now to play a quite insignificant rôle in Nature's economy.

Reptiles rose to their zenith; and their power was pro-

REPTILES 
claimed not only on land and sea, but also in the air. "Creeping " is indeed quite an inadequate appellation for the fraternity in Jurassic, and even in earlier times.

DINOSAURS Dinosaurs were now the leaders. Vegetarian as well as flesh-eating forms were extraordinarily abundant; and they presented the most extravagant and grotesque display of life that has ever existed on earth.

In both hemispheres they were in their glory ; but evidence points to the western parts of the North American continent as the scene of their grandest and wildest development. Here gigantic brutes were roaming, in the presence of which the largest elephant would have cut a poor figure. Take, for instance, the Diplodocus family, so named from certain branched or "double-beam" bones which its members possessed on the under-part of the tail. Some of these creatures were over eighty feet in length, and could raise their heads some thirty-five feet above the ground. They seem to have possessed little or no armour : but the tail was doubtless serviceable for dealing blows. The position of the nostrils-high up the head-points to aquatic habits; and. the animals, no doubt, subsisted mainly on the bed-herbage of lakes and rivers. In such haunts, the long neck would be of great service, enabling the animal to stand and browse, even in moderately deep water ; and, when disposed, to bring. its head above the surface. It, moreover, carried up the head as a watch-tower, and foes necessitated vigilance. The feet were fairly well adapted for land-locomotion; but their construction is suggestive of a sprawling gait. The animals. must have had to exercise great caution in swampy districts : for if by chance they strayed into miry ground, there they must have remained.

No remains of the Diplodocus family have been found outside the western area of the United States. Other very big herbivorous dinosaurs were also living in those regions (Atlantosaurida). Many of these measured sixty feet from snout to tail-end (Brontosaurus); whilst a few forms were twice that length (Atlantosaurus). Remains of some animals. belonging to this family have been found in England near Peterborough (Cetiosaurus Leedsi). In order to keep them- 


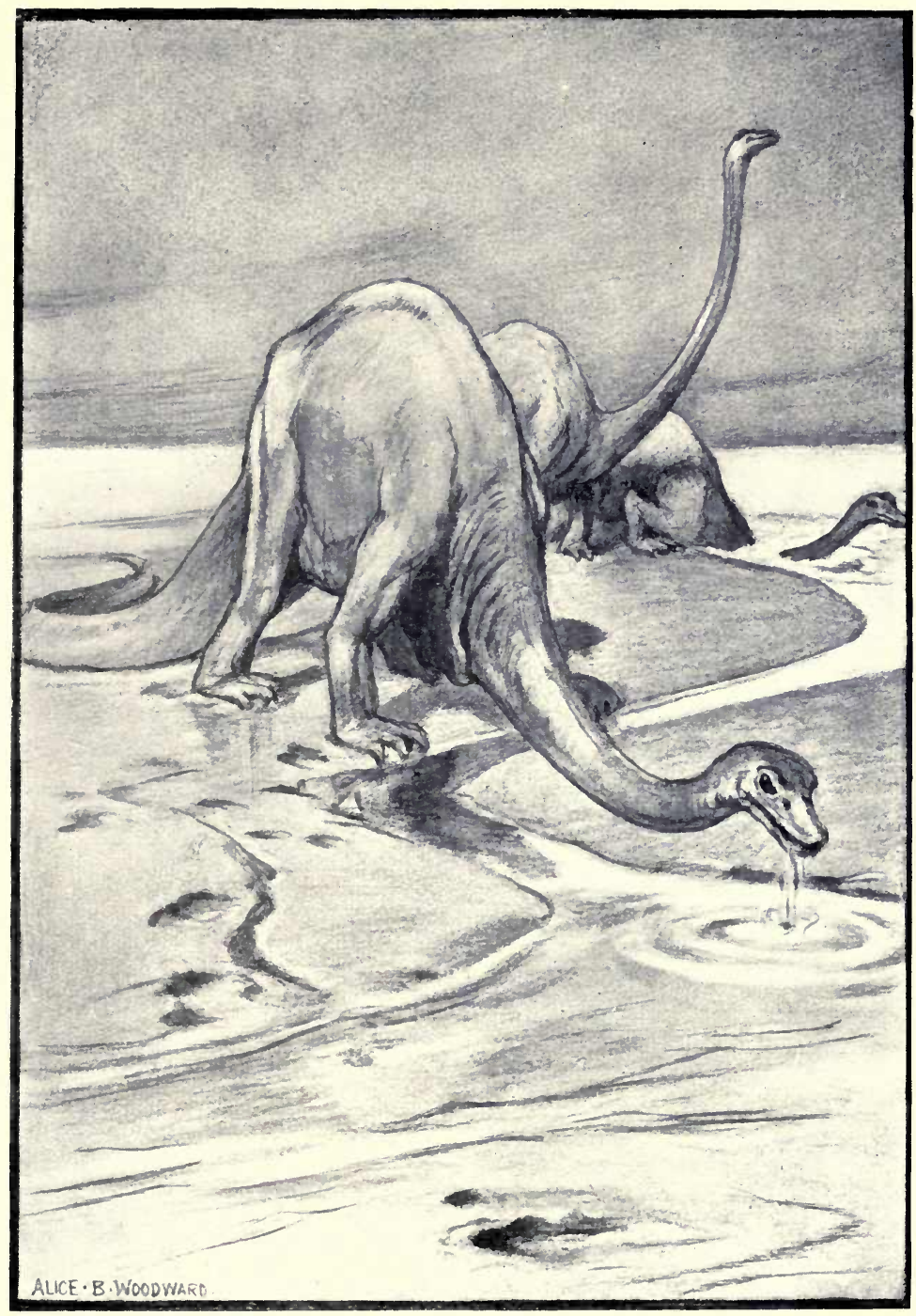

DIPLODOCUS CARNEGIEI

[To face page 90 (I) 



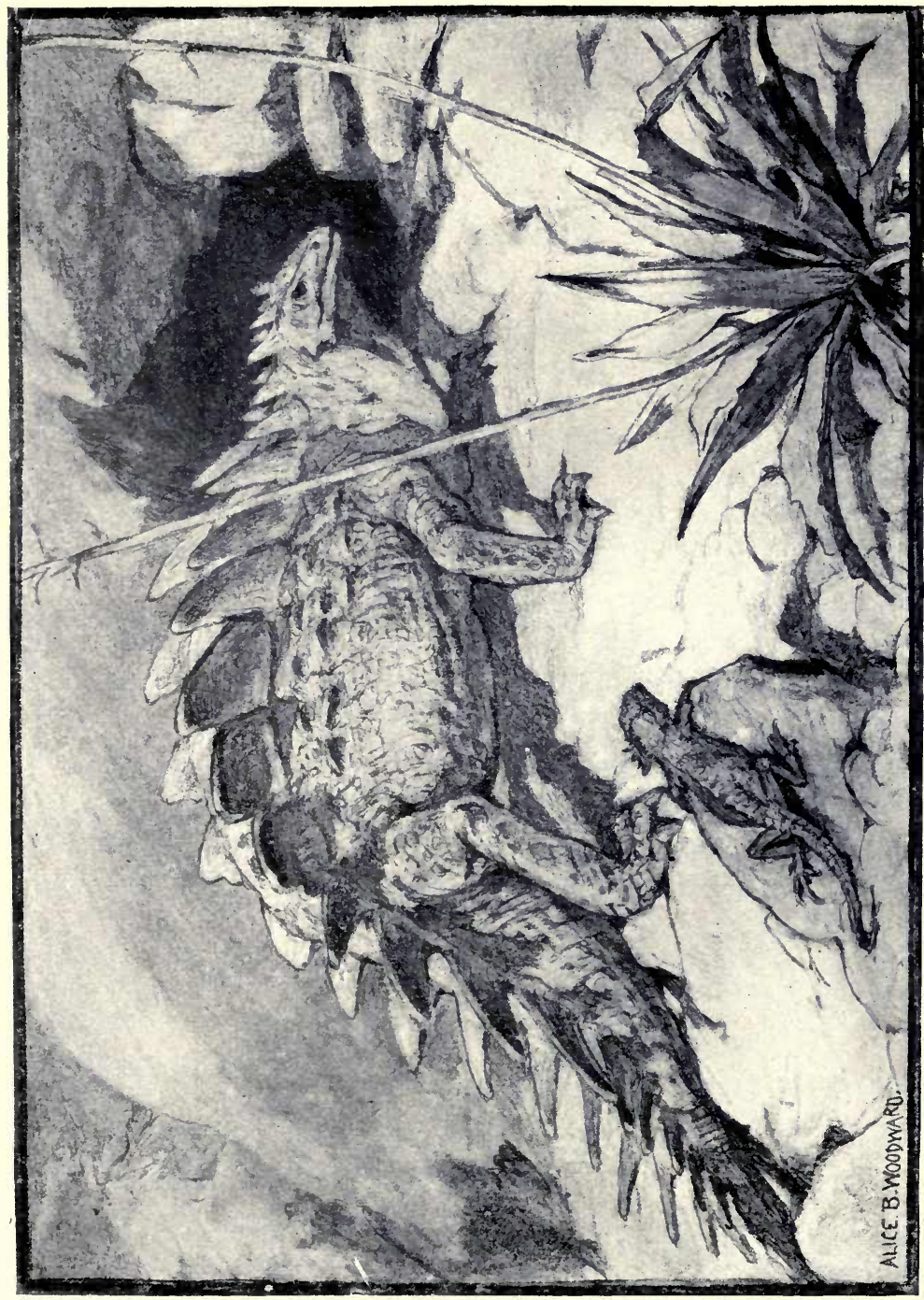

है 

selves in condition, these enormous vegetarians must have spent the greater part of their lives in eating.

Whilst some dinosaurs were chiefly remarkable for their colossal proportions, others were signalised rather by their grotesque appearance. Look at Stegosaurus, for instance, with his pikes and battlements. His dorsal castellation, no doubt, denied him the luxury of rolling on his back; but it kept him well guarded against assault in that quarter. A number of little bones well shielded his throat; whilst his flanks, though somewhat exposed, could doubtless be covered by a sweep of the spiky tail. The mere sight of such animals, standing in some cases eleven feet at the highest point of their fortifications, must have inspired some terror. They certainly required elaborate protection, for they were bulky, heavylimbed, and incapable of speedy flight. Nor were they like Diplodocus, capable of taking a wide survey, and catching early sight of danger. As they were vegetarians in diet, they were probably, in spite of grim aspect, peacefully enough disposed when unmolested.

Their intelligence must have been very limited; for their brains were excessively small, even for dinosaurs. Curiously enough a mass of nervous tissue-the result probably of a block caused by the smallness of the brain chamber-was lodged in the region of the haunches. It has been suggested that this second accumulation was in the nature of a supplementary brain-that it formed, in short, a second seat of intelligence. No doubt the "upper chamber" was of extraordinarily mean capacity; and, in the interests of good government, some check on its prerogatives may have been desirable ; but there is really no reason to suppose that the "lower chamber" contained any intelligence at all.

The Stegosaurus genus was confined to North America; but remains of distantly allied forms have been found in England (Scelidosaurus). These animals were capable of progression, in a somewhat laboured style, without requisitioning the "arms"; and the tail no doubt served as a useful appendage on which to take short rests. They possessed well-developed shoulder-spikes ; but they were not so elaborately armed as Stegosaurs. 
Herbivorous dinosaurs, footed like birds, were also in existence (Camptosaurus). These, like the Triassic carnivorous forms, were very short in the "arms," and effected locomotion in kangaroo fashion. They were models of activity in comparison with Diplodocus and Stegosaurus; and as they were not provided with armour, they probably took to flight, when threatened with serious danger.

Herbivorous dinosaurs must have had to keep a cautious look-out against their carnivorous relations, lurking in large numbers among the cycads and gingko trees. Ceratosaurus may be taken as a type of the flesh-eating dinosaurs. This animal stood some eight feet in height, and progressed, like some of the herbivorous forms, in bipedal fashion. His head was large for a dinosaur ; and he was doubtless better brained than his victims. He had, moreover, a weapon in the form of a horn on his snout. His greater brain power, nasal implement, and greater ability to move quickly from place to place, must have given him great advantages over such a creature as Stegosaurus. No wonder the latter required strong armour, if he was to keep a place in creation. Megalosaurus was an allied carnivorous form with powerful jaws furnished with saw-like teeth. It has only quite recently become known that this animal possessed, like Ceratosaurus, a horn on the snout.

Remains of an interesting dinosaur of small dimensions have been found in central Europe (Compsognathus). This creature was in existence in late Jurassic times; and was similar in shape to Ceratosaurus. Her height-the remains are probably those of a female-was about two feet when standing erect; and to judge by her hollow limb-bones and vertebræ, she was possessed of considerable agility. Birds were making their appearance at this time ; and she and her like were probably in the habit of chasing these incipient aeronauts. Indeed by eliminating the feebler flyers, they may have expedited the evolution of more powerfully winged birds.

It is a question if any of the dinosaurs brought forth their young alive. It certainly detracts from the dignity of the huge dinosaurs to suppose that they were layers of 


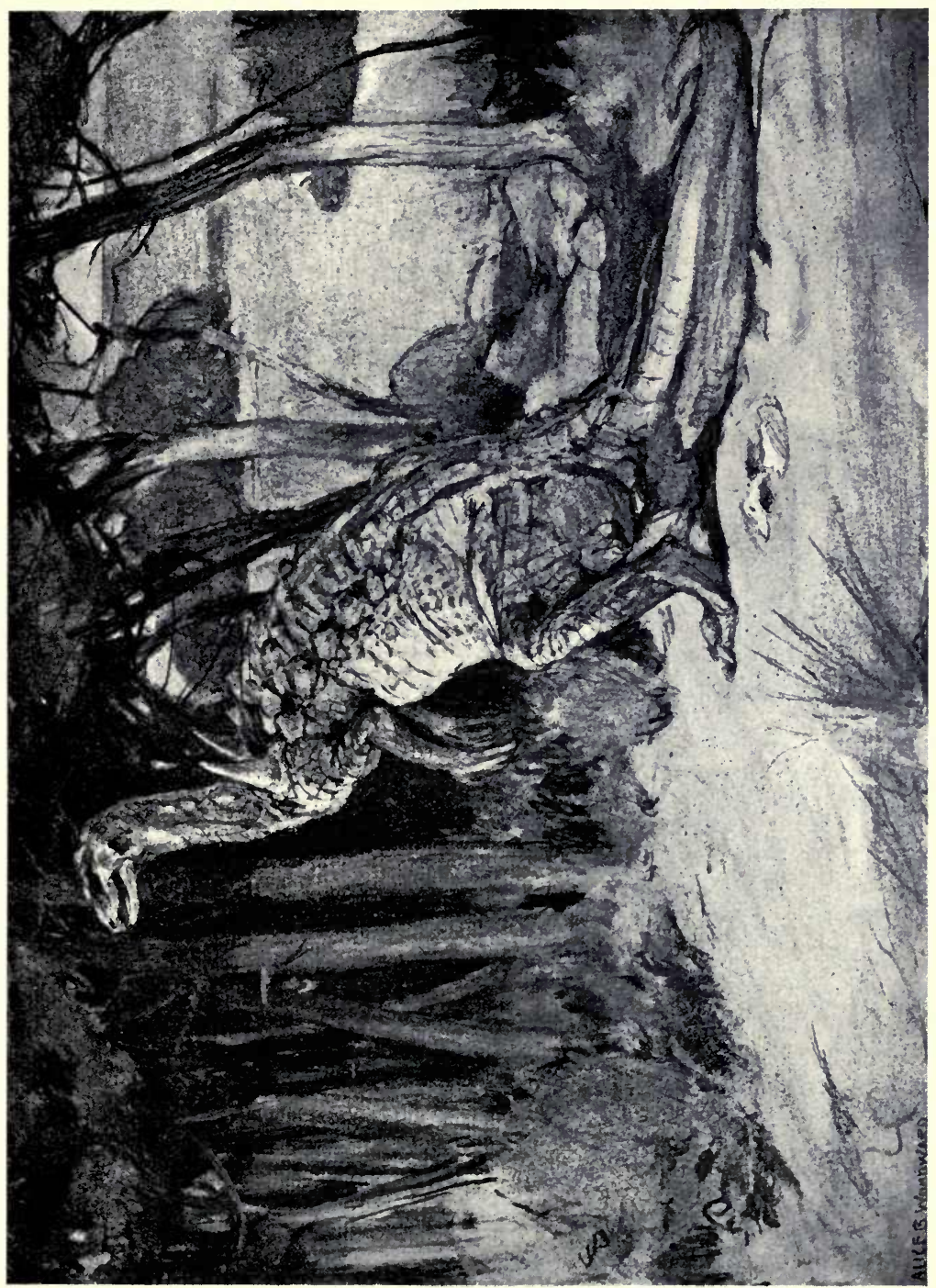

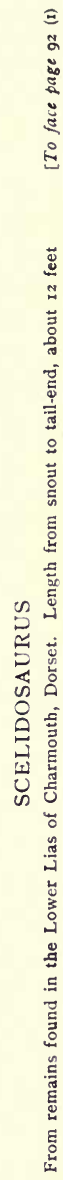





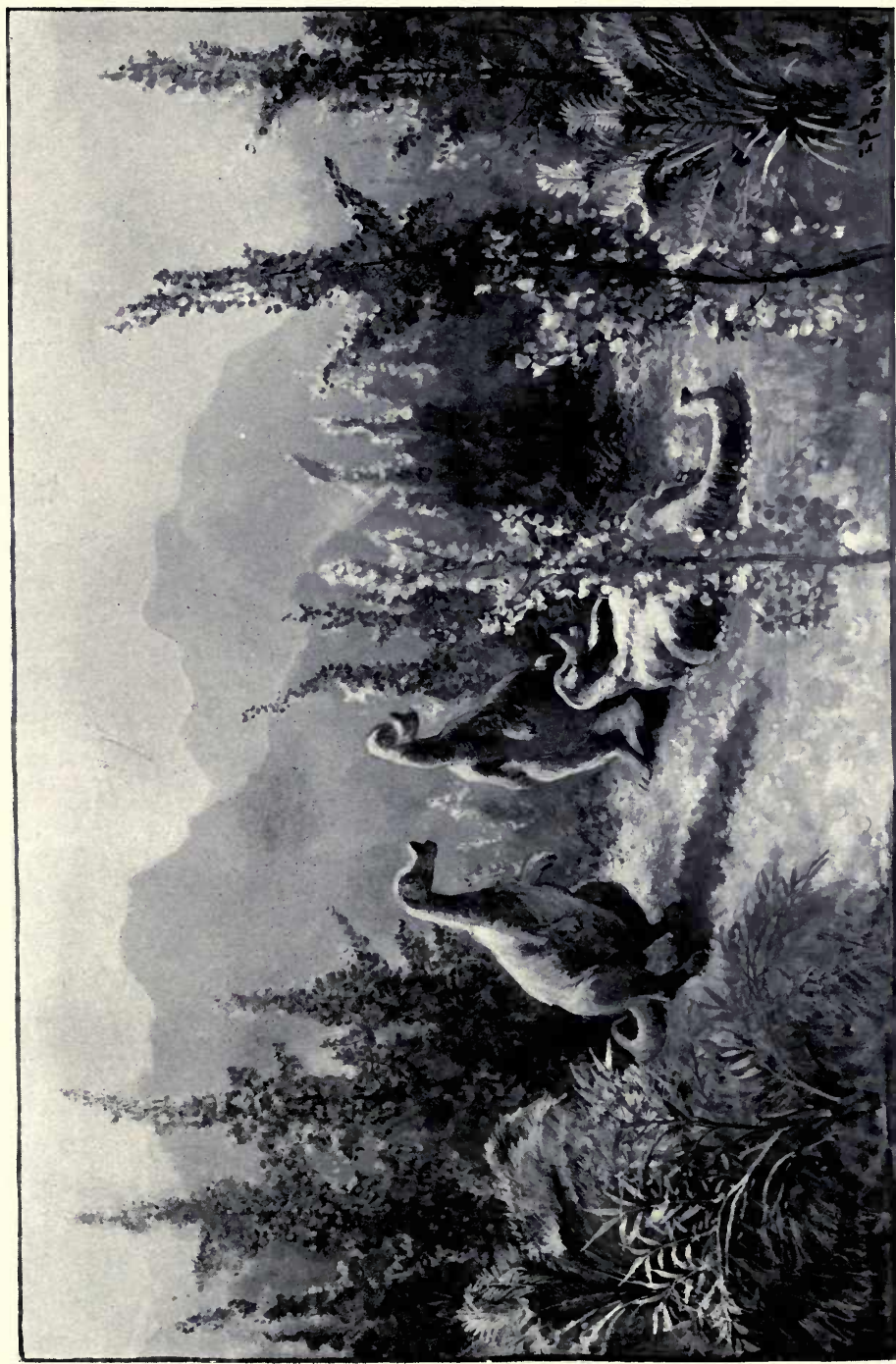

告 
$$
2
$$ 
eggs. But it is very likely they were ; for such dull-witted monsters can hardly have been equal to the parental duties entailed by the viviparous system. If any dinosaurs brought forth their young alive, such were to be found most probably among the small forms. There is indeed some, though not conclusive evidence that Compsognathus was a viviparous creature.

Although now quite thrown into the shade by the later developments of reptile-life, semi-lizard creatures of Sphenodon type abounded. And there is some evidence that true lizards were in existence before the close of the LIZARDS Period (Macellodus). The evidence is not undoubted; but it is highly probable that some primitive forms of those creatures had by this time emerged from the Sphenodon ranks.

Crocodiles had now assumed a definite character, having cRocodILES more or less lost the features which held their Triassic forerunners in close connection with dinosaurs, and lizard-like animals (Teleosaurida). They all seem, for the greater part of the Period, to have been creatures with long and slender snouts; and they no doubt closely resembled the gavials of our own time. They differed, however, from all crocodiles now living in some important respects. The backbonevertebræ were of primitive type, being concave at both ends. In the case of living crocodiles the vertebræ are convexconcave, fitting into each other like ball and socket; and the backbone, therefore, has a firmer and more powerful articulation. There was also greater disparity in the relative lengths of the fore and hind limbs than is the case with crocodiles now living. The hind-limbs were comparatively long, and must have been in great requisition for swimming; whereas with living crocodiles the hind-limbs are shortened, and swimming is effected almost entirely by movements of the tail. These old forms, moreover, differed from living crocodiles in not having their breathing passages so arranged that the mouth could be kept wide open under water without inconvenience. Hence, if seizing prey in their jaws, they endeavoured to submerge and drown it, they ran the risk of drowning themselves at the same time. There is some 
evidence that a structural modification to ensure them against this risk was in progress ; but it is not until the next Period that it is found in working order.

Jurassic crocodiles, although mostly of marine habits, did not, as a rule, venture far out to sea. Some of them, however, were to a certain extent sea-rovers, and had developed fish-like features (Metriorhynchus, Geosaurus). The limbs of these more venturesome animals had become modified into paddles. The fore-limbs, moreover, had been considerably reduced, and exhibited likeness to the pectoral fins of fishes. The hind-limbs had undergone less transformation, and were of good length, and retained a fair amount of scrambling ability. The animals no doubt enjoyed visiting the shore for a bask in the sun, and periodical visits would be necessary for the females for egg-laying purposes.

Towards the close of the Period some small crocodiles with broad and comparatively short snouts, and resembling the common crocodiles of to-day, made their appearance (Atoposaurus, Goniopholis). In some of these creatures the disparity between the fore and hind limbs was not so marked as in the case of their long-snouted relations. These shortsnouted forms, it is supposed, haunted lakes and rivers, and waylaid little mammals coming down to drink.

Crocodiles with backbones vertebrated in the modern manner, with a ball-and-socket arrangement, were possibly appearing at this time; but the evidence is not conclusive (Heterosuchus).

CHElonians Tortoises had now become very numerous; and various species of " hidden-necked" (Cryptodira), " side-necked" (Pleurodira), and intermediate forms were to be seen in the lakes and rivers.

There is no evidence that any tortoises had taken to living permanently on land. On the other hand some of them seem to have been occasionally issuing from the rivers and estuaries, and embarking on sea life-setting out in short to found sea-tortoise or turtle communities (Thalassemydida). This enterprise, however, was only in a preliminary stage in this Period.

Long-necked plesiosaurs were now to be seen of much 


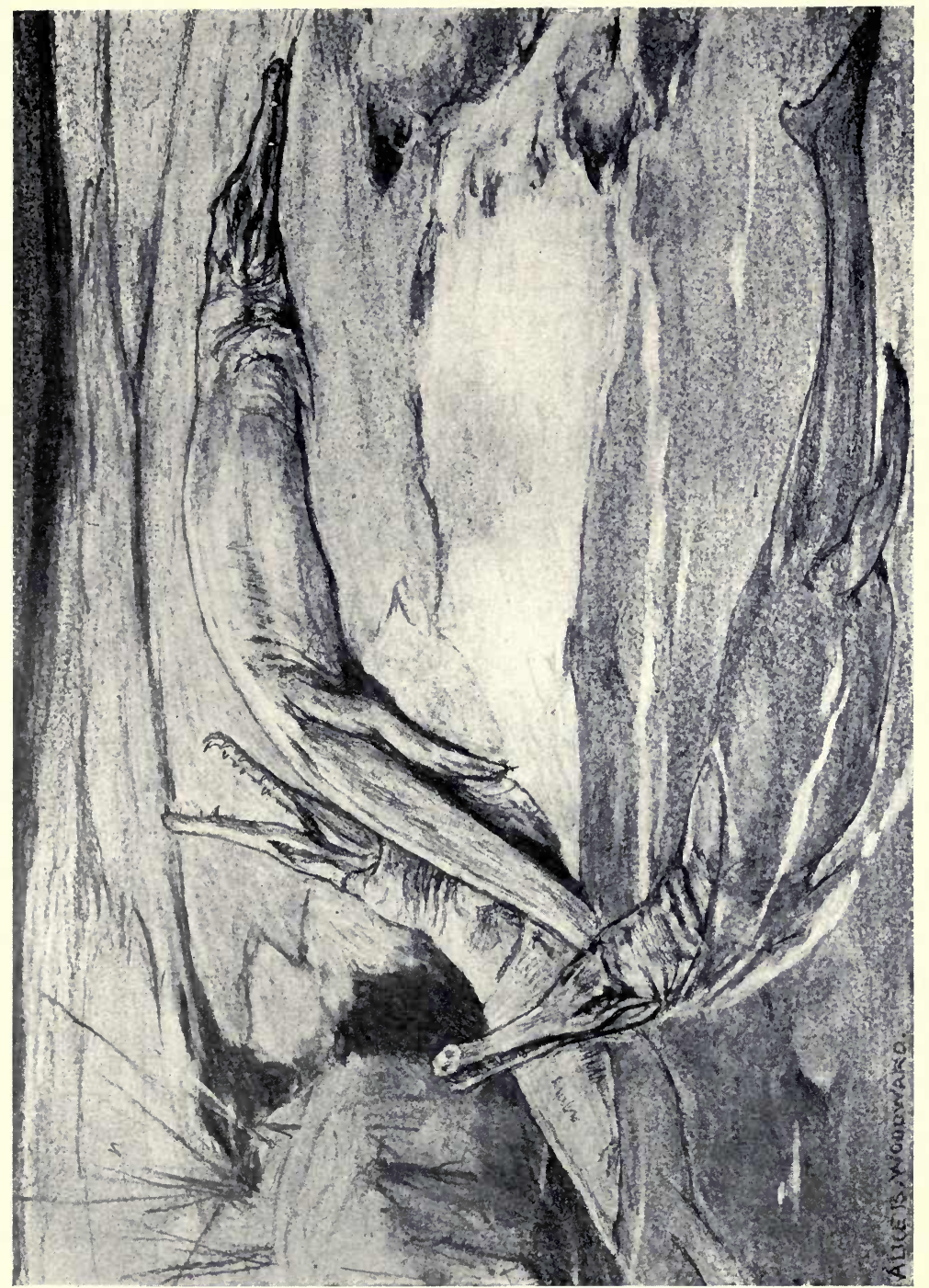

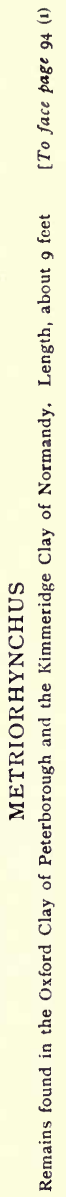




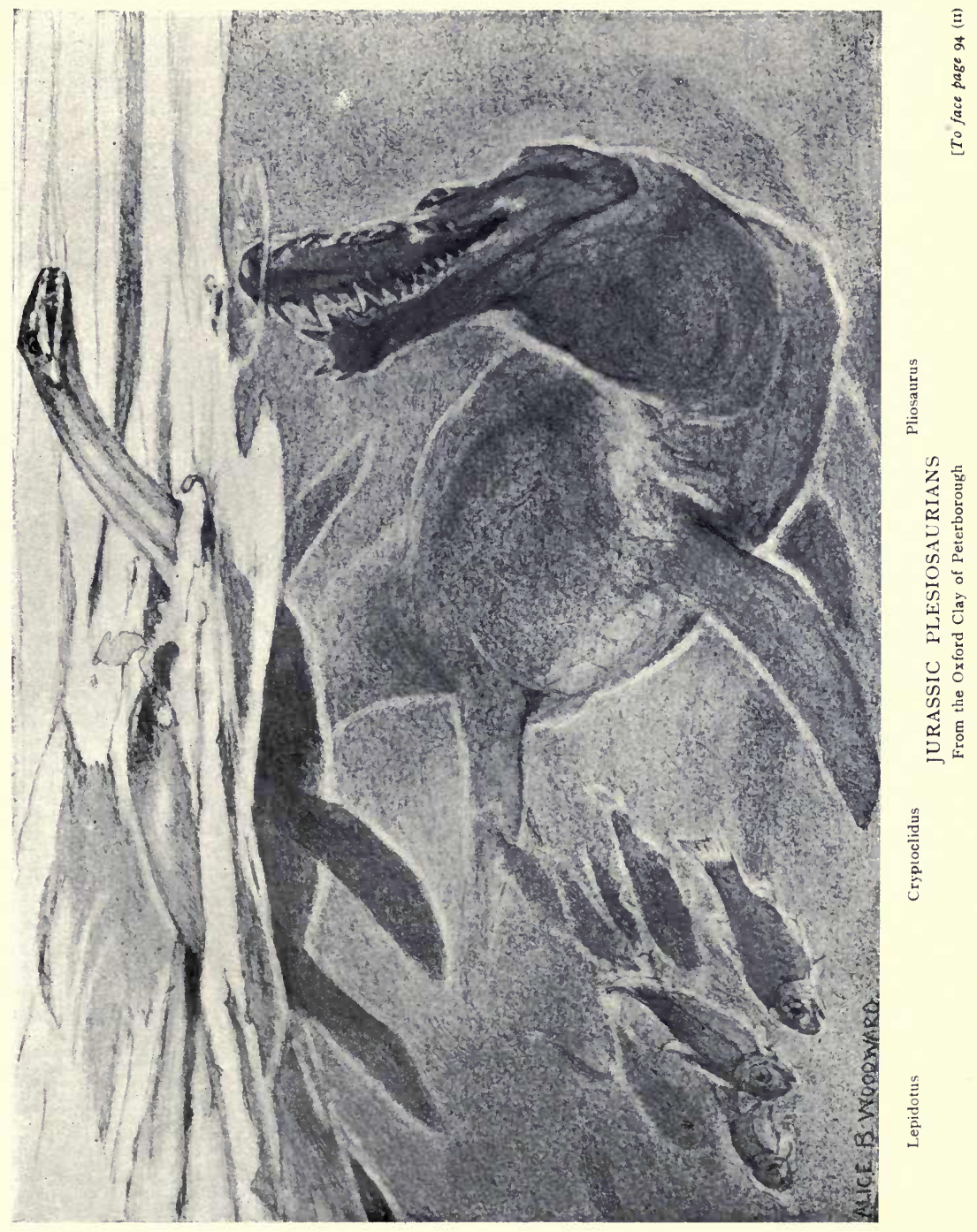



larger size-some attaining a length of fifteen feet (Crypto- PLEsioclidus). The limbs had become completely adapted to saURIANS swimming purposes, and a tail-fin-at least in some caseshad been developed ( $P$. macrocephalus). Some new forms, characterised by comparatively short necks, were also in the waters (Pliosaurus). These were formidable-looking brutes, attaining in some cases a length of thirty feet, and their teeth-long and sharp-no doubt occasionally met in the flesh of plesiosaurs.

Ichthyosaurs or "fish-lizards" were now to be seen forty ICHTHYofeet in length, and with limbs of more complete paddle-con- SAURIANS struction. Instead of coming to shore for egg-laying purposes, as probably did the earliest ichthyosaurs, the females brought forth their young alive out at sea : and it is doubtful if ichthyosaurs ever visited the land in Jurassic times.

Reptile-life had not exhausted its powers in the evolution of swimming, creeping, leaping, and walking forms: for creatures capable of rising from the ground, and navigating the air, had now emerged from the ranks.

These somewhat bird-like forms are variously known as FLYING " flying lizards," " wing-fingered" animals, and " dragons LIZARDS of the air" (Pterosaurs, Pterodactyls). According to the geological record they made a sudden appearance : but such of course cannot really have been the case. The modification of fore-limbs into organs for holding up folds of skin, and the ultimate adaptation to aerial flight-accompanied as it must have been by various bodily modifications-represented a long process: and there is no doubt that the known Jurassic forms were preceded by many small and imperfectly winged creatures, of which no trace has yet been found. From what particular group of reptiles they were derived is quite unknown.

The wing of a flying lizard in being of a membranous substance was like that of a bat; but its framework was different. It was supported by the " arm " and a greatly elongated "little" finger. The thumb had practically disappeared; but the first three fingers remained, and were free and usable as claws. A bat's wing, on the other hand, is supported by four fingers, and the thumb is the only free digit. 
Jurassic flying lizards were furnished with teeth ; and they subsisted, no doubt, chiefly on fish ; but dragon-flies and other large insects were not despised. The animals varied in size; some being no bigger than sparrows ( $P$. spectabilis); whilst others were as large as rooks (Rhamphorhynchus, $P$. crassirostris), and herons (Dimorphodon). Some species possessed long tails, designed, it may be supposed, chiefly for steering purposes (Rhamphorhynchus). The long tail, it would seem, proved inconvenient, for apparently no forms in the next Period possessed the apparatus.

BIRDS Towards the close of the Jurassic more important invaders of the air were in existence than flying lizards; for there is no doubt that on the site of Europe birds were then in being. They differed in some important respects from modern birds; but they were well-developed creatures. There is, therefore, no doubt that although they are the first known birds, they must have been preceded by many other forms. Their descent is lost in obscurity. They may have come down from some small Triassic Dinosaurs; or there may at one time have been a common stock from which birds and dinosaurs emerged.

The remains found consist of a few skeletons, and impressions of feathers; and all belong to one genus (Archaopteryx). In body these creatures were about the size of crows. The wing was small, but did not greatly differ from that of a living bird. The thumb, however, was developed as a claw; and the two surviving fingers, although supporting some of the flight feathers, were not joined together as with modern birds; and were, moreover, armed with claws. The bony tail-longer than the body-was a most remarkable feature. It consisted of twenty joints, each of which supported a pair of feathers. It was, in fact, a reptile's tail, decorated with feathers : and very different, of course, from the bony stump, and fan-like arranged plumage which constitute the tail of present-day birds. These strange creatures were also remarkable in possessing teeth-another feature connecting them with reptiles. The body was not lightened, as with modern birds, by a framework of hollow bones, and this fact, taken in connection with the small size 


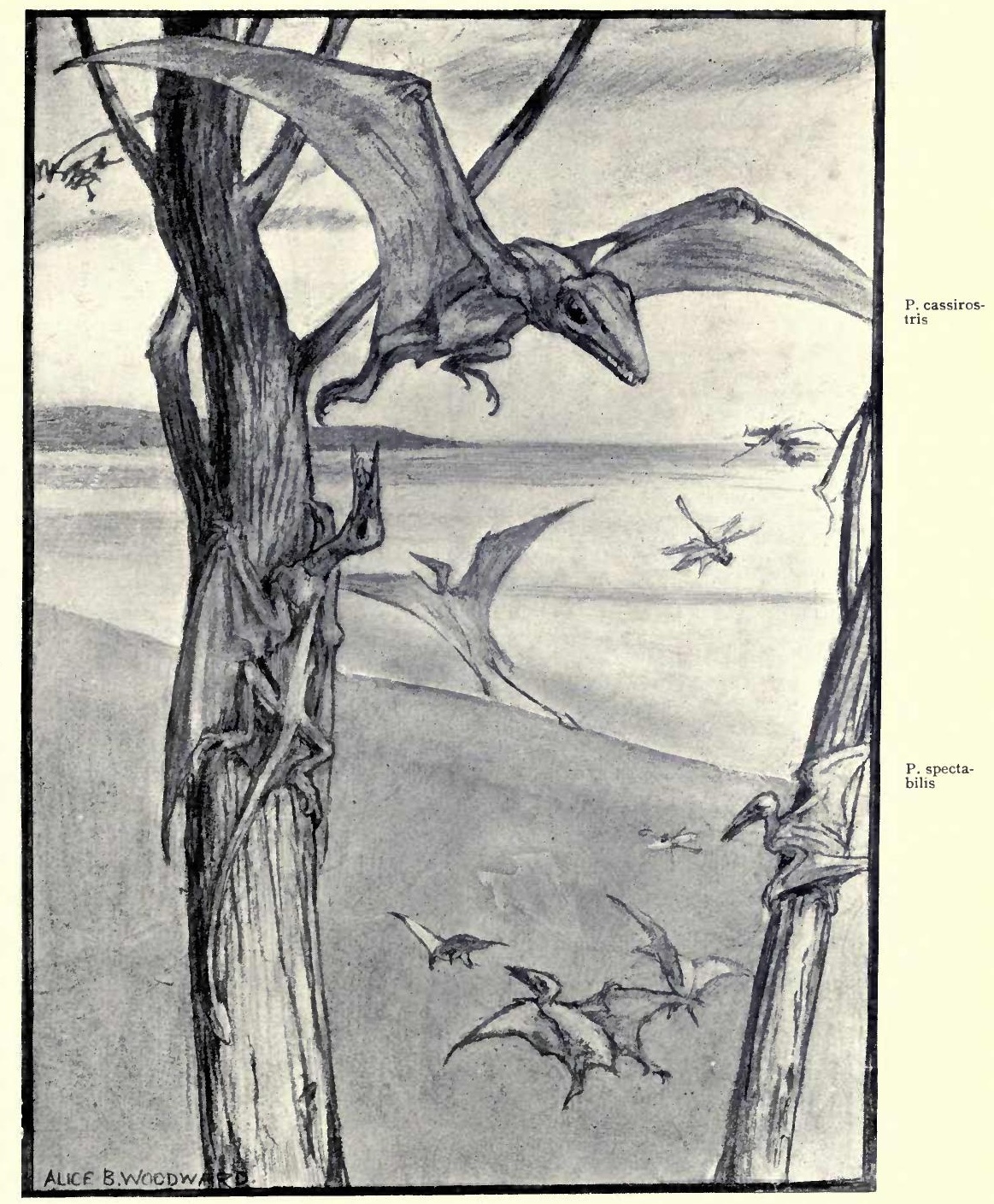

FLYING LIZARDS

Remains found in Jurassic strata: of Bavaria

[To face page 96 (1) 



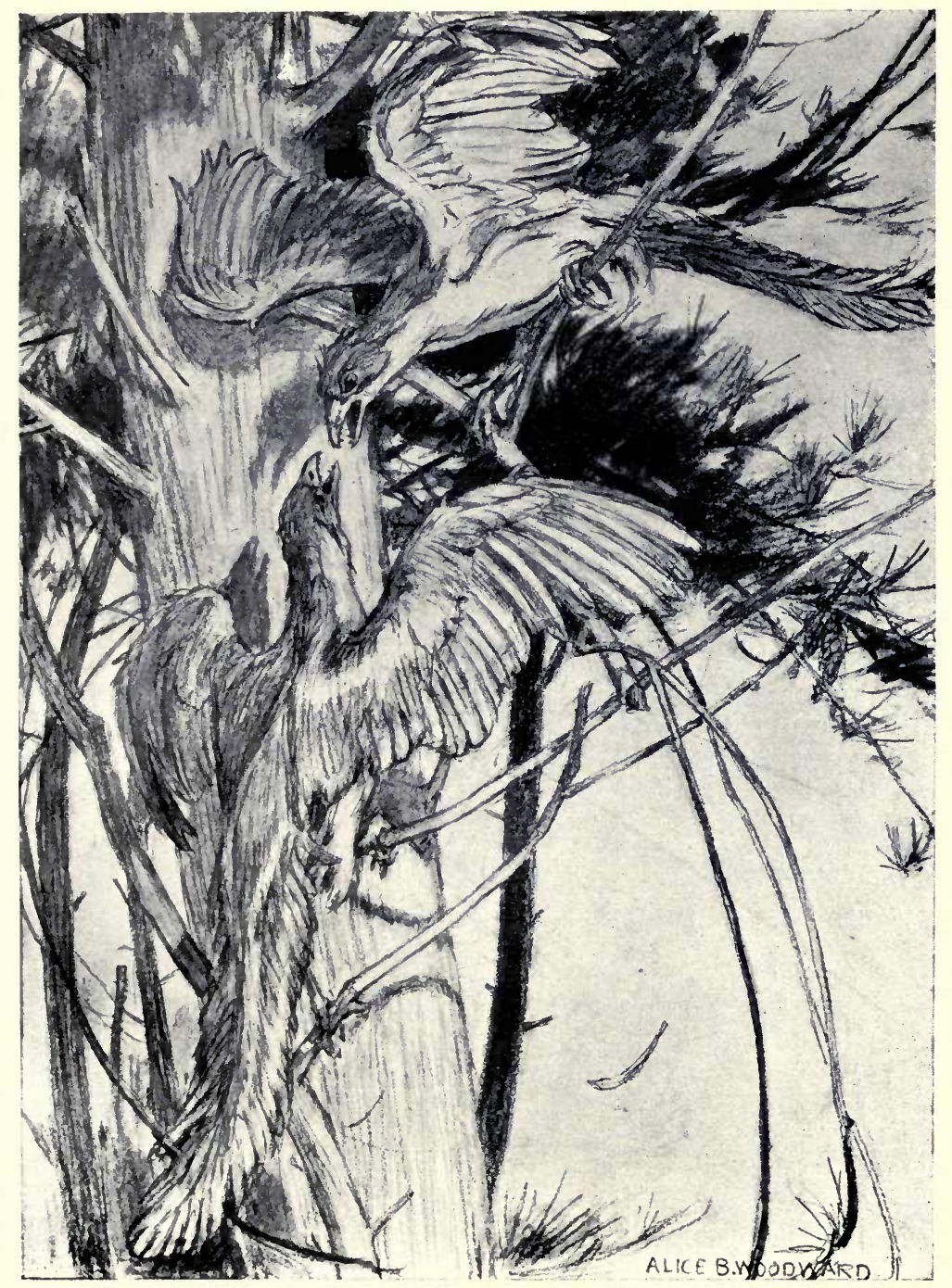

ARCH EOPTERYX

Remains found in Jurassic strata of Bavaria

[To face page 96 (I1) 

of the wing, and its deficiency of strength owing to the nonjunction of the fingers, leads one to suppose that these birds were not expert flyers. They, no doubt, indulged in occasional flights of short duration; but they probably scrambled up to perching-places on the trees by the aid chiefly of their legs and wing-claws. They must have been much persecuted by reptiles; for all new modes of life are sure to meet with violent opposition from the "authorities" of the time.

Mammals had now been long in existence; and doubtless had greatly increased in number; but they do not seem to have been much larger than their mouse- and rat-sized ancestors. Some, to judge by their teeth, were primitive insectivores, and may have been forerunners of moles ( $A m p h i$ therium). Some forms probably did not differ very much from living opossums (Phascolotherium); whilst others were apparently developing in the direction of squirrels and other rodents (Plagiaulax, Bolodon, etc.).

Some of the creatures had teeth far exceeding in number those of any living mammals; but in no case do the teeth indicate carnivorous habits.

Primitive mammals, therefore, were still in an age of innocence. But times were difficult; and they probably dwelt for the most part in holes and corners, and on high tree-branches; and rarely ventured from their retreats save under cover of darkness. 


\section{MESOZOIC AGE}

\section{CRETACEOUS PERIOD}

DINOSAURS THE reptile boom was now subsiding. Dinosaurs, it is true, continued fairly prosperous for some time. They had, however, passed their zenith, and soon after the early part of the Period their decline was somewhat rapid. Many changes were going on in the world; and the animals had become too slow in adaptation. They appear to have found some relief from high pressure by migrations. Not only in North America and Europe were they now living, but some had found their way to South America and India. And on eastern lands in Africa, just south of the equator, some huge forms were sprawling about with limb-bones twice the size of those of the great Diplodocus.

Among the vegetarians, none of the Diplodocus family were now to be seen; and only a few comparatively small forms represented the Atlantosaurida-famous, in Jurassic times, for creatures of extensive dimensions. Stegosaurus had left no descendants : but Polacanthus was no unworthy representative of the type. This animal-standing between three and four feet in height-had the anterior half of its back protected by a double row of erect plates in Stegosaurian style. The rest of the dorsal armour consisted of a large shield. The tail bore ten pairs of bony spikes similar to those of the Jurassic monster.

Other remarkable dinosaurs, flourishing in the early Cretaceous, are known as Iguanodonts, as their teeth resembled those of the Iguana lizard. Remains of the animals have been found in England, Belgium, and Germany. They were big bird-footed creatures, standing in some cases fifteen feet in height. In general appearance these veritable Gogs 


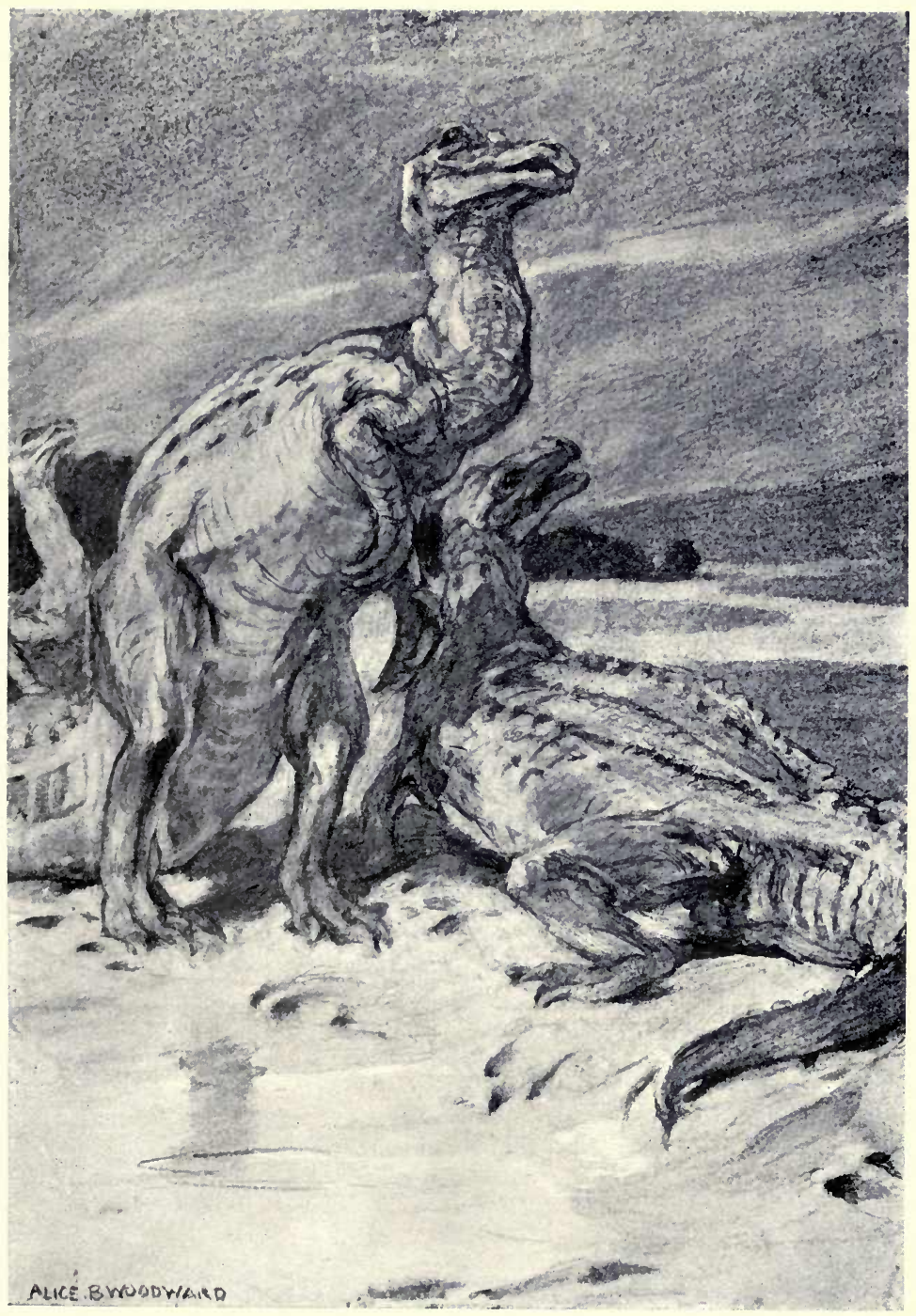

IGUANODONTS

Remains found in England and Belgium

[To face page 98 (I) 



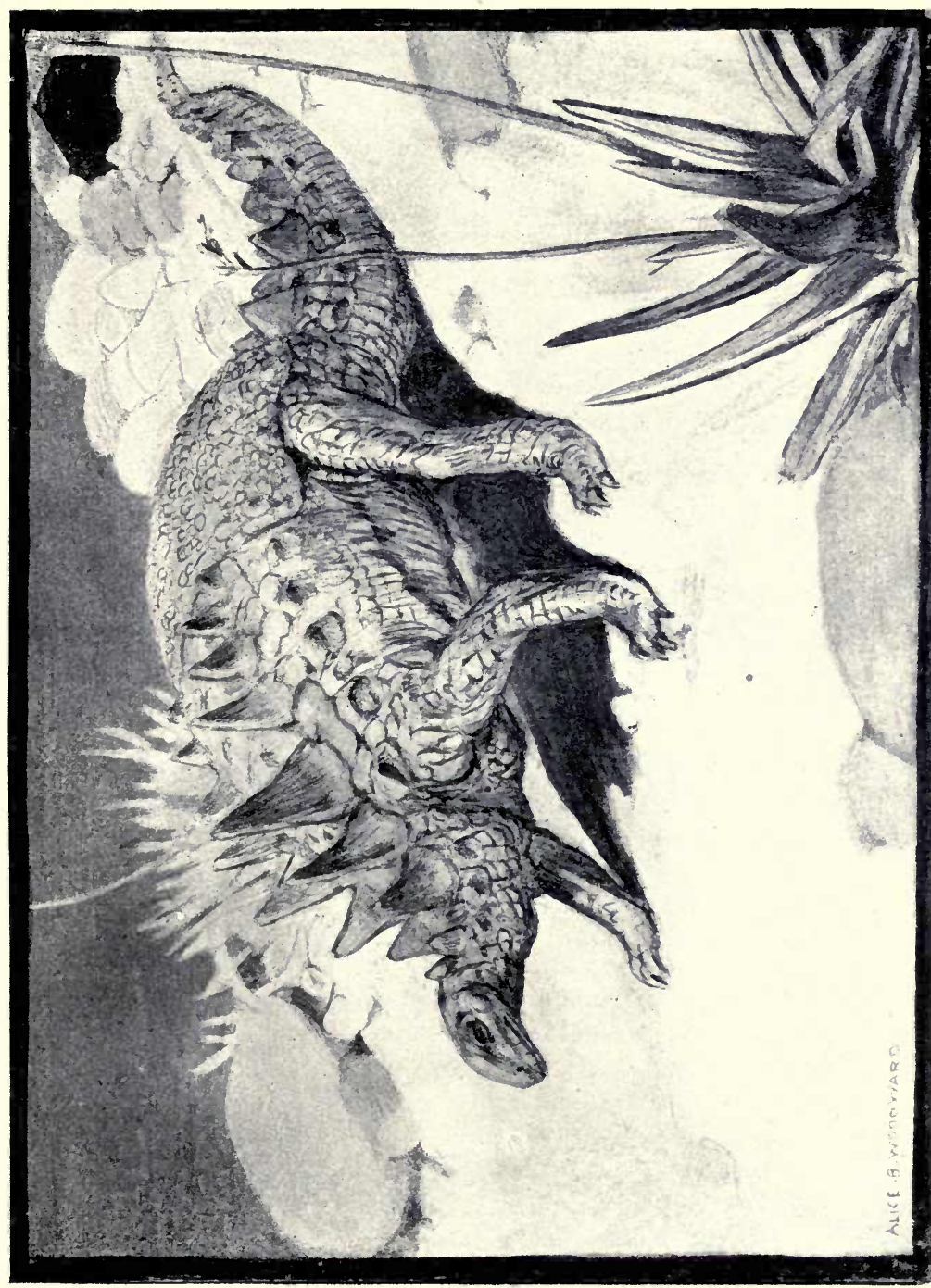


and Magogs resembled the bipedal dinosaurs of the last Period. The males were peculiar in having the thumb modified into a spur or spike, rigidly fixed at right angles to the palm of the hand. The thumb, in fact, had become a weapon, capable of inflicting severe wounds. It represented, no doubt, a retaliatory movement. Herbivorous dinosaurs had long been obliged to seek safety from carnivorous foes in flight, or by passive resistance under cover of heavy armour. Some of them at least were now capable of other tactics.

Big herbivorous dinosaurs, related to iguanodonts, were living in North America (Claosaurus). These animals, however, were practically thumbless. Their tails were remarkably thick and powerful. This stout appendage made with the hind-limbs a sort of three-legged stool; and the animals could feed off their favourite trees, comfortably seated. They were able to obtain much better food than hard cycads and conifers, as will be noted presently.

Carnivorous dinosaurs were well represented in the early Cretaceous by descendants of horn-snouted Megalosaurus of Jurassic fame. Later in the Period several allied forms were in existence. Some of these were remarkably light and agile, and must have caused the bulky vegetarians considerable discomfort (Lalaps).

On the North American continent reptile-life, in later Cretaceous times, was signalized by the appearance of some wonderful herbivorous dinosaurs. And, as after events proved, this was a last and supreme effort of the "terrible lizards " to keep a foothold on earth.

The most notable of these heroic brutes has been named Triceratops- " the three-horned." This quadrupedal creature had an enormous head, but very little in it in the form of brains. The bone of the skull did not stop at the ordinary limit, but - as a counterpoise to the frontal heaviness-was continued over the neck in a manner suggestive of an Elizabethan collar. There was, however, nothing else Elizabethan about this quaint monster. Two sharp, good-sized horns stuck out from his forehead, and a small horn surmounted the snout. He was therefore well 
equipped for frontal attacks; but as his capacious body was not protected with armour, he must have had to rely on his tail to deal with sudden flank assaults. His horns were doubtless of use for other purposes than fighting. If he had, like elephants, a partiality for roots, he could use them for digging up shrubs and trees. It is not likely that these appendages underwent any improvement as the result of what is called sexual selection. It would certainly be rash to suppose that these cold-blooded, dull-witted creatures exhibited much ardour or discrimination in their love affairs.

Other dinosaurs also brought a lustre to the waning line. These were remarkable for possessing duck-like bills, fitted out with an immense number of teeth-in some cases two thousand (Hadrosaurus). The dentition seems to have been designed purely for feeding purposes; at least it was illadapted for hostilities. The animals had little or no armour ; and unless they could trip up a foe, and roll over him, they must have fared ill in a quarrel. Possibly their lines for the most part were in out-of-the-way places, where they could feed on the herbage of lakes and streams in peace and comfort. Some portly creatures attained a length from snout to tail-end of nearly forty feet.

CROCODILES Whilst dinosaurs were all on side-paths leading to extinction, less lugubrious was the outlook of the crocodiles. Indications had been made in the last Period that these reptiles were to receive some structural benefits. The improvements were directed to increasing the flexibility of the backbone; and to so altering the breathing arrangements as to enable the animal to drown its prey without drowning itself. In early Cretaceous times many old-fashioned forms were still in existence (Pholidosaurus, Goniopholis); but later in the Period the improvements apparently were possessed by a vast majority of the crocodiles (Thoracosaurus, Holops).

The vertebræ of the backbone worked more freely, as they were of concave-convex pattern, fitting each other like ball and socket. The new breathing arrangement was still more remarkable. Under the old system the nasal passages. 


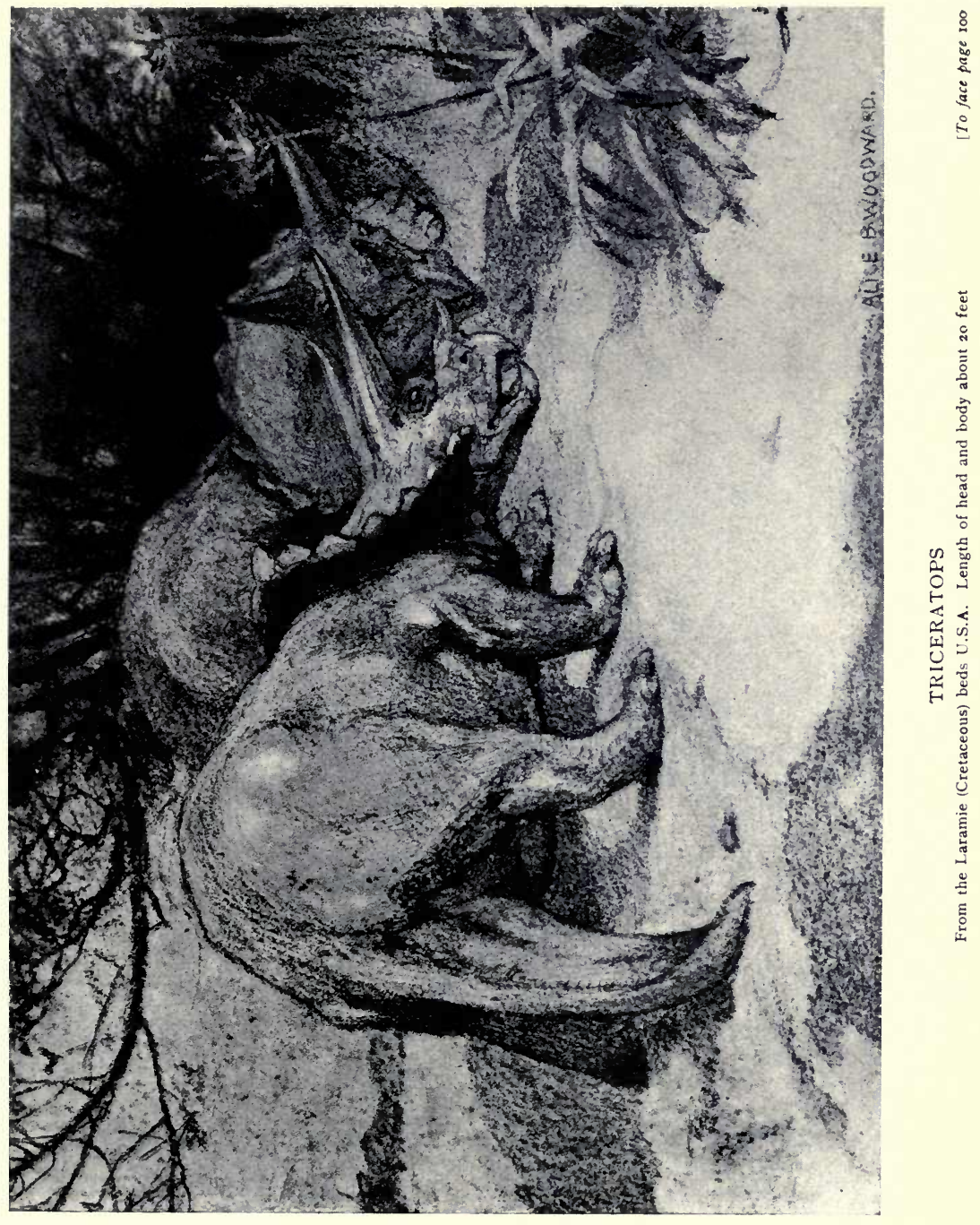



communicated with the windpipe, by running through the bony palate into the mouth; and to keep the mouth open under water would have been suicidal. To achieve the object in view, the anatomy had been considerably modified. The nasal passages had been carried further back; and could, with the windpipe, be shut off from the mouth by means of valves at the back of the tongue. A want long felt by crocodiles-enablement to drown prey without risk of self-drowning-had, therefore, been supplied.

Alligators seem to have been in existence at this time ALLIGATORS (Bottosaurus). These creatures were probably an offshoot of the crocodiles. Indeed, excepting for the manner in which some of the lower teeth bite into the upper jaw, alligators are practically identical with short-snouted crocodiles.

The sea-roving crocodiles (Metriorhynchus) of the last SEA-ROVING Period were no longer represented. Possibly they never CROcodILES became sufficiently expert swimmers for the manner of life they had adopted.

In some parts of Europe, however, reptiles of a different type had betaken themselves more or less to a watery life. DOLICHOThese were probably modified descendants of some of the semi-lizard creatures of Triassic times. In some respects they were developing in the direction of snakes. These dolichosaurs, or "long lizards" as they are called, did not, in early Cretaceous times, exceed a yard in length; but in the course of the Period, forms of twice and even thrice that length were in the waters (Dolichosaurus). They never became so far modified in their limbs as to become completely adapted to aquatic life.

In late Cretaceous times some thorough sea-going reptiles MOSASAURS -probably an offshoot of the "long lizards"-were abroad. These creatures have been named Mosasaurs, as remains of them were first found in the valley of the Meuse, or Mosa. Subsequent discoveries have shown that they were by no means confined to that region; but that they lived also in seas of North and South America, and extended their range as far as New Zealand. They possessed skulls lizard-like in shape, and long, snake-like bodies. Their limbs had become 
thoroughly adapted to marine life, being provided with powerful paddles. They further resembled snakes as regards the mouth. This organ was capable of considerable distension, as the head bones worked freely upon one another, and the two halves of the lower jaw, joined by elastic ligament, could be drawn well apart. The throat, no doubt, was also as with snakes capable of considerable expansion, and the animals were enabled to seize and swallow prey of large size. They possessed also snake-like teeth, pointed and curved backwards. Such teeth were, of course, useless for mastication, but they effectively prevented prey once seized from wriggling out of the mouth. As, however, the mosasaurs were also provided with masticating teeth, it is not likely that their manner of feeding was entirely snake-like. They attained in some instances to a length of fifty feet; and ably supplied the vacancy caused by the early collapse of other sea-going reptiles.

Some distantly related forms managed to hold their own for a time in the next Period (Champsosaurus); but dolichosaurs, and mosasaurs, strictly so called, all disappeared in the great reptile "slump" which set in at the close of the Cretaceous.

Chelonians Tortoises meanwhile had undergone but little change. But however stolid and conservative they may have been as a rule, a spirit of enterprise was in their ranks. A tendency, shown by some river-haunting forms in Jurassic times, to take to marine life had become strengthened in the course of years; and in late Cretaceous times sea-tortoises or-to speak more correctly-turtles, with limbs modified into true paddles, abounded in some of the shallow seas. Some of these animals seem to have been closely allied to " edible," some to "loggerhead" turtles (Allopleuron, Lytoloma) of our time.

Other chelonians had become more partial to mother earth, and buried themselves in mud more or less completely (Trionyx).

ICHTHYO- Whilst turtles were beginning to swell the ranks of marine SAURIANS life, the whale-shaped ichthyosaurs or fish-lizards were getting into a parlous condition. They had now lost their 
teeth-possibly as a result of racial old age. How far this deprivation affected their fortunes cannot be determined. Whatever the cause, they became practically extinct long before the close of the Period. Their career had probably been mainly in the shallows, where the competition of younger life may in time have become too keen. As a forlorn hope they may have migrated to deep waters, and in their new sphere have been starved and persecuted out of existence.

Plesiosaurs were also under great pressure; but their PLEsIOcollapse came later than that of the fish-lizards. The short- SAURIANS necked, sharp-toothed forms of Jurassic times had apparently left no descendants (Pliosaurus); but plesiosaurs resembling them at least as regards the teeth were in Cretaceous waters (Polyptychodon). For a considerable time the long-necked forms flourished greatly, and in many parts of the world; but they were submitted to severe tests in the latter part of the Period. Even then, however, some forms with " record " necks were to be seen. Elasmosaurus, for instance, had a neck twenty-two feet in length. Many curiously modified forms were also then in evidence. Some of these had long heads, obtained apparently at the cost of the neck (Trinacromerum). In some animals the head exceeded the neck in length (Dolichorhynchus). These modifications were, no doubt, desperate attempts to meet changing conditions; but they proved of no permanent avail. Indeed they were probably reversions to a form of structure such as their far-back unknown land-ancestors had possessed; and manifestations of atavism are not indicative of true energy. But however that may have been, plesiosaurs, long-headed and shortheaded, and with necks of whatever length, were one and all doomed. They were essentially creatures of old-fashioned type, and without sufficient elasticity to be effectively transformed. Difficulty in obtaining food, owing to the greater wariness, keener sight, and better swimming powers developed in fishes, may have been one of the causes which brought about their downfall. As also may have been the increase of large voracious fishes. But the closing portion of the Cretaceous is one of the darkest epochs in Geology; and the 
precise conditions under which various forms of life then disappeared cannot be ascertained.

FLYING Flying lizards were also doomed; but they showed LIZARDS considerable vitality for a long time. Those of the Jurassic were mostly of small size, but in this Period enormous creatures were navigating the air. Take Pteranodon, for instance. Here was an animal with an expanse of wing of eighteen feet; and other forms were about with even greater wing-spread. This development had necessitated an excise, which no doubt had been levied on the legs; for these had become much enfeebled. But however undignified these creatures may have appeared as they shuffled along on land, they must have been grand and graceful objects when sailing in the air.

The winged lizards of earlier times were more or less provided with teeth; but Pteranodon, and many other Cretaceous forms-especially on North American sceneswere toothless. In this they exhibited a change going on in bird-life. But in their case this breaking away from reptile traditions was of no good augury. Indeed it must be regarded as symptomatic of senility and decay in the no longer youthful Order.

Notice must now be taken of fishes, which, in addition to numberless commotions and cannibalities amongst themselves, were victimised by various sea-roving birds and reptiles. But internal dissensions and havoc from without had served in the past to bring out their wonderful adaptabilities; and a brisk progress continued.

sHARKS Although sharks had undergone some modifications resulting in the evolution of new forms-some specialised as Porbeagle sharks had now appeared-they were destined to remain in a primitive condition of development. The vertebral column continued of gristly substance, and still extended to the extremity of the tail. These features, indeed, have continued until the present day.

The most notable event in the Cretaceous annals of sharks and closely allied forms was the appearance of saw-fishes (Pristiophorus, Sclerorhynchus); but the rostrum-teeth, as might be supposed, were not of so trenchant a character 


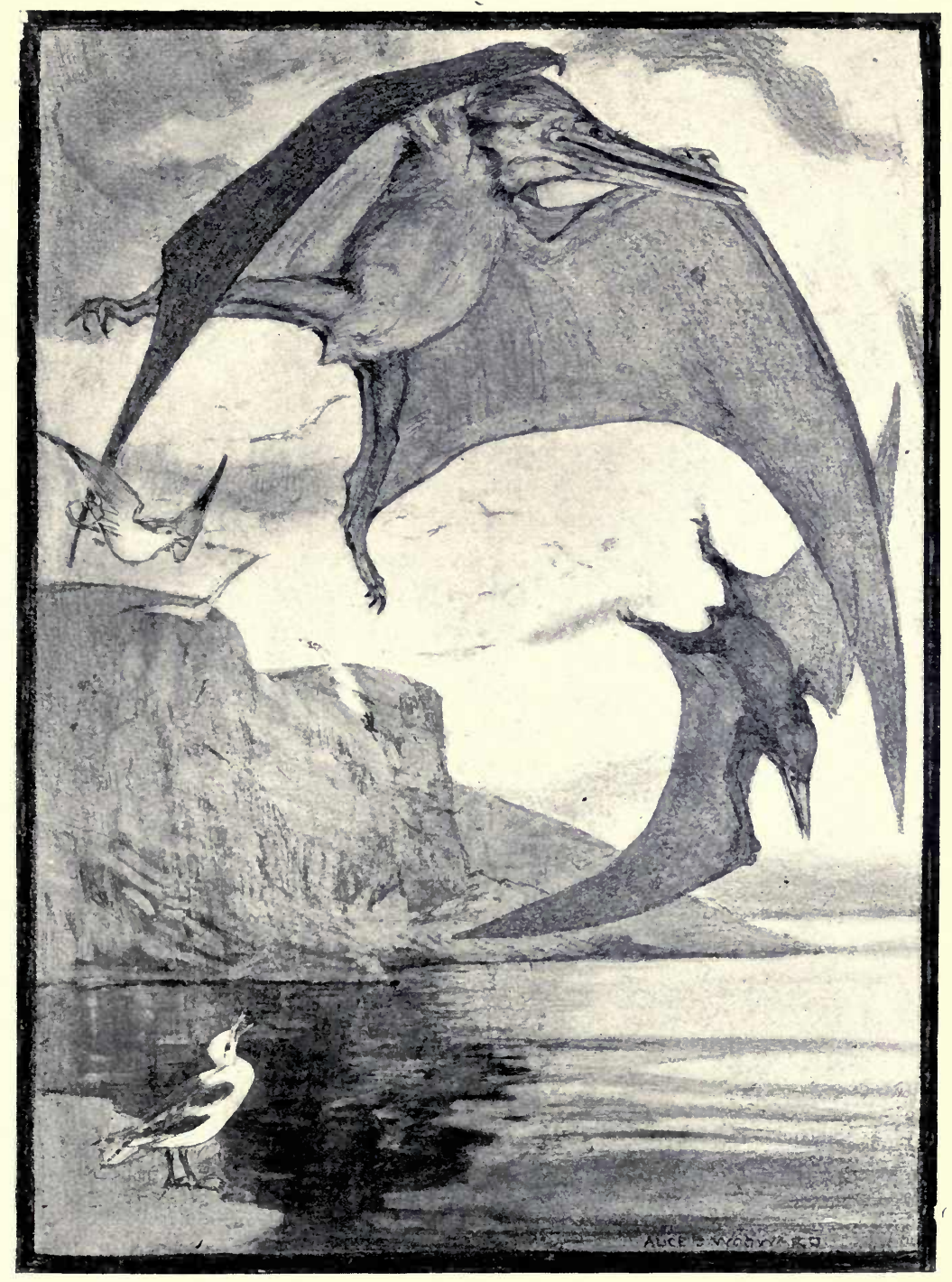

PTERANODON

From Cretaceous strata of Western Kansas, U.S.A.

[To face page 104 

as in later forms. Other members of the group were developing in the direction of eagle-rays, or "devil" fishes (Ptychodus).

Dipnoans or fishes of the lung-breathing type had retired DIPNOANS from the seas to take up permanent quarters in fresh waters; and no great future was in store for them.

Among the fringe-finned ganoids (Crossopterygii), one GANoIDS family-very little changed from Devonian times-con- (CROssoptinued in some force for the greater part of the Period, and TERYGIANS) then dwindled to extinction (Colacanthida). Other forms remained; but fishes of this Order were not destined to take much part in the finny life of the future; and it will not be necessary to refer to them in subsequent Periods. Their decline continued in after times; but they have struggled on, and are represented to-day by one small family, whose members are found in a few rivers of Africa (Polypterida).

The flexibly finned ganoids (Actinopterygii) had been (ACTINOPexhibiting advances in development ever since Devonian TERYGIANS) times, and had become well established in a variety of forms in the Jurassic. Towards the close of that Period a small number of them had attained the condition of being true bony fishes; and were, indeed, the immediate heralds of a great revolution.

During early Cretaceous times steady progress was no doubt made; but there is not much direct evidence as to this. It is clear, however, that when the Period was well advanced, bony fishes gained a decided predominance over the ganoids that had not attained the higher anatomical standard. Ganoids thus became reduced to the long-decadent fringe-finned forms, the flexibly finned fishes more or less resembling sturgeons, and bow-fins, and a few other types not closely comparable with living fishes.

Among the bony fishes shoals of herring of various species were in evidence (Pseudoberyx, Histiothrissa, etc.). Some large related forms with stout pointed teeth were also in the seas, living probably at the expense of their small relations (Portheus, Saurodon). These formidable fishes attained in some cases a length of six feet; and somewhat resembled

TELEOSTEANS 
the voracious dorabs of our own time (Chirocentrus). There were also many spiny-finned fishes. These evidently had an excessive supply of bony substance, and the surplus was finding its way along the fins. The most numerous of the company were closely related to the Beryx of our own time (Hoplopteryx). Others seem to have developed more or less into horse-mackerel (Aipicthys), sea-perches (Prolates), and sea-bream (Pagellus).

Fishes with the pelvic fins brought forward, and greatly enlarged as if for flying purposes, were also to be seen (Chirothrix). Fishes eel-shaped-and therefore degenerate -were numerous (Echidnocephalus, Dercetis, etc.); and true eels were in existence (Urenchelys). Here also were fishes of the family to which tarpons belong (Elopida); and many other forms were abroad, belonging to families which exist to-day (Albulida, Halosaurida, Scopelida, etc.).

In addition to these, there were various bony fishes, divers in form, and of uncertain affinities (Ctenothrissa, etc.). Indeed in late Cretaceous times there was a decided boom in the fish world, resulting from the new anatomy. An analogous outburst of activity may be witnessed on a small scale in human affairs, consequent on some great discovery or invention.

Notice must now be taken of the lower classes of the marine population.

CRUSTACEANS Many crustaceans in Jurassic times had become recognisable as shrimps, prawns, and lobsters. In the Cretaceous Period all these differentiated creatures became more distinctly defined, and of greater variety. New forms of prawns (Hoplophorus, etc.) and various small lobsters (Enoploclytia, Clytia Leachii, etc.) were now in being. Among the latter some essentially resembled the Norway lobster of our own time (Nephrops): other allied forms were probably indistinguishable from the modern Crawfish (Palinurus). There were also numbers of lobsters that had taken to embedding themselves in mud (Callianassa).

But it was in crab-life that the greatest developments were in progress. Crabs, although foreshadowed in far-back times, cannot be said to have expressed themselves un- 
mistakably before the Jurassic. Once established they seem to have advanced rapidly ; and they were present in Cretaceous seas with carapaces variously shaped. Some of the creatures apparently were very similar to the modern spongecrabs; and possessed special limbs for holding a sponge or other marine organism on the back for self-concealment (Dromiopsis). Other forms seem to have closely resembled the shore-crabs, masked-crabs, and frog-crabs of our own time (Necrocarcinus, Palaocorystes, Raniella).

Some barnacles were now to be seen directly fixed to their haunts by means of cement, the stalk apparently having gone to waste (Verruca). This method of attachment no doubt saved the animals some exertion; and life in barnacle circles became more inert than ever.

Whilst crustaceans were thus advancing, hard times had AMmonITES set in for most of the cephalopods. The ammonites, it will be remembered, had a large measure of prosperity in the Jurassic Period; but clear signs were not then wanting of impending trouble. Matters became far more serious in the Cretaceous; and the resources of these enterprising molluscs were tried to the uttermost. Surely no creatures ever battled more strenuously with adversity. Some appear to have wooed Fortune with elaborate ornamentations of the shell (Hoplites, Douvilleiceras). Many ceased indeed to be ammonites in the sense of creatures with shells suggestive of a ram's horn. Some forms had their shells twisted into little towers (Turrilites). Others were more or less uncoiling themselves -reversing engines, as it were, in view of dangers ahead (Hamites, etc.). Some indeed had become completely uncoiled (Baculites). But whatever their adaptations, ammonites continued to decline; and in the next Period this once great Order was represented by a mere remnant of moribund forms.

The squid-like Belemnites well maintained their position BELEMNITES for a time; and many new forms made their appearance. Curiously enough when their arch-enemies, the Ichthyosaurs, were in extremis, they themselves commenced to decline. Gradually dwindling down to a few genera, they became at the close of the Period wellnigh extinct. 
OCTOPI The decline of the belemnites may have been in part caused by the rise of allied and more active creatures, known as octopuses. These voracious molluscs-now appearinghad hardly any shelly substance to carry. A handicap to elasticity of movement-inherited from remote sluggish ancestors-had, therefore, been practically removed (Palceoctopus).

NAUTILI The decay in ammonite and belemnite ranks was in part counterbalanced by the success of cephalopods of more ancient lineage. Some exceptionally large forms of nautiluses now made their appearance. The old blood was reasserting itself.

UNIVALVED Marine gastropods or sea-snails do not seem to have been MOLLUSCS much affected by the changes going on around. Those with the improved breathing apparatus, initiated in the Trias, and largely in evidence in the Jurassic, were greatly on the increase. But old-fashioned siphonless forms that carried on respiration simply through the skin, or by means of gills and slightly modified mantle-edges, were probably still in a large majority.

BIVALVED Bivalved molluscs had at no time proved unequal to the MOLLUSCS struggles of life; nor did the Cretaceous Period find them otherwise.

There is nothing notable to report about the mussels, scallops, cockles, and oysters; except that among the last were some exceptionally large forms. Several present-day families of bivalves with burrowing habits first become known in this Period (Mactrida, Saxicavida, etc.). Other bivalves were following out experiments made in the Jurassic; and they met with temporary success. The animals appear to have been related to clams; but they were very unlike clams now living. Their shells had assumed a horn-like shape; and some rather later forms resided in long; funnel-shaped shells, protected at the top by a lid (Hippurites). These wellaccommodated animals became very numerous and widely distributed. But the ostentatious shelly residence was not really significant of great wealth within. The creatures certainly kept up appearances for a long time; but towards the close of the Cretaceous they failed to meet the 


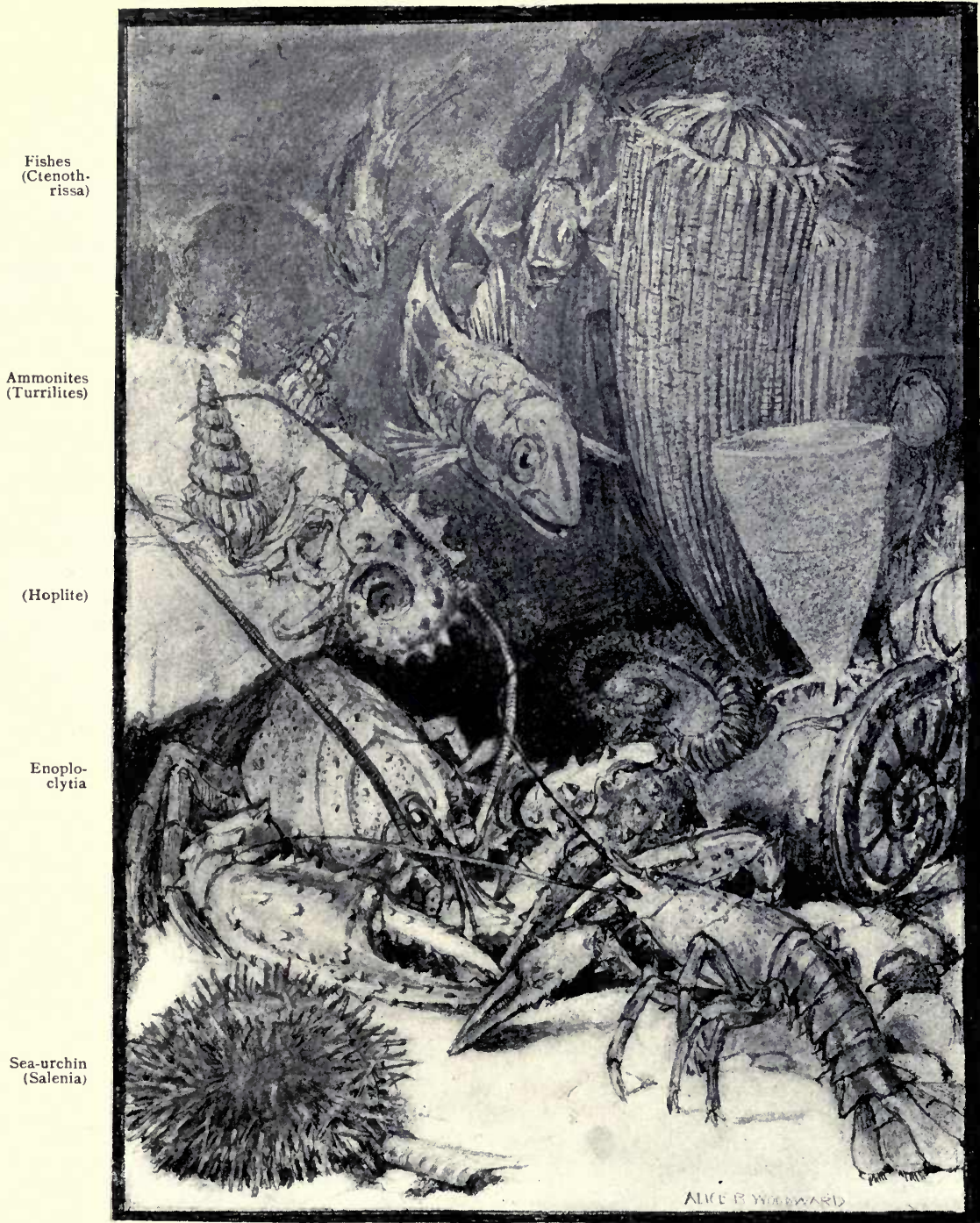

Hippurites

Siphonia

Coscino-

pora

Ammonites

(Hamite)

(Hoplite)

Clytia

Leachii

Baculite

CRETACEOUS PERIOD

To face page 108 

demands of Evolution, and were struck off the molluscan roll.

The most remarkable feature in the Cretaceous annals LAMPSHELLS of brachiopods, or lampshells, was the great prosperity attending an old family, which had in Ordovician times dissented from other brachiopods. The dissent consisted in discarding the stalk, and developing a cement as means of fixation (Craniide). This persevering nonconformist family is still living. Two other old families-notable for beaked shells-that had taken a new lease of life in the Trias, were also much to the fore in the Cretaceous Period (Terebratulida, Rhynchonellida).

Among polyzoans, the older-developed colonies, with POLYzoANs zooids in open-mouthed tubes (Cyclostomata), were for a great part of the Period keeping well ahead of the "lidmouthed" colonies (Cheilostomata). In late Cretaceous times, the latter seem to have drawn abreast of their rivals. The reformed colonies, flushed with success, were in some cases effecting changes in their social system. Certain zooids were losing their status by being modified into organs (avicularia) for keeping off intruders, and for seizing food for their fellow-colonists (Cellaria, Onychocella). Zooids in close proximity to these transformed individuals must have lived in great ease and luxury. A privileged class, in short, had risen in the community. Another change was in progress in some colonies. Certain zooids were being transformed into menial appendages (vibracula) for bringing a colony to anchor (Lunulites).

Sea-urchins continued dominant among the spiny-skinned SEA-URCHINS creatures, and underwent great developments as the Period advanced. Old forms of more or less sedentary habits, with circular tests, were very numerous ; and new forms of these were making their appearance (Salenia). But it was among the more inquisitive urchins, that had, by burrowing or more active locomotion, lost their circularity, that a notable increase was taking place. Heart-shaped forms-sometimes termed heart-urchins-were very much in evidence (Holaster, Micraster, etc.); and some were becoming still more like ordinary bilateral animals, as the mouth was well in process 
of being brought forward from its old central position on the under-part of the body. These creatures must have been living on softer food than their ancestors, for the anatomical alterations had been accompanied by a total loss of the teeth.

SEA-LILIES Crinoids, or "sea-lilies," after much depression, revived somewhat in the Jurassic; but their fortunes do not seem to have further improved in the Cretaceous Period. The work of emancipation, however, from a rooted existence was in progress; and stemless forms were becoming more prominent (Marsupites, Uintacrinus).

CORALS Reef-building corals were still greatly in force in parts of central Europe. In some regions gracefully branching coralcolonies, resembling the "sea-fans" of our own time, were now to be seen (Gorgoniida). And red coral is first met with in this Period (Corallium).

SPONGES Sponges with flinty skeletons were abundant; and the nodules of flint, found in the Chalk formations, probably represent their remains, increased in volume by the accretion of other flinty materials in the rocks.

Sponges fortified with six-rayed needles were spreading far and wide (Hexactinellids); and species with the needles wrought into elaborate frameworks, and possessing strong roots composed partly of a flinty substance, were much in evidence (Coscinopora, etc). Some of the forms resembled the "Venus Flower Basket" of our own time, and added not a little to the beauty of submarine life (Ventriculites). Prosperous also were four-rayed sponges and allied forms (Tetractinellids, Lithisda). Indeed at no other time are they known in such variety. Some of bud-like shape were peculiar, having developed long stalks well rooted at the base (Siphonia). Sponges with lime needles shared for a time the good fortune of their flinty brethren, but towards the close of the Period they met with checks in their onward career.

PROTOZOANS The lowest forms of animal life-Protozoans-were well represented by foraminifers and radiolarians. The former must have been as sand-grains in the sea. By appropriating lime held in solution in order to form their shells, and 



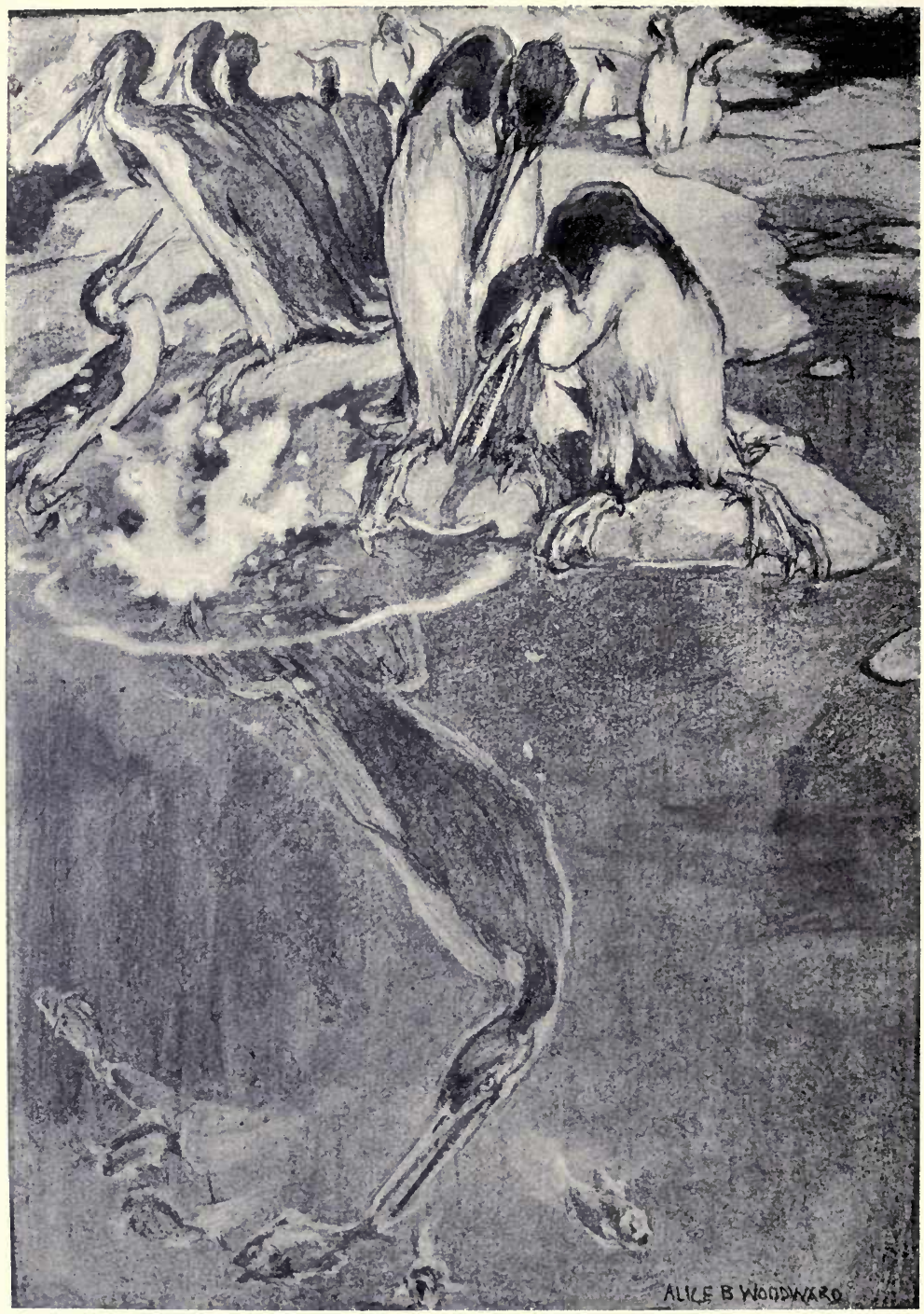


by force of prolificness, they became true rock-builders; for the chalk is largely composed of their shelly coverings. It has been estimated that one cubic inch of chalk represents the remains of more than a million minute organisms, mostly foraminifers.

Along the coasts and estuaries birds of various kinds were in evidence, water-habits having come greatly into vogue. As the remains found all belong to the latter part of the Period, a wide hiatus occurs in bird history, and great changes cause no surprise.

Toothed birds, however, continued; but the tail had undergone important modifications. It did not now consist of a long lizard-like structure decked with feathers. The bone had been considerably shortened; and the feathers were doubtless so arranged as to spread out more or less fanwise as in the case of modern birds. Another link, therefore, with reptiles had been broken. Nor were wings, so far as is known, provided with usable claws.

Birds exhibited still more changes. Some genera, for instance, had been through a series of modifications resulting in the loss of the power of flying. It would seem from this, that in certain regions birds must have found it safe and convenient to abandon, more or less, aerial flight; and that their habits had been confirmed by successive generations. In this way, through long disuse, a posterity had in time appeared entirely deprived of power to fly. These Cretaceous birds had little left to show that their remote ancestors possessed usable wings ; for the bone of the upper part of the fore-limb alone remained to testify to this. They may be said, moreover, to have wellnigh lost their "land legs"; for their limbs turned outwards from the body and pedestrianism must have been a laborious proceeding.

The life of these birds no doubt was spent mostly in the water, as in the case of grebes and divers. Indeed they were, so to speak, compounds of those birds, and probably their ancestral forms. They had doubtless become highly expert at catching fish, for their advanced specialisation for aquatic life points to long acquaintance with the art. 
Remains of them have been found in Europe (Enaliornis); but these do not indicate creatures of large size. In North America some forms attained a length of nearly four feet (Hesperornis).

Whilst some birds had thus lost a long-neglected endowment, others, suggestive of solan geese considerably undersized, had greatly improved their powers of flight. These, as a result of long-continued flying habits, had gained a strong framework for the wing, and also well developed breast-bones, with which to cleave the air and water (Ichthyornis). They had by no means grown out of affinities with reptiles to the same extent as living birds. In addition to the presence of teeth, connecting links remained in several parts of the anatomy, notably in the vertebræ of the backbone, which were concave at both ends as were those of early crocodilian forms. They were also, as were the diver-grebes, small-brained creatures for the size of their bodies.

Other birds-derived from the same stock as the semisolans-were modernised, especially in being toothless. Some apparently were a complication of storks and flamingoes (Scaniornis): others seem to have been forerunners of cormorants (Graculavus). Other forms had descended from a different stock. Some of these were rail-like birds (Telmatornis), some possessed close affinities with the dunlins of our time (Palcotringa). Doubtless many birds of various kinds haunted the inland valleys and plains, but their remains have perished, or at least have not been discovered.

VEGETATION The sylvan scenes of the early Cretaceous presented for the most part much the same aspect as those of the Jurassic. Sequoia firs were represented by primitive forms of the "big tree" (S. gigantea), and the "red-wood" (S. sempervirens). And these and other conifers, as well as ferns and cycads, extended far and wide, with as yet no serious competitors to dispute their long-held territories.

ANGIOSPERMS But in some unknown regions-possibly in the far northeast of the North American continent-shrubs and trees of a different character must for a long time have been developing. 
Under the stress of climate and inter-competition these vigorous growths had shown wonderful and varied resources -notably in the formation of deciduous habits. The power of adaptation, however, has its limits; and, owing to the increasing severity of climate, a time came when the various species had for self-preservation to migrate to lower latitudes. In the early Cretaceous there were distinct signs on North American scenes of such migration. Here and there south of Canada growths leaved like fig-trees, willows, sassafras, and magnolia were reconnoitring ; and as time went on, primitive forms of oaks, poplars, birches, and other deciduous growths joined the movement. Progress was necessarily slow. Every inch of ground was more or less disputed by old-established vegetation; and the emigrants themselves naturally competed with one another. But the new types pressed steadily on, enlivening the landscapes with brighter foliage, and greater display of flower. And so successful was the advance that, in the course of the long Cretaceous years, they became in some districts the dominant form of vegetation. "Horsetails " struggled on, and with some success, in their swampy holdings ; but conifers and cycads-the latter especiallydisappeared from many long-tenanted positions. The most progressive cycads (Bennettitea), that had given promise in their well-protected seeds of plants of higher type than cycads and conifers, (and, so far as is known, the nearest in development to the new vegetation) became extinct long before the close of the Period.

This invasion rather brings to mind the northern barbarians moving down on the Roman Empire. These Cretaceous hordes, however, were not barbarians of their kind. They were true angiosperms, and in the advanced methods they had developed for the production and welfare of their seeds, they illustrated more strongly than any earlier growths the principle of parental care.

In the early portion of the Cretaceous Period, though somewhat later in time than in North America, some primitive oaks, planes, and other angiosperms made their appearance in what is now known as the Spanish peninsula. How the seeds whence they sprang reached that territory-whether 
through the agency of birds, or by sea-transport, or by landconnections which no longer exist-it is difficult to say. Having, however, once obtained a footing, the invaders gradually extended their range, being reinforced from time to time by various other emigrants of their class. So successful was the progress that in the latter part of the Period fig trees, eucalyptus, oaks, poplars, grasses and other angiosperms had annexed large districts in Europe. But although conifers were being displaced in many parts of Europe and in America, they still flourished over vast areas on both continents. In addition to the nine points of the law in their favour, the soil in many districts was doubtless more suitable to them than to the new-comers.

Palms also were making their appearance. There is little doubt they were descendants of some early forms of cycads. This effort to confront new conditions was another sign of the resourcefulness of that Order.

INSECTS Hosts of insects must have accompanied the new vegetation, for plants and insects, then as now, were doubtless in many cases dependent on each other-the insects for food, and the plants for the transference of their pollen. Bees, butterflies, and moths are helpful in fertilisation; but it is impossible to say how far the vegetation was benefited by insects at this time. The evidence of insect-life in the Cretaceous is very meagre. Bees had appeared in the Jurassic, but the evidence as to butterflies at that time is not satisfactory; nor is there better evidence in the Cretaceous. There is, however, good reason to think that moths had by this time made their appearance (Tineide, Tortricida).

mammals Here then were trees, shrubs, and grasses as a table spread for mammals; but so far as is known these creatures exhibited very little progress over their forerunners (Dryolestes, Didelphops, etc.). They all appear to have been of small size; and no remains of forms of higher rank than marsupials have as yet been discovered. Reptiles still held the field. It is, however, extremely probable that in some lands, the strata of which have as yet been very little explored, mammals of higher type had come into being. But 
whether this was the case or no, this new vegetation was not to be enjoyed for long by grotesque plant-eating reptiles, although they doubtless battened on it for a time. An inrush of mammal life, no less wonderful than that of the new vegetation, was not long to be delayed. 


\section{CAINOZOIC AGE}

\section{EOCENE PERIOD}

THE passage time from the Cretaceous to the succeeding Eocene is shrouded in darkness: and the "new dawn" follows a long night. It is as if the lights in a playhouse had been abruptly extinguished, and after a lapse had been restored, disclosing a stage crowded with new characters.

The transition times were doubtless of long duration, and full of stirring events; but their archives for the most part have either been destroyed, or have yet to be discovered. The results, however, of what then took place are plain enough. There had been a great elimination of old forms of reptile and other life; and mammals had become dominant. Dinosaurs, herbivorous and carnivorous, had one and all vanished from the scene-iguanodonts with their spiked thumbs, stegosaurs with their battlemented backs, and the rest of the fraternity. Old Triceratops with his thrice-horned head, and Elizabethan frill, seems to have held out as long as any; but fortune failed him at last. In short, the old reptile nobility, unable to march with the times, had been swept away. Nor had ichthyosaurs, plesiosaurs, mosasaurs, and flying lizards fared any better. They had all quitted the stage, never to return.

MAMmaLs Mammal life, now triumphant, was represented by forms far surpassing in variety and importance the primitive creatures known in earlier times. The predominance of mammal over reptile life can hardly have been obtained by brute force; for there is no reason to suppose that primitive mammals were either warriors or flesh-eaters. Various geographical and climatic changes may have helped to shift the sovereignty; but the superior intelligence and higher 
moral qualities of the mammals were undoubtedly great factors in the dynastic question.

So far as evidence goes none of the mammals before this Period were of higher rank than pouched creatures, bringing forth their young in an extremely immature condition. And it is not until the beginning of Eocene times that remains of placental animals are found; i.e. of animals whose young are well nourished and developed before birth.

There can be little doubt that the Eocene placentals had been developed from marsupials of earlier days ; and as might be supposed they retained close affinities with the latter. They were doubtless more intelligent; but the brain, as with marsupials, was small in proportion to the size of the body.

The animals had not become so far differentiated as to make them closely comparable with any members of the existing mammal Orders. But intermixed though they were in affinities, they exhibited some notable differences. It is clear, therefore, that some important divergences had taken place before the " new dawn."

Some of the first-known creatures wandering about Eocene cONDYprairies and woodlands, are called the "knuckle-jointed" LARTHRA (Condylarthra), owing to a peculiarity in the structure of their feet. The animals were of small size, and probably bore greater resemblance to coneys (Hyrax) than to any other creatures now living. They differed markedly from coneys, however, in having long tails and five-toed feet. Their toes cannot be said to have been either hoofed or clawed; but the horny sheaths with which they terminated showed a tendency to become hoofs rather than claws. To judge from their teeth, the "knuckle-jointed" creatures subsisted on a vegetation diet, varied occasionally by feasts on insects.

Other forms, probably suggestive of bear-cubs and baby AMBLYPoDs hippo's rolled into one, are known as amblypods, as they possessed feet of a short and stumpy character. They also were five-toed animals, as, no doubt, was the rule with all primitive mammals-and the toes seem to have been guarded by little hoofs (Pantolambda). The " blunt-footed " creatures 
may not have been averse to flesh when obtainable without risk, but their staple fare consisted probably of vegetables.

CREDONTS Small, long-tailed creatures of more bear-like appearance were also abroad. These possessed teeth of a trenchant type, showing that flesh-eating had become a habit (Arctocyon). In the shape of the skull, and the claw-like termination of the feet, they were also developing in the direction of true carnivores. Some mammals, it is clear, had passed out of the Age of Innocence.

These primitive flesh-eaters are classed as Creodonts ("flesh-teeth"); but their close relationship with the " knuckle-jointed" vegetarians was attested by many anatomical features.

Mammal life was thus in process of important developments, foreshadowing the two great Orders of ungulates or hoofed animals, and carnivores. Nor was the promise of future development limited to those directions. Other contemporary animals seem to have been setting out to EDENTATES found the Edentates-the somnolent Order which comprises sloths, ant-eaters, and armadillos. Edentates ("toothless ") is not altogether a happy name ; for many edentates possess at least cheek teeth. Teeth, however, are not a strong point with any living members of the Order.

These Edentate pioneers-known as Ganodonts-were about the size of small dogs; were well supplied with teeth; and were probably not so drowsy as their present representatives (Hemiganus). Their dentition became somewhat reduced even during the early part of the Period. In the course of time teeth, and it may be added toes and tails, have frequently been in the melting-pot of Evolution; and edentates were destined to undergo great dental suppressions in times to come.

INSECTIVORES Other developments in the mammal world were also taking place Insectivores-the Order which comprises shrews, moles, and hedgehogs-had been foreshadowed so far back as the Jurassic Period, at least in marsupial form. In early Eocene times shrew-like creatures of higher rank than marsupials were certainly poking about in the thick grasses (Adiposorex). 



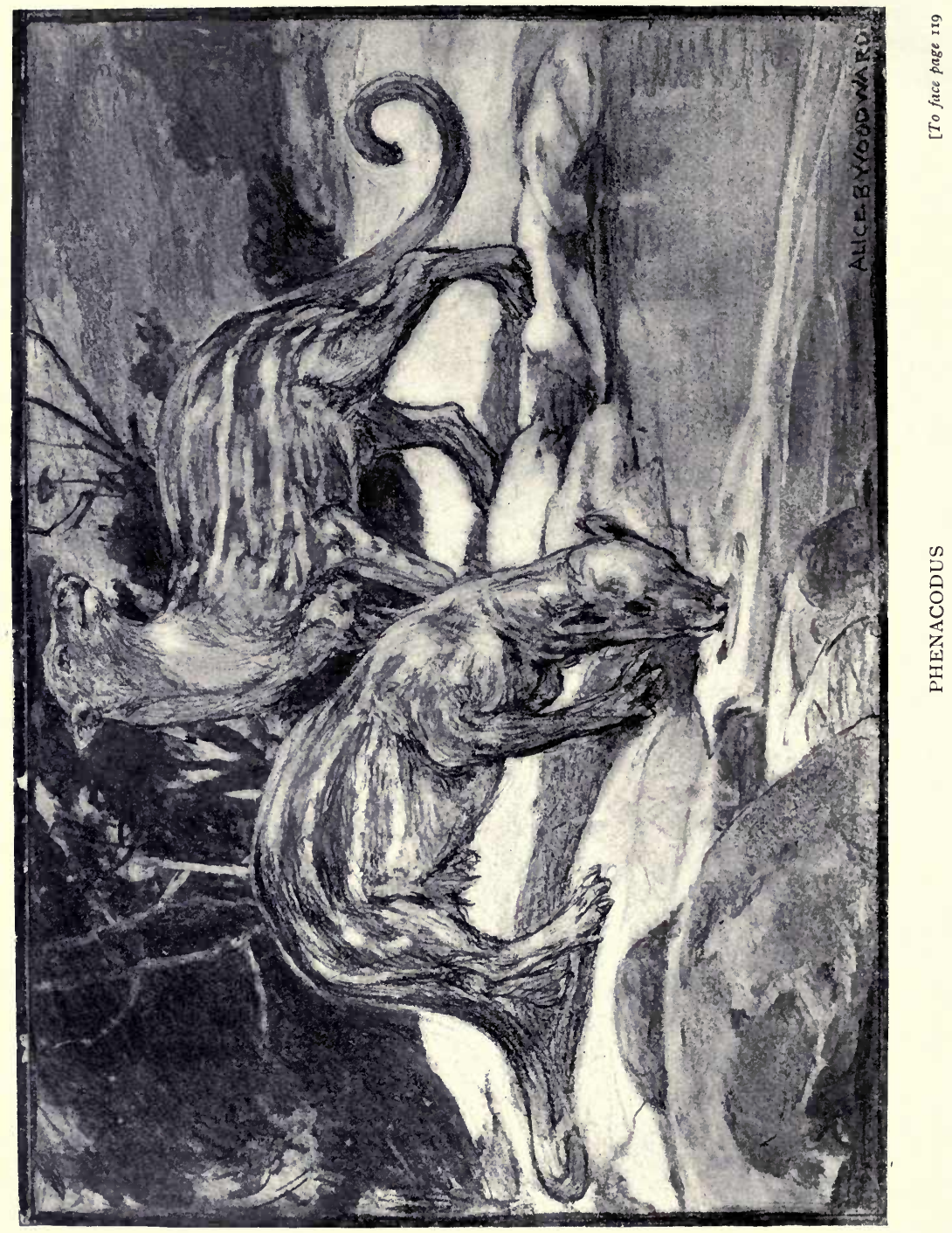


Yet other creatures, living probably in densely wooded LEMURS regions, were developing in the direction of lemurs. Some of these were as yet but little distinguishable from insectivores (Mixodectes, Indrodon, Protoadapis); whilst others seem to have had close affinities with the primitive flesh-eaters (Chriacus).

When, therefore, the curtain rises on the first-known scene of the "new dawn," there were not only new but highly important characters on the stage-forerunners of hoofed animals, carnivores, edentates, insectivores, and " fourhanded" animals. The Orders were certainly not sharply distinguished from one another, but the evidence of progress is not thereby deprived of its significance. It is clear that Evolution had been busily at work; and one may well ask where. The remains of the "knuckle-jointed" and the "blunt-footed" animals have been found in North America; the evidence of the insectivores comes from Europe; whilst the primitive flesh-eaters and the lemur-like animals left their bones on both continents. It does not, of course, follow that any of these animals originated in North America, or in Europe. No traces of their immediate ancestors have been found in either country; and it is probable that they were emigrants from other lands. Evolution had probably been at its highest activity in parts of Asia and Africa ; and if ever the missing links in early mammal life be forthcoming, it will probably be from the unexplored strata of one or other of those continents. Africa, it is thought, contains the more hopeful strata.

Marsupials, no doubt, continued to flourish; but they MARSUPIALS were now to play a subordinate part in mammal life. Opossums were apparently in some force in Europe during this Period, and also in North America. In Australia, which in pre-Eocene times must have lost its mainland connections, marsupial life was no doubt undergoing special developments in the absence of animals of higher rank.

As the Period advanced, the "knuckle-jointed" (Condyl- condyLarthra) were in evidence in some variety. One of the most ARTHRA remarkable forms is known as Phenacodus-represented both in Europe and in North America. 
PHENACodus Phenacodus affords a good example of what may be called an omnibus animal - that is, a highly generalised creature containing in its anatomy several features, which in course of time are not found combined in any one form. It had affinities with deer, pigs, tapirs, horses, and apes, and was tailed like a carnivore.

Some members of the genus did not exceed small dogs in size; whilst some were as big as tapirs. The fore-limbs had apparently some grasping power; and the toes terminated with sheaths of a mixed hoof and claw description. The teeth were adapted to an omnivorous diet; but they were not of a powerful character. And as the skull indicates but slight mental calibre, it is clear that these animals were not forcibly endowed either in mind or body: and long before the close of the Eocene they and closely allied forms became extinct.

Their great foes, no doubt, were the flesh-eaters, which greatly increased in the course of the Period, and became of more decided carnivorous type. Nature, however, does not leave comparatively defenceless animals without resources; and the phenacodi when seriously threatened must frequently have found salvation in flight.

They were, no doubt, capable of speedy movements; for they were of slender build, and although they may have walked in a more or less plantigrade manner, the limbconstruction shows that in running they no doubt raised themselves well on the toes; and were, therefore, capable of the digitigrade method characteristic of fleet-footed mammals.

LOPHIODONTS More or less closely related to the Phenacodi were other animals known, on account of a peculiarity in tooth-structure, as lophiodonts ("crest-tooth"). These were undoubtedly hoofed creatures; and when in motion the weight of the body was thrown entirely on certain of the toes, with the heel or hock high-raised. As a result of disuse some of the shorter toes had become atrophied; and the foot, thus rendered more compact, was better adapted for fast running.

The most notable of these animals were about the size of HORSES fox-terriers; and they probably roamed about in herds 



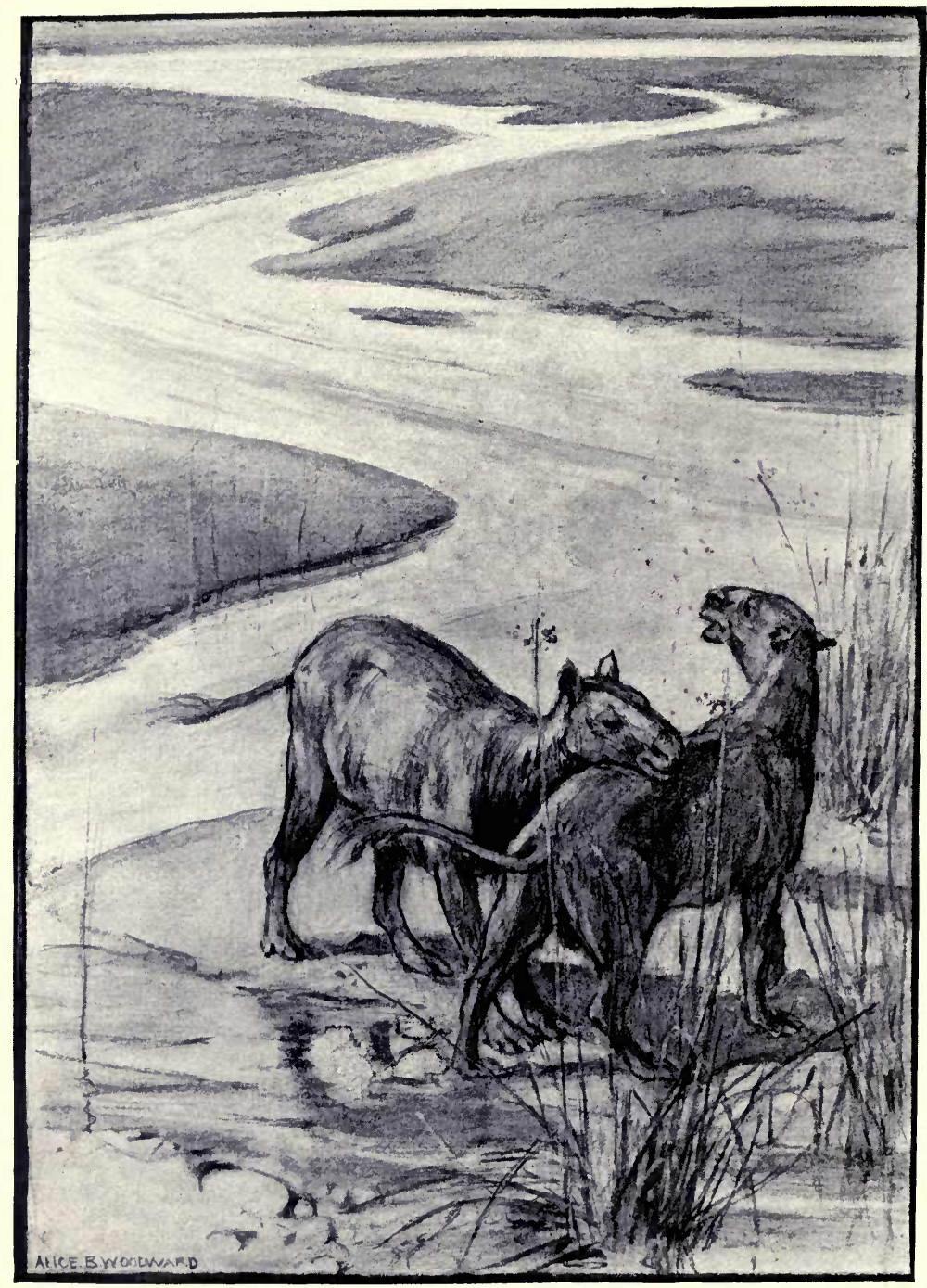

HYRACOTHERIUM

The most primitive horse-like form known. Remains found in the London Clay 
(Hyracotherium). The fore and hind limbs were four toed and three-toed respectively; but in a few cases there was a rudimentary fifth digit or "thumb" on the fore-leg (Eohippus). The teeth were not strongly crowned, and seem to have been adapted only for succulent vegetation. In appearance the creatures were somewhat horse-like; and indeed they are generally regarded as remote ancestors of modern horses.

In the course of the Period this branch of the lophiodont family made distinct progress. The teeth became harder and more like those of living horses; and were capable, therefore, of masticating a more varied vegetation. As a result probably of an extended dietary, the animals increased in size, and became as big as foxes (Pachynolophus, Orohippus). The toes underwent no reduction in number. The animals, however, were evidently rising more on the feet in order to obtain greater speed: for the second toe-the central of the primitive five-had become considerably developed; and the other toes had diminished in size.

Other members of the highly-charged lophiodont family TAPIRS were developing in the direction of tapirs (Systemodon). Excepting as regards the teeth, they can have differed but little from the equines. They had probably the same number of toes as those animals (4-3); and that indeed is the number possessed by modern tapirs. They had, it is true, an atrophying digit on the hind-foot, and to that extent possessed an "extra" toe. They had, moreover, two teeth more than their now living descendants. These excesses, however, were not serious obstacles in the path to modern tapirism.

In mid-Eocene times yet other members of the lophiodont RHINOfamily were, it would seem, diverging in the direction of CEROSES rhinoceroses (Hyrachyus). These animals were confined to North America.

In late Eocene times there were certainly some big brutes with rhinoceros-like skulls on that continent (Titanotheria). Many of them were destitute of horns (Palcosyops); but apparently the snouts of some were being prepared for those weapons (Telmatotherium). Their later representatives, how- 
ever, never became rhinoceroses; nor indeed were they ever modified so far as to bear close resemblance to any animals. now in existence. Other forms, then living, seem to have been developing more steadily on the line (Amynodon); but neither did any of their descendants ever really reach the goal. Allied to these were some European forms, of which very little is known (Cadurcotherium).

PALEO- The true rhinoceroses of the future were possibly derived. THERES from some animals named Palæotheres-first known in midEocene times. These creatures, so far as evidence goes, were confined to Europe ; and were probably another offshoot of the great family (Lophiodonts) whence the budding equines and tapirs had sprung. They certainly much resembled. tapirs, especially in the shape of the skull. The Palæothere escutcheon, therefore, was rather confusedly charged at this. time.

In late Eocene times the palæotheres varied greatly in size, and some forms were to be seen as big as rhinoceroses. The skull, so far as is known, retained in all cases its old. tapir shape ; and horns were not even in faintest promise.

AMBLYPODS Animals with so-called "stumpy" feet and of bear-cumhippopotamus build (Amblypoda) - in view at the dawn of the Period-made considerable progress. In course of time forms of heavier structure than their forerunners, and in some cases as large as oxen, made their appearance (Coryphodon). The heads of these animals were large, and lightened by air chambers; and were certainly not burdened with brains. Some of the animals, when locomoting, were developing a habit of rising on the toes of their broad, spreading feet. As a rule, however, they probably walked. more or less flat-footed like a bear. Flight in times of danger was not with them a matter of vital importance; for they were doubtless able to show fight, as evidenced by their canine teeth, which had been developed into tusks.

Coryphodont prosperity in Europe was not enduring, for the animals became extinct in that part of the world long before the close of the Period.

The disappearance of Coryphodonts brought Amblypod. annals to a close in Europe. In North America these- 


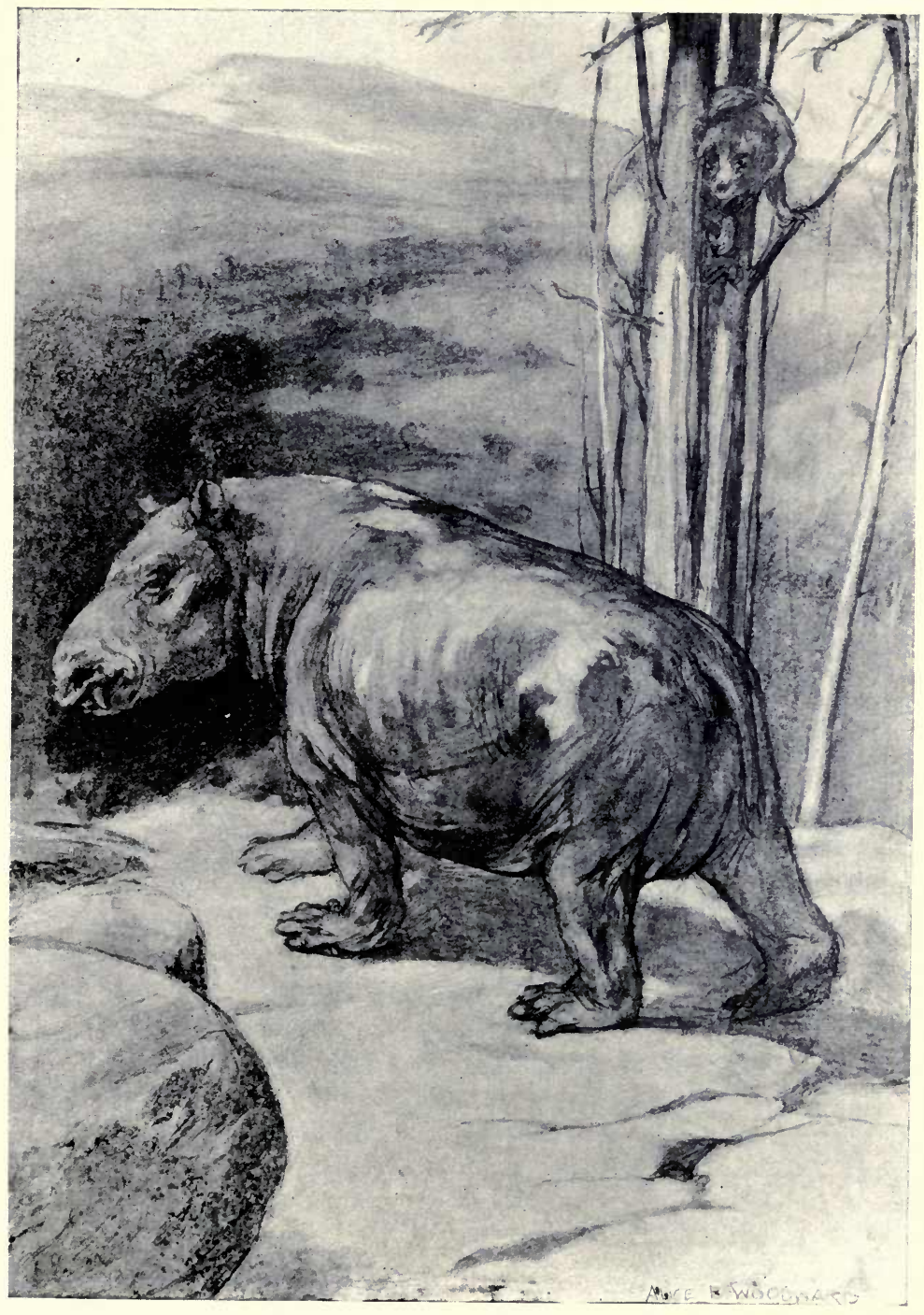

CORYPHODON

Remains found in Europe and North America

[To fa:e page 122 

creatures disappeared about the same time: but in late Eocene times the Order was represented on that continent by beasts, with still less brains, it is true, but of much more imposing aspect (Dinocerata). Some of these animals were as large as elephants, and were well armed (Dinoceras). Not only were their upper canines developed into powerful tusks ; but their heads were furnished with four horns, and a pair of knobs adorned the snout. They had also improved on their forerunners in locomotive powers, for they had become distinctly digitigrade. One might suppose that such lordly creatures would have held their own in the world for a long time; but such was not the case; for at the close of the Period they became quite extinct. There is little doubt that intelligence was beginning to play a very important part in animal progress; and as regards brains these animals were excessively deficient. Dinoceras is suggestive of a battle-ship in charge of a child.

Meanwhile the Order of Rodents (which comprises squirrels, RODENTS hares, rats, and other animals with chisel-shaped incisor teeth) was coming into view. As far back as Jurassic times certain primitive mammals were developing teeth of a rodent or gnawing type: but so far as is known neither those animals, nor their Cretaceous successors, were much advanced on the way to becoming true rodents. In early Eocene times much more clearly defined rodent mammals were in existence (Esthonyx). These on account of their "tearing" teeth are known as Tillodonts, and they are generally regarded as the ancestors of living rodents.

As regards teeth these ancestral forms were more liberally supplied than are the living representatives of the Order. Abundance of teeth, however, was a great feature with early mammals. Dental modification, in course of time, resulted in reducing the number, and increasing the efficiency of the remainder for the various habits of life that were being adopted. This reduction appears, geologically speaking, to have been a rapid process in the case of the rodents; for as the Period advanced one pair of the upper incisors was disappearing (Anchippodus). Provision was at the same time being made for the continuous growth of the large 
rodent-like incisors. These teeth were, no doubt, being submitted to ever-increasing demands, and their rapid wearing away necessitated a new economy.

Eocene rodents were in a somewhat mixed condition of development, but dormice and squirrels were, so to speak, coming out of the hotch-potch.

EDENTATES Edentates of somewhat modern aspect were also appearing. The animals, indeed, save for the absence of a bony shield, seem to have closely resembled armadillos now living (Metacheiromysis, N.A.).

ELEPHANTS A glance must now be taken at Africa, where some highly important animals were in process of evolution. Valuable knowledge on this subject has been obtained through the exertions of Mr. Beadnell, Dr. C. W. Andrews, of the British Museum, and other explorers.

From discoveries which he made in Igor near Lake Moeris in the Fayum Desert (Egypt), Dr. Andrews has shown that in mid-Eocene times forerunners of elephants were living in Africa (Moeritherium). These interesting quadrupeds stood about three feet at the shoulder; and were long enough in the neck to get their heads to the ground. Their sloping faces were certainly unlike the almost vertical face of living elephants ; but the bones of the skull were falling into position in a manner peculiar to proboscideans; and there was at least promise of a trunk. Certain of the incisor teeth in the upper jaw were developed into small tusks ; and on the front part of the lower jaw a pair of tusk-like teeth protruded. The cheek teeth were much of the pattern of those of elephants of later times.

These "beasts of Moeris," no doubt, wandered about in herds; were quite at home in the water; and subsisted chiefly on marsh and aquatic vegetation.

They had well-developed brains for their size; and their intelligence was probably much above the average of the time.

It is a matter of no small interest to have these primitive forms brought into view; and the knowledge gained of elephants "in the making" does not stop here. In later Eocene times " beasts of Moeris" were still living in Egypt; 


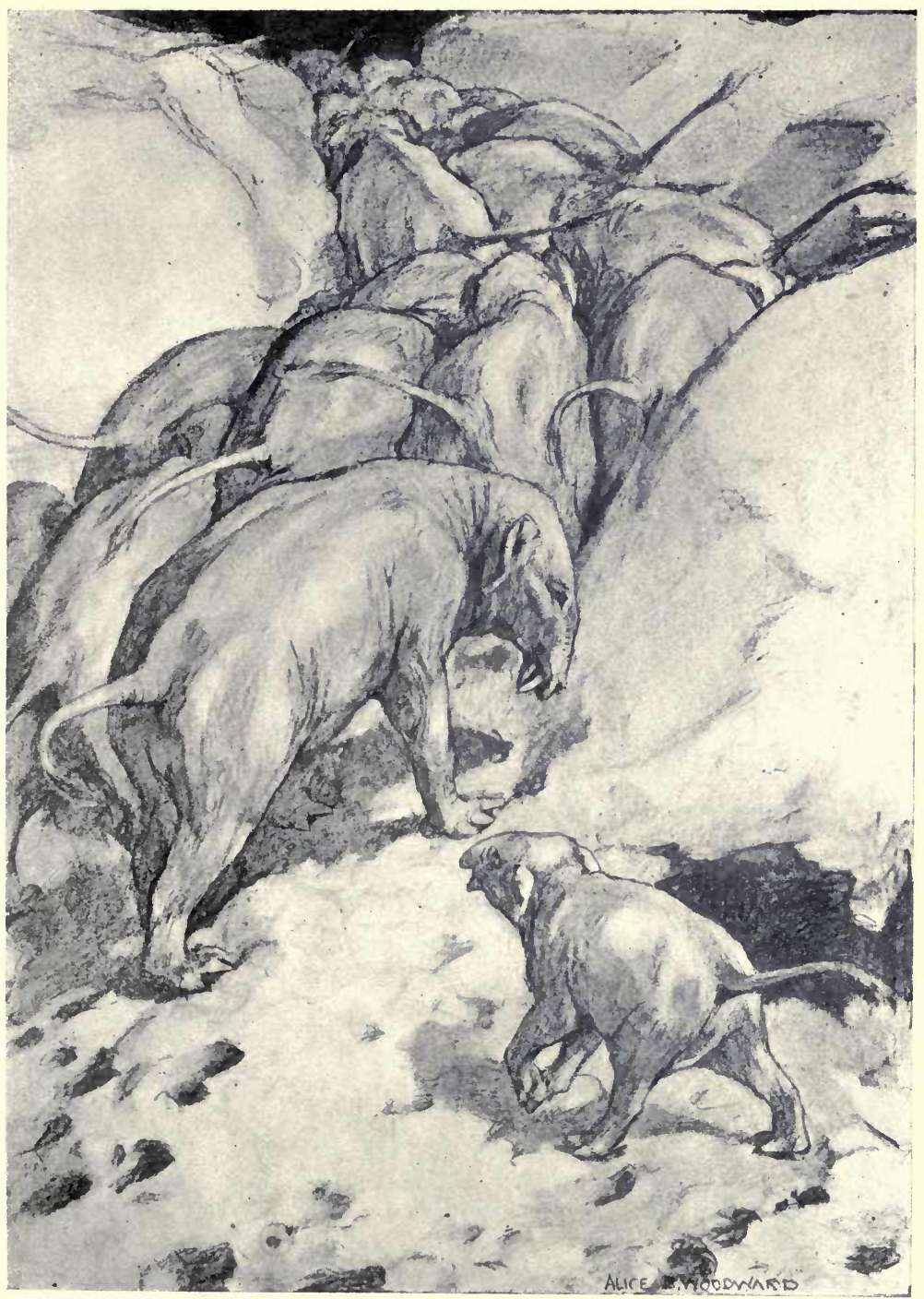



but other forms, probably derived from them, and of a more advanced type, were then on the scene (Palcomastodon). These animals, like their forerunners, were fairly long in the neck. They were certainly bigger animals, and in some cases must have stood fully six feet at the shoulder. The lower jaw had been elongated considerably, and terminated -as with the "beasts of Moeris "-with tusks of small size, usable for digging and uprooting purposes.

This lengthening of the lower jaw is perhaps the most remarkable feature. The chief purpose of it seems to have been to form a support for the trunk, which was in process of development. Probably the short proboscis already possessed at its extremity a fair amount of prehensile power ; but it was not yet sufficiently developed to be left, so to speak, to itself. A developing organ intimately connected with breathing and feeding must have required very careful nursing; and the under jaw was acting as a sort of fostermother.

These creatures possessed sloping faces like the Moeris animals, but the skull was more elephantine in shape. They were also approaching true elephants as regards teeth; for these were fewer in number than in the more primitive forms, and some were considerably enlarged.

These more elephant-like beasts lived, it is supposed, more or less habitually on land. Here they could obtain a more varied and substantial vegetation than that which satisfied their lake-dwelling relatives. They were certainly more enterprising, and probably far more intelligent than the latter.

Some doubtful remains of swine have been found in the SwINE same district (Geniohyus Andrewesi); but our eyes must revert to North America for a clearer view of porcine patriarchs. Here in mid-Eocene times animals were certainly living more or less distinguishable as swine (Homacodon). Pig-life on these scenes was beginning in a small way; for the creatures were not bigger than hares. Although in common with mammals of primitive type their feet were five-toed, they were practically four-toed animals, as one of the digits on each foot had been withdrawn from active 
service. That reduction at the extremities, however, left them with twice as many functional toes as living pigs possess. Tusks, characteristic of later boars, were not as yet developed; but the enlarged canine teeth gave promise of these.

In later Eocene times porcine forms of larger size were wandering about Europe (Chceropotamus). Some of these seem to have had close affinities with monkeys, showing the entanglements of mammal life at this time (Cebochoerus). The toe question cannot be determined, for these quaint creatures have come down to us minus their feet.

BATS At the time when pig-life was coming into view, North American life was also being diversified by small mammals that had acquired the art of flying (Vesperugo). These " wing-handed" creatures can hardly as yet have exhibited much variety of form, and many of them were probably poor flyers. Still, there were forms among them that did not differ much from some of the numerous kinds of bats now living. Unfortunately no forerunners of these new invaders of the air have been brought to light; and, so far as geological evidence goes, bats fluttered into the world as suddenly as the flying lizards seem to have done in earlier times. Probably their ancestors had branched off from some insectivorous animals, such as were living at the very commencement of the Period. The wings, it may well be supposed, had originated as simple folds of skin stretching from $\operatorname{limb}$ to limb, resembling the parachute of the flying squirrel of our own time (Pteromys).

Well-developed bats were also in Europe in the course of the Period, but they made their appearance later there than on American scenes.

PRIMATES Lemur-like creatures, holding affinities-as did the batswith primitive insectivores, were visible, it may be remembered, on the earliest glimpse of Eocene life. They were followed before mid-Eocene times by various forms, mostly of a more definite type (Tomitherium, Microsyops, Hyopodus, etc.). Small, fox-faced, large-eyed creatures were some of these, with well-developed brains indicating mental powers of a comparatively high order (Anaptomorphus). 


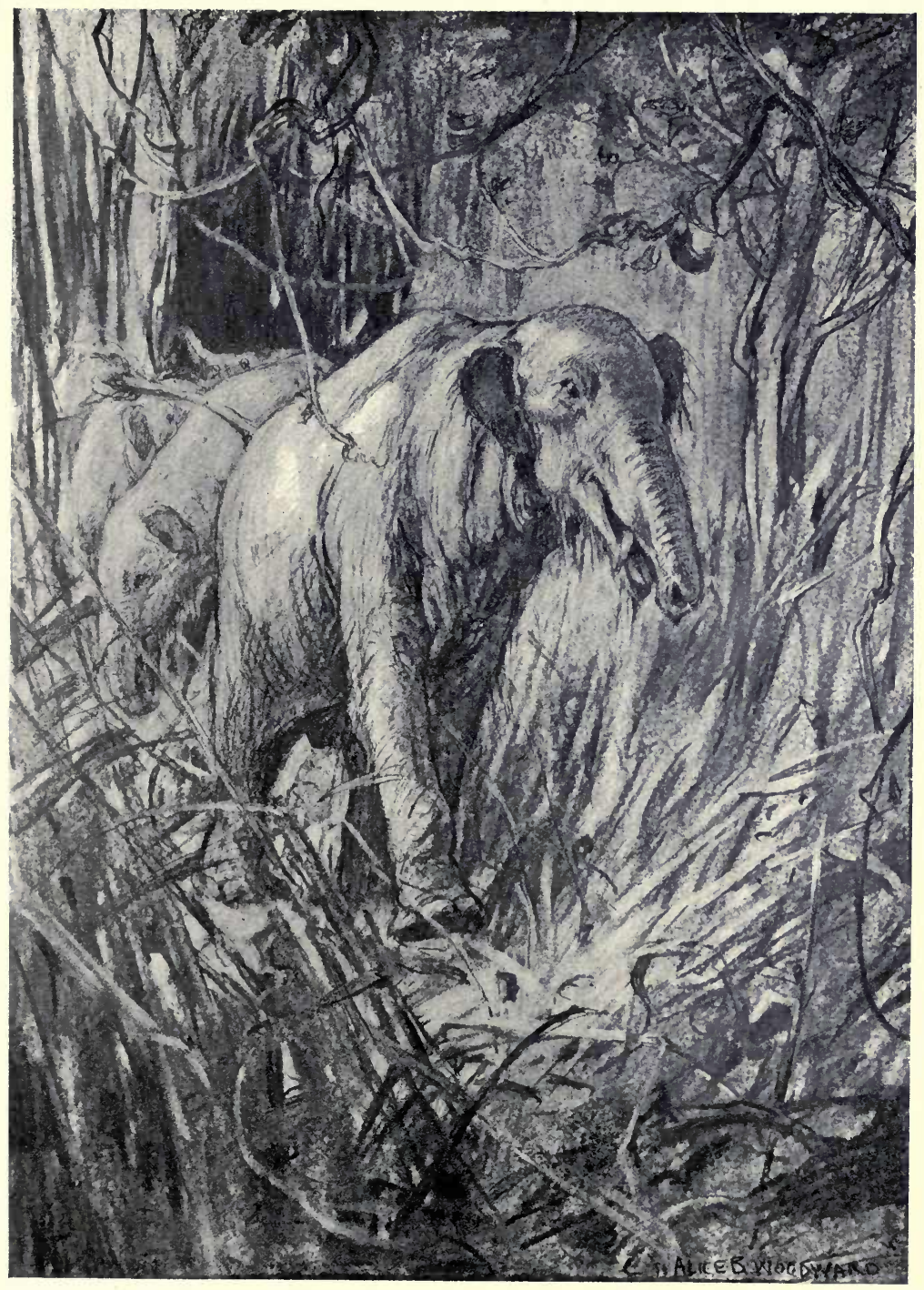



Their teeth, it may be mentioned, were thirty-two in number -as with human beings.

All these lemurine animals were probably of more or less arboreal habits-and " monkey-puzzlers" had ceased to be a prominent feature of the forests. Some of the creatures can hardly have been such accomplished climbers as forms now living, as they were deficient in grasping power, not being able to oppose the thumb to the other digits (Pelycodus).

Later in the Period new types of lemur-like animals appeared. All of these were much more numerously toothed than lemurs now living. Some of them, to judge by their skulls, were developing into apes (Adapis).

Some quite recent discoveries in the Fayum of Egypt (Dr. Max Schlosser, I9I0) prove the existence in late Eocene times of some transitional creatures of a more monkey character (Parapithecus). And some forms (Propliopithecus) may have belonged to a stock whence sprang two lines of evolution, one leading to anthropoid apes, one to human beings.

The peace and quiet of herbivorous mammals must often have been disturbed by carnivores. Small "flesh-toothed," bear-like forms were, it may be remembered, living at the commencement of the Period. As herbivorous mammals increased in number and variety, so also did their natural foes. The latter in mid-Eocene times were doubtless closely approaching the status of true carnivores; but they were less effectively toothed than later forms, as none of their back teeth had as yet been so highly modified to tearing uses. In outward form many of them more or less resembled wolves, hyænas, polecats, and civets (Pachycna, Sinopa, Stypolophus, Palaonictis, Proviverra, etc.); and in the matter of speed they were doubtless superior to their more or less flat-footed forerunners. Their intelligence, no doubt, was being developed owing to the skill and cunning they had to practise in order to get a living. They were, however, small-brained animals, resembling in this respect their farback marsupial ancestors, and falling, therefore, far short of the brain power of modern carnivores.

In North America strange forms were abroad. Some of 
these were long-tailed, web-footed creatures; and appear to have been compounds, so to speak, of cats and otters (Patriofelis). Being of aquatic habits they probably sustained themselves chiefly on fishes and reptiles. Nothing is known of their later history. It was at one time supposed that they were remote ancestors of seals ; but this compliment is not now paid to their remains.

Other animals, living in the same region, were long-bodied creatures, and appear to have been an interweave, so to speak, of wolves and hyænas (Mesonyx). In the course of their lives they sampled probably a great variety of meat, fresh and otherwise; but it is supposed they had a special liking for turtle-flesh.

Flesh-eaters of old type still abounded in late Eocene times; and new forms, rather smaller than hyænas, made their appearance (Hyanodon). The teeth of these animals had been modified, but they were not so much of butcher pattern as those of true carnivores. They were smallbrained brutes, and rather weak in the limb. They ranged, however, far and wide ; for remains of them have been found in Europe, Egypt, and North America.

Before the close of the Period some of the flesh-eaters, both in tooth and limb, closely resembled living members of the Dog family (Cynodictis). They may, therefore, be described as true carnivores. Owing to the shape of their skulls they must have looked more like civets than dogs. They were in a sense, therefore, an amalgam of animals now belonging to different families.

RUMINANTS

The dangers of feeding in public had compelled some of the herbivores to adopt a new mode of living. Among the hoofed animals of late Eocene times forms appeared who, to judge by their teeth, bolted vegetable food and then betook themselves to some obscure retreat, where the pabulum was brought back to the mouth to be chewed and reswallowed.

Among these incipient cud-chewers, or ruminants, were certain animals of somewhat pig-like aspect (Anthracotherium). Others were small, long-necked, long-tailed creatures of deer-like appearance (Anoplotheria). The latter 
"defenceless" animals were, as their name suggests, not built on martial lines, and must have trusted to flight when disturbed in their ruminations. They were probably good swimmers, and no doubt used their long and exceptionally strong tails to speed their passage through the waters.

Other forms were gazelle-like in appearance (Xiphodon), and about the size of chevrotains. They also were defenceless animals, so far as regards actual weapons.

All these primitive cud-chewers seem to have been confined to Europe; but North America was not without animals of similar type (Protoreodon). Those, however, were not so far advanced in ruminancy as the European forms.

The nearest relatives at the present day of the early ruminants are, no doubt, the chevrotains. These are the smallest hoofed animals now living ; and are of a primitive, composite character, holding affinities both with pigs and deer. In possessing tusks they certainly surpass their defenceless forerunners.

On North American scenes, in late Eocene times, animals, more or less allied to the early ruminants, had set out, apparently, to found the Camel family (Protylopus). They were of diminutive size-not above a foot in height. But all developments in Nature resulting in new types were probably initiated by very small creatures of their kind. It is not surprising, therefore, that Camel-life commenced in a small way.

Some remarkable animals were living in Egypt in late Eocene times. Coneys now are not larger than rabbits, but conEYs here were some as big as donkeys, and well-tusked to boot (Megalohyrax Andrewsi). These giants were possibly the wisest of the then Egyptians. Even the degenerate coneys of Solomon's time were " exceeding wise."

But there were some far more remarkable forms in Africa than gigantic coneys. Remains of these more notable brutes were first found by Mr. Beadnell in Igor. As the discovery was made in a locality where the Egyptian Queen Arsinoe ARsINOIhad a palace, the animals have been named after that unhappy THERIUM lady (Arsinoitherium).

These strange creatures were in some cases as large as $\mathrm{K}$ 
good-sized rhinoceroses, and they somewhat resembled those creatures in appearance. Their skulls were adorned on the forehead with a pair of small horns, whilst the greatly enlarged nasal bones supplied a second pair of comparatively huge dimensions. A good-sized Arsinoitherium was therefore an imposing figure. He certainly was the outcome of a long course of evolution; and was, indeed, at the end of it, for his family is not known after this Period. As to his ancestry zoologists as yet know little more than did the creature himself.

Some forms of primitive elephants were living in his neighbourhood; and Arsinoitherium may have enjoyed the society of these fellow-vegetarians. But he stood out in strange contrast with them. They were in the dawn of their history : he was hasting to his setting.

Other discoveries have been made in Egyptian strata which show that some mammals had taken to an aquatic life, after the manner of certain reptiles in earlier times.

SIRENIA Some of these were "sea-cows" of primitive type, and are represented to-day by the dugongs and manatees (Eotherium, Eosiren Andrewsi). These pioneers seem to have been related to the small, marsh-dwelling elephants; but they must long have quitted the original fold. In possessing hind-limbs they presented a notable difference from sea-cows now living. This difference, however, is not to be wondered at; for the appendages, indispensable to their land-frequenting ancestors, must have been too welldeveloped to dwindle away rapidly. Nor had the hindlimbs in the next Period entirely disappeared.

WHALES Other mammals that had taken to the water were toothed much as the primitive carnivores, but resembled whales as regards the skull (Protocetus). These creatures were rather long in the neck; but their bodies were assuming a fish-like shape ; and their " arms" were probably being modified into fins. The supersession of lungs by gills was not to be expected; for there was no dormant gill-apparatus to be aroused to action.

These creatures were followed during the Period by similar forms: but these had undergone dental modifica- 


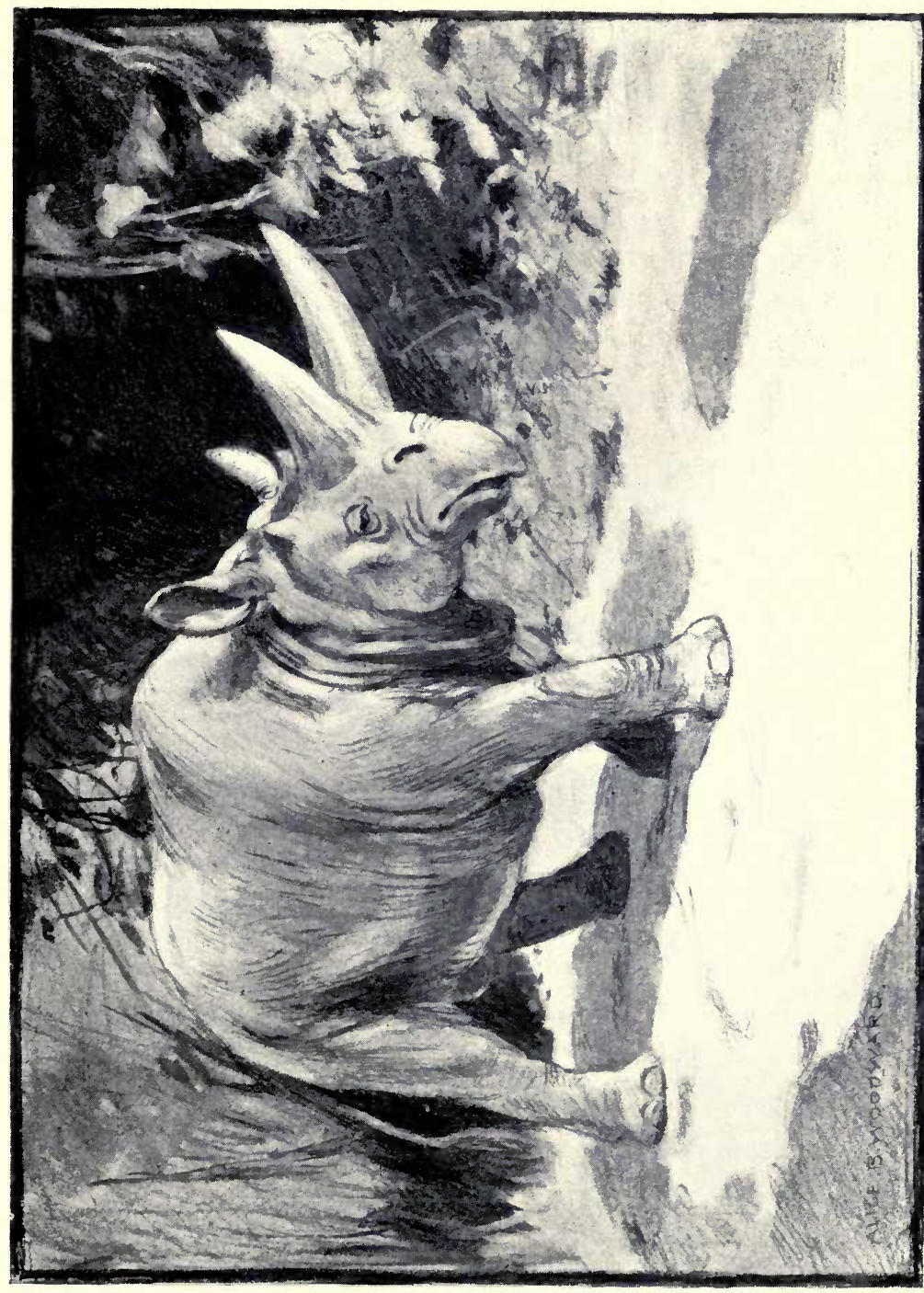

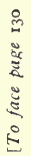

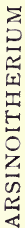



tions (Prozeuglodon), and in some cases the teeth had been reduced in number (Zeuglodon).

These pioneer, whale-like forms may have been ancestors of the toothed whales (Odontoceti), represented to-day by sperm-whales, dolphins, and porpoises. They probably possessed, like the incipient sea-cows, usable hind-limbs. Remains indeed of such appendages, although not externally visible, are found in living whales.

Before the close of the Period these adventurous mammals had greatly extended their range, having found their way to North and South American seas. Here some of them attained gigantic proportions.

Whether persecution by some carnivorous reptiles, a gradually developed taste for the salt-water population, or geographical changes impelled the first adventurers to put out to sea cannot be determined. The experiment at any rate was attended with success; and whales-no less than sea-cows-have never since shown a disposition to quit the adopted element.

Eocene bird-life, as may be supposed, has its surprises BIRDS as well as mammaldom : and it can only be very imperfectly linked with the bird-life of the preceding Period.

Toothed birds had become extinct at the close of the Cretaceous, and another affinity with reptiles had been completely lost. There were, however, some gannet-like birds in early Eocene times with what may be called false teeth, for their beaks were notched and serrated like the edge of a saw (Odontopteryx).

Forms heralding the Albatross were now in being (Argillornis), and geese-like birds as large as ostriches (Gastornis). Rails, more or less foreshadowed in Cretaceous times, seem now to have been established (Gypsornis); and some related forms-apparently primitive cranes-were wandering about the swamps (Palaogrus). Flamingoes and storks, foreshadowed in a composite ancestry in the last Period, had now, so to speak, parted company (Agnopterus, Propelargus): and birds derived from the same stock, and resembling ibises, were also on the scene (Ibidopsis). Some forms more or less nearly related were herons of primitive description (Prohe- 
rodius). Descendants of the Cretaceous dunlin-like birds were now in some force (Tringa); and birds of a kingfisher type were making their appearance (Halcyornis). In farsouthern seas some relatives of the Diver-grebes of the last Period, specialised as penguins, were hobbling about, and busy among the fishes (Palaeudyptes).

The feathery tribes were not living in a state of universal harmony. Various falcony forms-descended from the same stock as the flamingoes and herons-were now on the wing. Some of these were blends of falcons and vultures (Lithornis), and a few were true falcons (Falco). Other birds of prey were compounds of eagles, buzzards, and ospreys (Palcocircus). Some primitive forms of owls were also making things uncomfortable (Bubo). Among the birds of milder manners, some apparently were godwits (Limosa)-relations of the dunlin-like birds. Hornbills (Cryptornis), woodpeckers (Uintornis), and swifts (Egialornis)-all distant relatives of the owls-were also in being. Ancestors of modern game birds were coming into view. Some were quail and capercaillie of primitive character (Coturnix, Tetrao); others were partridges somewhat obscured by strong guinea-fowl and turkey features (Taoperdix). Numerous "sparrow-shaped" birds (Passeriformes) such as nuthatches (Sitta), and starlings (Laurillardia) were enlivening the woodlands with their chirps and chatterings. And sounds more melodious than these may have been heard, for remains of larks and warblers have also been brought to light (Protornis, Palagithalus).

VEGETATION The sylvan scenes are met with after a break in their history; but no changes, comparable with those in animal development, had taken place in the interval. The new vegetation had established itself far and wide in the Cretaceous Period, and on many scenes had gained a predominance long held by cycads and conifers. Since then it had carried its conquests further; and in its exuberance had become enriched with many new varieties and species.

Grand must have been the verdant display in some regions. In the neighbourhood of Liége, for instance, early Eocene plant remains have been found in abundance. Here oaks of many species, and chestnuts were luxuriating in forest. 
wealth, along with cinnamon trees, camphor trees, laurels, ivy growths, guelder-rose shrubs, and azaleas; whilst here and there yews, firs, pines, and cypresses recalled the sombre sway of earlier times. In some parts of France walnut trees, limes, alders, and willows were living in the neighbourhood of bamboos, palms, tree-ferns, vines of Asiatic type, and many plants of sub-tropical character.

The association of these various growths is remarkable, for one would suppose that the climate, so to speak, could not befriend them all. One, therefore, is led to think that plants had more plastic constitutions then than now. Adaptability, however, had its limits, and as the Period advanced troubles began.

Much remains to be known about Eocene plant-life; but it is certain that, in some regions, it came to be seriously affected by a great rise of temperature. England, for instance-which was and had been from very early times part and parcel of the continent-yields evidence of this. It is clear, from remains of plant-life in the Eocene London Clay, that before the Period was far advanced the heat must have become excessively trying to some of the growths of far northern origin. There is little doubt indeed that many succumbed in consequence. Shrubs and trees well adapted to higher temperature were ready to supply the vacancies; and naturally made the most of their opportunities. Sabal and Nipa palms with fan-shaped leaves, Custard Apple trees, and many species of Acacia extended their sway. Melons and gourds revelled, and multiplied in the warmth. Very different, therefore, was the vegetation from that now on and about the site of London. And the scene was rendered still more strange by the presence of crocodiles and turtles, and the big gannet-like birds with notched beaks.

These climatic conditions were to continue for a long time. The leaf-beds of Alum Bay and Bovey Tracey yield evidence of a heat-loving vegetation in mid-Eocene times. Fan palms, and feather palms, screw pines, eucalyptus, nettle, and spindle trees, and various kinds of climbing plants, now more or less confined to the tropics, adorned the scenes. Similar 
evidence is found in other parts of Europe ; whilst in North America palms and bananas were thriving in latitudes that now are temperate.

The heat, however trying to many of the more robust forest trees, did not wholly overcome them. Oaks, planes, beeches and other deciduous growths, if banished from the lowlands, could still live and prosper on neighbouring hillheights, and high table-lands.

The warmth was doubtless welcome to the reptiles. These animals, it is true, had been deposed from leadership in creation, but they continued to play a great part in Nature's economy.

CROCODILES Crocodiles were present in vast numbers; and many of the waterways must have been held by them in force. The ability to drown prey, without self-drowning, had now become the common heritage of all crocodiles. Earth, therefore, was not a complete elysium, even for the most powerful of the mammals.

ALLIGATORS Alligators, known only in North America in the last Period, were now displaying their physiognomy in Europe (Diplocynodon).

CHELonians Chelonians were widely dispersed, and in greater variety than in Cretaceous times. Descendants of some Cretaceous tortoises of amphibious habits had now quitted the dangerous vicinity of crocodiles, having taken to residing permanently on land (Hadrianus). Here they must have competed with birds, as well as with lemurs and other mammals, in raids on worms, snails, and insects ; but some of them, no doubt, were becoming vegetarians. Among those that continued land-and-water habits, some differed very little from the marsh-tortoises of our own time (Emys). Descendants also were on the scenes of forms that, so far back as in Triassic times, had been experimenting with elongated necks. The experiment was meeting with some success; for welldeveloped long-necked creatures were now in evidence (Rhinemys). The long neck, no doubt, brought advantages in the matter of obtaining food, and of keeping a good look-out against dangers. But it had its risks, for it could not be drawn back within the walls of the carapace. Long-necked 
tortoises, at the present time, are known only south of the equator.

The move to marine life initiated by some Jurassic tortoises, and further developed by Cretaceous forms, continued without serious check. And sea-tortoises, or turtles, were now becoming a power in the seas. Leathery turtles (so-called from the leathery skin which does duty on the carapace for the ordinary bony plates) were in existence: and some large forms were enjoying life on the site of London (Eosphargis).

Lizards were now decidedly more recognisable as such LIZARDS than in earlier times. Not only iguanas, but monitor lizards, and creatures of chameleon type basked in the Eocene sunshine (Iguanavus, Tinosaurus, Chamaleontida).

Snakes were also in being. These had probably sprung sNakes from some ancient lizard-like forms that had more or less lost their limbs. Those ancestral creatures, it may be supposed, had found it more advantageous in obtaining food, and for self-preservation generally, to move along by the aid of their ribs; and as the result of disuse the limbs became atrophied. Pythons, it may be mentioned, retain vestiges of hind-limbs.

The Eocene snakes of which remains have been found seem to have been of aquatic habits, and closely related to the pythons of our own time (Palcophis, etc.). In Egyptian waters some of the animals were nearly thirty feet in length (Gigantophis garstini). No venomous snakes, it would seem, had as yet appeared.

The long-languishing ranks of amphibians were now AMPHIBIANS recuperated by the appearance of little creatures in a tailless condition. At least they were probably so as adults, having, in juvenile days, used their tails, first for swimming purposes, and then as food for the body.

These, the first-known of the frog fraternity, seem to have been much of the stamp of certain small frogs now living in India (Oxyglossus).

Fishes had meanwhile been developing into a decidedly modern aspect. Shark-life was being further diversified SHARKS by the evolution of forms to which the blue-sharks of our own 
time are closely allied (Carcharias). And eagle-rays, foreshadowed in the last Period, were now represented by some gigantic specimens (Myliobatis). Electric rays were also in evidence (Torpedo). These, so far as is known, were the first creatures equipped with electrical organs for the battle of life.

GANOIDS Flexibly finned ganoids, although greatly reduced at the close of the Cretaceous Period, were in some force in the Eocene. Deep-bodied pycnodonts, for instance, with powerful teeth still held their own. They apparently differed in no respect from their Jurassic forefathers; and they remained, moreover, practically unchanged until the close of the Period. In common with other part-modernised forms-suggestive of old bottles carrying a modicum of new wine-they then became extinct. With better outlook were the descendants of the sturgeon-like fishes. Various forms of these seem to have differed little, if at all, from species of sturgeon now in existence. Long-nosed garpike were also abroad (Lepidosteus). These ganoids seem to have commenced their career in the Eocene : and they are represented to-day by some voracious forms in North American rivers.

TELEOSTEANS Ganoid glory, however, had now quite passed away, owing to the rapid oncoming of bony fishes. Fishes of this Order (overwhelmingly predominant at the present time) were already in a wonderful condition of development in Eocene seas. To enumerate the various new forms would be to make a list of some length, and not of general interest. Suffice it to say that all the Orders and Sub-orders into which existing bony fishes are generally divided were more or less represented. The approximation was even closer than this, for many existing families of the Sub-orders were represented, and even existing genera of some families. Remains, for instance, have been found of present-day genera of herrings and wrasses.

Countless genera, and many families of Eocene fishes were destined to disappear in course of time; but, in the light of present knowledge, it can be said that no fishes were henceforth to appear with any important modifications of the skeleton. 
Owing to defects in the geological record fish-life seems to have suddenly attained a decidedly modern aspect. "Writ in water" largely applies to fish genealogies. And indeed practically all life is met with in the Eocene after a break in its history.

Among the invertebrate marine masses, crabs exhibited CRABS considerable development. Swimming crabs (Portunites), long-beaked spider-crabs (Oxyrhyncha), sharp-nosed crabs (Matuta), and crabs in carapaces shaped like that of the modern land-crab (Catometopa) were all in evidence. Hermitcrabs-classed, on account of their long tails, with lobstershad also made their appearance (Pagurida).

A remnant of Ammonites lived on, but their annals soon CEPHALOPODS closed. Belemnites were represented only by a few forms with the internal shell much reduced in size. Some of them seem to have been becoming very much like the ordinary sepia or cuttle-fish of our own times (Belosepia). Others resembled those modern cuttle-fishes in which the shell has almost disappeared (Spirula). Nautili continued prosperous, and were thus restored, after a long eclipse, to a position of importance among cephalopods.

Gastropods were assuming a modern aspect. Siphoned Univalved forms, which had been improving their position ever since MOLLuscs the Trias, were now the prevailing type-whelks (Buccinum), cowries (Cypraa), mitre-shells (Mitra), and olive-shells (Oliva) being in great force. Some forms were living in turreted shells half a yard in length (Ceritheum). Oldfashioned siphonless sea-snails, although relatively quite unimportant, were well represented by some old genera that had held on from the Trias (Natica, etc.).

Chitons were now of modern type, with the shell plates well attached to the margin of the mantle (Ischnochitonida).

Many genera of bivalved molluscs had now been super- BIVALved seded by modified forms. Existing genera of mussels (Ano- MOLLusCS donta), sponge-borers $(\mathrm{Vulsella})$, and various burrowing bivalves had become distinct (Cytherea, etc.): and clams approximated much more to living forms (Byssocardium, Lithocardium).

Lampshells, so far at least as regards reduction of families, LAMPSHELLS now rested on the bed-rock of their depression. 
POLYZOANS Of polyzoans it may be remarked that the highly organised colonies with zooids in lidded tubes, and with a depressed class of slave-zooids (Cheilostomata), now far surpassed the once dominant lidless colonies (Cyclostomata). The latter showed no sign of changing their democratic character.

SEA-URCHINS Sea-urchins were not so diversified as in the last Period; but bilateral forms with the mouth well brought forward were becoming predominant; and some present-day genera. SEA-LILIES were beginning to appear (Hemiaster, etc.). Crinoids seem once again to have been "minished and brought low."

CORALS Corals for the most part closely resembled some of the forms now living. Solitary corals of existing genera were numerous (Turbinolia, etc.). Reef-building was chiefly being carried on by the Porites-a genus still prominent in coral life. Of Madrepora corals-the most important of the reefbuilders at the present time-there is no evidence.

PROTOZOANS Perhaps the most remarkable feature of Eocene invertebrate life was to be found in the lowest division-the protozoans. The wonderful amount of rock-building done in Cretaceous. times by these individually insignificant creatures has already been referred to ; and the part played by them in the Eocene was no less astonishing. On a great part of northern France, then submerged, countless millions of foraminifers lived and died (Miliola, etc.). In course of time their accumulated shells resulted in the formation of thick layers of rock, now known as Miolitic limestone. In modern times recourse has. been made to this vast and closely packed protozoan cemetery for the building of many stately mansions.

Another family of protozoans was in innumerable force in the Mediterranean-a much larger sea then than now. These rock-builders, on account of the coin-like form of their shells, have been named Nummulites. They varied in dimension from minute size up to that of a crown piece; and their shelly wealth is now known as nummulitic limestone. Eocene nummulites are commemorated in the Pyramids, and also in mountains. The Pyrenees, Alps, Carpathians, and Himalayas are all largely composed, even at their highest levels, of nummulitic remains. Those lofty ranges, therefore, cannot have been raised above sea-level before the Eocene Period. 
The Eocene world no doubt contained a great deal of vaguely developed and highly composite life; but it possessed a marine population - vertebrate and invertebratenot greatly differing from that of our own times. Quaint reptile forms-land-dwellers, sea-rovers, and voyagers in the air-had become extinct ; and reptiles of all existing Orders and Sub-orders were on the scene. Various birds, comparable with living forms, were appearing; and divers mammals abounded, awaiting indeed differentiation in many cases, but more or less representative of all existing Orders. Trees also and shrubs intimately related to growths of our own time were spreading far and wide. Modern life had dawned. 


\section{CAINOZOIC AGE}

\section{OLIGOCENE PERIOD}

INVERTE- BEYOND the fact that it showed a decidedly closer resem-

BRATES blance to that now existing, there is little calling for remark as to the condition of invertebrate life. The gastropods or seasnails with the breathing apparatus, initiated in the Trias, were greatly increasing their predominance over species of older fashion. In coral life ancestral forms of some very important reef-builders of the present day made their appearance (Madrepora). Coin-like nummulites-multitudinous in Eocene times-were now being called in.

There is nothing of particular note to report either about AMPHIBIANS fishes or reptiles. In amphibian life, the frog fraternity was diversified by the rise of forms closely related to the Indian bull-frog ( $R$. tigrina). And small toads-probably of the green kind-were by this time attesting the successful development of tailless amphibians (Bufo viridis).

MARSUPIALS Marsupials were still represented in Europe by opossums (Didelphys) ; but there is not much evidence as to " pouched" life in other parts of the world.

The higher mammal life had lost some of its quaint and primitive features. The variously related Phenacodi had become extinct; and Lophiodonts and Palæotheres-with affinities to horses, tapirs, and rhinoceroses-were passing away, having, as it were, shot their bolts.

ANCYLOPODS But the days of strange beasts were far from being at an end. Among other such creatures some hyæna-shaped brutes, toothed like hoofed animals, but with clawed feet, were at this time enjoying life in parts of Europe and North America 


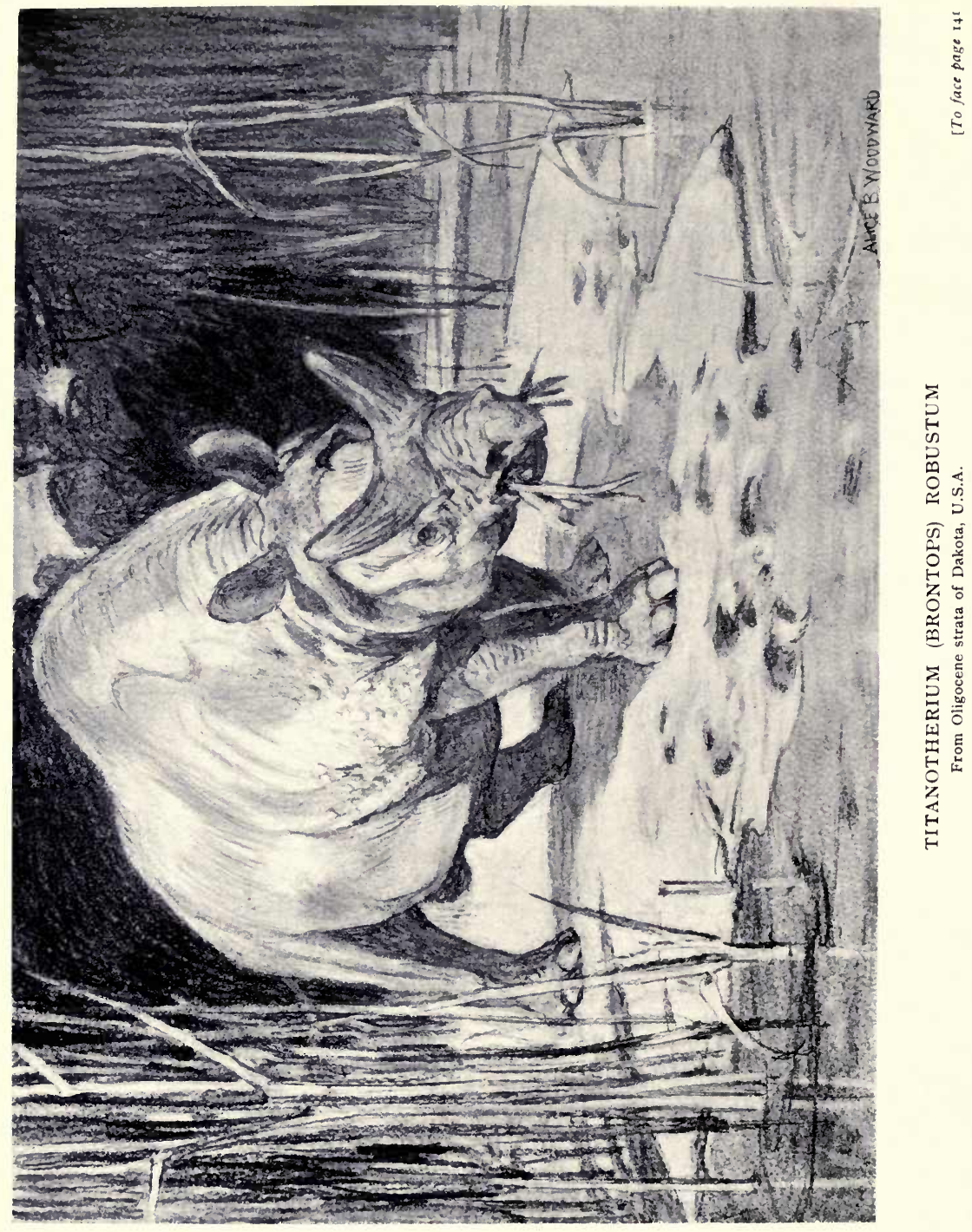


(Chalicotheriida). These quaint quadrupeds moved about with the weight of the body thrown on the outside edge of the foot, the feet being bent and twisted as in the case of some existing ant-eaters. They were not forerunners of sloths and ant-eaters, nor, indeed, of any animals outside their own peculiar line. The family, however, possessed considerable staminal qualities: for it did not leave the arena of life until the early Pliocene.

Ganodonts-notable in the Eocene for edentate pro- EDENTATES clivities-had quite died out. Certain small creatures allied to aard-varks and scaly ant-eaters were certainly appearing in Oligocene times (Palceorycteropus, Necromanis, Leptomanis): but how far ganodonts were responsible for these cannot be determined.

Among the survivors of strange herbivores of Eocene TITANotimes, the rhinoceros-like titanotheres were the most remark- THERES able. The Oligocene forms were of much less benignant aspect than their Eocene forerunners. The latter were for the most part unarmed beasts; a few species only having horns in faint sign or promise. Of very different aspect were these later forms. Not only were they of larger size; but they had become grim-visaged with paired horns (Brontops). The horns, certainly, may not have been as serviceable as they appeared. They were located in the region of the nose-not a very strong foundation - and were placed, not one in front of the other as with two-horned rhinoceroses, but transversely. They cannot, therefore, have been equal to great strains.

Titanotheres, in spite of these structural achievements, still retained no small power of adaptation; and in the course of the Period they received strong calls to justify their existence. In response to these demands the skull underwent several modifications, and the horns increased in length. The teeth also joined in the family effort. After this display of energy the animals met with some success. But it was only for a short time; for long before the close of the Period they one and all disappeared. They never seem to have enjoyed an extensive range, for hardly any remains of them are found outside limited areas in North America. 
Indeed they appear to have been little more than incidental expenses incurred by Nature in her efforts in rhinoceros development.

RHINO- The more truly rhinoceros forms, although in advance of CEROSES their Eocene forerunners, were as yet in experimental stages. Some small animals-not so big as Shetland ponies-were toothed somewhat after the manner of modern rhinoceroses ; but they had comparatively long necks, and somewhat resembled ponies in appearance (Hyracodon). They probably roved in herds about the open country; and as they were footed like the early equines, and were somewhat lightly built, they were doubtless fair gallopers. Fleetness in flight was indeed of importance, for they were too poorly equipped to confront formidable foes. They lived chiefly in North America, and were probably an offshoot of the old Lophiodont family-so rich in affinities. Their career was of no long span. Indeed in the course of the Period they became extinct-wiped out, probably, by the rapidly increasing carnivores. Possibly they never developed sufficient speed for the mode of life they had adopted, and their sentinel system may have been defective. It was nevertheless enterprising of the little creatures to seek to better themselves by quitting the swamps and thickets of their forefathers. And their untimely fate excites one's sympathy even at this distance of time.

Other creatures living in Europe and North America were more stoutly built, and more nearly resembled modern rhinoceroses (Cadurcotherium, Metamynodon). They were, however, hornless; and they also differed from existing forms in being over-toothed and over-toed. They differed, moreover, in habits, for they haunted lakes and rivers. No trace of these aquatic rhino's has been found after this Period. It would seem, therefore, they were no more successful than their relatives of the plains.

The genius of rhinoceros-life, however, was by no means defeated. In thickly wooded regions in Europe yet other forms were living (Aceratherium); and these, in the matter of teeth and toes, were drawing near to rhinoceroses now living. As the creatures were heavily built and hornless, they 


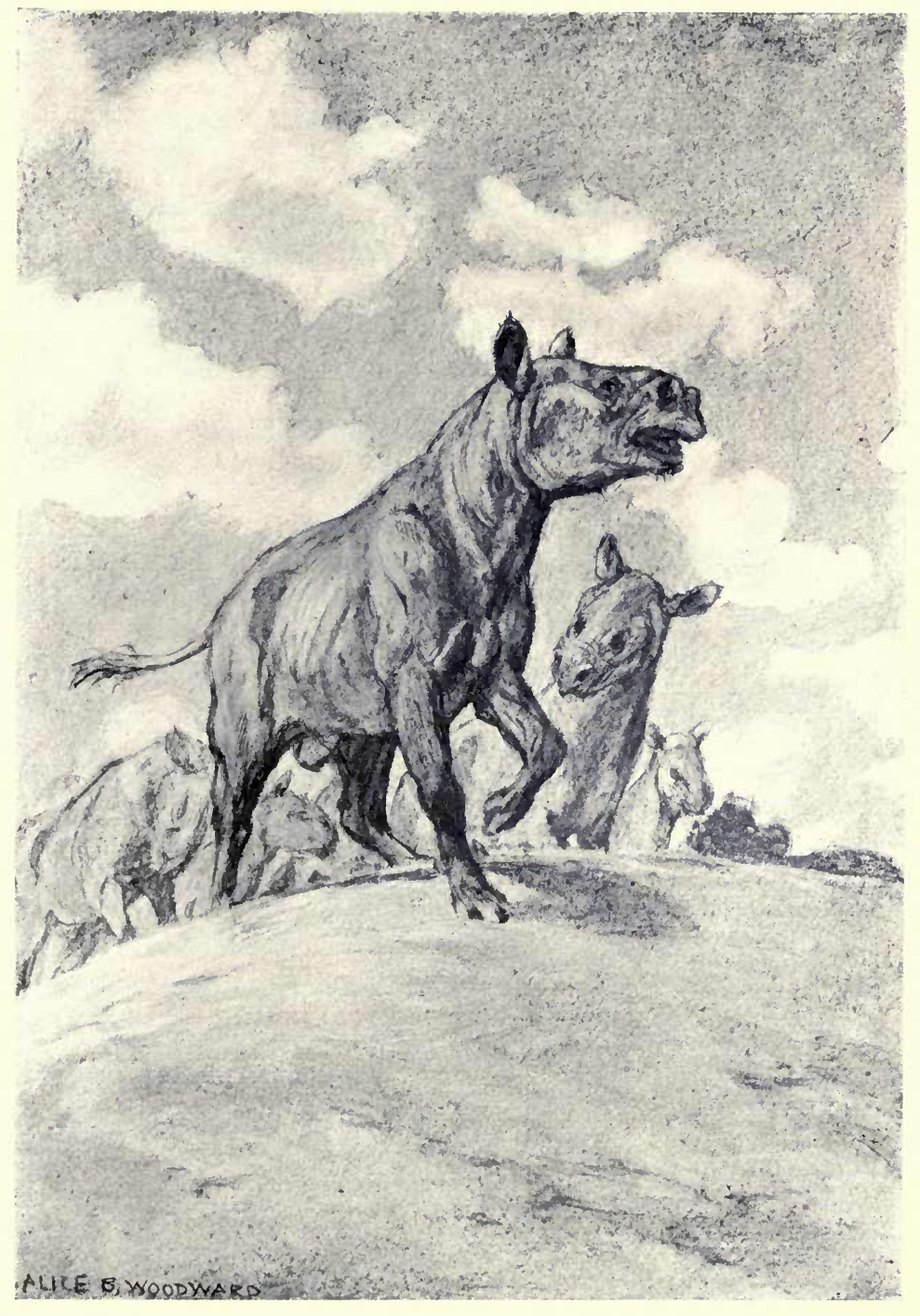

HYRACODON

To face page $\mathrm{I}_{42}$ 

doubtless exercised a wise discretion in living in strict retirement.

At the close of the Eocene, ancestral horses had had their HORSES teeth more strongly crowned, enabling them to masticate a more varied vegetation. They had also increased from the size of fox-terriers to that of foxes; and their feet, although continuing four-toed and three-toed, were more compact than those of the earlier forms. The record of the race in Europe in Oligocene times is unfortunately very imperfect. It is clear, however, that the teeth of the animals, although still short-crowned, were stouter and stronger than those of earlier forms (Anchilophus). From North America fuller evidence of progress has been obtained. Here, too, the little creatures were becoming more strongly toothed (Mesohippus). They were also larger-headed and taller, attaining in some cases the height of good-sized harriers. They also exhibited progress in a greater compactness of the feet, as they were three-toed on the fore as well as on the hind limbs. The side-toes, no doubt, touched the ground when the animal was grazing, but they were probably little more than passengers in the gallop.

Pig-life was progressing, for some forms as large as wild swiNE boars (Hyotherium, etc.), and much bigger, therefore, than the hare-sized creatures of Eocene times, were now grubbing about in the forests. All the animals seem to have had four usable toes on each foot, as with the earlier forms; but the canine teeth, although not of tusky status, were now well developed. The creatures were of a composite character, some of them partly pig, and partly - though to a less degreepeccary. In some North American forms the pig and peccary characteristics were in reverse proportion (Perchcerus).

There were also various other pig-like creatures; but they were, so to speak, merely players of incidental music to the main theme. Some fine-looking brutes were among them, as large as rhinoceroses (Elotherium). These probably had long given up frequenting boggy lands, for their feet were more compact than those of modern pigs. Indeed the sidetoes, which would have been of service for resistance in swamps, had all but disappeared. 
Other pig-like brutes known as Anthracotheres, and first in view in the Eocene, became prominent during Oligocene times. In Europe Hyopotamus was a distinguished genus of this family, and was represented by many forms. The skulls of most of these animals were shaped much like that of an opossum; but some forms, chiefly North American, had skulls shorter and more pig-like. As anthracotheres had four toes on each foot, and all the toes touched the ground, they doubtless spent the best part of their time in swampy regions. Anatomically they were certainly in a somewhat anomalous condition; for, to judge by their teeth, they indulged in cud-chewing. Evidently, therefore, they were not turning the wheel of pig-evolution; nor were they more than in the backwaters of ruminant life.

RUMINANTS Primitive ruminants of small size, and deer and gazellelike in shape, had made their appearance in the Eocene (Xiphodon, Anoplotherium); and some of their Oligocene descendants apparently had undergone no modification. Some forms, however, were now timidly chewing their food with teeth of a more decidedly ruminant type (Canotherium). These little creatures - they were not as a rule more than a foot in length-became very numerous in parts of Europe. They were decidedly of chevrotain character; and some indeed were probably identical in form with living chevrotains (Prodremotherium, Hyamoschus).

Creatures of well advanced chevrotain type were also in some force in North America (Leptomeryx). On that continent also were some allied forms, long-tailed, and of the size of sheep. These were not only primitive in respect to the teeth, but for hoofed animals they were so far old-fashioned as to have their front feet terminating with five toes (Oreodon). There were also a few forms of a more decided archaic character, with the feet clawed instead of hoofed (Agriochoerus).

All the ruminants so far referred to were hornless; but in North America the males of some allied forms were elaborately armed (Protoceras). The skull was surmounted by a pair of small horns; and a comparatively large pair adorned the snout; whilst two good-sized tusks shot down 


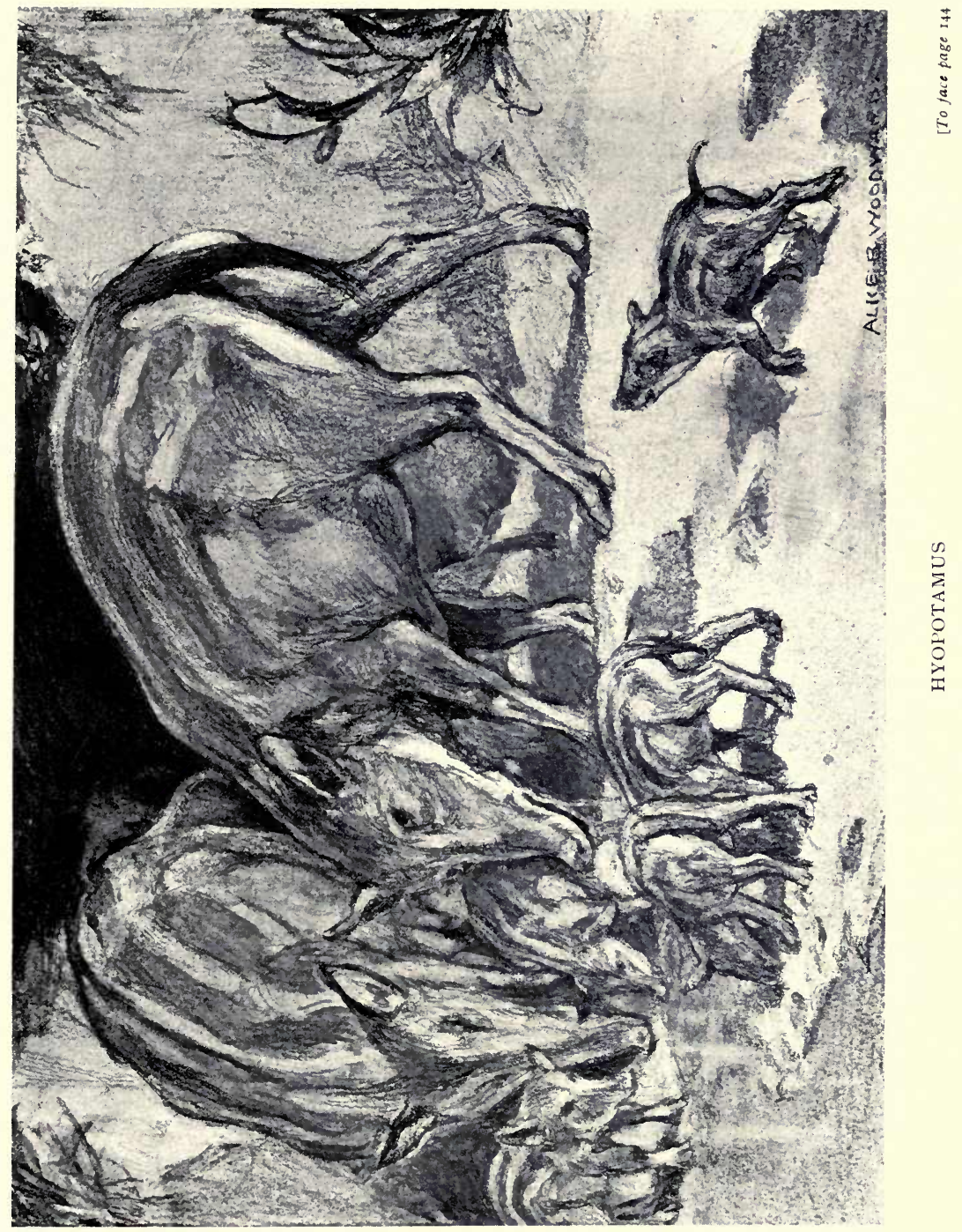


. 
from the upper jaw. These animals were, therefore, able to confront some of their difficulties with their heads, when their fellow-ruminants had to take to their heels. Doubtless too they were busy with their horns in times of courtship.

This profusion of horns recalls some stumpy-footed brutes of the Eocene (Tinoceras), but the resemblance ends there. Those monsters were elephantine in size, heavy and clumsy, and deficient in brain power; whilst these fearsome-headed animals were not much larger than sheep. They were, moreover, of graceful deer-like outline, and had exceptionally well-developed brains. Among living animals chevrotains, deer, and giraffes all hold some affinities with them. They were, therefore, of a comprehensive, patriarchal type. But they were as patriarchs that had lost their fire; for in the Oligocene they were not on the active list of Evolution.

Meanwhile out of the still tangled mammal life some deer DEER of primitive form had emerged. The largest of these did not stand more than two feet in height-the height of the Musk deer; and they probably closely resembled that animal in appearance (Dremotherium, Amphitragulus). They were all hornless, and probably took to flight on the first sign of danger. Some of them, indeed, had long canine teeth, which may have proved useful in a struggle : but the fortunes of cervine life, and indeed of all more or less defenceless mammals, must for a time have trembled in the balance.

Ruminants were also gaining importance by camel-like CAMELs developments. Whilst some Eocene ruminants of this type were only about the size of pug-dogs, Oligocene forms were at least as large as good-sized poodles (Poëbrotherium). In form they probably resembled the Lama, and their harmless aspect added another peaceful feature to the fauna. Indeed with the horned titanotheres dismissed from the scene early in the Period, with boars untusked, with rhinoceroses, and practically all the ruminants, hornless, it looked as if a reign of peace might arise in the mammal world. But the sign was only surface deep ; and carnivores, moreover, were a standing menace to a millennium. 
CARNIVORES Carnivores in some cases were becoming quicker-paced, and more deadly in dentition. Faster movement, no doubt, had been necessitated by the increased fleetness of herbivores. Mental developments were, doubtless, also going on in both ranks. Herbivores had long been victimised; and as a consequence their faculties of observation must have become sharpened, and the bump of caution developed. This mental evolution, it may be supposed, was being matched on the part of the carnivores by an increased cunning. On both sides, therefore, the mental standard was being raised.

It is clear, however, that carnivorous brutes of primitive type (Creodonts) were still able to pick up a living, although their brains were diminutive, and their dentition not of the most approved pattern (Hyanodon). These, however, were now quite unimportant in comparison with the forms with better brains, and with up-to-date cutting and crushing teeth. Small animals of this superior stamp, toothed like dogs, and civet-like in appearance, had, it may be remembered, come to the fore in late Eocene times (Cynodictis). Descendants of these animals were now very numerous; and they were supplemented by forms of wolf-size, and more resembling dogs in aspect than civets (Cephalogale).

Other forms abroad, flat-footed and with dog-like skulls, seem to have been a combination of dogs and bears; and they probably represented a stock out of which bears were ultimately to emerge (Amphicyon).

Some of the Eocene carnivores, although mainly canine in structure, more resembled cats, no doubt, in some anatomical features. Such-like generalised forms-skulled and toothed as wolves but tailed like leopards, and possessing claws that could in part be retracted-were certainly in existence in this Period (Daphnaus, N.A.). In certain of the Eocene carnivores, however, the cat must have become, so to speak, the predominant partner in the body. This may be inferred from the existence of decidedly cat-like forms in Oligocene times. The latter animals, moreover, were evident on two lines of evolution, that had issued, no doubt, from a common stock. Some of them were slenderly limbed, and fleet of foot; and their upper canines were so far developed 
as to earn them the name of "sabre-toothed " cats (Machærodonts : Alurictis, Dinictis, Nimravus). Other forms were TоOTHs" heavily built (Hoplophoneus, Eusmilus), and possessed extraordinarily big upper canines, finely indented along the edges. Against these terrible weapons not even the thickest-hided of the herbivores can have been invulnerable. The animals, it may be supposed, were not fleet runners, and in order to get to close quarters with their prey, they must frequently have had to exercise considerable stealth.

In Oligocene times some of the "sabre-tooths" attained the size of hyænas and jaguars. Some of their descendants, as will be noted hereafter, were much bigger animals; and there were not many lands which "sabre-tooths" failed to explore.

Civets had been more or less distinctly foreshadowed in cIVETS some of the Eocene carnivores (Proviverra); and in the Oligocene Period some of their descendants apparently were identical in form with living civets (Viverra). This early appearance of civets in, so to say, a completed condition is remarkable. Mammal life, as a whole, was destined to undergo many modifications, and to experience in some of its departures absolute extinction. Civets, amid surrounding change and decay, were to hold their own without practically having to adopt any structural reforms.

Other animals, although still closely allied to the civets, WEASELS had really dissolved partnership with them, and were developing into weasels. Animals of this type, however, were to undergo important modifications; for these Oligocene pioneers differed in tooth and skull from existing weasels, and in some cases were longer in the limb (Plesictis, Palcoprionodon, Stenoplesictis, etc.). Yet other civet allies were oTTERS diverging, and in no uncertain manner, in the direction of otters (Potamotherium).

The otter-like and weasel-like creatures were sufficiently differentiated from the family to which the civets belonged (Viverrida) to constitute a new carnivore family (Mustelida). Their principal diet consisted probably of fishes, birds, and small reptiles; but their presence was doubtless felt among mammals of a humble character. 
Carnivores were thus present in great variety; and the environment of the gentler animals was alive with dangers. Some part, however, of carnivore ferocity found outlets in its own ranks, for the animals no doubt preyed to a certain extent on one another. Their mode of life, moreover, was conducive to internal dissensions; and wild beasts do not settle their differences by arbitration.

RODENTS Rodents-which may have fallen frequent victims to incipient weasels and otters-had now spread far and wide. Many changes had been wrought in their ranks, and the highly intermixed condition of development, which had characterised their Eocene forerunners, was now a thing of the past. Unlike their predecessors-and like modern rodents-they were without canine teeth; and compensation had come by the development of very powerful incisors, thoroughly adapted to gnawing purposes. The animals, moreover, were branching out in various directions. Some of them were practically indistinguishable from living squirrels (Sciurus). Other forms, though closely linked with squirrels, seem to have been developing in the direction of cavies and porcupines (Sciuroides, Ischyromys). In yet other forms a beaver proclivity was decidedly marked (Steneofiber). And rats (Eumys, Cricetodon), dormice (Myoxus), hares and rabbits (Palcolagus, Titanomys), all more or less of modern aspect, were by this time in existence.

INSECTIVORES Insectivores, i.e. mammals with their teeth specially adapted to an insect diet, were in evidence in Eocene times in certain shrew-like forms, that had been foreshadowed as far back as the Jurassic Period. From insectivorous creatures, more or less of this humble description, some higher forms of life had no doubt arisen; but developments continued more or less on the old lines. It is clear from the condition of the Oligocene insectivores that consequent, it may be supposed, on some enforced changes of habit, important modifications had taken place. Some of the animals had taken to living underground, and were in fact moles, though their limbs were not so well adapted for burrowing as in the case of living forms (Protalpa). Others seem to have been in a hesitating condition between moles and hedgehogs (Tetracus); 
whilst some had so far advanced as to be real hedgehogs, although they differed in some minor points from modern forms (Palceorinaceus). Creatures almost shrews, and also completed shrews, were now abroad (Amphisorex, Sorex), and in some cases probably were adopting aquatic habits.

Thus underground, on the ground, and probably in the water was this ancient line of life grappling with the problems of existence.

It is supposed by many that from the ancestral stock of PRIMATES these various insectivores certain forms must have diverged, in times prior to the Eocene, and given rise to the Order of Primates. As early mammal life was so much intermixed, the question of the origin of particular groups is beset with difficulties; but it is certain that some of the Eocene lemurs or half-monkeys held strong affinities with the insecteaters.

The Primate Order was represented in the earliest Eocene by some vaguely defined lemur-like animals; and as the Period advanced some animals more closely resembling lemurs made their appearance. In Oligocene times animals were in being that, in regard to the number of teeth and the shape of the skull, still more resembled lemurs as now known (Necrolemur).

Certain of the Eocene lemuroids seem to have been developing in the direction of apes (Adapis); and animals identical in form with these were living in Oligocene times; but no remains of more advanced primates have been discovered. Animals which have been referred to the apes were living in European forests; but they seem to have had quite as close affinities with pigs as with apes, and they were probably a disappearing race (Cebochorus). Some interesting primates were living in Africa in late Eocene times, but their descendants of the Oligocene have not yet been brought to light.

Before leaving the mammals notice must be taken of certain creatures whose far-back ancestors had quitted the land for a seafaring life. Before the close of the Eocene some whale-like forms, known as Zeuglodonts, were exploring the seas in many parts of the world. Descendants of these

WHALES 
were living in the Oligocene Period, but, so far as is known, they were in a decadent condition. New forms, however, were abroad that in respect of the skull were certainly nearer to the whales of our own time (Squalodon). They were in fact true whales; but the family is now quite extinct (Squalodontida).

SIRENIANS Sea-cows closely resembling manatees were off the Oligocene coasts (Halitherium). They, however, still retained well-defined vestiges of hind-limbs, and differed, therefore, in this respect from living forms. The latter also present a difference in being more numerously toothed; prolonged life in the seas having, in their case, proved conducive to tooth multiplication.

BIRDS Bird-life comes before us in the Oligocene shorn of much antique character, and reinforced by many new forms. Compound creatures, awaiting differentiations-or extinction-were, no doubt, still in existence; but most of the birds known to be then living resembled more or less closely some of the present-day forms. It must, however, be admitted that the annals of bird-life have not been well kept by the rocks ; and many kinds of birds must have lived and died of which absolutely nothing is known.

The best evidence of Oligocene birds has been obtained from strata in France ; and it is clear that a variety of birds disported in the waters of that region. Some were of composite character, and were probably on the line of descent to modern grebes and divers (Colymboides). Others, related to the albatross-like forms of the Eocene, closely resembled the sea-skimming shearwaters of to-day (Puffinus). Solan geese quite of modern type were plunging after prey (Sula). Cormorants-vaguely in promise in Cretaceous times-were now completely evolved (Phalacrocorax); and gulls, much resembling living forms, were also on the wing (Larus). Pelicans and big, quaint birds with affinities to gannets and pelicans were fish-hunting in the shallows (Pelacanus, Pelagornis). Ibises and flamingoes of modern genera had now taken the place of their less sharply defined Eocene ancestors (Ibis, Phonicopterus). But some flamingo-like birds with very mixed affinities were here and there-presumably 
on their last legs-competing with the waders of more upto-date structure (Palcoolodus). Rails had been for some time in existence; and cranes-represented by primitive forms in the Eocene-were now much as their modern brethren.

Redshanks (Totanus), stilts (Himantopus) and other birds of plover relationship (Camascelus) haunted seaside and inland swamps and marshes. Here too were primitive ducks grubbing and quacking (Anas).

Over grassy and sandy plains bustards were to be seen and sandgrouse (Otis, Pterocles). Partridges also were abroad, rid of strong affinities with turkeys and guinea-fowl (Palcoperdix). Pheasants running about the woods attested another divergence from a long-confused game fraternity (Phasianus). Parrots, of unknown origin, were holding discourse in leafy retreats (Psittacus), and the notes of pigeon were also to be heard (Columba). The sylvan scenes were further enlivened by hoopoes, trogons, and crossbills (Limnatornis, Trogon, Loxia). Woodpeckers-already distinguishable in the Eocene-had become modernised: and crows and shrikes had emerged from some unknown prior states of mixed affinities (Corvus, Lanius). New songsters too had appeared: and thrushes and finches were adding their notes to the music of the woods.

Their music, it is to be feared, did little to soothe the savage breasts of the birds of prey. Various forms of these disturbers of the peace were certainly on the scene. Not only were birds abroad well advanced to becoming eagles (Palcohierax), but true eagles were also on the wing (Aquila). Kites, too, were about (Milvus), and buzzards (Buteo). Whilst these various feathery cannibals carried on, it may be supposed, their depredations in the daylight, no little destruction was doubtless caused in the "stilly hours" by the owls. These nocturnal hunters were more varied than in Eocene times, and included forerunners of the Screeching Owl (Strix). Secretary vultures were also in existence (Serpentarius). These may have preferred reptiles and insects to other means of regalement.

The remains of vast numbers of Oligocene insects have INSECTS 
been brought to light; and insect-eating birds, and other animals with like tastes, certainly had a variety of victims at their mercy. Many of the insects have been found entombed in amber cast ashore by the Baltic waves. As amber is the fossilised gum of certain pine trees, the little animals evidently got caught in the liquid resin, and were unable to extricate themselves. Much additional evidence of an abundant and varied insect-life has been found in other parts of Europe, and in the State of Colorado, U.S.A.

At the close of the Cretaceous Period all the Orders into which insects are now divided were to a certain extent represented ; unless indeed thrips-first known in the Oligocene-are regarded as a separate Order. The Oligocene record brings out the fact that in some of these Orders there had been a great branching out into families. Among the "straight-winged" insects (Orthoptera) forms had appeared of " praying " insects-so called from the devotional attitude they occasionally assume (Mantida). Saw-flies (Tenthredinida), gall-flies (Cynipida), wasps (Vespa), hornets ( $V$. crabroniformis), and new forms of bees-apparently honeybees (Apis proava) and bumble-bees (Bombus)-diversified the ranks of the "membrane-winged" Order (Hymenoptera). The "sheath-winged" Order (Coleoptera) was reinforced by tiger-beetles (Cicindelida), stag-beetles (Lucanida), pillbeetles (Byrrhida), and blister-beetles (Cantharida). In the " double-winged" Order (Diptera) gad-flies and bot-flies had now arisen, much to the annoyance, no doubt, of the mammals (Tabanida, Estrida); but they were doubtless held in check by spiders, which at this time were exceedingly numerous. In the scale-winged Order (Lepidoptera) new forms of moths were on the wing, including hawk-moths (Sphingide) and violet-moths (Noctuida). Butterflies also were here and there fluttering about. These greeted guests of the flowers seem to have been allied to the "blues," "meadow browns," and "tortoise-shells" of our own day (Lycanida, Satyrites, Nimphalides).

VEGETATION The vegetation in Europe was of much the same character as in the Eocene, indicating a continuance of high temperature. Palm trees were flourishing on the northlands of 


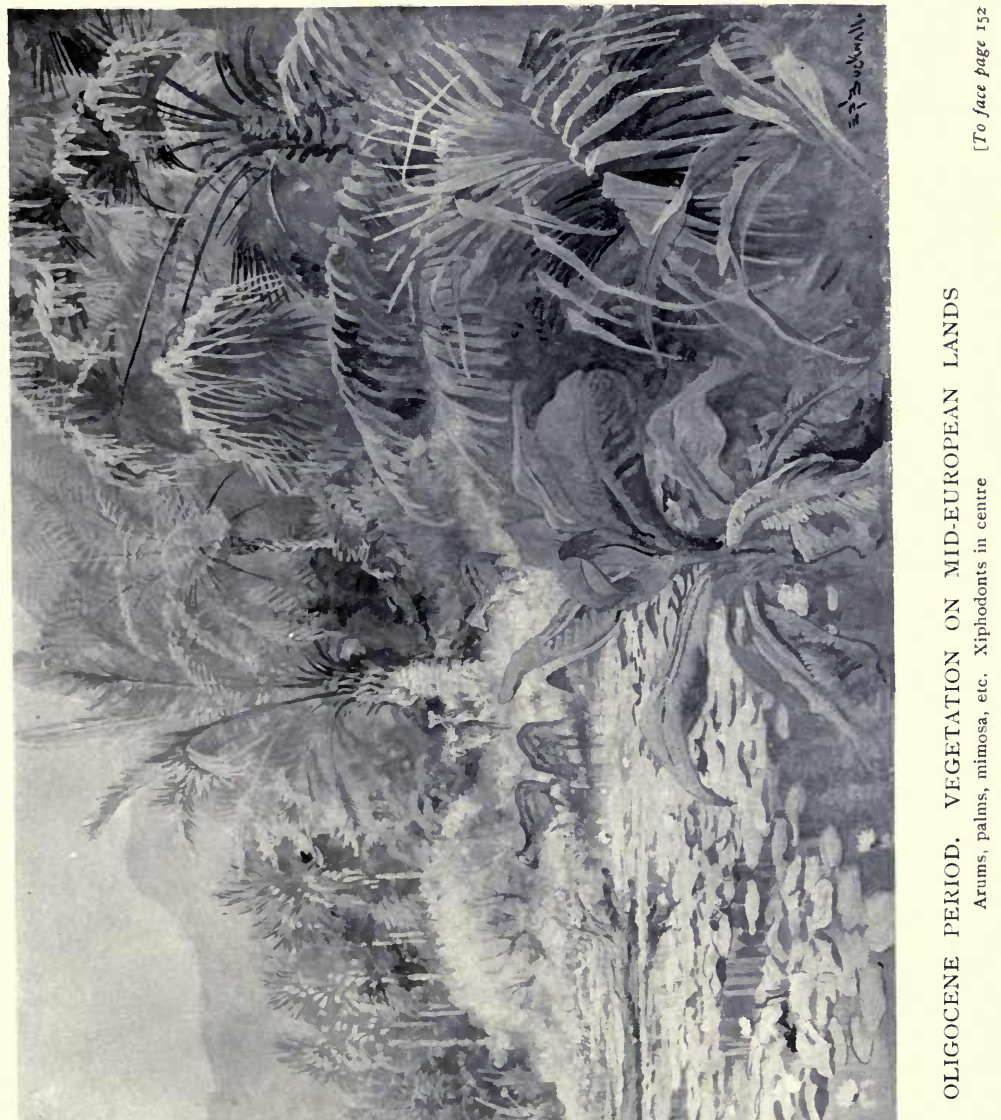


Germany ; and tree-ferns, ebony, olive, jujube, dragon trees, and big-leaved arums were luxuriating in scenes where today they would perish with cold.

In North America the heat must have declined, as palms were being driven from many of their old haunts, and hardier growths, such as conifers, grasses, and deciduous trees, were spreading over the forsaken sites. 


\section{CAINOZOIC AGE}

\section{MIOCENE PERIOD}

VEgetation The high temperature continued in Europe for some time during this Period, and the central lands of the continent remained rich with sub-tropical vegetation. Meanwhile the hardier growths had pressed far to the north. Conifers, poplars, hazels, oaks, limes, walnuts and various other trees. were now thriving in Spitzbergen, North Greenland, and other lands within the arctic circle. Some indeed were well within 600 miles of the pole.

In the course of the Period, some decline of the European temperature took place, for palms began to languish; and conifers, grasses, and various deciduous trees reoccupied. portions of their lost southern territory. The reduction in the heat, however, cannot have been very great; for camphor and cinnamon trees continued in abundance; and palms, though greatly reduced in number, were not entirely suppressed.

Remains of several familiar flowering plants have been found in Miocene strata. Irises, pinks, clematis, poppies, violets, and roses were here and there in bloom. Heather was. spreading over highland scenes. And plum trees, almond trees, and pineapple plants were ripening their fruit in the: Miocene sunshine.

PRIMATES Bright and bounteous though the landscapes must have been, and congenial the clime, lemurs or half-monkeys seem to have deserted Europe at the beginning of the Period. The Primate Order, however, came to be represented on the continent by creatures of higher stamp. There had, indeed, been promise of such in former times, although the evidence is scanty enough. It is certain, however, that in the course- 


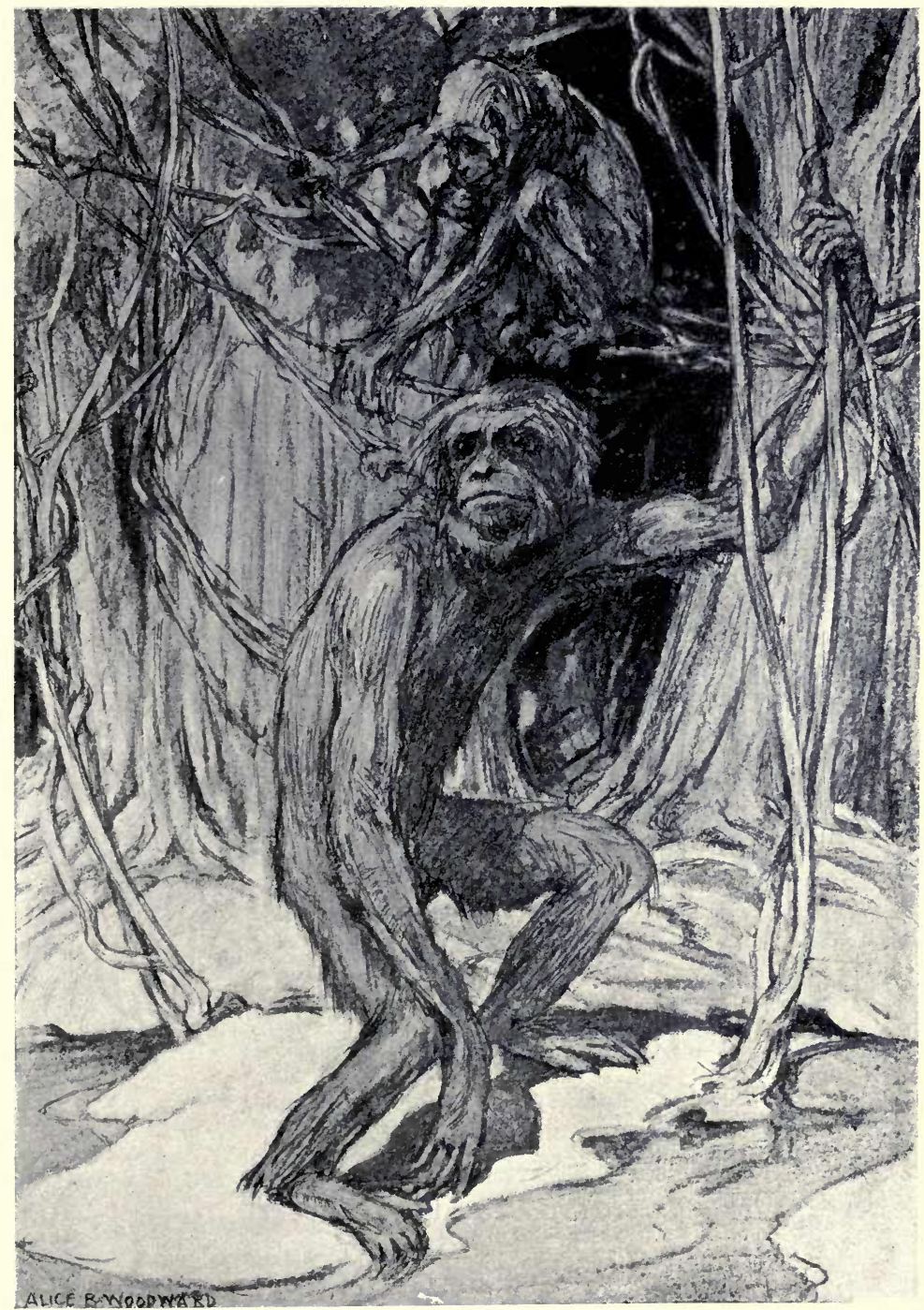

PLIOPITHECUS

Remains found in the Miocene of Sansan, Gers, France

[To face page 154 

of this Period monkeys and apes existed in Europe in more than shadowy outlines. These creatures, however, had not so far developed as to resemble closely any existing members of the Order. They were, rather, combinations of forms which now are quite distinct. Some of them seem to have been a blend or composition of baboons and anthropoid apes (Oreopithecus) : others to have been a combination of existing genera of the latter. Dryopithecus, for instance, was in part a chimpanzee, in part a gorilla. Some forms, however, seem to have been so far developed as to approach very closely the gibbon apes of our time (Pliopithecus).

Primates, compelled in the first instance to take to trees for safety, had probably long before this time become more or less permanently arboreal in habit. It was not a dignified mode of life for the highest order of mammals. But the creatures were, by nature, not well off for weapons; and they had not the wit to manufacture them. Possibly they had not even become so far civilised as to practise the art of throwing sticks and stones.

At this time, however, some of the animals probably did not confine themselves to arboreal life. Indeed, by means of their long arms, and occasional adventitious aid, they may have pedestrianised in a fairly erect manner.

Insectivores-near relatives of the primates-were now INSECTIVORES of little importance. The adaptabilities of these animals, however, were great, as attested in the Oligocene by burrowing moles, shrews of aquatic habits, and hedgehogs. The Miocene yields evidence that yet another mode of living had been resorted to, as some of the animals had taken to haunting trees (Lantanotherium). It only remained for insectivores to fly; and it is interesting to note that the now living "flying lemur" (Galeopithecus) seems really to belong to the Insectivore Order.

Some developments had taken place among the rodents. RODENTS Porcupines, not clearly distinguishable in the Oligocene from squirrels, had now so far diverged as to form a distinct family (Hystricida) ; and beavers, "half-create "-to use a poet's phrase-in the last Period, were now completely evolved (Castor). 
Some of the rodents in North America were intermediate in structure between squirrels and beavers, and were remarkable for having a horn on the snout (Mylagaulus). As they were of burrowing habits, the implement may have considerably expedited their work underground.

CARNIVORES Cat-dogs were still in existence in North America (Daphanus, Daphcenodon), but became extinct before the close of the Period. Other old-fashioned flesh-eaters were also fast dying out in North America and in Europe (Hyanodon); and on both continents the butcher element was represented almost entirely by carnivores of later type.

Among the weasel-like animals some forms had now become specialised as martens (Mustela), and polecats ( $M$. putorius). Otters also had an established identity (Enhydra); and before the close of the Period some seem to have been of modern type (Lutra). Some true cats, suggestive of an animal between a leopard and a polecat, were also appearing (Pseudalurus); and a few forms were toothed as modern cats (Felis). The lightly built "sabre-tooths" were now extinct (Dinictis, etc.); but it was probably from them that the cats of higher grade had been derived. The new forms, however, were not the champion felines of the time, for the heavily built "sabre-tooths" had gone on from strength to strength, and were now, moreover, in great force (Macharodus). Whilst these and the newer cat-forms probably preferred to attack prey " sitting," other carnivores exulted in the joys of the chase. Horses, deer, and other herbivores were doubtless pursued over the grassy plains and up the hillsides by wolf-like animals (Dinocyon); and foxes-by this time more or less clearly defined-no doubt joined eagerly in the hunt (C. Eningensis).

Bears were also abroad. Such animals had in Oligocene times been looming in forms with well-marked canine points in their anatomy (Amphicyon); and similarly compounded animals lived through a portion of the Miocene. Some allied forms, however, had now so far swamped their canine affinities as to be describable as bears (Hyanarctos); whilst a few creatures seem to have been true bears-the dog 


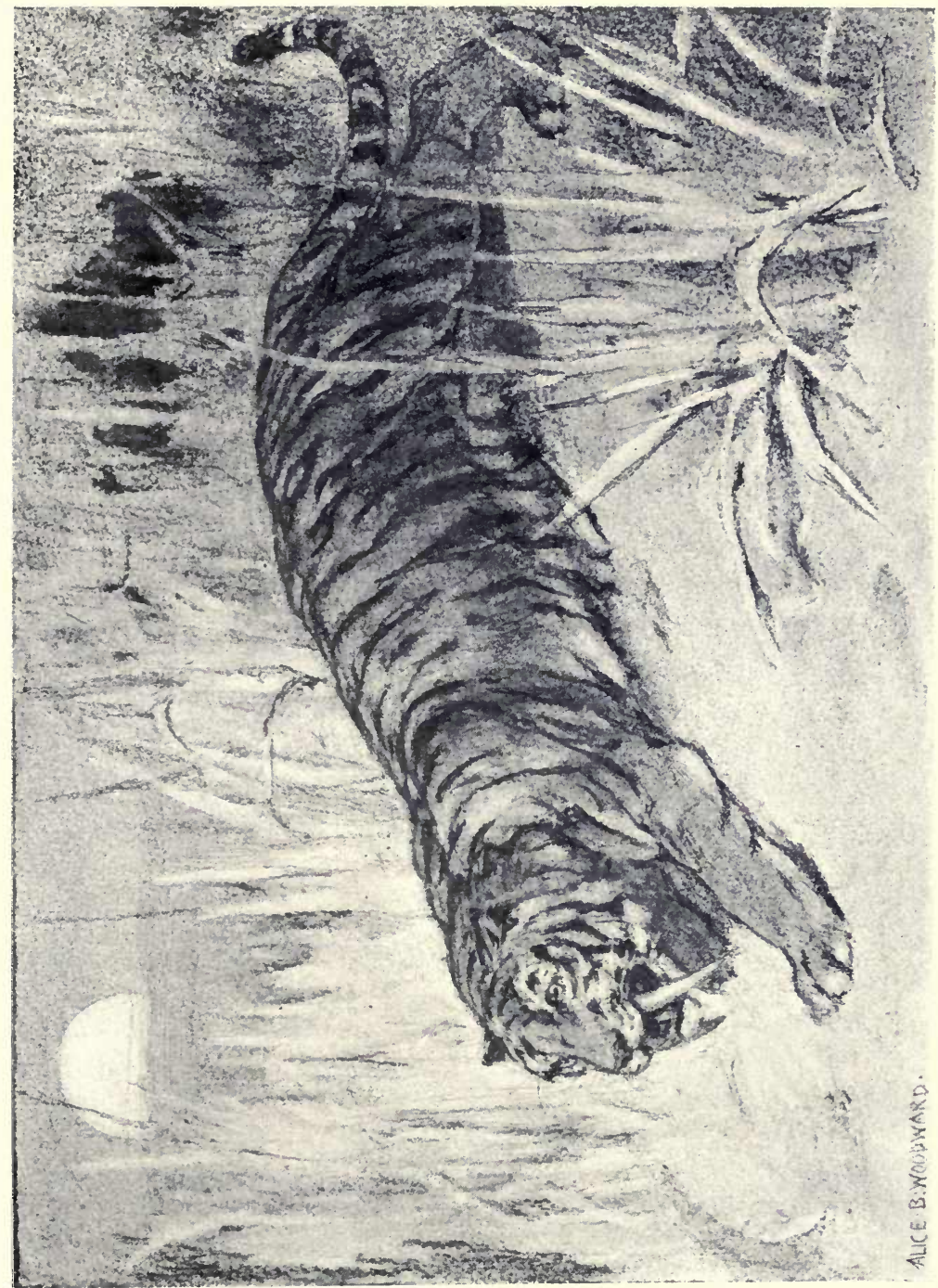



quartering, so to speak, having been removed from the family escutcheon (Ursavus). The habits of these various animals were probably much as those of bears now living. At any rate, they were too heavily built and too flat of foot to be successful in the chase. The same may be said of certain North American forms which at this time were developing into raccoons (Leptarctus). The latter animals, indeed, may have subsisted chiefly on fish.

Some extinctions and many developments had taken place among plant-eating animals. Old families from which tapirs, horses, and rhinoceroses had been derived, had passed away (Lophiodontida, Palceotheriida). And a like fate had overtaken xiphodonts, and other forerunners of ruminants (Anoplotheria).

Rhinoceroses were now represented by forms old and RHINonew. Old-fashioned hornless brutes were still living in CEROSES Europe and in North America (Aceratherium). On the latter continent these animals were now supplemented by a few creatures, whose snouts exhibited some promise of being supplied with horns (Diceratherium). The descendant forms, however, were never endowed with those weapons; and rhinoceroses, as developed in America, proved too innocuous for survival. Very different was the fortune of the family in the old world. Here many of the animals had well-weaponed snouts ( $R$. sansaniensis); and thus armed were able to face the course of events, whilst their hornless relatives dwindled to extinction.

Deer-hornless in the last Period-were now being equipped DEER for combat (Dicroceros elegans). The antlers were not as yet of an elaborate kind, as the shaft or beam never seems to have borne more than one tine. The shafts were supported on good-sized, bony pedicles; and the appearance of the armature must have been very much as that of the Muntjac deer now living in Asia. The appendages, it is clear, were not permanent like the horns of the rhinoceroses, but were shed and renewed periodically as in the case of modern deer.

The four-horned, deer-like animals of the Oligocene (Protoceras) were now represented by a few vanishing forms (Syndyoceras). The horns had become so big and mutually 
interfering as to be-except in appearance-quite ineffective. The race, it is clear, was suffering from old age and consequential eccentricities; and at the close of the Period it returned to "the friendly elements."

ANTELOPE In North America some of the ruminants were developing into antelopes (Cosoryx), some into mule and other deer (Blastomeryx). In Europe a few small short-horned creatures were not far short of being true antelopes (Protragoceras). SHEEP And-probably from the same parent stock-some primitive forms of sheep were now appearing (Criotherium).

CAMELS Camels certainly were becoming of nobler stature than their poodle-sized forerunners. In North America-where camel-life seems to have originated-animals were now to be seen nearly as big as modern camels, although of somewhat lighter build (Procamelus). Whether they were humped or not, it is impossible to say. Masses of fat, if ever they did rise on the back, must long ago have been demolished by Time, if not by quicker consumers. The backbone, it may be mentioned, affords no information as to hump-building; for its outline would not have been affected by fatty superstructure.

The cervical vertebræ of some of these forms (Alticamelus) had become greatly elongated, resulting in a giraffe-like neck. The legs had also been lengthened; and the hind-limbs were longer than those of a giraffe. The animals could thus feed on foliage out of the reach of most members of the family. The adaptations were, of course, advantageous to animals in lands where low-growing vegetation was scarce or uninviting. To judge from the size of the brain-case, these creatures were far less intelligent than existing camels-which places their mental calibre very low. There is no evidence of the survival of the race in the next Period.

Giraffes, so far as evidence goes, had not yet appeared. It is not, however, supposed that these long-necked camels were on the line to Giraffe evolution. It is well known that animals of different groups occasionally develop similar structures under the stress of similar conditions.

LAMAS Some of the camel-like animals, it is clear, were developing into lamas (Pliauchenia). This humpless, and almost 


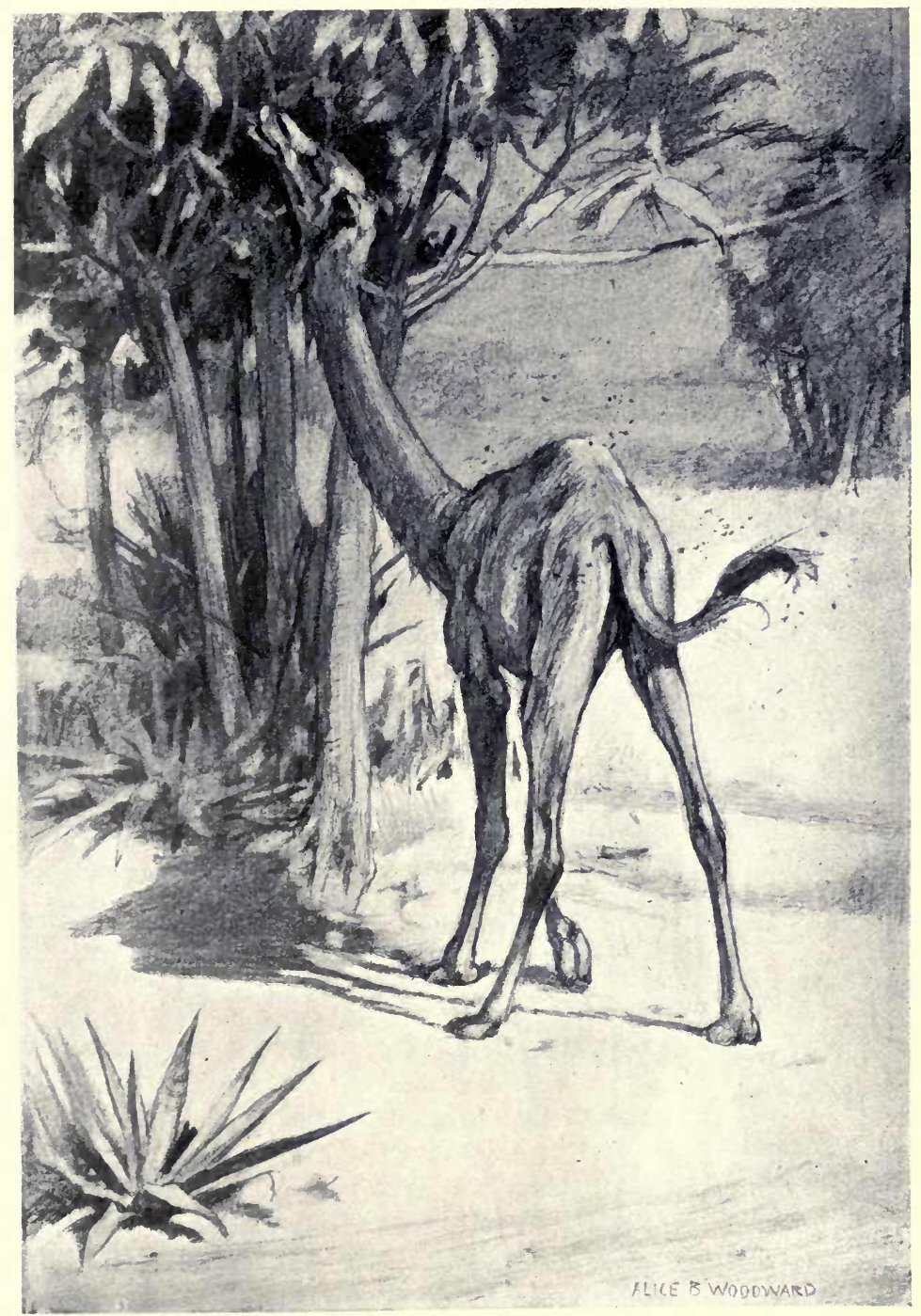

ALTECAMELUS

A giraffe-camel Remains found in Miocene of Coloradn, L'.S.A. 
tailless branch of the family migrated in later times to South America, and there attained considerable prosperity.

Horses had increased in stature. Some as large as good- HORSES sized Shetland ponies were now succeeding the harrier-sized creatures of the last Period. The North American forms probably were capable of much greater speed than their predecessors, as their " extra " toes, though still in evidence, were quite off the ground (Protohippus, Neohipparion). The European forms do not seem to have attained the same compactness of foot (Anchitherium); nor were their teeth so strongly crowned as those of their American relations.

At the same time there were horses in North America with well-developed and usable side-toes (Hyohippus). These creatures probably frequented swampy regions, where wellsplayed feet must have been of advantage. Their teeth, moreover, were of an old-fashioned, weakly crowned typemore fitted for marsh vegetation than for the hard grasses of the plains.

Pigs with their partiality for miry places were, like the swINE last-named horses, keeping their " extra" toes in a usable condition. It is probable, however, that at this time the main weight of the body was being thrown on the two inner toes of the four. Some of these marsh-dwellers were becoming more decided pigs as regards the shape of the skull ( $L i s-$ triodon); but in some respects their dentition was rather that of tapirs than of pigs; and, at best, they were uncanonical pigs. The most modern-like forms on European scenes were some diminutive creatures (Sus choroides) that must have closely resembled little pigs that now haunt the forests of the Andaman Islands. And as they embraced the essential articles of pig anatomy, they may be spoken of as orthodox pigs.

Like rhinoceroses, pigs in North America never made much progress; and it was reserved for the old world to bring porcine life into importance. The highest forms in America in Miocene times seem to have developed into peccaries; and swine of higher stamp than peccaries were not destined to explore the forests of that continent. Big, two-toed piglike brutes, such as were in evidence in the last Period, were 
still living in America and in Europe (Elotherium). But these were distinctly heretical pigs; and towards the close of the Period they were roasted, one and all, in the inquisition-fires of Natural Selection.

ELEPHANTS Animals of far more lordly appearance than pigs were now in European forests, for thither had elephant-like creatures found their way. It is interesting again to meet this form of life, as its fortunes during the Oligocene are unknownunless certain strata of doubtful age in the Vienna basin are to be referred to that Period. It seems safer, on the whole, to refer those deposits to the Miocene; and elephant-life thus reappears after a somewhat long break in its history.

It will be remembered that towards the close of the Eocene Period this branch of life was represented by some small, marsh-dwelling forms (Mceritherium), and also by some medium-sized and more truly elephant-like creatures (Palcomastodon). A notable feature of the latter was the lengthened lower jaw, one of the purposes of which was to afford support for the trunk in process of development. This elongation of the mandible must have continued during the Oligocene, for some European elephants of Miocene times possessed under-jaws of enormous length (Tetrabelodon). This, coupled with the fact that like their forerunners the animals were rather long-necked, shows that it was possible for the animal when standing to get its mouth to the ground. The trunk had doubtless become longer, and had increased in grasping power, but it was not, it may be supposed, sufficiently developed to render the projecting lower jaw unnecessary. At this stage, however, the trunk and the long mandible must have been getting somewhat in each other's way. And if one was to go, it was clearly the elongated chin, which had served chiefly as a scaffolding.

These animals stood rather over six feet, and were therefore about the size of the larger forms of earlier times. They, however, more closely resembled modern elephants in the shape of the skull. The tusks, moreover, excepting that they were partly enamelled, were of modern type.

Elephants, as now known, were not yet in existence. 


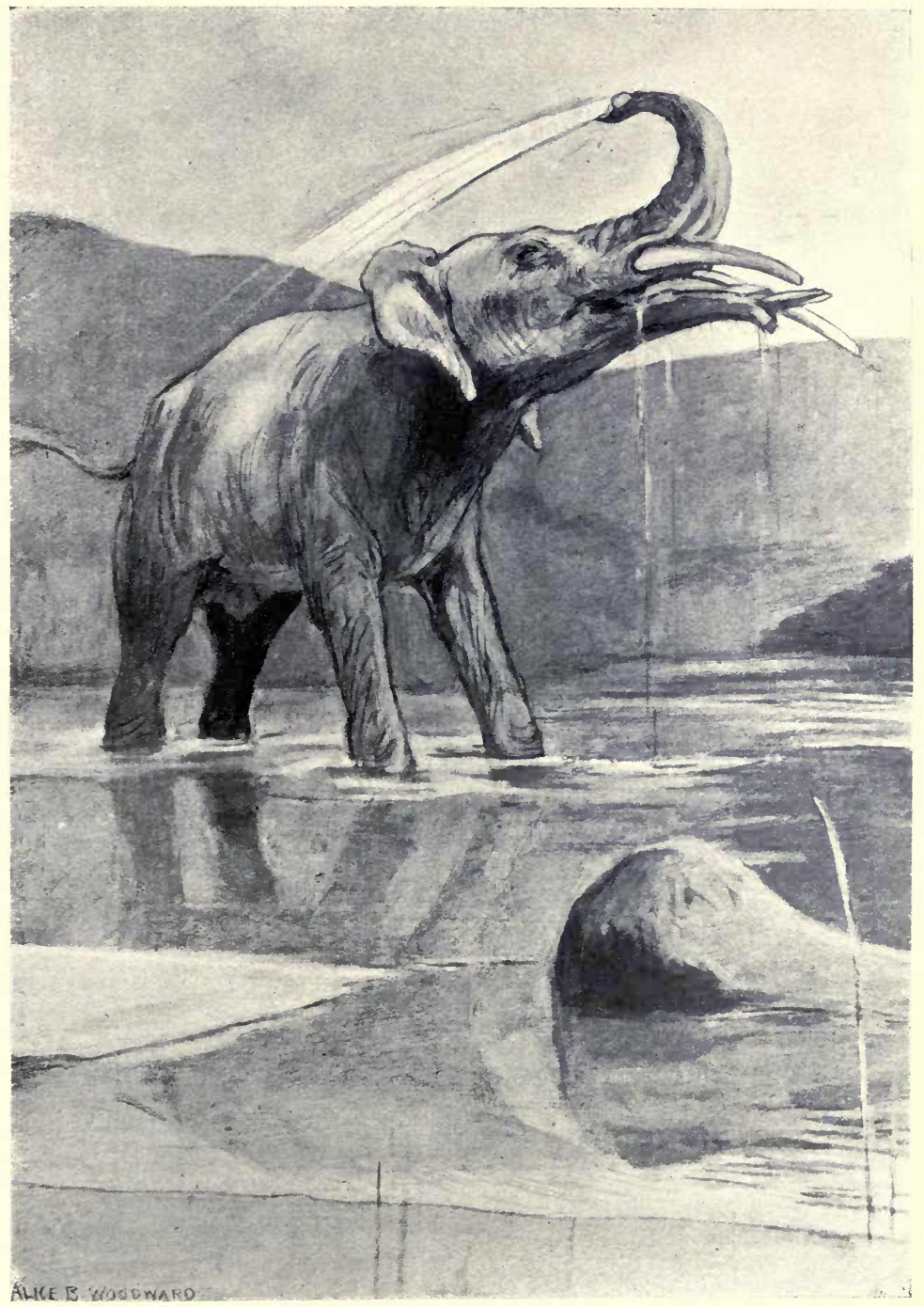

TETRABELODON

Restored from skeleton found in the Miocene of Sansan, France 

They were still in the making; and in the process some curious brutes had incidentally appeared, as had Titanotheres in the gradual evolving of rhinoceros life. These elephantine by-products are known as Dinotheres. They had long sloping faces, much unlike those of modern elephants; and they possessed also elongated lower jaws. This jaw, instead of shooting straight out, had a strong downward curve, as if the trunk no longer required its support. The upper jaw seems to have been tuskless, but the bent chin terminated with a pair of powerful sabre-shaped "ivories." The animals doubtless used these implements in self-defence, and also industrially, such as for rooting up plants ; and in times of drought they may have employed them in turning over big stones in dried-up river-beds, in hopes of finding water.

Dinotheres wandered about Europe, Africa, and Asia in this and part of the succeeding Period. So far as is known they never found their way to America. The straight-chinned forms, on the other hand, discovered North America at the close of this Period (Tetrabelodon). They had probably travelled from Asia by means of a land connection existing on or near the site of Behring Strait.

South America was not at this time connected with the south northern continent, and its mammal life was for the most AMERICA part of a peculiar and sleepy character. Sloths, armadillos, and such-like unenterprising animals here held an important position. They were, moreover, far from their zenith; for in later times, as will be seen, they developed to an astonishing extent.

Ground-sloths abounded in a variety of forms ; but their GROUNDanatomical differences were naturally not so marked as sLOTHS were those of later species. The nearer the source the greater the resemblance. Many of them were quite diminutive creatures-mere pigmies in comparison with later forms; nor do they seem to have walked so much on the outer side of the feet as did succeeding ground-sloths. Some large forms were also abroad-five feet and more in length; and by raising themselves on their hind-limbs they must have been able to get the pick of the foliage (Hapalops). Many of the 
Miocene species of ground-sloths failed to survive the Period; but it is probable that some of those of which remains have been found (Prepotherium, Nematherium, Analcitherium) were forerunners, if not actual ancestors, of some of the gigantic ground-sloths of later times.

ARMADILLOS Armadillos of various types were about the land. Some were very small animals (Prozaëdius); others (Stegotherium, Proeutatus) attained a length of two feet, and therefore nearly rivalled in size the largest of armadillos now living. They probably differed but little in appearance from existing forms ; and like the latter their carapaces had movable bands, enabling the animals more or less to roll themselves up for protection.

GLYPTODONTS Other forms, closely allied to the armadillos, are known on account of their " carved" or fluted teeth as Glyptodonts. They differed in some parts of their anatomy from armadillos, and were not, like the latter, adapted for burrowing. Their carapaces, moreover, were far less flexible. Except in a few cases they did not exceed the biggest of the armadillos in length, great though be the disparity in nomenclature (Propalaohoplophorus). Glyptodonts were destined to make a mark in South American mammal life; and some of the known Miocene forms (Metopoxotus) probably were ancestors of the monster glyptodonts that subsequently appeared.

No remains of ant-eaters or tree-sloths have been found; but ground-sloths had some strong points of resemblance to tree-sloths, and also to ant-eaters. Ground-sloths, treesloths, and ant-eaters, therefore, were probably all derived from a common ancestry. Moreover, it is probable that at one time there was a still older stock which held potentially not those animals only, but also armadillos and glyptodonts.

Many kinds of creatures besides ground-sloths and armadillos were at this time in South America. The most notable of these were hoofed animals ; but it is not possible to bring them into close line with any ungulates now living.

TOxoDonts Some of them are grouped together as Toxodonts, as the typical forms had "bow"-shaped grinding teeth. These strange animals were for the most part about the size of 
sheep, with an outward appearance of coneys grown to gigantic dimensions (Nesodon).

Other allied forms have been named Astrapotheres, or ASTRAPO"lightning-beasts" ; and they must have presented a start- THERES ling appearance. They were as large as rhinoceroses; and, though not related to those animals, they probably bore an outward resemblance to them. Some of the brutes were provided with a pair of long and powerful tusks in the lower as well as the upper jaw ; and the tusks were so brought into contact as to ensure a mutual sharpening. As the monsters were vegetarians, one may suppose that their well-stropped blades were chiefly used in quarrels about females.

Here also were other hoofed animals known as Litopterns LITOPTERNS -a name having reference to an anatomical feature of the heel-bones. They were for the most part long-necked creatures, nearly as big in some cases as lamas, and the majority of them were not unlike those animals in general appearance (Oxyodontotherium). Their feet, as a rule, were three-toed, and all the toes were in use. In some rather short-necked and somewhat horse-like forms the "extra" toes had become dwarfed and useless (Proterotherium), as was the case with many of the horses then living on the northern continent. There is, therefore, no doubt that, in regard to the feet, these animals and the horses were converging in development. Indeed, a few of them were in that respect in advance of the horses; for they had quite lost their sidetoes, and were toed, therefore, like the modern horse (Thoatherium). They were, however, far inferior to the horses on the neighbouring continent not only as regards flexibility of limb, but also in tooth-structure and brainpower.

Yet other animals, known as Typotheres, were perhaps TYPOTHERES the most curious of all (Pachyrucus). They were about the size of hares, and probably looked like guinea-pigs much overgrown. Mr. Lydekker has shown that they were more or less closely allied to the Toxodonts, and so belonged to the hoofed Order. They had, however, by a series of modifications, converged to the rodent type, as regards teeth and toes, and also in other respects. The squirrels, hares, and 
other rodents that were then in the world had reached their condition of development quite independently of the hoofed animals. But here were rival forms that had issued from the ranks of the ungulates. In other words, creatures were climbing into the rodent fold by another way. This intrusion, as after events proved, was not to be tolerated.

No animals describable as elephants seem to have been in the fauna. But brutes were here (Pyrotherium) somewhat of the type of the hippopotamus-bears that in other parts of the world had long since passed away (Amblypoda).

Life in South America was thus developing in a somewhat peculiar manner ; and a fairly tranquil environment ensured it a large measure of prosperity. Apparently no true carnivores were here to disturb the somnolence of the sloths, and the long feeding hours of the toxodonts and other quaint herbivores. Boisterous scenes there doubtless were among the "lightning-beasts"; but these, after all, were occasioned by a laudable affection for the fair sex.

CARNIVORES Lovers of meat, however, were in the land (Prothylacinus, SPARAsso- Borhycena). These long-tailed and somewhat wolf-like DONTS animals, in being dull-witted, were to that extent in harmony with the prevailing tone. They possessed strong affinities with marsupials, and are classed as such by some good authorities. Their powers for scenting prey were exceptionally well developed; and some of them seem to have been adapted to arboreal habits (Cladosictis). Their teeth, it must be admitted, were not of up-to-date type; but the animals, no doubt, fared sumptuously on the sleepy herbivores. Their feasts-probably indulged in at night-led not infrequently to squabbles among themselves, and there is evidence that ugly wounds were inflicted in altercations.

MONKEys The highest class of the population consisted of feebleminded, flat-nosed monkeys of the "howler" type (Homunculus). The first comers had probably arrived by chance from lands north of the existing isthmus, having been carried across the dividing sea on drifting tree-trunks. Their advent was, no doubt, much resented by the old quiet-loving residents.

MARSUPIALS Undoubted marsupials seem to have been limited in 
variety, consisting chiefly of small opossums (Microbiotherium), and somewhat phalanger-toothed opossum-rats (Palcothentes, Canolestida).

Marsupials seem also to have been but scantily represented on the northern continent. In Europe they had long been on the decline; and the opossums of the Oligocene Period were, so far as is known, the last of pouched life on that continent.

In Australia this ancient Order was probably full of vigour and abounding in a variety of forms, as its development had not been complicated by mammals of higher type. Evidence, however, is wanting as to the condition of Miocene marsupials in that part of the world.

If, as there is every reason to believe, no mammals of wHALES higher rank than marsupials were living in Australia, such, in the form of whales, were flourishing off her coasts. These were creatures of the newer fashion, such as had come into view in the last Period (Prosqualodon, Squalodon). The Zeuglodonts-the earliest known whales-apparently had now quite died out. During the last Period they had been dwindling in numbers, and the new divergent forms, more nearly resembling the toothed whales of to-day, had become well established. In South American waters some forms of a still more advanced type were in existence. These may be described as sperm whales, although they differed from their present-day descendants in having their teeth enamelled, and, moreover, in possessing teeth in the upper as well as the lower jaw (Physodon). Other forms apparently were in a condition between toothed whales and whalebone whales (Argyrocetus); and a few seem to have reached a stage constituting them whales of the latter category (Cetotherium). In European waters some members of the "white whale" genus of the Dolphin family were in evidence ( $\mathrm{Del}$ phinapterus). Here also were whales, some qualifying for "Bottle-nose," some for "Hump-back" distinction; but the special features, it would seem, were not fully developed until the next Period (Hyperoodon, Megaptera).

The success of the seaward move of some ancient landmammals was, it will be admitted, beyond question. Con- 
gratulations, though not feasible, were well deserved, for the animals were insusceptible of any essential modification of their land-designed machinery for breathing, and for the bringing forth and suckling of young.

sEALS Other mammals, it is clear, had followed the example of the whale-ancestors by relinquishing land for a sea life. The exchange of elements in this case had resulted in seals, a few species of which were now in view (Prophoca). Their tangled course of descent is quite unknown. Their nearest relatives in the Miocene were probably the otters.

BIRDS More remarkable than the evolution of seals and whales from land-mammals was the rise of birds from reptiles, and their subsequent development into a vast variety of forms.

Deficient though be the record, several glimpses of the progress have been yielded by Miocene strata.

In river-swamps and fenny solitudes heron quite of modern type were seeking their miscellaneous food (Ardea). Storks were much more in line with present-day forms. Some, indeed, seem to have been of the same genus as the Adjutant Stork (Leptotilus); others were primitive wood-ibises (Tantalus). New forms of more or less plover origin had become specialised as auks, guillemots, and curlew (Mancalla, Uria, Numenius). Gulls, an earlier offshoot of the stock, probably consisted at this time of many species.

Turkeys, hardly semi-existent, so far as is known, in the Eocene, had now become completely evolved in North America (Meleagris). And plantain-eaters (relatives of parrots) augmented bird-life in Europe, where a genial clime provided them with bananas and other fruits they loved (Necrornis).

CROCODILES The continuance of a widespread warmth enabled crocodiles and alligators to thrive in scenes which are now denied them; and crocodiles, indistinguishable from long-snouted forms now confined to the tropics, were haunting European rivers (Tomistoma).

chelonians Huge tortoises, allied to the Greek Tortoise, were creeping about the inland scenes. Water-haunting forms, known as alligator terrapins, were in the lakes and tidal waters (Chelydra); and turtles closely allied to the Hawksbills or tortoise-shell-bearers were also in evidence (Chelone girondica). 
Tortoises, turtles, crocodiles, and alligators, however, seem to have been less rich in species than of old, and probably in most parts of the world they were in a declining condition.

Lizards and snakes, on the other hand, were steadily LIZARDS advancing. Of the former reptiles, in addition to creatures closely resembling those of earlier times, various new kinds abounded. Some of these are not identifiable with living genera ; but spotted or " eyed " lizards, skunk lizards, and so-called "glass snakes" seem now to have issued from the more or less hotch-potch condition of old lizard-life (Dracanasaurus, Locellata, Ophisaurus). Snakes-comprising SNAKES hitherto innocuous forms only-were now diversified by cobras, rattle-snakes, and other purveyors of venom (Naia, Neurodronicus, Bitis).

Amphibian life had for a long time been on the decline, AMPHIBIANS and from once possessing huge warriors had come down to a humble representation consisting of frogs, toads, newts, and salamanders. In this Period, however, some revivalists of lost glory appeared in the form of big frogs and salamanders. The largest of the frogs were some eight inches in length. These giants of their kind were probably ancestors of the venomous horned frogs now living in Brazil (Latonia). Some of the salamanders attained a length of over three feet (Cryptobranchus). They were certainly big for salamanders, but they fell far short of the " roofed-head " giants of Triassic and still remoter times (Stegocephs). Indeed, the total length of the largest of them did not equal the skull-length of some of the old " roofed heads." Nor did they hold any close relationship with those amphibious monsters. Like the big frogs, they were not without an elixir of life; and at the present day salamanders are to be found in Japanese waters quite as big as their Miocene forefathers.

Although fishes had in the Eocene attained the main FISHES features of their modern development, numerous new species had doubtless since arisen in the various families. Not very much is known on this subject, but it may be mentioned that hammer-headed sharks and thresher sharks were now in the ranks of the long-established non-bony fishes (Sphyrna, 
Alopecias). As regards fresh-water fishes geological history is extremely slight. From discoveries made in Swiss strata (Eningen) it is clear that pike, perch, loach, tench, and carp were all in existence in this Period.

INVERTE- Invertebrate life calls for little notice. The known molBRATES luscs, as in the last two Periods, consisted mostly of species of a tropical character; and a large proportion of them belonged to species still in existence.

Europe, with its palm trees, apes, elephants, crocodiles, and turtles-to say nothing of the absence of human beings -was very different in its life aspects from what it is to-day. Nor was it geographically the same; for the Mediterranean was flowing over many parts of the continent which are now dry land. The Alps, however, and Carpathians - in the making of which the Eocene nummulites had played so important a part-were now well in view above the surface of the waters. 


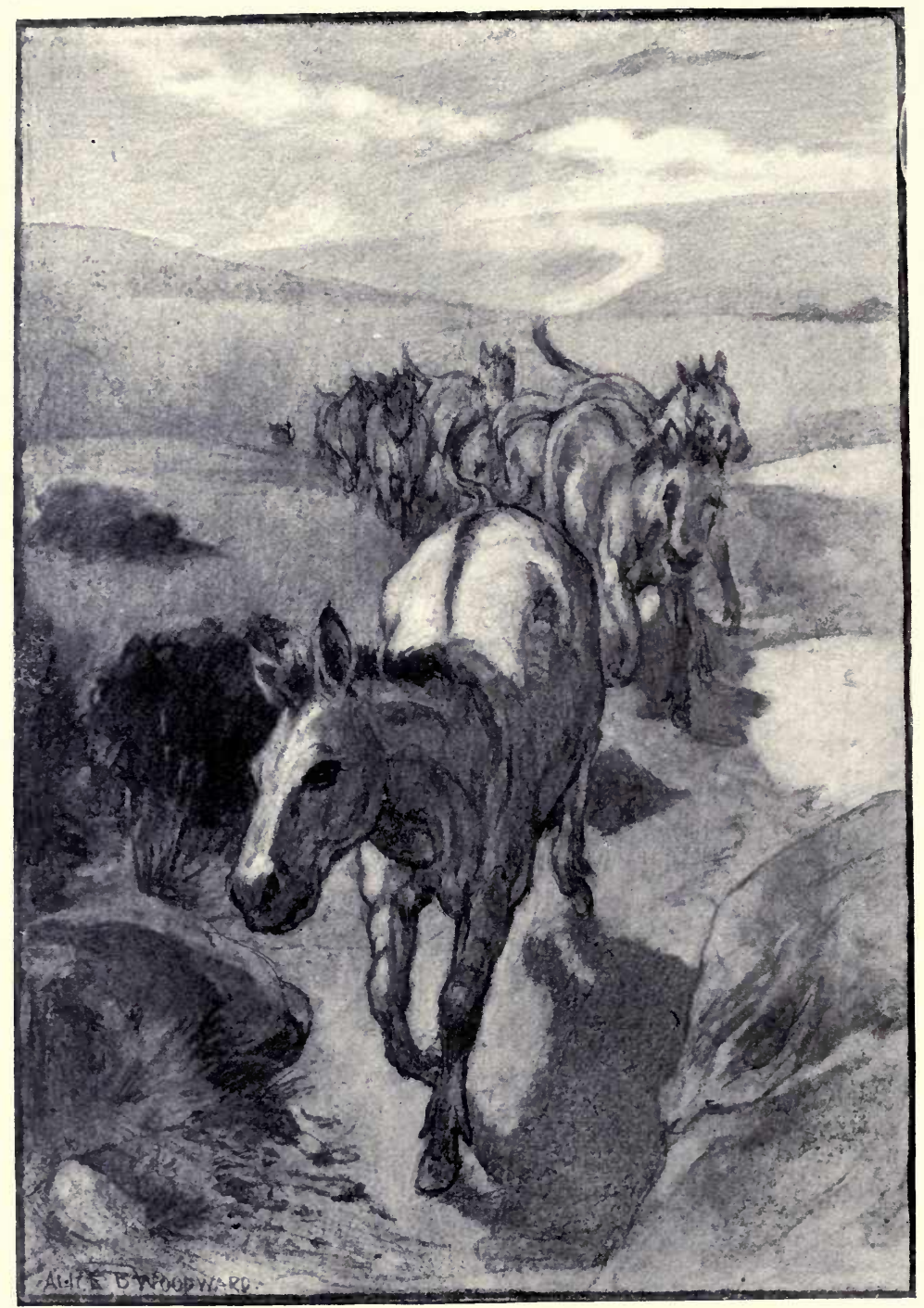




\section{CAINOZOIC AGE}

\section{PLIOCENE PERIOD}

\section{EARLIER EPOCH}

OwING to various earth-movements in the course of this Period the Mediterranean Sea was gradually forced back, and the continent of Europe attained a shape and extent not differing greatly from that of to-day. The climate, although still of higher temperature than now, was becoming less warm. Signs of a change were evident towards the close of the Miocene in the decline of the palms. At the commencement of the Pliocene these warmth-loving growths had almost disappeared; and the climatic changes were driving crocodiles from old European haunts. Meanwhile the lowering of the temperature had stimulated the growth of deciduous trees ; and grasses, spreading more freely, were now displayed as rich and extensive pastures.

Herbivorous animals were enjoying the verdant scenes in ANTELOPE vast numbers; and the antelopes of primitive type were succeeded by various, though for the most part small forms. Most of these were of mixed affinities. Some, with spirally twisted horns, combined kudu and eland features (Palaorias): others, also of twofold character, gave promise of the oryx and the sable antelope (Palcooryx); whilst certain forms in some points were decidedly goat-like (Tragoceros). Some of the animals were more specialised, and may be described as harnessed antelopes. Gazelles, more or less indistinguishable from modern forms, had also been launched on their career (Protragelaphus).

Whilst antelope herds fed and prospered on the grassy GIRAFFEs. grounds, other animals browsed on the foliage of the trees. 
These ruminants are the first known members of the Giraffe family. A few of them, excepting that they were shorter limbed, seem to have borne a more or less close resemblance to modern forms ( $G$. attica). Most of them, however, held strong affinities both with antelope and deer, and were far from having attained the stately and unique appearance of modern giraffes. They were much shorter in the neck; and the limbs were not only shorter, but of nearly equal length. Well-developed horns, moreover, crowned the heads of some of the animals (Samotherium, Palceotragus). These weapons, no doubt, were manageable, but as the neck became elongated their efficiency must have been reduced. Indeed, in some of the longer-necked Pliocene forms, living in Europe, the horns had become insignificant (Helladotherium). It is not surprising, therefore, that modern giraffes-extremely necky animals-possess horns only in vestigial condition. Not one of the known primitive species seems to have survived the Pliocene Period. But it is an interesting fact that at the present time animals closely allied to them are living in primeval forests of the Congo. This discovery was made by the intrepid traveller Sir Harry Johnston in Igor. The name of "Okapi" has been bestowed on the animals by Sir E. Ray Lankester, who has no doubt of their relationship to primitive giraffes. Their outward appearance is certainly very different from that of other giraffes now living, as they are striped, not spotted; and, like Pliocene forms, they are comparatively short in the neck. They live, it is stated, in the deepest recesses of the forests-victimised, it may be supposed, by civilisation.

HORSES Horses were now to be seen on the plains with more compact feet than the Miocene forms (Hipparion). The " extra" toes were quite off the ground, and dangled at the sides of the well-developed central toe as useless appendages. Similarly developed horses were certainly in North America in Miocene times, so the European animals were only following. in the wake of the American. Horses more highly developed were living elsewhere in this Period, as will be noted shortly.

TAPIRS Tapirs of the Eocene notably differed from tapirs now living merely in regard to teeth and toes. As the toe differ- 



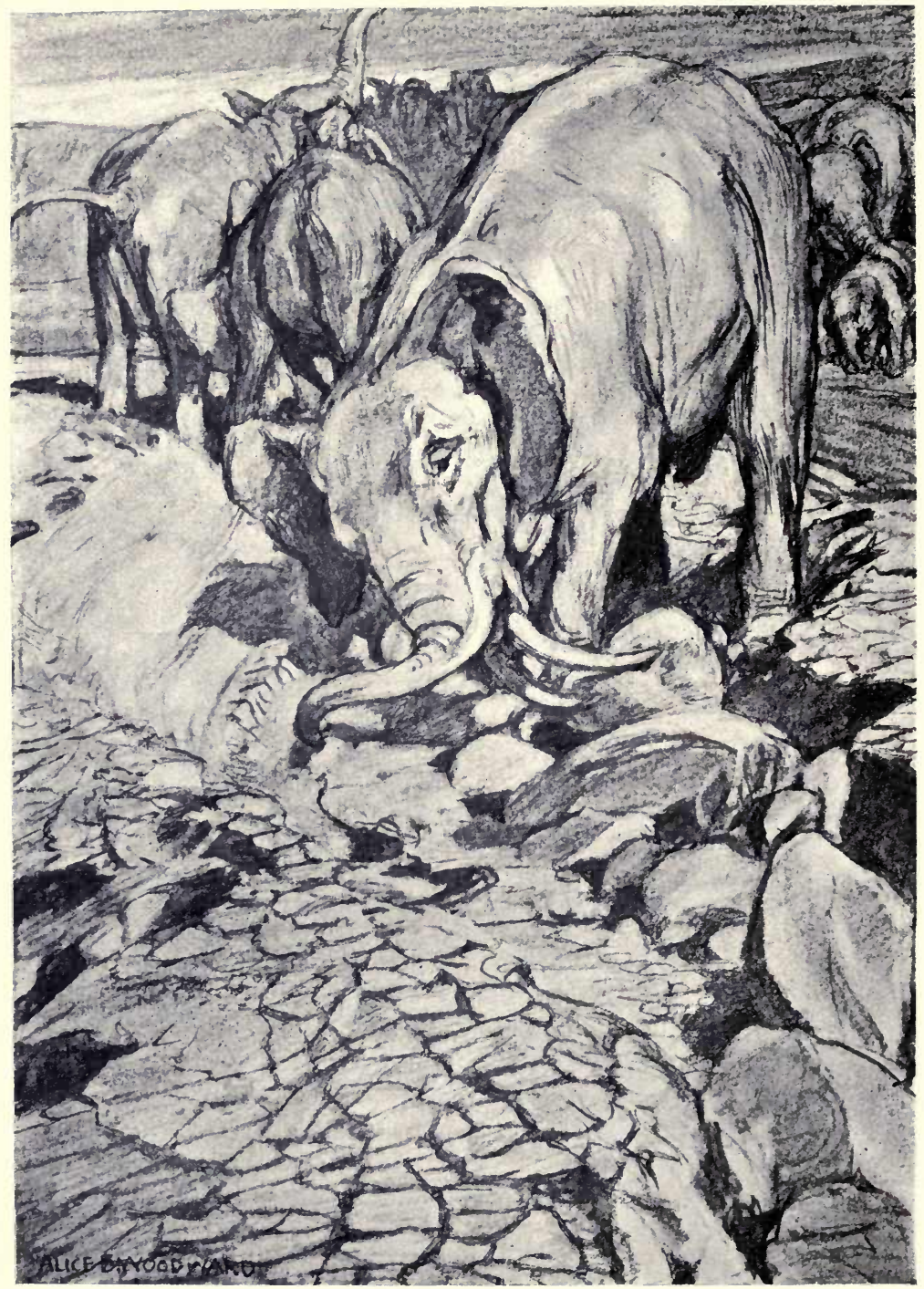


ence had been adjusted in the Miocene, and the tooth dissimilarity had now disappeared, the animals were practically indistinguishable from modern tapirs. They were certainly prosperous in Europe at this time. At the present day their descendants, like the okapi, lead obscure lives in very limited areas.

Herds of elephants were still enjoying life in Europe ELEPHANTS amid the high grasses and in woodland scenes. They appear to have been identical in form with those of the last Periodthe four-tusked animals with greatly elongated lower jaws (Tetrabelodon), and the still quainter creatures with downward-bent chins terminating with sabre-like "ivories" (Dinotherium). The latter animals were of larger size than earlier forms ; but, beyond that fact, no European proboscideans showed any advance in development. Elephants, however, had made considerable progress elsewhere, as will be seen when we reach India.

Rhinoceros-life in Europe presented some fresh phases of RHINOevolution. The oncoming horned animals were more modern- CEROSES ised, and variously developed. Some of them seem to have been close-allied to the now living Sumatran species $(R$. Schleiermacheri); whilst others were intimately related to the so-called Black Rhinoceros now confined to Africa (R. pachygnathus). Hornless male rhinoceroses, with a lineage dating to a remote past, were now on their last legs (Aceratherium); and long before the close of the Period they became extinct. The only hornless rhinoceroses of the future were of the gentler sex. If any female rhinoceroses in early Pliocene times were horned is doubtful. A cry of "horns for women" certainly came in later times, and was to a certain extent successful.

Here and there a few hyæna-shaped beasts, with claws bent ANCYLOPODS like a scaly ant-eater's, were grinding grassy. food with teeth much as those of a rhinoceros. These and some fellow-forms that had found their way to Asia were, no doubt, survivors and also final representatives of an old family well in view in the Oligocene Period (Chalicotheriide).

Away on the hills deer of various kinds were roaming. DEER Some of them had antlers simply forked like the modern 
muntjacs, and were therefore in this respect not in advance of Miocene deer (Cervulus dicranoceros). Many of them, however, were antlered more elaborately. Some of these with three-tined antlers were, no doubt, closely related to the spotted deer now living in India ( $C$. pardinensis). Others were abroad with four-tined antlers, of a pattern now quite unknown ( $C$. tetraceros). However long they lived, deer do not seem at this time ever to have possessed antlers with more than four tines or points.

swine Other animals belonged to the swine family. This branch of life ever since it commenced in a small way in Eocene times had been progressing ; but it was not until the Miocene that animals appeared describable as true pigs. Those were all small forms, and were closely allied to the pigs now living in the Andaman Islands. Several pig-like brutes of much larger size had certainly appeared before then; but they were unorthodox in some of their tooth or toe tenets. In early Pliocene times orthodox pigs of small size were in some force in the forests; but the family was now dignified by pigs of much larger dimensions. Some of these, although not so well tusked as the Wild Boars of our own time, were bigger than those animals ( $S$. erymantheus). They were not, however, so big in the body as some of the old unorthodox forms, and were feebly tusked in comparison.

PRIMATES The most important tenants of the woods were undoubtedly the apes. Their importance was, of course, mainly morphological; for it is not to be supposed that they were primates in the sense of being chiefs or rulers. Some of the creatures were anthropoid or man-like apes, but their remains are too fragmentary for more precise identification (Paidopithex). Others had affinities with the Langurs, or "Holy Apes" of India, as well as with the Macaque apes, a species of which now lives at Gibraltar (Mesopithecus); whilst a few, although sanctification was as yet a far-off event, seem to have been "holy" apes pure and simple (Semnopithecus).

CARNIVORES Heavily limbed "sabre-tooth" cats were still the most formidable of the carnivores (Macharodus); and new flesh- 
eaters were now on European scenes in the form of hyænas. Some of the latter were of primitive description, retaining close affinities with civets (Palhycena, Ictitherium). But Nature had produced more than preliminary hyæna sketches ; for some of the animals were not far short of being hyænas as now known (Lycyana, Hyanictis). Certain of them, indeed, seem to have been closely allied to the existing striped species ( $H$. striata). Whether scavenging was at this time the family profession, it is difficult to say. There must have been carrion in plenty, and some of the animals may have disposed of it, and with no little advantage to public health.

Bear-life in Europe, so far as is known, consisted only of BEARS old-fashioned brutes that either retained strong affinities with dogs (Simocyon), or in which certain canine features had not been quite obliterated (Hycenarctos). Some descendants, however, of the true bears of the Miocene may well have been about the scenes.

A glance must now be taken at early Pliocene life in India. INDIA This has been rendered possible by extensive discoveries made in the Siwalik Hills; and a very interesting picture is brought in view. The ubiquitous "sabre-toothed" cats CARNIVORES (Macharodus) were about the land as might be supposedespecially as elephants, their favourite prey, were there in plenty. Various other cats, large and small, abounded. Some of these seem to have been intermediate in development between tigers and jaguars ( $F$. cristata); others had developed into cheetahs or hunting leopards (Cyncelurus brachygnatha); and some small forms had reached the status of true tigers. Civets were numerous; and here and there big forms prowled about, unequalled in size by earlier or later relatives. The Dog family was represented by wolves and jackals, not differing much from forms now living (Canis Cautleyi, C. aureus).

Whilst the land was thus haunted by carnivores of a more or less modern aspect, flesh-eaters of a very ancient race-extinct in other parts of the world-still lingered on (Hyconodon). So far as can be gathered, these animals remained in just the same condition of development as their 
Eocene ancestors-small-brained, weak-limbed, and with teeth less efficient than those of true carnivores. Once in the very front rank of flesh-eating animals, their line had now sunk into utter insignificance. It was long since they had enjoyed "uppermost rooms at feasts," and they had probably by this time come down to subsisting entirely on carrion. Even in that field of regalement they must have had keen competitors; and it is not surprising that during early Pliocene times their annals came to a close.

Bears with vanishing affinities to dogs and indistinguishable from forms in Europe were about the land, but in dwindling numbers (Hyanarctos). Other forms abroad no longer laboured under the suspicion of being partially dogs (Ursus Theobaldi). Indeed, they seem to have been closely allied to the modern sloth bear.

Badgers were certainly in existence in parts of Asia at this time; but from what holes or burrows of the misty past they had found their way into creation is quite unknown.

ELEPHANTS Trunky life was well in view in India in forms new and old. Here, as in Europe, were quaint but stately brutes, some with protrusive under-jaws (Tetrabelodon), others with chins bent and sabre-tusked (Dinotherium). The career, however, of these old-fashioned types was fast drawing to a close, and the antiqueness of the animals was accentuated in India by the presence of various species more advanced in development. Among these were some imposing brutes which, on account of the character of their molar teeth, have received the name of Mastodon, or " nipple tooth" (M. sivalensis). The molars of these animals were ridged across the surface much as in the case of modern elephants; but the ridges were not so numerous, and the inter-ridgeal spaces, instead of being filled with cement, were usually raised up into little knobs or nipples. But it was not merely in possessing teeth which, by reason of their ridged surfaces, resembled in character the teeth of modern elephants, that mastodons were remarkable; for the long-jawed brutes of earlier appearance had their teeth more or less ridged in the same manner. Distinguishing features of the new forms 
consisted of the shortening of the neck (in consequence of which the animal, when standing, could not get its head to the ground); the great reduction of the scaffolding under-jaw ; the verticalising of the sloping face; and the development of the trunk into a powerful grasping organ, with free play in all directions. Mastodons, however, were not elephants as strictly defined; for the teeth of elephants, although ridged, are not " nippled." Mastodons differed also from true elephants, as did the earlier long-chinned forms, in having their tusks partly banded with enamel.

In certain districts some of the proboscideans possessed teeth that had undergone further modifications. The ridges were sharply defined into gable shapes; and the name of " roof tooth" has accordingly been bestowed on these animals (Stegodon). The bosses or nipples had disappeared; and the spaces between the ridges were beginning to be filled with some of the inner tooth substance known as dentine, modified into a cement. The teeth thus resembled very closely those of modern elephants. The tusks, moreover, were no longer enamelled; and the animals may fairly be regarded as having passed out of the Mastodon stage and become true elephants.

Even these were not the most advanced of the trunked animals on India's scenes. Other elephants were munching their food with teeth still more modified ( $E$. planifrons, Euelephas). Their teeth, in fact, were of a quite modern character-very deeply ridged, with the interspaces filled up with cement. The teeth thus had rough though fairly level surfaces, and were excellently adapted for grinding purposes. As after events proved, elephants toothed in this manner were alone destined to survive. Teeth, it need hardly be said, have been an important factor in mammal fortunes.

Horses in vast numbers were on the plains and hill-sides. HORSES Most of them were identical in form with those that were living in Europe at this time-three-toed animals about the size of Shetland ponies, and with grinding teeth of inferior construction to those of modern horses (Hipparion). Evolution, however, in India had proceeded farther; for animals 
were in the herds with teeth of modern type, and the " extra " toes-only dwarfed in other forms-had practically disappeared. The animals, in fact, although of humble stature, were true horses (E. sivalensis). Professor Ewart considers that Arabs, barbs, thoroughbreds, and other modern breeds have mainly sprung from these Indian Pliocene forms.

RHINo- Many must have been the paths made through the grasses CEROSES and brushwood by the heavy tread of rhinoceroses. Frequent, too, must have been their conflicts with sabre-toothed cats, to say nothing of love-quarrels among themselves. In addition to some members of the moribund, hornless line (Aceratherium), there were certain two-horned forms ( $R$. platyrhinus), ancestors probably of the so-called "white rhinoceros" of Africa. Other animals were of a species no members of which ever seem to have wandered beyond the limits of Asia ( $R$. sivalensis, $R$. palaindicus). These animals are generally regarded as having been the ancestors of the onehorned rhinoceroses now living in India. In course of time the one-horned forms entirely supplanted the two-horned in that country.

swine Pigs, resembling for the most part those in Europe, were common in the woods and swamps; but the Indian animals of the wild boar type were, as a rule, of larger size than their European relations. In some cases, indeed, they were as big as mules (S. titan). Others (S. punjabiensis) were extremely small ; and probably were ancestors of the pigmy hogs of our own time (S. salvanius). There were also pigs - not found in Europe-that seem to have been developing in the direction of the Wart-hog, whose forbidding physiognomy is now confined to Africa (Phacochorus).

In addition to these various true pigs there were a number of unconventional, though allied, forms. Old-fashioned swamp-loving brutes with opossum-shaped skulls, and teeth of a partly ruminant character, were surviving here, although they had long been extinct in Europe (Anthracotherium); and other uncanonical pigs were grubbing about with toothpeculiarities still more pronounced (Merycopotamus etc.). All these anomalous creatures were shortly to disappear.

It is possible that some of the pig-like brutes of earlier 
times had adopted more or less aquatic habits, and that their HIPPOdescendants underwent various modifications, and finally POTAMUSES issued as hippopotamuses. However that may have been, hippopotamuses of primitive type-with more teeth than modern forms-were certainly at this time puffing and grunting in Indian waters ( $H$. sivalensis, $H$. iravaticus).

Long-necked giraffes were here and there plucking the GIRAFFES foliage of mimosa and acacia trees. So far as can be ascertained these animals did not differ from modern giraffes. The giraffe family, however, was not represented in India solely by these highly developed forms. As in Europe there were many short-necked and heavily built animals more or less representative of earlier stages of evolution. These vanishing types were well-armed beasts, and in some cases almost attained the dimensions of elephants. Sivatherium, the most notable of this strange company, was crowned with stout antlers, and further armed with a pair of horns, just above the eyes. Such beasts, though unable, like their long-necked relatives, to note the approach of danger at great distances, were of course much better able to take care of themselves when pressed at close quarters. In spite, however, of their bulk and elaborate armature, they were not on the roll of Evolution's effectives.

In the desert regions camels, content with poor fare, CAMELS wandered in comparative safety (Camelus). They were doubtless descendants of North American forms, that had found their way to Asia by a land connection existing on or near the site of Behring Strait. The animals of which remains have been found in India more nearly resembled modern camels than did their Miocene ancestors of the American continent, as their teeth were reduced to the present regulation number. The character, however, of their molars shows that their distinction from lamas was not so great as is the case with camels of our own time.

Goats were scrambling about the heights, preferring, GOATS like the camels, peace and simple fare to the luxurious but risky life in lowland pastures. This is the first appearance of these animals in geological history; but as there were several species, their annals must have commenced in much 
earlier times. For a long time their forerunners probably remained but little distinguishable from primitive antelopes; but in the earlier Pliocene goats had so far progressed as to resemble species now living in the Himalayan mountain ranges. Some with back-curved horns seem to have been closely related to the Thar (Capra sivalensis, Hemitragus); others, similarly horned, were forerunners apparently of ibexes ( $C$. sibirica); whilst yet other forms resembled, at least in their straight spiral horns, the bearded Markhorsthe champions of the goat-world ( $C$. Falconeri).

GOAT-OXEN Other related animals-that possibly had not taken to a mountain life-were of less pronounced development, being goat-like as regards the head, but toothed as oxen (Bucapra). In common with the short-necked giraffes, the ruminant-toothed pig-like animals, the hornless rhinoceroses, the three-toed horses, and the long-chinned, and the bentchinned elephants, these animals stood out in strange contrast with the more modernised mammals. Nor were they OXEN harbingers of oxen, for animals closely allied to the living Yak had already appeared (Bos sivalensis). Primitive bison were also about in herds, and small animals closely allied to our domestic cattle (B. planifrons).

ANTELOPE Whatever horned ruminants may have branched off from primitive antelopes, antelope-life was well developed in the linear direction. The evidence of this in Europe is more than confirmed by that derived from India. Nilgai-looking animals (ancestors of the cow-like short-horned antelopes now living in that country) were certainly on the scene (Boselaphus). Kudus and elands, more or less in an intervolved condition in Europe, were in India separately established (Strepsiceros, Orias). Sable antelopes were also to be seen, no longer characterised, as in the West, by strongly marked affinities with the Oryx (Hippotragus). Whilst fourhorned antelopes (Tetraceros), hartebeests (Bubalis), and small forms of water-buck (Cobus) bore further witness to the varied development which antelope-life had undergone. No nilgai ever seem to have left their Indian habitats; but in course of time kudus, elands, sable antelopes, hartebeests, and water-buck all forsook their ancient haunts; 
and, excepting some hartebeests which did not proceed further than Arabia, wandered away into Africa.

Chevrotains had by this time become almost extinct cHEVRoTAINs in Europe and North America, but in India many of these hornless deer-like animals were haunting the jungles (Tragulus). Owing to their small size, and defenceless condition, they were probably of shy habits, keeping, like their living descendants, in strict retirement during the daytime. Certain species closely allied to water-chevrotains were also on the scene ; but these were not destined for a prolonged career in any part of Asia (Dorcatherium).

Some early ancestral species of deer, which had become DEER extinct in Europe in the last Period, were still living in parts of India; but they were now fast drawing to their end (Palceomeryx). Small antlerless creatures were numerous, and some of these were probably the immediate ancestors of musk-deer (Moschus); whilst other forms, adorned with antlers, were closely allied to the living Swamp deer $(C$. sivalensis). Deer do not appear at any time to have found their way to the continent of Africa.

Ape-life comes out more distinctly than in Europe. PRIMATES "Holy" apes were carrying on their pranks in the woods; and macaques, more or less obscured in the West by strong affinities with the "holies," were here of no doubtful identity (Macacus). Baboons, by the suppression of features which had closely connected their forerunners with man-like apes, had also gained an individuality (Papio). Chimpanzees were no longer in dubious condition by reason of gorilla characteristics (Anthropopithecus); and forms closely allied to gorillas were now in view (Sivapithecus). Well-developed orangs were also abroad, and of more cheerful countenance, it is to be hoped, than their descendants of to-day (Simia).

Here and there, in more open country, small parties ostriches of ostriches were to be seen-their first known appearance in life (Struthio). To judge, however, by primitive features in its anatomy, the "camel-bird" may well have strode the earth long before Pliocene times.

Animals coming down to slake their thirst at lakes and CROCODILES rivers had need of caution, for crocodiles, long-snouted, 
and short-snouted, abounded. Among long-snouted forms ancestors of the modern Ganges gavials were to be seen ( $G$. gangeticus). Some members of this species were formidable creatures, much larger than their present-day descendants. But they were surpassed in their day by monsters over fifty feet in length, belonging to a species now long extinct (Rhamphosuchus). Hippopotamuses, one might suppose, must have found such giants unpleasant bathing companions. It is stated, however, by recent travellers that hippopotamuses and crocodiles live on excellent terms with one another. Possibly this " mixed" bathing was innocently carried on in Pliocene times.

TORTOISES No less remarkable for size were some of the tortoises. Remains have been found of one of these animals whose shell was eight feet in length (Colossochelys atlas). This huge creature, safe in some insular habitat, must have died full of years-possibly at an age of three hundred.

NORTH A journey must now be made from Asia to North America. AMERICA This, as already stated, could be accomplished entirely on land. Unfortunately but little is known of the "new" world life at this time. As in India, among horses with diminishing " extra" toes some one-toed forms were to be seen. Rhinoceroses-never successful in this part of the world-were dying out. By reductions in number both of teeth and toes these animals had certainly drawn nearer to modern rhinoceroses, but they all continued hornless (Aphelops). American rhinoceros-life, therefore, went down to its grave with no slight imperfections on its head. Some descendants of the early camel-like creatures had now definitely developed into lamas (Auchenia). Descendants of some of the Miocene pig-like creatures had distinctly emerged as peccaries (Dicotyles); and old-fashioned elephants, long-chinned and four-tusked (Tetrabelodon), were now supplemented by forms of Mastodon type (Dibelodon).

Burrowing beaver-squirrels, horned on the snout-such as appeared in North America in the Miocene-were still in being (Mylagaulus), and new species had arisen (Epigaulus). From some unknown cause all these curious underground workers became extinct at the close of this epoch of the 
Pliocene. Nor did they ever extend their range beyond their native continent.

In South America the record is almost a blank; but the soutH peculiar fauna was doubtless prosperous, as may be inferred AMERICA from its condition in the later part of the Period. This continent had for a very long time been separate from its northern neighbour, and its animal life had lagged far behind. By the upheaval, however, of the Isthmus of Panama in early Pliocene times, great additions to the native fauna became possible. The tariff wall, so to speak, had ceased to be; and Southern American mammal-products were no longer "protected." Northern mammals were now finding their way to the long-inaccessible continent ; and, as a countermove, a few armadillos embraced the opportunity of trying their fortunes in the North (Carioderma). 


\section{CAINOZOIC AGE}

\section{PLIOCENE PERIOD}

\section{LATER EPOCH}

LATER Pliocene strata record many changes in animal life, both in development and distribution. The old-fashioned long-chinned elephants (Tetrabelodon), and the brutes with tusks curving down from a bent under-jaw (Dinotherium), seem to have become quite extinct, not only in Europe, but in other lands.

EUROPE Europe was now invaded by mastodons ( $M$. arvernensis, ELEPHANTS $M$. Borsoni), and thither also had true elephants made their way. Among the latter were some fine beasts (E. meridionalis), standing fully fourteen feet high-three feet taller than "Jumbo" of recent fame.

HORSES One-toed horses which, so far as is known, were confined in the earlier Pliocene to Asia and North America, were now grazing on European pastures. Some seem to have been of zebra character (E. stenonis); others were possibly ancestors of Exmoor and other ponies of the socalled Keltic type (E. ligeris). Old-fashioned horses with " extra" toes were still to be seen, but they were insignificant in number, and fast disappearing (Hipparion).

TAPIRS Tapirs-numerous on the continent in earlier Pliocene times-were evidently finding conditions unfavourable, for

RHINo- they were much reduced in numbers. Rhinoceroses, howCEROSES ever, still continued in force ; and some of them were now furnished with big horns, effectively supported by increased

HIPPO- ossifications on the snout ( $R$. etruscus). Hippopotamuses POTAMUSES were bathing in the waters. These European forms, owing to a reduced dentition, were more in line with modern hippo- 



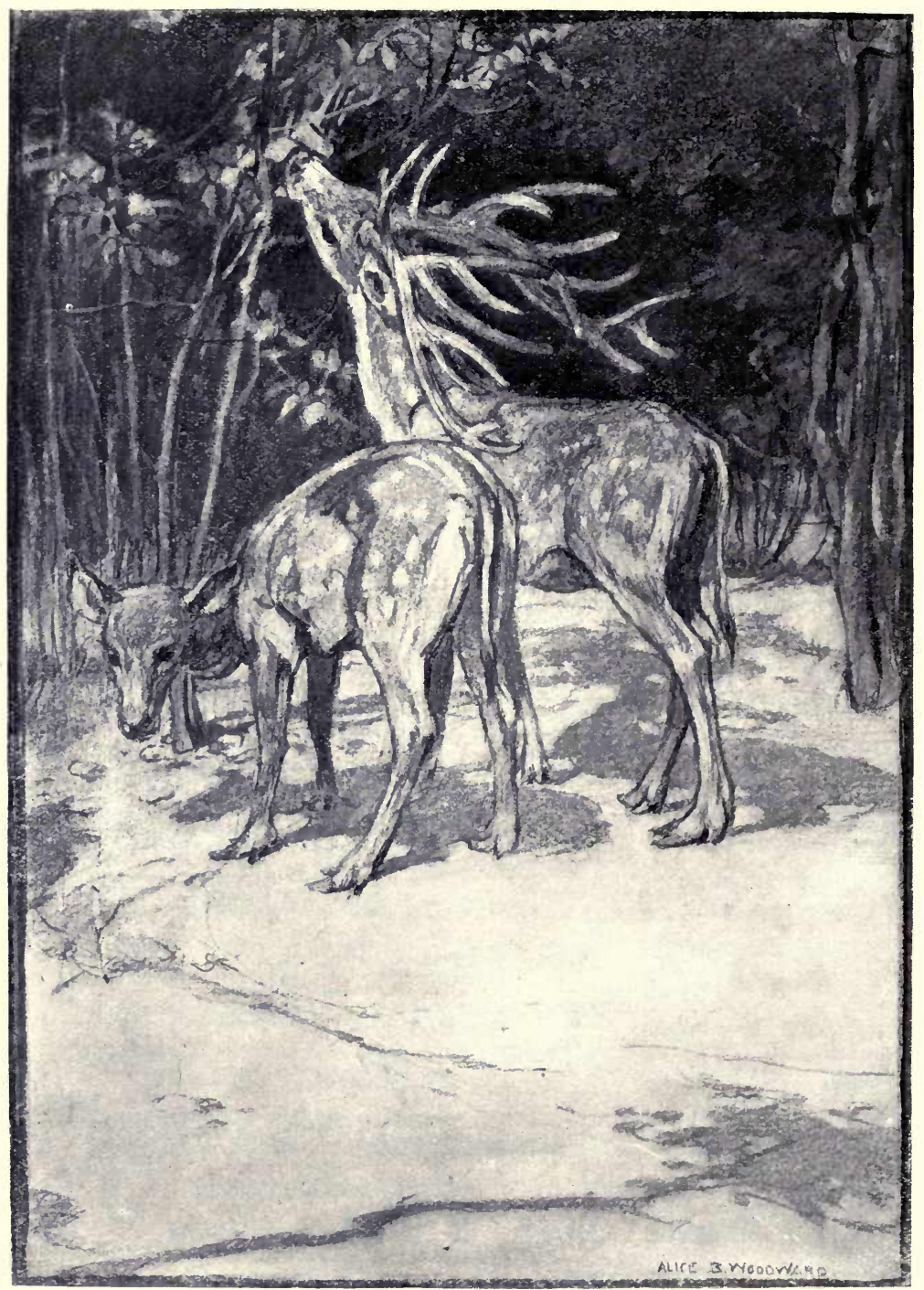

CERVUS SEDGWICKI

Remains found in later Pliocene of Great Britain and Northern Italy

[To face page 183 
potamuses than their Indian forerunners of the early Pliocene (H. amphibius). Ancestors of the modern wild boars of SwINE

Europe were now to be seen among the swine (S. scrofa); also some new pig-forms (S. arvernensis). The latter seem to have been related to the Bush pigs of Africa, and had, it may be supposed, come from that continent-probably by land-routes that have long since been submerged. Giraffes had migrated to other scenes. Antelopes were still in Europe, GIRAFFES but, like the tapirs, they were greatly diminished in number. Many of them, doubtless, had crossed to Africa. Ruminants, however, were well represented by oxen, and several species oxEN of deer. Some of the latter were simply antlered, and appear DEER to have been descendants of the muntjac-like deer of the earlier Pliocene (Cervulus). Whilst other forms possessed antlers of roe-deer pattern (C. cusanus); and forefathers of the red deer were also exploring the plains ( $C$. elephus).

Remains have been found of a wonderfully antlered form (C. Sedgwicki). This animal-probably broad-footed like the Marsh Deer, and well-tailed like the Eland-possessed antlers of excessive size and elaboration. Indeed, the armature must have been too cumbersome and complex for effective service. As exaggerated development is often a symptom of racial old age, this over-antlered form probably represented a race of deer approaching extinction. The history of the race in its youth and prime is quite unknown. Indeed, almost in a single breath, one gives greeting and farewell to these picturesque creatures.

Oxen, although in Asia in the earlier Pliocene, do not oxen appear to have invaded Europe during that epoch, but they were certainly there in the latter part of the Period. They may well have been of more active habits than our domestic cattle; but probably they differed very little from them in structure (Bos primigenius). It is doubtful, however, if any of the females on either continent had as yet been provided with horns.

Wolves abounded in Europe; but the "sabre-toothed" CARNIVORES cats still continued the most formidable of the carnivores (Macharodus). The latter, however, doubtless paid most attention to mastodons, elephants, and rhinoceroses, whose 
tough integuments they were specially qualified to penetrate. Among numerous other cat-forms some were shaping, so to speak, into lions, some into lynxes. True bears were numerous at this time in Europe, where also hyænas were still to be seen.

PRIMATES Carnivores in quest of prey no longer caught sight of anthropoid or man-like apes, for these had now deserted Europe. Primates of lower rank were still represented, at least in the southern parts of the continent, by "Holy Apes" (Semnopithecus). Macaques or Barbary Apes were also in the forests (Macacus); as well as some long-headed apes of a kind now quite unknown (Dolichopithecus).

CLIMATE The departure of many animals from Europe was doubtless owing to a fall in the temperature, and not a few that remained in the northern regions were finding themselves in " the winter of their discontent." A moist and almost tropical climate had prevailed on the continent during the Eocene and Oligocene Periods, and had continued through the greater portion of the Miocene. Towards the close of the last Period it is clear that climatic changes were in progress, as the palms ceased to flourish. That the temperature was still declining in the early Pliocene is shown by the continued dwindling of the palms, the suppression of much warmth-loving vegetation, the increase of grasses and deciduous trees, and the retreat of crocodiles. In the later Pliocene, palms and other tropical and subtropical growths seem to have disappeared entirely, and the verdant scenes presented an aspect much as that of to-day.

Further evidence of a falling temperature in Europe is afforded by the migrations of molluscan life. In Eocene and Oligocene times the molluscs more or less resembled or belonged to species that now thrive in tropical regions. Towards the close of the Miocene various warm-water species had moved southward. This migration continued in the Pliocene, and the relinquished haunts were occupied by hardier molluscs from northern latitudes.

NORTH Little has as yet been discovered of later Pliocene life AMERICA in North America. Some remains have been found which suggest lion-like animals; and there is evidence that some 



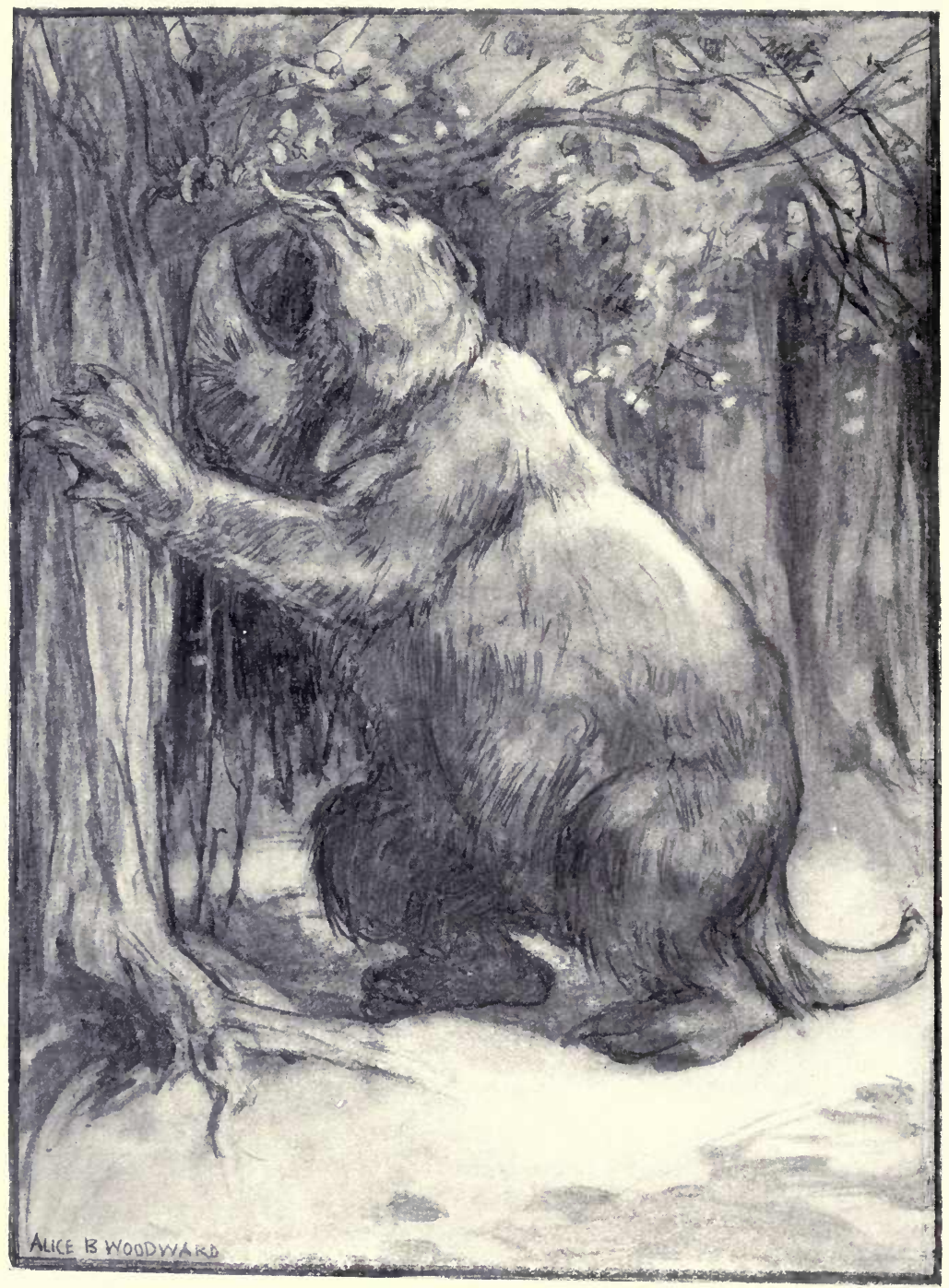

MEGATHERIUN]

A gigantic ground-sloth

[To face page 185 
of the horses were taller than the pony-sized creatures of earlier times. Ground-sloths of South America had now crossed the Isthmus (Megalonyx), adding a new feature to the fauna.

Many animals had quitted the northern for the southern continent, availing themselves of the recently raised land connection. Horses, mastodons, tapirs, lamas, and other herbivorous emigrants were now well south of the isthmus; and carnivores, dog-like and cat-like, were not losing sight of their commissariat. Marsupial life was augmented by the arrival of some good-sized opossums.

This invasion cannot have been without effect on the southern fauna. But the continent was of vast extent, and, so far as can be gathered, the development of the native animals was not as a rule seriously checked. In some regions, indeed, it progressed remarkably. Ground-sloths of larger size than the Miocene forms were now in the forests (Megatherium, Mylodon); and other Edentates were abroad, resembling ant-eaters at least as regards the skull (Scelidotherium). Armadillo-life was not only characterised by much larger animals, but by a great variety of forms rigidly encased. Some of the new kinds were shielded more elaborately than their forerunners, and their tails were protected by bony tubes and rings (Dadicurus, Panocthus). Ground-sloths and armadillos were, therefore, rising to the occasion; and, as their later history will show, they had by no means exhausted their adaptabilities.

The various strange types of hoofed animals, such as lived in South America in the Miocene, had by this time undergone many changes and some losses. The astrapotheres, remarkable for doubly-tusked brutes of rhinoceros size, had become extinct. As some animals more or less allied, but less formidably armed, were still in existence, the " lightningbeasts" can hardly have perished from lack of brute force. Brute force, however, had long been a declining power in creation; and it was probably owing in the main to mental deficiencies that the astrapotheres failed to survive.

Among their relatives, known as toxodonts, and suggestive ToxoDonTs in appearance of coneys overgrown, new species had arisen.

SOUTH

AMERICA

EDENTATES

ASTRA-

POTHERES 
These for the most part consisted of larger animals than their Miocene forerunners; and it is evident from their teeth that they were converging more closely to creatures of the rodent

TYPOTHERES

LITOPTERNS

AUSTRALIA

MARSUPIALS type (Toxodontotherium). The still more rodent-like typotheres, with an aspect of guinea-pigs grown to giants, had also increased in size.

The lama-like litopterns do not seem to have improved in stature; but it is of interest to note that in the case of some of the animals the breathing aperture in the skull was located higher up than in the Miocene forms (Scalabrina). This suggests that a proboscis was in process of evolution. The nasal modification, as will be seen, was carried still further in litopterns of the next Period. The small forms, which had anticipated horses in developing one-toed feet, seem by this time to have been on the verge of extinction (Proterotheriida); whilst the antiquated hippopotamus-bears had quite passed away (Pyrotherium).

Although there were losses, it must be admitted that the native fauna, at least in some regions, continued to prosper. In parts of the continent, however, the quaint aborigines were experiencing different treatment. Alien carnivores were levying heavy tributes, and extensive areas of fertile land were being appropriated by hordes of new herbivores. In short, a state of affairs was in prospect analogous to that experienced by the South American natives when the Spaniards invaded their dominions.

Whilst the native fauna of South America had, as a whole, lagged behind the animal-development in most parts of the world, a still more backward condition existed in Australia. Indeed, no mammals of higher rank than marsupials inhabited that territory. This was doubtless owing to its having become enisled before the commencement of the Eocene Period. It had thus been cut off from the great originating countries; and the mammal life-already far committed to marsupialism-proceeded with limited anatomical resources.

These resources, though restricted in scope, came well into play, as testified by the variety of the fauna. Generalised creatures with affinities to wombats as well as to kangaroos 


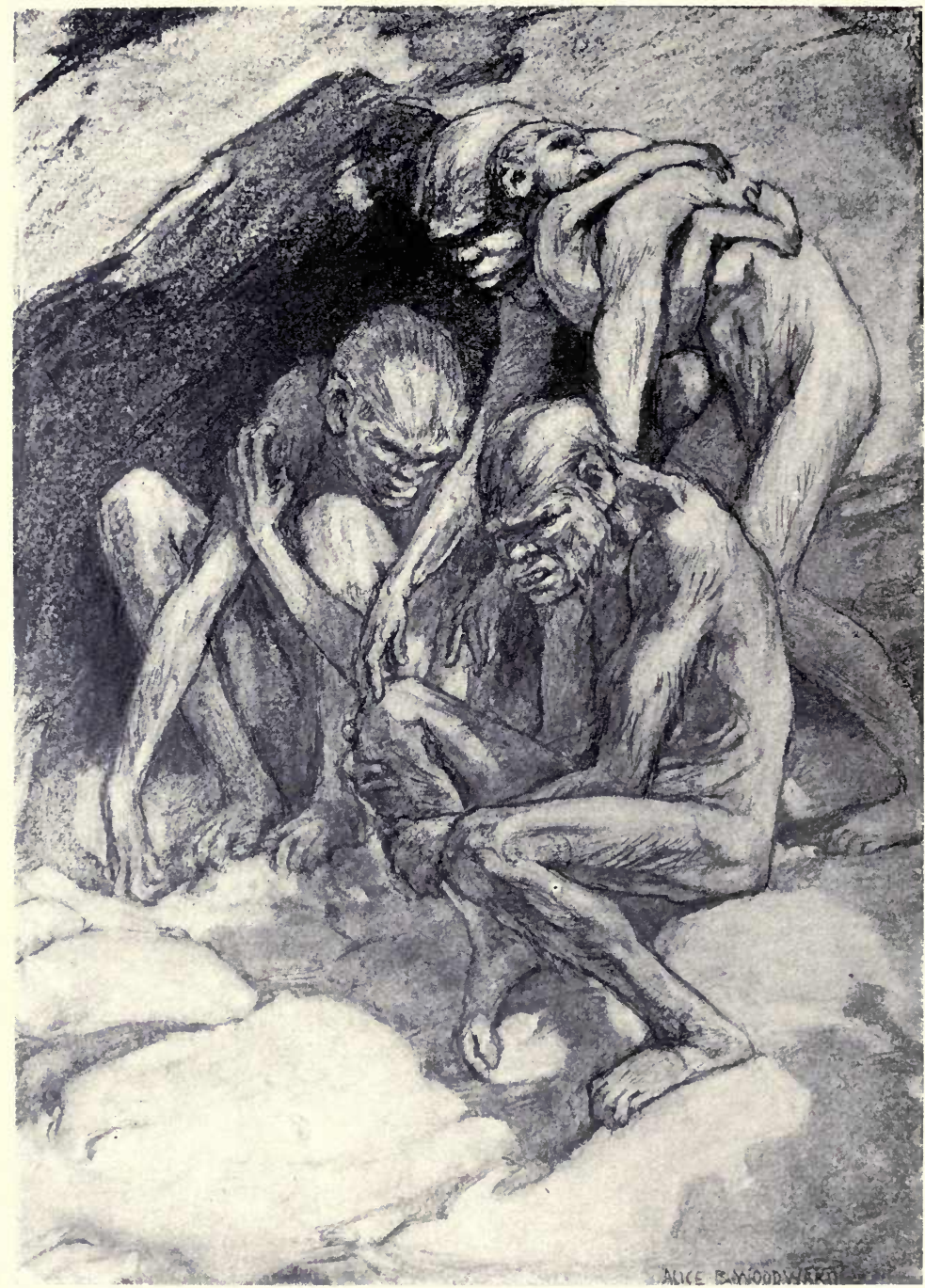


were about the land (Diprotodon) ; and also animals specialised into one or other of those forms (Phascolomys, Macropus). There were also creatures somewhat of phalanger type, and known as "pouched lions" (Thylacoleo); and animals civetlike in outward appearance were roaming about (Dasyurus). But it was in the next Period that Australian marsupials reached the climax of their development.

As anthropoid or man-like apes had emerged in the Miocene, APES it would cause no surprise if proof were found of contemporary AND MAN creatures of still higher type. It is not, of course, supposed that man is descended from gorillas, chimpanzees, or other of the anthropoid apes ; but it is generally thought that man and the anthropoids have come down from a common stock, represented possibly by Propliopithecus of the late Eocene. Some members of the stock had at some time diverged, and resulted in the Miocene as man-like apes. And it is not unreasonable to suppose that there had been another divergence from the stock in the direction of human beings. If such were the case it may fairly be assumed that these more progressive creatures-having possibly developed a taste for meat-had gained greater brain power, and were no longer so intimidated by their surroundings as to pass most of their lives in the trees of the forests. Although at first indifferent pedestrians, such individuals, as their walking habits became confirmed, would tend naturally to assume the erect posture.

There is, however, no satisfactory evidence of such superior PITHECanimals either in Oligocene or Miocene times; but it is clear ANTHROPUS from remains found by Eugène Dubois in 1894 in Java that such were living in the latter part of the Pliocene (Pithecanthropus erectus). These Javan remains are very scanty, consisting only of the upper portion of a skull, a thigh-bone, and three teeth. These are presumably all relics of one individual, that stood probably about five feet in height. The skull has massive ape-like brow-ridges; but it must have contained brains larger than those of any anthropoid ape now existing, and, indeed, equal in amount to those of some of the lowest savages of to-day. The thigh-bone cannot be described definitely as that of a human being, 
as it has some simian characters; and the same remark applies to the teeth. It seems, therefore, that Pithecanthropus fell short of being a human creature, but was something above an ape. He may, therefore, be regarded as a member of the more progressive section that had diverged from the stock in which anthropoids and men had existed as intermixed possibilities. He may, in short, be termed a super-ape.

As to his manner of life but little can be surmised. His food probably consisted of small mammals, eggs, roots, and berries. Big game certainly haunted his neighbourhood - elephants, rhinoceroses, and hippopotamuses; and there were also wild boar and oxen. But it is doubtful if he had the wit or the power to overcome any of these animals. The particular individual of which remains have been found cannot, it may be mentioned, have been of very active habits; for the state of his thigh-bone shows that he was a martyr to rheumatic gout. This affliction, it is to be feared, he had to abide without remedy.

Whether he and his fellows-for there must have been others of his kind-had learned to manufacture tools and weapons cannot, for want of evidence, be determined. It is highly probable they had some skill in chipping stones, for rude flint implements, known as eoliths, have certainly been brought to light from later Pliocene strata. These relics, however, have not been found in Java.

Many eoliths, indeed, have been discovered in equivalent strata of France and England. It would seem, therefore, that in the later Pliocene, super-apes, if not men, were living in western Europe. No other signs, however, of such beings have been discovered. The increasing coolness of the climate leads one to suppose that these explorers, if not astute enough to clothe themselves with the skins of animals, must have had their bodies well covered with hair. In any case, their conditions must have become exceedingly trying as the Great Glaciation approached. 



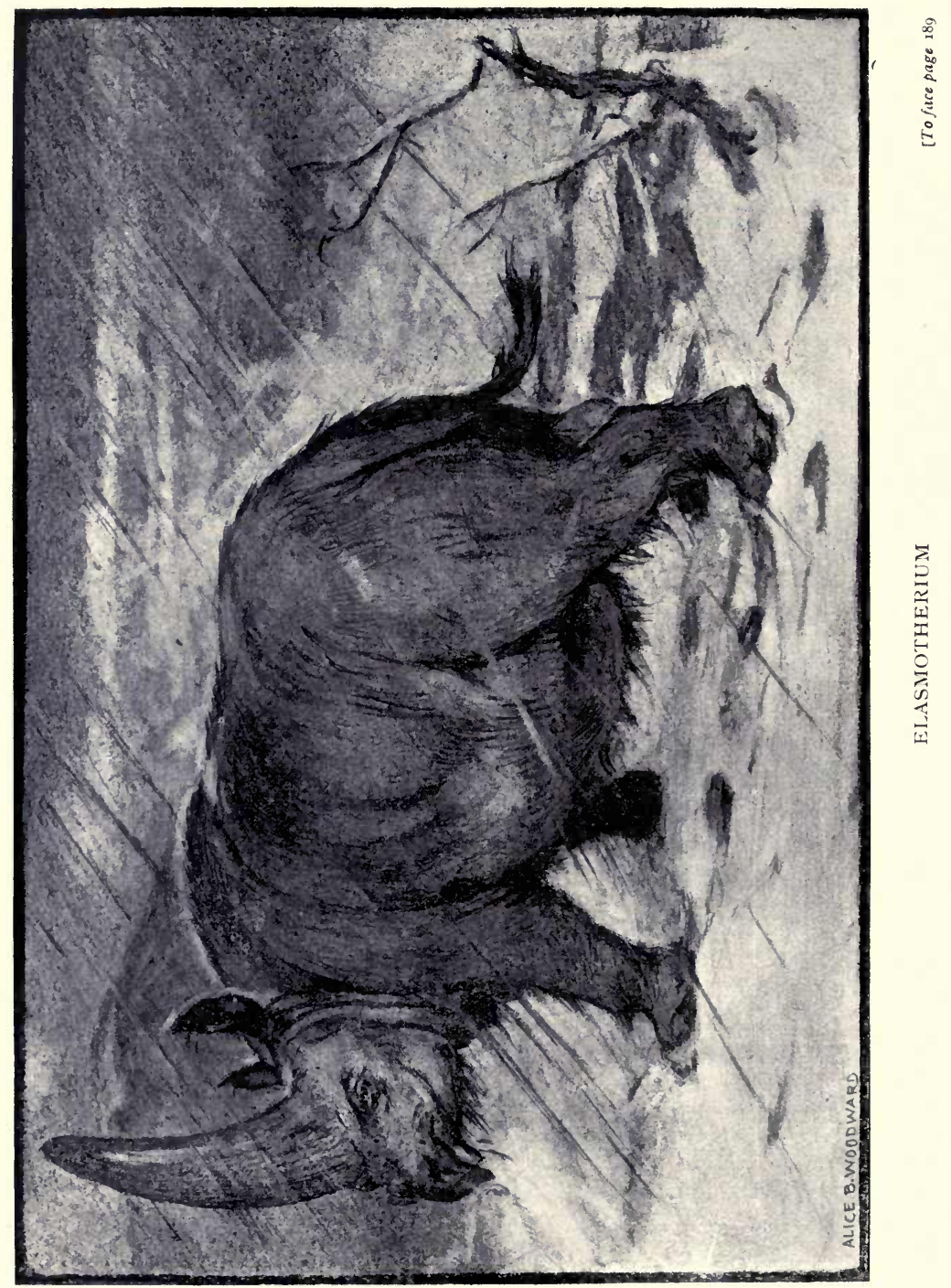




\section{QUATERNARY AGE}

\section{PLEISTOCENE PERIOD}

THE temperature of the northern hemisphere had been more or less declining ever since the later Miocene. This, no doubt, had in great part been owing to long-sustained land-upheavals. At the close of the Pliocene and the commencement of the Pleistocene the cold was steadily increasing.

Apes and tapirs, it would seem, had migrated from Europe EUROPE by this time; and climate had doubtless caused many other migrations, and also some extinctions. The temperature, however, had not sunk so low as to prevent hippopotamuses making excursions to the continent, at least in the summer months. Huge elephants of the same species as those of the last Period were also still able to find suitable accommodation (E. meridionalis); and the presence of some straight-tusked forms testified to fresh arrivals of proboscidean life ( $E$. antiquus). Horses of a new species were now on the plains (E. caballus), as well as descendants of the zebra-like forms of the Pliocene (E. stenonis). The new-comers had migrated probably from some inhospitable scenes in the north of Asia; for they bore close resemblance to the wild horses now living on the deserts of that continent (E. Przewalskii). Other forms appear to have been intermediate between the lastnamed and the zebra-like animals (E. Heidelbergensis).

Climate, however, in the more northern latitudes was fast driving life down from old abodes. Many of the trees and other growths in those regions must have been suffering from the cold, for even the hardy Spruce Fir (Abies excelsa) was beginning to retreat from its far northern ground. And wolves, gluttons or wolverines (Gulo), elk (Alces latifrons), musk-oxen (O. moschatus), mountain sheep (O. Savigni), and 
grizzly cave-bears ( $U$. spelaus) were wandering far south of ancient haunts.

PRE-GLACIAL There is some scanty evidence of the presence of man MAN in Europe at this time (Homo Heidelbergensis). The remains are too imperfect to afford much information as to his condition of development. The evidence points to an ape-like physiognomy - an under-jaw massive and chinless, and characterised by other pithecoid features. The roots of the teeth were remarkably stout and strong, but the crowns were of human character. The powerful jaw must have had great crushing power, and the man, one may well suppose, was much better at biting than at talking. His speech indeed, such as it was, probably required considerable gesture and grimace in order to render it intelligible. It seems to have been the custom of the race to bury flint flakes with the dead. Possibly, therefore, belief was held in an after-life in which implements would still be required. Physically these people may not have differed much from the contemporary anthropoid apes-fellow-descendants from a common stock; but in the matter of culture the difference, one may infer, was already well pronounced.

GLACiation As the Period advanced, land-upheavals continued, and refrigeration of the climate became more marked. Vast elevated areas, especially in Scandinavia, became the gathering grounds of immense quantities of snow ; and huge glaciers issuing from the snow-fields streamed through the valleys, and over the plains. They even invaded the Atlantic; but here they were soon undermined and broken up into bergs. Great migrations of the fauna must have ensued in all the affected lands, and much of it doubtless perished. Forlorn enough must have been the look of the landscapes. Trees withered away, or grew scarcely bigger than bushes; and on once genial and fertile scenes of lower latitudes, polar willows (Salix polaris), dwarf birches (Betula nana), boreal mosses (Hypnum turgescens) and other arctic migrants alone possessed the ground.

ASIA Similar conditions prevailed in parts of Asia. Great glaciers were travelling from the Ural Mountains in an easterly direction; and Siberia was threatened with ex- 



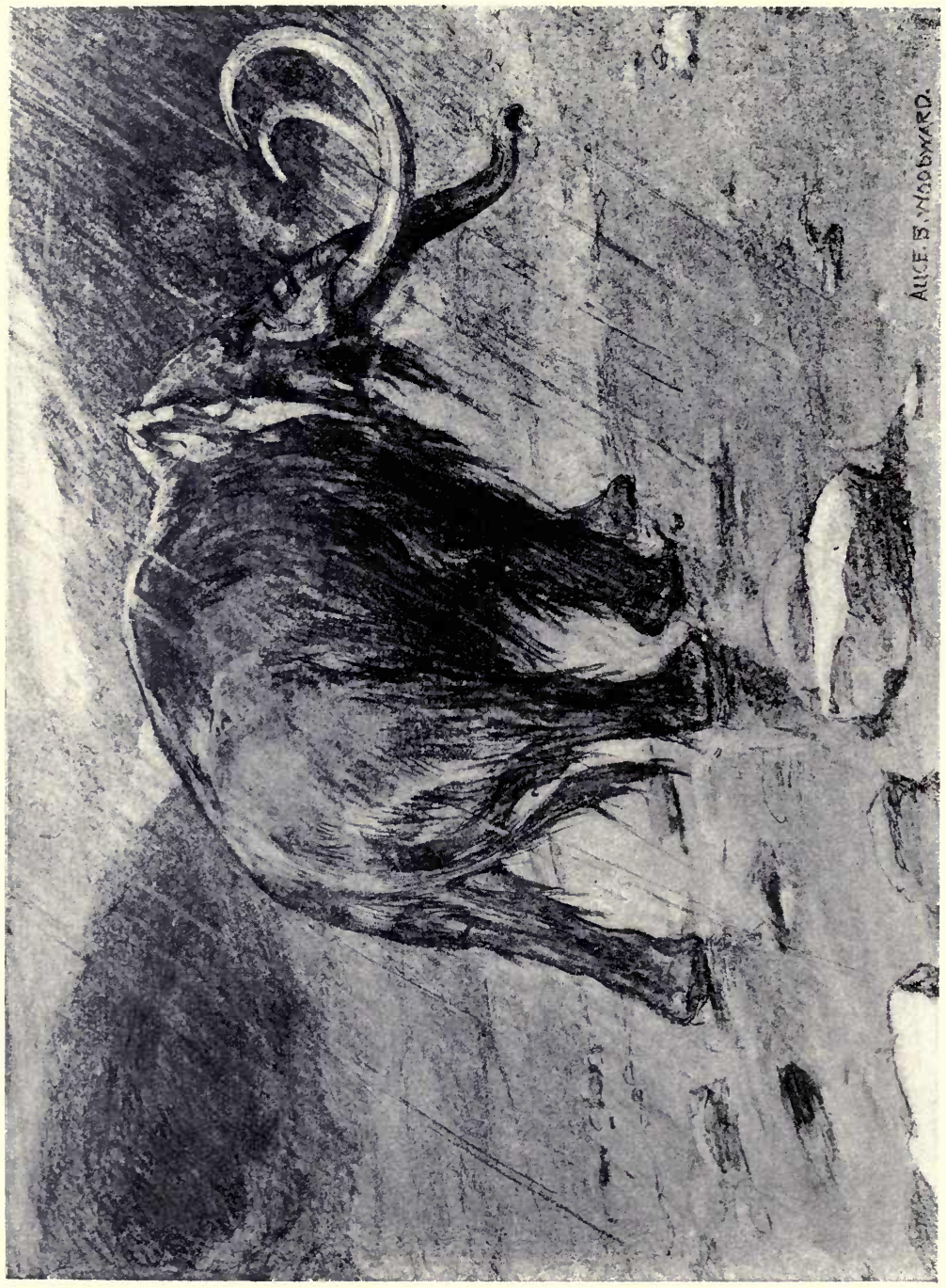


ceptionally severe conditions. Thick-haired mammothelephants with big curling tusks ( $E$. primigenius), and rhinoceroses in woolly apparel ( $R$. tichorhinus), that had long gathered sustenance in those frosty regions from spruces and junipers, were now seeking new feeding grounds. Many of the mammoths, no doubt, were moving to less inhospitable parts of Asia ; some were seeking European pastures; others were migrating to North America on the land-way then existing in the Behring Strait region. Some of the woolly rhinoceroses wandered into Europe-among them a few curious forms with a huge horn rising unicorn-like from the forehead (Elasmotherium). So far as is known no rhinoceroses faced the terrible north-eastern journey, undertaken by some of the mammoths.

Nor were the central and southern parts of Asia wholly exempt from great ice visitations. The Himalayas certainly formed a centre for ice dispersal; and numerous glaciers rolled to the south and west from the snow-hidden mountains.

From elevated lands of Labrador in the east, from central NORTH snow-fields amassed in Keewatin, and from half-buried "Rockies" away in the west, glaciers were bringing vast stretches of North America much into the condition of that of northern Europe.

The increase of the cold had been gradual; and many animals by timely retreat had doubtless escaped suffering and death. The destruction of life, however, in North America must have been very great, as well as in Europe and Asia.

In the long course of years the glaciers, increasing in EUROPE volume, rose high up the mountain-sides that hemmed them in. Finally the heights were overridden; and numerous glaciers, uniting across the topmost ridges, formed vast sheets of continuous ice. An ice-sheet seems to have extended practically over the whole of northern Europe; for evidence shows that Ireland, Wales, Scotland, England (as far as the Thames Valley), the North Sea, Norway, Sweden, Denmark, Holland, Germany (as far south as Dresden), the greater part of Russia, and the whole of the Baltic Sea were covered with ice and snow. Switzerland 
also was completely overspread; but the ice-sheet here seems to have been formed independently by local glaciers. Over scenes in Germany, where in earlier times palms and cinnamons had flourished, polar bears were roaming. Great indeed had been the change.

NORTH The moraines show that the southern extension of the AMERICA sheet in North America was much greater in the east than in the west; but more than half the continent was covered with thick ice from the Atlantic to the Pacific. The massiveness of the ice in some regions was enormous. In parts of North America (and in parts of Scandinavia) the thickness must have been fully 3000 feet. And in regions far beyond the limits of the ice-sheets the cold must have been intense.

EUROPE These conditions, varied by occasional relaxations, continued for a long time. At length in Europe, owing chiefly to land subsidences in the more northern latitudes, a steady change towards mild conditions set in. Exposed masses of pushed-on debris now marked the lost frontiers of the icy sway. Traversed rocks reappeared, scratched and polished after long entombment ; and huge glacier-transported boulders were to be seen perched on mountain-tops, hundreds of miles away from their pre-glacial abodes.

INTER- We now reach in Europe what can only be called an InterGLACIAL glacial Epoch, for in course of time a second Great Glaciation EPOCH IN took place. Although there were several relaxations of the EUROPE intense cold in North America, it is not at all clear that there was any inter-glacial epoch of importance such as occurred in Europe.

The gradual melting of the ice, and an abundant rainfall, resulted in great floods, and the removal of vast amounts of surface earth from place to place. New lakes were formed in basins hollowed out by the glaciers; and in some cases old rivers, finding their former channels blocked by glacial debris, were making their way by new routes to the sea.

The change of climate in Europe, involving the recession of the ice, was followed naturally by many migrations of life. Polar willows, dwarf birches, hardy forms of saxifrage, and other cold-climate growths were gradually advancing 
over the ice-vacated lands. Spruces and junipers were also northward bound, and grasses were once more carpeting desolated valleys and plains. Poplars, oaks, hornbeams, sycamores, and other deciduous trees were also coming up from southern exile; and old landscapes, open again to sunshine, slowly recovered a long-lost wealth and beauty.

Many vigorous species long survived in the southerly latitudes to which they had been driven; and as the warmth increased they sought and found congenial conditions on hill and mountain altitudes.

Northward, too, was animal life pressing, with seals and polar bears in the van, followed by mammoths, woolly rhinoceroses, wolverines, musk-oxen, elk, and other hardy animals.

What, it may be asked, had become of the descendants of the European Pliocene fauna when the Great Glaciation was prevailing - the elephants, rhinoceroses, hippopotamuses, horses, deer, "sabre-toothed" cats, and other forms of life? Some species had, no doubt, died out. Some had found congenial quarters in the south of Europe, others had crossed to Africa. As the refrigeration increased great migrations must have taken place to the latter continent; for it was easy of access, being connected at that time not only with Spain across the Gibraltar Strait, but with Italy also by continuous land now represented only by Malta and Sicily. As genial conditions returned, the exiled species sought out the haunts of their forefathers; and straighttusked elephants ( $E$. antiquus), rhinoceroses of a non-woolly kind ( $R$. etruscus), hippopotamuses, and other descendants of the earlier fauna were to be seen well north of the Mediterranean. The species of zebra-like horses which had arrived in Europe in the later Pliocene (E. stenonis), and was represented there in the early Pleistocene, seems to have become extinct at the time of the Great Glaciation. The later species arriving in Europe in the early part of the Pleistocene, and resembling the wild horses now living in Asia, was certainly again in Europe when the ice was in retreat (E. caballus). The species of elephant in view in the early portion of the Period, and notable for extra- 
ordinarily big animals, appears to have become extinct (E. meridionalis). "Sabre-toothed" cats were certainly in Europe at the commencement of the Period, but it is not clear if they formed a part of the inter-glacial fauna. The principal butchers on the continent seem to have been big lions of African type (Felis spelaa).

SIBERIA The condition of Siberia during the Inter-glacial Epoch cannot, for want of data, be determined. It seems probable that its climatic fluctuations had not been moving pari passu with those of Europe. At any rate an influx of animals from western Siberia to Europe took place during the Inter-glacial Epoch; and the various emigrants formed a significant portion of the fauna. There may have been some important changes in Siberian climate to prompt this movement; or it may have been the result of greater facilities for migration, owing to some redistribution of land and water on the border lands. The route of the emigrants seems to have been between the Ural Mountains and the Caspian Sea, across the site of the moss-clad, treeless plains now known as the Kirghiz Steppes. From these dreary scenes herds of reindeer (Rangifer tarandus), and saiga antelope (Saiga tartarica)

EUROPE were now appearing in various parts of Europe. Arctic foxes (C. lagopus), and badgers (Meles) were also among the new arrivals; and elk, musk-oxen, wolverines, and " cave " bears-frequenters of Europe during the Glaciationwere greatly reinforced. The so-called Gigantic Irish Deer (C. giganteus) was also in Europe at this time. It is not clear if the species originated in Europe; in later times it was represented in Ireland in great numbers. These animals were closely allied to the fallow deer, and must have been magnificent creatures. The antlers in some instances measured as much as twelve feet across, and weighed over a hundredweight.

There was thus a strange collection of life on the continent during the Inter-glacial Epoch. The climate, however, was of course not uniform, and must have varied from warm and temperate to an intense cold in the plateaux and mountainous regions. A great deal of the land, released from ice, probably had only a scanty covering of mosses and scrub 
vegetation; but such forlorn scenes were well suited at least to the steppe-loving reindeer and the saiga antelope.

Here was a happy hunting-ground for man, and there is evidence of his presence. Indeed, the pursuit of prey may well have drawn him to this well-stocked scene. As to his abilities as a hunter, it is impossible to form a precise idea. Many of the animals were probably too formidable for him or too fleet of foot ; and except in the case of sickly animals, and those disabled by accident, capture of big game must have required considerable strategy. He certainly possessed pieces of flint chipped down to a sharp edge, and in some cases rudely wrought into scraper-form. How far these implements-known as palæoliths-were useful in the chase it is impossible to say. One cannot imagine their effectiveness to have been great; and as a rule it was probably by means of cunningly concealed pits that big game was captured. When, however, the prey had been secured, the implements, no doubt, proved highly serviceable for cutting up the carcase for food, and scraping out the skin for clothing.

These implements, although rudely manufactured, exhibit, nevertheless, more skilful workmanship than the eoliths of the last Period. And the better workmanship tends to show that the possessors were more highly cultured than the men or super-apes of the Pliocene. The human race was progressing, but its hardships and dangers must have been very great.

If the remains discovered in the Neander Valley near Stuttgart may be taken as relating to this time, these interglacial hunters were sturdily built, and stood about five and a half feet in height. Their skulls were of a low type, much depressed at the top; and their foreheads were receding, and without width or depth. Their brow-ridges, like those of Pithecanthropus, were massive and projecting; and this must have given them an ape-like physiognomy. Their cranial capacity was, however, much greater than that of the Javan super-ape. Some parts of the skeleton-notably the outer bone of the forearm and the shoulder-bladepossessed simian characters. The thigh-bones in being slightly curved resembled those of human beings, and so 
differed from the straight, ape-like thigh-bone of Pithecanthropus. As regards hands, the individuals were quite human.

It is clear from the remains that one of these inter-glacial hunters met with a severe accident, resulting in the dislocation of his elbow-joint. This injury had been neglected, owing probably to sheer ignorance as to how to deal with it.

Other remains recently (I907) discovered also probably belong to this epoch ( $H$. mousteriensis Hauseri). These men had markedly receding foreheads. Their jaws were much protruded, giving the face an ape-like muzzle, such as is possessed by some of the Australian aborigines. They also resembled those savages - and, indeed, all negroidsin possessing wide and flattened noses. Their dentition was of a powerful character; and the teeth, in being very strongly rooted, possessed a simian character. In disquieting circumstances these were doubtless displayed in true animal style.

The aborigines of Australia probably come nearest to these old wandering hunters, both as regards physiognomy and culture. But even they - the lowest of living savagespossess skulls of higher type.

Thus then Europe revived, and became the scene of a miscellany of brute life such as had never before been gathered within her borders. Man, too, was there; destined to kingship, but as yet far from the establishment of his sovereignty.

These inter-glacial conditions, including minor fluctuations, may have lasted some thousands of years; but it is. impossible to ascertain their duration. Certain it is that in course of time, owing chiefly to land-upheavals, there was. a persistent lowering of temperature; and great glacial streams once more overran northern Europe.

RE-GLACIA- Gradually Ireland and Scotland were re-buried under ice TION OF and snow; so also were parts of northern England. The EUROPE North Sea was frozen over from coast to coast ; and Norway, Sweden, Finland, and Denmark were once again overwhelmed. The ice-sheet, however, never became so extensive as at the maximum of the first glaciation. The greater part of England, 


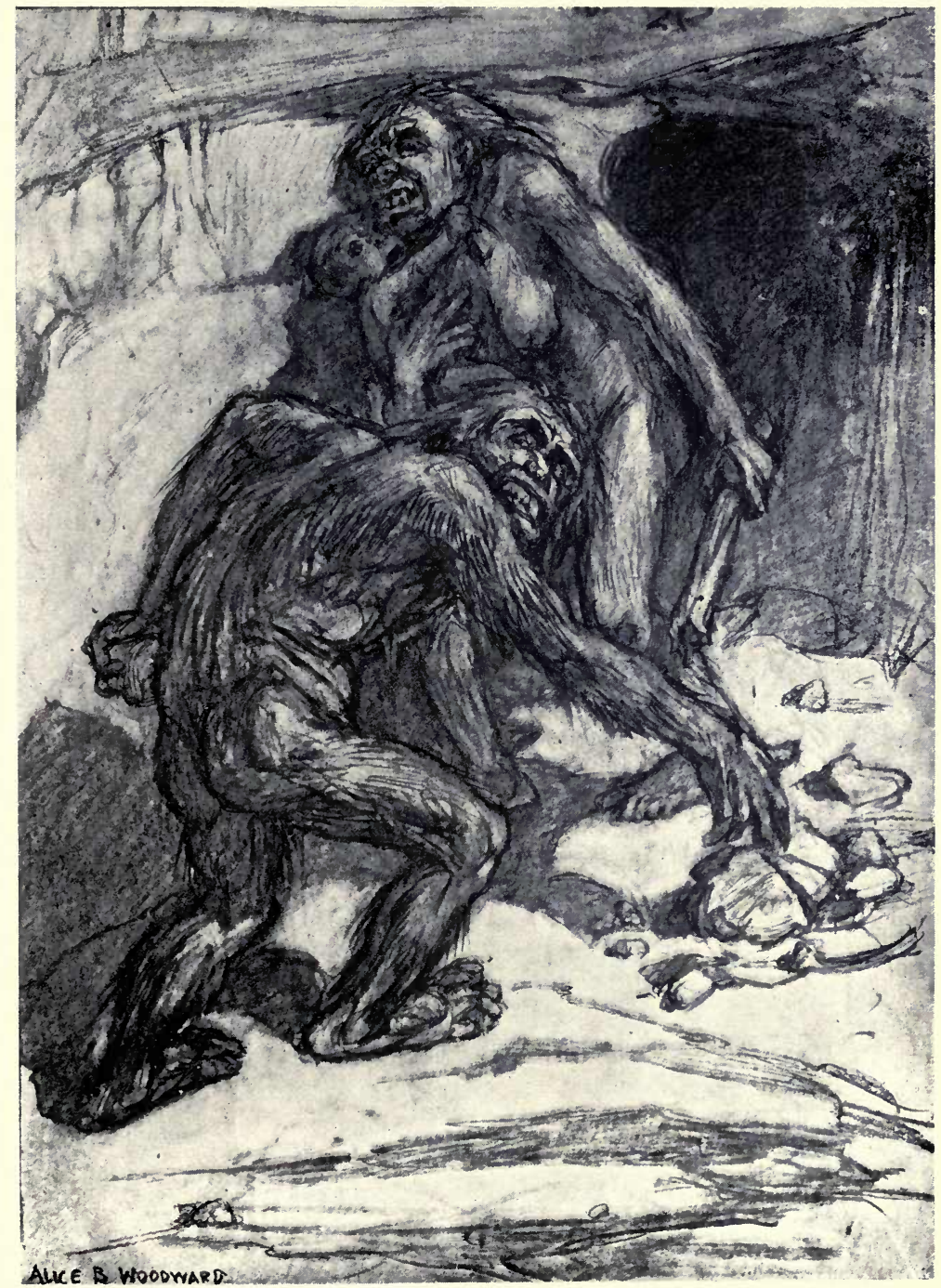

HOMO MOUSTERIENSIS 

and the whole of Holland, escaped it ; its southern reach was less in Germany: and nearly the whole of Russia seems to have been free. Switzerland, however, was again entombed by locally formed glaciers.

This second glaciation, though less widespread than the first, must have entailed many migrations, and some extinctions of life. Where retreat was not cut off, animals, that had penetrated to the north, naturally moved down to lower latitudes, and elephants and hippopotamuses probably migrated as far south as Africa. At the same time northern species of plants spread in southerly directions, following in the wake of temperate species seeking congenial conditions further south. The cold must, at times, have been very great, even in central Europe, for reindeer, arctic foxes, and wolverines occasionally came as far south as the Mediterranean.

As the conditions in Siberia seem at this time not to have SIBERIA been exceptionally severe, and as most of Russia was free of the ice-sheet, some of the mammoths, woolly rhinoceroses, and other descendants of Siberian emigrants in Europe may have returned to the lands of their forefathers. It is likely, however, that most of them remained in Europe, as in many parts they must have found the climate quite tolerable and food sufficient. And if they remained in force, so also would carnivores.

Long was the greater part of northern Europe under EUROPE the icy mantle; and, save for the sweep of air currents, the silentness of vast expanses of country remained unbroken.

But all things, however unpleasant, come to an end. Upheaved lands in course of time subsided; the accumulation of snow on the great gathering grounds grew less and less; the vast ice-sheet was again in retreat, and great migrations of life ensued. This retreat of the ice may be spoken of as final, for the earth has not since experienced a glacial visitation.

There is no evidence to show if the descendants of the inter-glacial hunters remained in Europe during the second great glaciation. But as soon as the ice commenced to retire men were roving about the continent. 
POST-GLACIAL Taking the remains discovered at Spy in Belgium as belongHUNTERS IN ing to this time, some of these men seem to have been of EUROPE the same race as the inter-glacial hunters. Their heads were very similar-narrow, depressed at the top, heavily browed, and low-foreheaded; whilst in the outer bone of the forearm, and in the shoulder-blade, there were the same simian characters. The remains further bring to light that they were large-footed individuals, and possessed massive chinless jaws with projecting incisor teeth, and molars of simian character. The adults were probably not far short of having attained an erect posture when walking; but from the construction of the leg-bones below the knee, the body must have had a distinctly forward bend. The children may have had to wait for some years before dispensing with the arms in locomotion.

But although physically these people closely resembled the inter-glacial hunters, they were in the enjoyment of a somewhat higher culture. Their stone implements, though rudely wrought, were better fashioned and more varied in shape. In addition to flints roughly chipped for cutting and scraping purposes, they possessed hand-hatchets and borers; and also "duck and drake" stones with chipped edges for use as missiles. It is doubtful, however, if they possessed any weapons which would make them successful hunters of big game.

Contemporary more or less with these rude hunters were men of another race [Galley Hill skeleton (I888), Homo Aurignacensis Hauseri (I9Io)]. These individuals-if the remains are typical-were about five feet in height, and possessed disproportionately long thighs. Their heads were long and narrow; the face was short but well foreheaded; whilst the neck was that of a gorilla for thickness. As regards brains they were certainly better off than the men of the other race. Moreover, they were graced with chins, although not of high type ; and their under-jaws were of lighter structure. From the development of the mandible it is supposed they were able to talk with far greater facility than the bigjawed, chinless hunters. Indeed, the speech of those men was probably little better than a confused jabber. 
These races flourished in Europe for a time; but long before the mammoth and woolly rhinoceroses had quitted the scenes, and whilst herds of reindeer still roamed over the central lands, they were superseded by another race of men. If we may take human remains discovered at Mentone, at Engis on the Meuse, and at Cromagnon in the Dordogne as typical of the new men, there was no close relationship between them and the earlier races - certainly not with the big-jawed hunters. Their skulls were wellpitched-not depressed-at the top. The brow-ridges, it is true, were strongly developed, but not to an ape-like extent. Moreover, the forehead was not receding; the nose, though flattened at the root, projected well from the face; and the chin was considerably developed.

These new-comers to Europe are generally known as THE CAVE "Cave Men," as our knowledge of them is derived chiefly MEN from deposits in ancient caves. The implements which they had in use were still of the type known as palæolithic or "old stone" - rudely fashioned, and showing no signs of having been ground or polished. There is, however, evidence that the implements were better adapted for use.

How far it had occurred to the earlier races of men that their implements might be made more effective by being fixed to shafts and handles is not certain; but these men undoubtedly had the knowledge, and made no little use of it. Handled hatchets were taking the place of hand-hatchets. Lances and javelins were in use, and greater success in the chase must have been obtained. Moreover, there was thus better provision against ferocious animals. Lions, wolves, and bears were abroad; and "sabre-toothed" cats were certainly again in Europe at this time.

These men were mighty hunters, and they seem to have coveted the reindeer beyond all other beasts. Indeed, the reindeer was a good " all-round " animal for the men of those days-the flesh and marrow-bones for food, the horns for tools and weapons, the skin for clothing and cave-curtains, and (when cut into strips) for binding on lance-heads and hatchet-handles. They were able, if necessary, to saw the 
horns and bones, as they possessed-what the earlier men lacked-flakes of flint toothed on the edge.

Besides reindeer, horses ( $E$. caballus) were slain and eaten. Bison also were dragged back to the caves in triumph. Woolly rhinoceroses were now and again victimised; and even mammoths were at times secured, and their curly tusks no doubt set up as trophies.

In some cases fishing was undertaken, apparently with a sort of harpoon made of bone; and salmon coming up the rivers to spawn were occasionally captured. Fowling was also carried on; and the cave evidence shows that ptarmigan, willow-grouse, capercaillie, and other species of northern birds fell to the craft of the fowler.

The Cave men, therefore, at least during some parts of the year, lived well ; and as they were acquainted with fire, they probably cooked their food.

The remains of bone needles prove that the art of sewing was known. Probably reindeer sinew-another use of the animal-furnished the thread.

There are grounds for believing that in some districts the people daubed themselves with a mixture of grease and red chalk. Pierced teeth and sea-shells give further evidence of a love for personal decoration. Some of the shells used were fossil, and may, indeed, have been prized on account of their rarity.

The artistic tastes, however, of the people were not expressed only in necklaces and body-painting. They were well able to scratch pictures on horn, bone, and ivory; and numerous clever and spirited representations of mammoths, reindeer, and other animals of the chase have been brought to light. There is also evidence that fresco-painting was attempted in the cave-dwellings (Cretas, and Cogul in Spain).

It will be admitted, therefore, that the Cave men had got well beyond the evolutionary stage in which attention is focussed almost entirely on eating, drinking, and multiplying.

Quarrels may have been frequent. From remains discovered in the Dordogne it is clear that one of the women 
had been the recipient of a blow on the head, probably from a hatchet. "First Aid," apparently, was available, for medical experts, after careful examination of the skull, declare that some rude sort of operation was performed. What success attended this primitive surgery is unknown.

A glance must now be taken across the Atlantic, where NORTH North America was left under thick ice. As the ice-sheet AMERICA extended its range, a course of events similar to that of Europe must have taken place, involving great migrations to lower latitudes.

Not far south of the fringe of the ice-sheet arctic willows, dwarf birches, and other cold-climate vegetation furnished a meagre adornment to the landscape. Here, too, were mammoths, musk-oxen, reindeer, and other animals inured to cold. Further south, horses, lamas, bison, and mastodons found quarters pleasant enough, save for the wolves and "sabre-toothed" cats that followed them to exile. California, there is reason to believe, became a great rendezvous at this time for glacial refugees. Some of the tapirs, peccaries, mule-deer, and many of the mastodons probably migrated across the Isthmus into South America. In that direction also-towards the ancestral home-must many descendants of the Pliocene emigrant sloths and armadillos have been retreating. Even in southern latitudes the cold must occasionally have been very severe; for mammothsdenizens of chilly regions-were at times down south as far as Mexico.

Numerous must the migrations have been ; and there is no reason to suppose that the destruction of animal life was absolutely appalling. The oncoming of the ice was gradual, and the facilities for migration were great.

In course of time, after several occasional relaxations, ICE RETREAT a persistent rise of temperature set in, and better days were IN NORTH in dawn.

AMERICA

At no time had the thick ice originating in Canada advanced very far into the western States of North America. But in the eastern States it travelled down over five hundred miles. As the ice yielded, Illinois, Iowa, Indiana, Ohio, Michigan, Wisconsin, Minnesota, Pennsylvania, New York, and other 
States long buried gradually reappeared; and in course of time vast tracts of Canada were relieved of their load.

What has been said about Europe at the time of the ice retreat applies more or less to North America. Great floods followed-more destructive, perhaps, to animal life than had been the gradual extension of the ice-sheet. The Missouri and Mississippi Rivers, with vastly widened courses, must have fairly plunged along. New lakes were formed in many parts of the country; and desolated scenes were slowly clothed with a northward-bound scrub vegetation of arctic character. Forests, in time, began to form in favoured districts ; and a general trend of animal life set in from the congested southern areas.

In course of time so genial did the climate become that mastodons roamed over the northern States, and even entered Canada. Mastodons had become extinct in the old world in Pliocene times; and they are not known anywhere after the Pleistocene. Many of them were ending their days in America somewhat ingloriously-wandering into boggy lands (apparently in search of salt), and perishing after vain efforts to extricate themselves. Mammoths, by this time, must have wandered far away north.

There is no satisfactory evidence that man was in North America in pre-glacial times. Nor is it certainly known that he was there during or even soon after the glaciation. Implements, apparently palæolithic, have been exhumed; but there is no general consensus of opinion as to the date of the beds in which they have been found. Indeed, it is affirmed by some authorities that these so-called palæoliths are the refuse flakes of well-finished implements made by Indians in much later times. But whatever be the true date of the relics, the human race was probably represented in Europe much earlier than in North America.

SourH South America was also visited with an exceptional amount AMERICA of ice; but this may have been later in the Period than the time of the great northern glaciation. In the region of the Andes the valleys were blocked with ice. There was also an ice-invasion from the far south, but this did not extend north of Patagonia. The ice, however, never seems to 


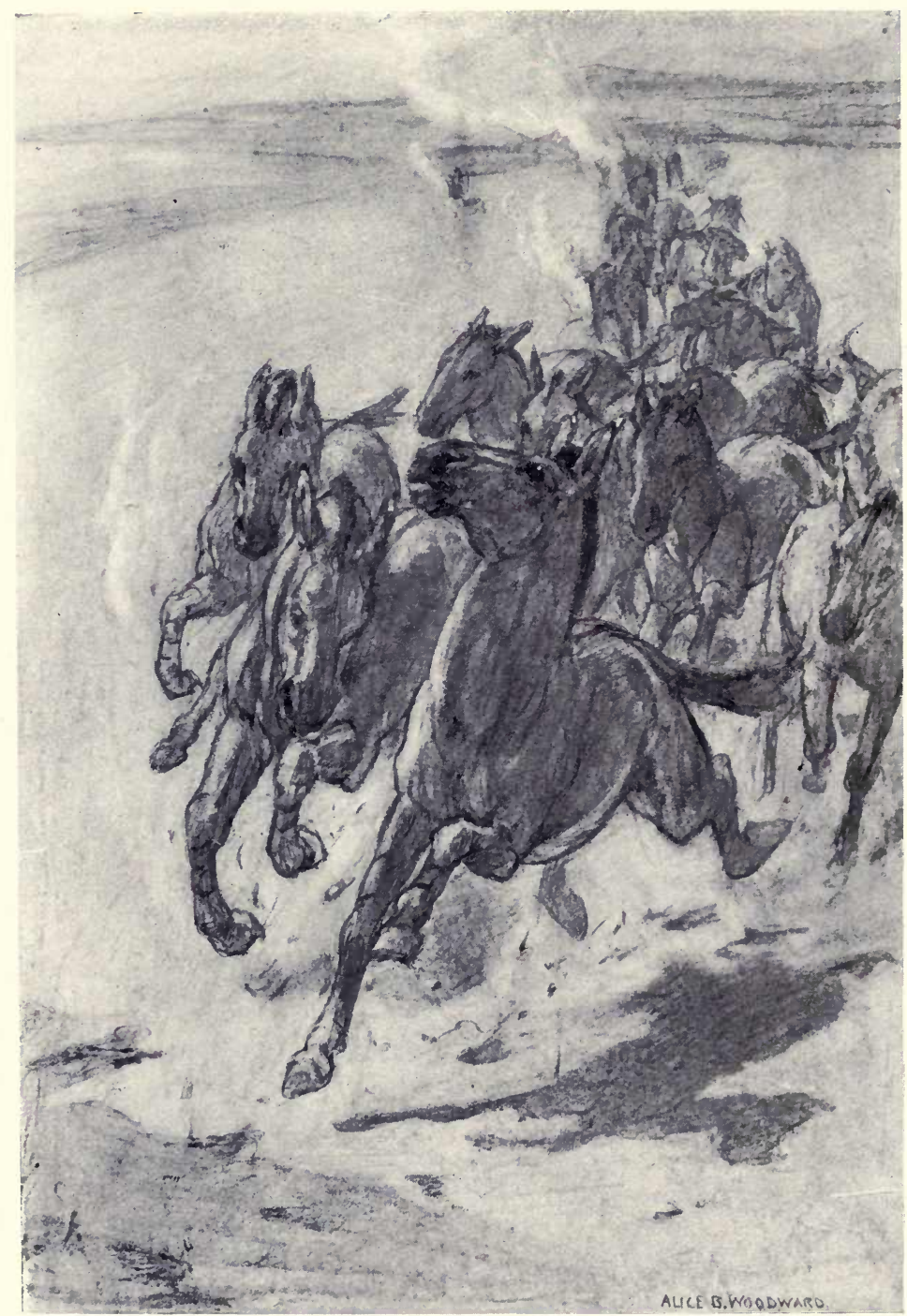

HIPPIDIUM

South American desert horses of the Pleistocene Period 
have assumed appalling dimensions in any part of the continent.

By the upheaval in the Pliocene of the land now known as the Isthmus of Panama the animal life of South America had been greatly enriched. And horses, mastodons, tapirs, lamas, and other animals had come to mingle with the native fauna. The exports of South America fell far short of her imports, for, beyond some armadillos and ground-sloths, she seems to have sent but little in return to her northern neighbour. Great gain, moreover, had resulted to her from the migrations of North American life consequent on the great glaciation. As the glaciation relaxed, counter-migrations led, no doubt, to some losses in her fauna. She had, however, been permanently enriched. Horses, mastodons, peccaries, and mule-deer did not wholly desert her; whilst some forms of life-notably lamas-never recrossed the isthmus, and became lost to North America.

Some of her horses now exhibited certain differences from their emigrant ancestors of the last Period. The most notable of these modified forms were about the size of Shetland ponies; and their heads were disproportionately large for their bodies (Hippidium, Onohippidium). The most striking feature of the animals was the elongation of the nasal bones, giving the head greater depth than that of the other horses. And the nostrils, it may be assumed, were somewhat drawn back. The scenes which these animals frequented were probably different from those of their relations living on grassy plains. Mr. Lydekker considers that the nasal modification was probably a special adaptation to desert life ; and that by its means particles of sand were prevented from reaching the organ of smell. Towards the close of the Period horses became extinct in South America. Professor Fairfield Osborn considers this to have been caused by some widespread epidemic.

South America, as has been seen, was not merely a collector of animals from other lands ; and some of her whilom native products have acquired considerable posthumous fame.

Her ground-sloths and armadillos-first in view in the Miocene Period-had gone on steadily from strength to 
strength, or at any rate from size to size. This progress was noticeable in the Pliocene, and, in the course of the Pleistocene, the animals assumed in some cases colossal proportions. Sloths raised upon their hind-legs were gathering foliage twenty feet from the ground (Megatherium Americanum). In order to take their meals in comfort, they doubtless arranged the limbs and long bony tail in old Dinosaurian style so as to constitute a sort of three-legged stool. Thus seated they proceeded, we may suppose, to bend down the tree-branches with their arms, and to tear off the foliage with their long, curling tongues. Most of the time not spent in eating was probably devoted to sleep. Some of them (Mylodon) possessed a certain amount of bony armour embedded in the hide, and thus protected slept, no doubt, all the more soundly.

Some imposing representatives of armadillo-life were now on the scene in the form of gigantic glyptodonts. Dædicurus stands out as the most extraordinary of these. His length from nose to tail-end was about twelve feet. The top of his head was protected by a bony cap, and his body by a rigid carapace. The tail, which contributed five feet to his total length, was encased partly by rings of bone and partly by a tube of like substance, enlarged and well-spiked at the end. The tail, with its armour, must have been of immense weight, and it is difficult to imagine that it ever left the ground. Elaborate armature was, no doubt, a much-needed protection to Dædicurus, for he was poorly endowed with brains, phlegmatic in temperament, and probably wholly lacking in courage.

Other glyptodonts were abroad that equalled Dædicurus in total length, but they were longer in the body, and shorter in the tail (Glyptodon clavipes). Their tails, moreover, tapered to a point. It is not likely that the appendage responded to happy sensations of head or heart, but it was certainly more manageable than the heavy, battle-axe tail of Dædicurus.

The peculiar South American hoofed animals had also increased in stature. Toxodonts-in Miocene times looking as though coneys had grown to the size of sheep-were now in 


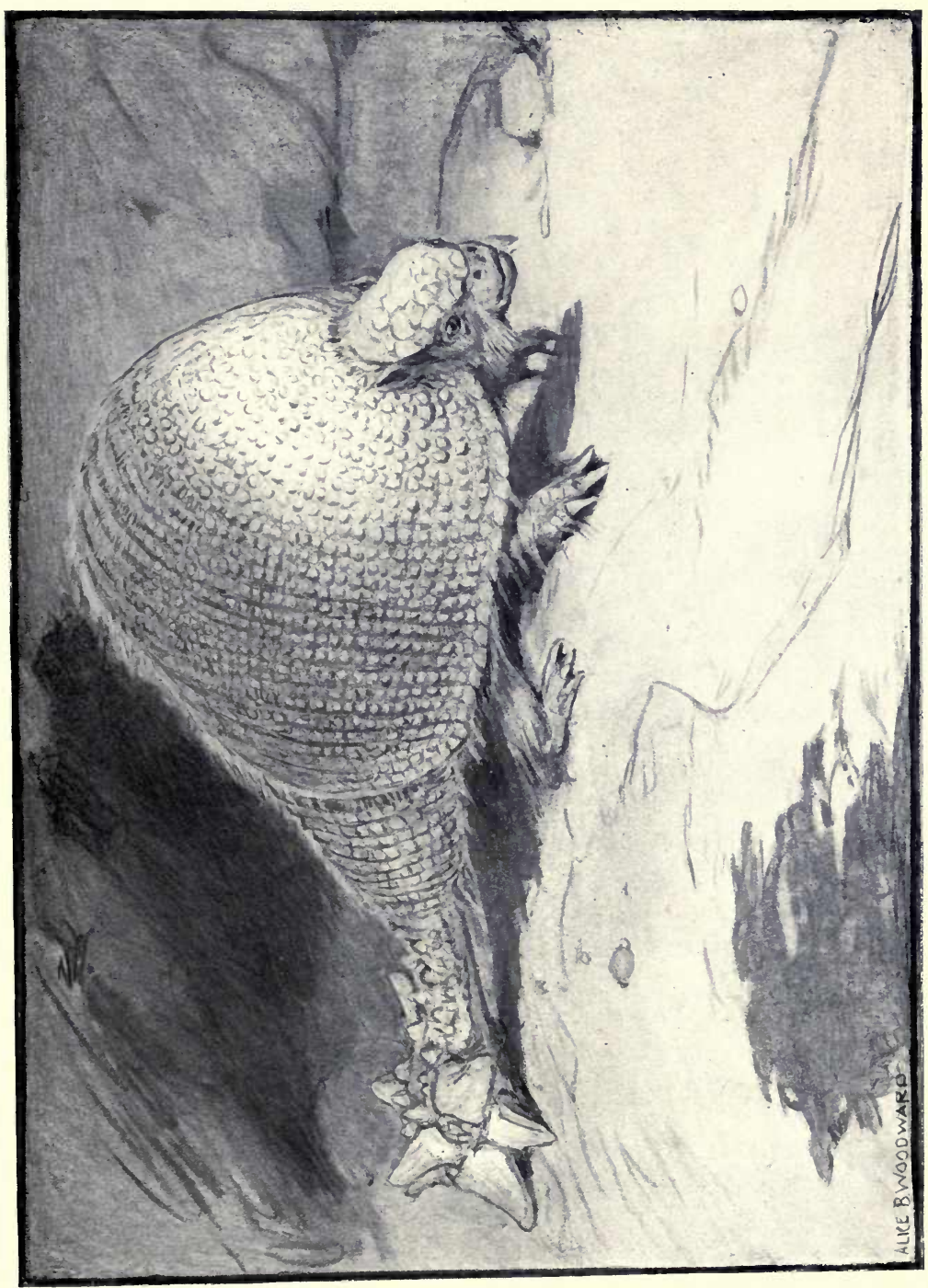



some cases as large as rhinoceroses (Toxodon). The guineapig-shaped typotheres were also much bigger, some of the animals having skulls a foot in length ( $T$, cristatum). These creatures had further converged to true rodents by the loss of their canine teeth. Among the lama-like litopterns, forms were now to be seen as large as camels (Macrauchenia). In the Pliocene Period some of the litopterns were remarkable in having the nasal aperture much higher up the skull than in the earlier forms. This shifting process had been continued, and the aperture was now located between the eyes. This leads one to suppose that a short trunk had been evolved. Macrauchenia, the typical form, was, so to speak, playing many parts. In bodily shape and the length of the neck it resembled a lama; its limbs - the fore being longer than the hind-were suggestive of a giraffe; its head resembled in structure that of a horse; its proboscis that of a primitive elephant; its teeth, those of a rhinoceros; whilst its feet were much as those of the primitive three-toed horses.

There was thus in South America a remarkable medley of animals savouring of primitive times in mammal evolution. The mosaic anatomy of Macrauchenia was quite out of date. The dissipated constitution of toxodonts exhibited a want of concentration almost as anachronic. Animals, smallbrained and heavily armoured-represented by glyptodontshad long been more or less condemned in other parts of the world. Brain power had come well to the fore, and heavy armour was being discarded. Had not man been evolved ?-a well-brained creature with practically no armour to shield him from his foes. It is, therefore, no matter for surprise that as soon as South America became, as it were, opened up, a good deal of the native fauna failed to hold its own. It was victimised, in short, by what may be called mammal free trade. Litopterns, toxodonts, typotheres, and glyptodonts slowly passed away; and are not known after this Period. Carnivores from the north had, no doubt, much to do with this; for to judge by the size of the "sabre-toothed " cats (Smilo$d o n)$, and certain wolf-like animals ( $C$. moreni), these brutes were living well. Ground-sloths survived the other forms, for they were certainly in existence when in later times man 
found his way to the continent. All ground-sloths, however, have now gone to their long sleep-a condition for which they were well prepared.

The "sabre-toothed" cats, big and bloated though they had become in a land of plenty, were, however, now drawing to their end. Carnivores better brained, and less enormously tusked, such as jaguars and ocelots, were already in the land; and pumas were probably working their way down from North America. "Sabre-tooths" had certainly had a long and widespread career. Originating apparently in Europe in the Oligocene Period, they had spread to Asia, thence to North America, and were now making havoc among the fauna of the Southern continent. Their end seems to have been somewhat abrupt, as no trace is found of them in any country after this Period. Professor Flower expressed an opinion that the tusks ultimately became so inconveniently long as to render it almost impossible for the animals to eat. Creatures in such predicament, with palatable prey near but not negotiable, bring to mind the fate of Tantalus.

AUSTRALIA Australia had long been cut off by the sea from the benefits of what may be called advancing civilisation; and her vast territory of over $3,000,000$ square miles was dominated by marsupials. Here, far away from the "madding crowd," these creatures had branched and re-branched in various directions; and whilst their relatives in other lands had sunk into utter insignificance, they themselves were enjoying a golden age.

A great part of the island-continent was probably then, as now, more or less desert in character; but the coastal regions, refreshed by heavy rains, doubtless abounded with rich feeding grounds. And there is geological evidence that some of the now arid central lands were in Pleistocene times well watered and fertile.

Favoured in some districts by vegetation ample and nutritious, the animals were of huge dimensions. Creatures of wombat form, but as large as hippopotamuses (Diprotodon), and kindred brutes, suggestive of tapirs overgrown (Nototherium), testified to a prosperity continued through many generations. Kangaroos with skulls nearly a yard in length were here, looking as if some old bipedal dinosaurs had 


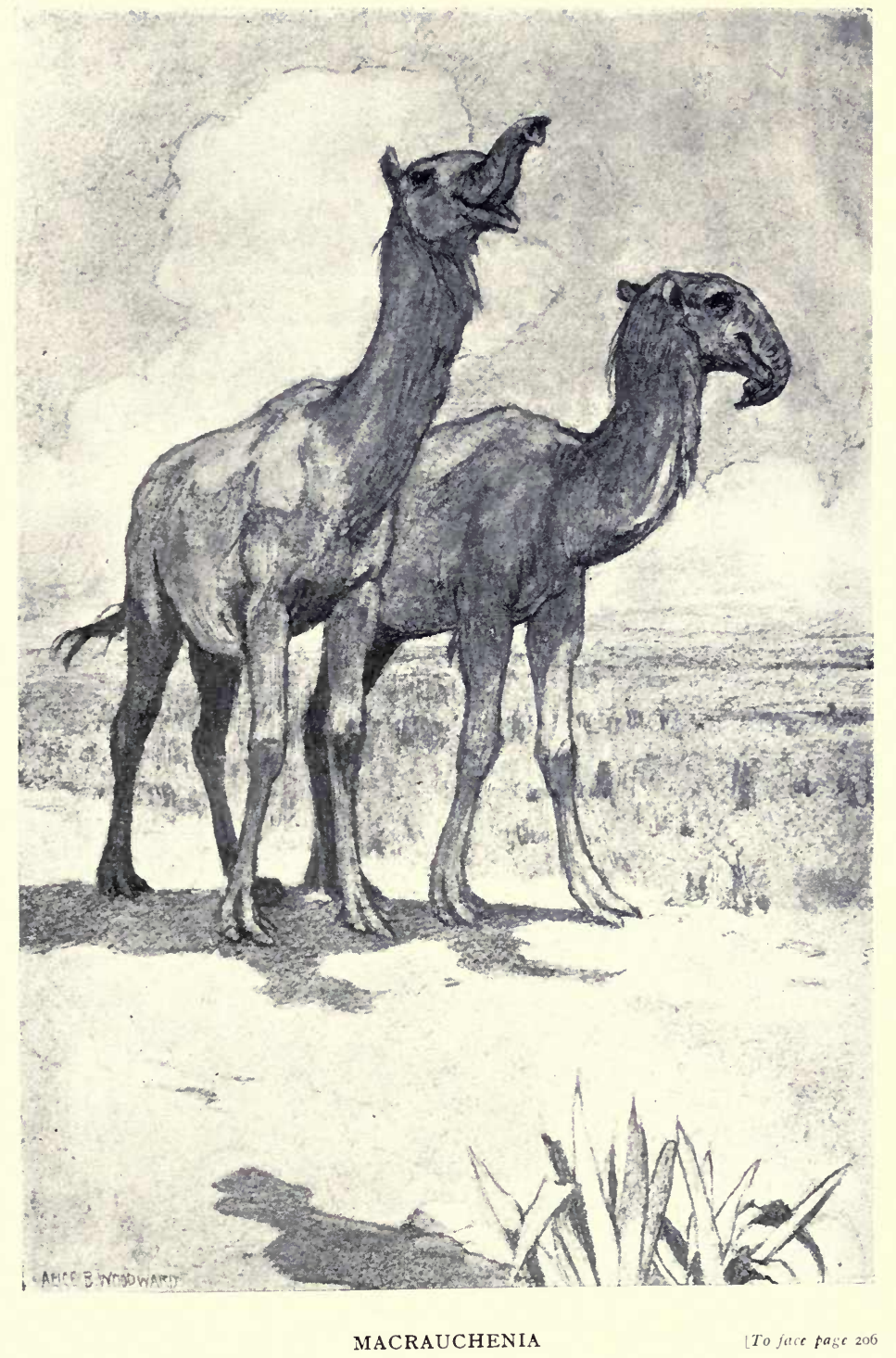



risen from earth glorified as mammals (Macropus titan). Phalanger-like animals, as large as big bears and sometimes termed " pouched lions," were also about the scenes (Thylacoleo).

The prosperity of the vegetarians was naturally reflected in the carnivores. Tasmanian "devils," or sarcophiles, were abroad, much larger than their modern badger-sized representatives (Sarcophilus). Pouched wolves prospered greatly (Thylacinus); and-to judge by their teeth-the "pouched lions," in addition to vegetables, indulged occasionally in animal food (Thylacoleo).

The fauna was rendered additionally grotesque by the presence of gigantic birds, wingless and small-skulled. Some of these carried their diminutive heads twelve feet up in the air (Moa, Dinornis).

It might well be thought that by this time some of the mammals would have developed into creatures of higher grade. It must be concluded, therefore, that their remote ancestors who invaded the land, and were then isolated by the sea cutting off continental connections, were so far anatomically committed to marsupialism as to be inconvertible. It is, however, interesting to note that the idea, if one may so speak, worked out in the higher rank of mammals was more or less expressed in Australia on the lower plane. An approach to ungulates was evidenced in kangaroos, to rodents in wombats, to insectivores and carnivores in " native cats" and thylacines. And had marsupialism continued free to develop, some pouched animals with resemblance to anthropoid apes, and even to human beings, might have appeared.

These prospects, however, were probably at an end as soon as man invaded the island-continent. When this event took place is quite unknown. The first arrivals were probably wandering hunters from New Guinea. Savages of low type they may well have been according to modern ideas; but in order to reach Australia they must have known how to construct rafts or canoes. Indeed, they must long have had some seafaring knowledge, for without it New Guinea could not have been reached.

As to what race of men the invaders belonged opens up 
DISPERSAL the difficult question of the early dispersal of mankind. It is OF MANKIND generally supposed that mankind originated on the mainland of Southern Asia, formerly of vaster extent by the inclusion of territory now submerged by the Arabian Sea. Owing to increase of population a dispersal, in course of time, must have taken place; and men, brought under various climatic and other conditions, gradually differentiated into three groups, known as Negroid or Black, Mongolian or Yellow, and Caucasian or White.

MIGRATION One migratory movement from the cradle-land pursued, TO AUSTRALIA no doubt, a south-easterly direction across the East Indian Archipelago. In course of time some of the wanderers, it may be supposed, reached New Guinea, and thence crossed the Torres Strait to Australia. These emigrants, at the time of their arrival in Australia, may not have been already "blacks" ; but it is reasonable to assume that they were well on the way to becoming so.

In the opinion of many, the Tasmanians, who became extinct in 1876 , were descendants of the men that first reached Australia. Their presence in Tasmania was caused, it is supposed, by their ancestors having been gradually forced south by the arrival in Australia of a second Asiatic horde or race. These second invaders-blended possibly with some of the earlier race-are now represented, it is thought, by the Australian aborigines.

These migrations did not bring any laurels to humanity. The Tasmanians never showed any signs of becoming civilised ; and the Australian aborigines are the lowest of savages. Indeed, it is doubtful if they are in a much higher state of culture than were the inter-glacial hunters. The cause is not far to seek. By long isolation the animal life of Australia had remained in a lowly condition of development; and so the aborigines of old, away from "the great world," with its denser populations, and keener competitions, lost all share in its evolving civilisation.

MIGRATIONS Another migration from the cradle-land led to the peopling TO CENTRAL of Africa south of the Sahara. These wanderers, coming AND SOUTH- across the land now submerged by the Arabian Sea, spread ERN AFRICA over various districts of the "dark" continent, and gave 


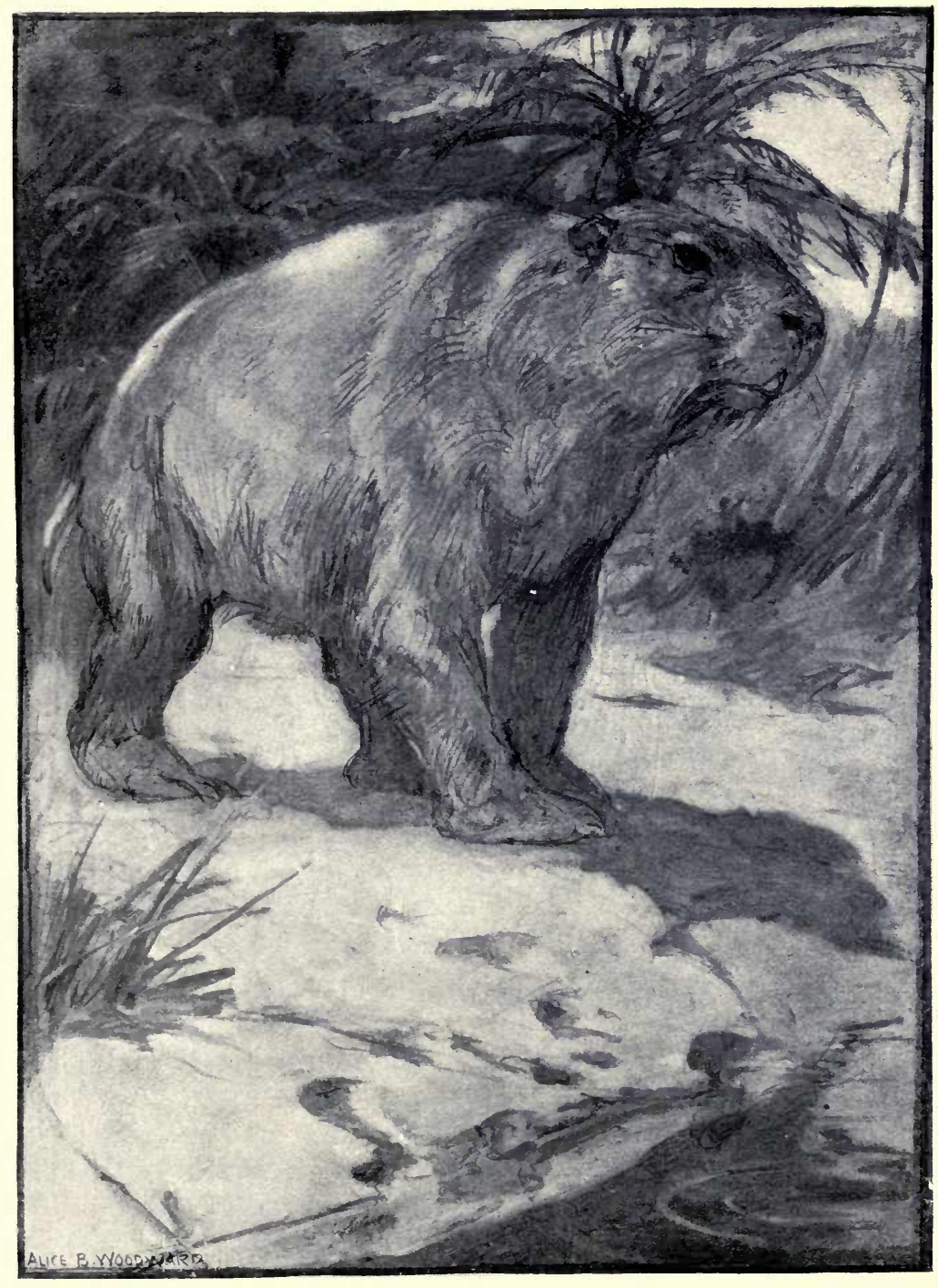

DIPROTODON

A gigantic wombat living in Australia in the Pleistocene Period 

rise in time to many scattered tribes and races of negroids. But it cannot be said that any of these ever adorned humanity. The conditions, owing to the vastness of the land area, and the nature of the climate, were not, it may be supposed, sufficiently stimulating.

In the more enclosed and salutary regions to the north of MIGRATIONS the Sahara more important movements were in progress. TO NORTH From the quantities of palæolithic implements found in the AFRICA ancient limestone and gravel formations of Egypt, it is clear that that country was occupied in Pleistocene times, and probably very much earlier. The Pleistocene Egyptians, no doubt, had become very different from their fellowcreatures south of the Sahara. Indeed, they may well have become so far differentiated as to be describable as primitive members of the Caucasian or White group-destined to great fame in times to come. How long these "dark whites" remained in Egypt cannot be determined; but doubtless they were driven in course of time along the coastal regions of North Africa by other and more civilised "dark whites," sweeping into Egypt from the East. In occupying Egypt they themselves, no doubt, had driven on less civilised tribes along the coasts in the direction of Tunis, Tripoli, Algeria, and Morocco. And it was probably under this more or less constant pressure of emigration from the east that the inter-glacial hunters and the Cave men had been forced along the coast, until in time they crossed from Africa to Europe by one of the old and long since submerged land connections.

Another migration from the cradle-land led to the occupa- MIGRATIONS tion of China and Siberia; and the differentiation of the TO CENTRAL Yellow group of races. It was, doubtless, an offshoot of this AND NORTHmigration which brought the " new" world its first human ERN ASIA, beings.

AND TO

Unfortunately but little is known as to how humanity AMERICA was faring in the cradle-land during Pleistocene times. In the alluvial plains of the Tigris and Euphrates, fertile THE CRADLE soil and abundance of food must have led many people to live LAND not as scattered and wandering families, but in tribal settlements. And a civilisation must have been forming, which had, as yet, been but faintly reflected in Europe. 
Of this higher civilisation Egypt was undoubtedly an outpost; but it was not from that quarter that Europe was to derive her vigorous races.

EUROPE AT Before the close of the Period the climate of Europe became

CLOSE OF so warm as to drive mammoths, woolly rhinoceroses, and PLEISTOCENE other hardy animals to distant scenes. Lions, leopards, and jungle-cats multiplied on the continent; and hippopotamuses and straight-tusked elephants (E. antiquus) penetrated far into Britain, which still formed part of the European mainland. The high temperature, however, was not greatly prolonged; and the warm-climate animals gradually withdrew to more congenial scenes, excepting the straight-tusked elephants ( $E$. antiquus), which appear to have become extinct. 


\section{QUATERNARY AGE}

\section{PRESENT PERIOD}

THE climate of Europe had now settled down to much as it is at the present day; and the same may broadly be said of the fauna and the vegetation. This state of things may date back fifty thousand years or more; but until historic times are reached all dates are conjectural.

No trace, artistic or otherwise, is to be found in this Period of the Cave men. Some of them may have been absorbed by new invaders of Europe. In any case pictorial art on the continent had declined; for the artist-work of the new lords of the soil was far inferior to that of the "old masters."

The earliest chronicles that have been found of man in DANISH Europe in the Present Period consist of the ancient shell- sHELLmounds of Denmark. On the coasts of Jutland, and along Mounds some of the fiords of Zealand, men were living in more or less permanent settlements. The fact best recorded about these people is that they were great consumers of oysters, cockles, mussels, and periwinkles. From the size of the shells it is evident that the molluscs were in "fine" condition; and it may be presumed that the Baltic waters then contained more salt than now.

These settlers, however, did not subsist entirely on molluscs. They were also lovers of pork and venison. In the neighbouring forests numbers of wild boar, red deer, and roe deer fell to their skill and cunning. In the art of hunting they certainly surpassed the Cave men, as they possessed dogs of a jackal type trained to be of service in the chase. Their diet was further varied by fish and fowl ; and there is evidence that the wild swan and the great auk occasionally enriched 
their repasts. There is no reason to suppose that they ever cultivated the soil.

Weapons and implements they had in plenty ; but although these in a few cases were polished, and, therefore, of neolithic or " new stone" type, they were as a rule little superior to those of the Cave men. Pottery, roughly made, was certainly in use. This is a luxury which, it is believed, the Cave men did not possess.

Unfortunately no human remains have been found in the shell-mounds. There are numerous burial-mounds, belonging to a round-headed race of men, in the neighbourhood, but none of these can be assigned definitely to the consumers of the molluscs.

The domestication of the wild dog is a fact of the highest significance. Indeed, the discovery-made many thousands of years ago-that wild animals could be brought into man's service is one of the greatest triumphs in the history of mankind. The mollusc-eaters, it may safely be said, did not make the discovery, nor had they put it much in practice. Doubtless it had originated, and had already been considerably developed, in the East, where also other highly important discoveries had been made.

EARLY LAKE- Among the many tribes that were arriving in Europe, DWELLERS whilst the mollusc-eaters were enjoying life in Denmark, some certainly had not only jackals in a domesticated condition, but also goats and oxen. Nor were these men merely wandering shepherds and graziers; for there is evidence that at least some of them cultivated the soil, and raised crops of wheat, barley, and millet.

Some of these agriculturists, as may be gathered from the evidence of the earliest lake-dwellings of Switzerland, lived on the borders of lakes in rude huts, resting on piles driven into the mud. This peculiar kind of habitation was adopted, it may be supposed, as a protection from wild beasts and incursions of hostile tribes. It was certainly much in use, and greatly elaborated in later times. Even the earliest lake-dwellers did not wholly rely on skins for their clothing, for they were acquainted with the art of spinning. This, as well as their pottery, rudely manufac- 
tured though it was, testified to a well-advanced standard of culture.

The mollusc-eaters and the lake-dwellers both probably came more or less directly from the East, having worked their way up the valley of the Danube. And they were doubtless forerunners of that division of the White or Caucasian group, known in history as Aryans.

Other very distantly related tribes came in time from sEmITICs; Africa, having availed themselves of the land connection which obtained on the site of the Strait of Gibraltar. These, it is supposed, were a dark-skinned people, belonging to the Semitic division of the Caucasian group. And there is little doubt that they had been pushed on by the great migratory movements that had been proceeding along the coast-lands of northern Africa.

These men do not seem to have settled to any great extent in the north of Europe, but they became numerous in Spain and France. Like the early lake-dwellers, they tilled the soil, but they were in a higher state of culture than those men. They were well acquainted with the art of grinding and polishing stone implements, and were certainly, therefore, in what is known as the neolithic or new stone age of culture. They were also, it would seem, in possession of bows and arrows. Their domestic animals consisted of dogs, horses, oxen, goats, and deer. And they were well acquainted with spinning, and with the potter's art.

In addition to these accomplishments, they were able to construct canoes ; and this enabled some of the more adventurous spirits to visit Britain-separated at this time from the mainland.

They buried their dead in regular graves-a practice not pursued, so far as is known, by the mollusc-eaters and the early lake-dwellers. As they deposited various articles in the tombs, they believed probably in an after-life, more or less occupied with human pursuits.

The warlike Silures, who so long resisted the Roman arms in Britain, were, it is supposed, descendants of these swarthy tillers of the soil. And the latter are probably still represented in Europe by the Basques of France and Spain. 
Some Welshmen of to-day may also be inheritors of the blood.

KELTS Successive waves of emigration from Asia brought in time various so-called Keltic tribes to Europe, and a knowledge of bronze. But here we must draw to a close. Indeed, while the .dark-skinned agriculturists from Africa were bringing new ideas to Europe, historic times were beginning to run at least in Egypt. For on that long-trodden soil in 4400 B.C. - more than two thousand years before the time of Abraham-Menes founded a dynasty. And there he reigned over a well-civilised people, until a hippopotamus brought his rule abruptly to an end.

DECLINE OF

The undignified death of the monarch was not portentous BRUTE-LIFE of a turn in the fortunes of brute-life. Indeed, that life had long been steadily declining, and it continued to do so. This decline commenced probably in the Pliocene Period, was accelerated in the Pleistocene, and has continued ever since. To-day brute-life, except in a domesticated condition, is at a very low ebb. This long-continued downward course is doubtless in part ascribable to climatic changes and disease ; but in its later stages it has beyond question been brought about chiefly by man. The helplessness of wild-brute life has been forcibly brought out of late. In some territories wild beasts only continue to exist owing to Government protection.

How great the fall has been may also be gathered from the present distribution and condition of some familiar animals. Elephants, at one time consisting of many species, were prosperous in Europe, Asia, Africa, and North and South America. Now they are reduced to one African and one Indian species. As the family has shown itself willing enough and able to co-operate with man, the majestic old line may long continue. Rhinoceroses, once ranging freely over several continents, are now known only in restricted areas of Africa, India, and the Malayan countries. Their range, too, is bound to diminish, for the animals have no stomach for civilisation, and are never likely to be seen drawing the plough, or otherwise toiling in man's service. Camels exist no longer in a truly wild state. Tapirs, once 
dwellers in Europe, Asia, and both continents of the new world, are to-day found only in isolated districts of Central and South America, and the Malayan countries. Horses in a wild state exist only on the arid plains of Central Asia, and are rapidly approaching extinction. Zebras, resentful of domestication, lead precarious lives in parts of Africa. The closely allied Quagga has recently become extinct. Wild asses have sought safety in sandy deserts, or amid mountain snows, in Africa and Asia. Lions, leopards, and other ferocious carnivores are being rapidly exterminated; and a like fate is overtaking the innocuous giraffe. Man-like apes at the present time possess very limited territories, and are ending their days in strict retirement. Orangs and chimpanzees flourished in India, and probably in many other parts of Asia, in Pliocene times. The former are now found only on the islands of Borneo and Sumatra; and chimpanzees are restricted to equatorial forests in Africa. Gibbons alone survive in south-eastern Asia. Gorillas-the most man-like of the apes-have found a last retreat on the west coast of Africa in French Congo territory.

Man meanwhile has made a wonderful progress. Master of brute-life, he has also acquired no small control over the blind forces that pervade the universe; and in various other ways he has travelled far from a purely animal condition. It cannot, however, yet be said that he has gained complete mastery of the brute passions and impulses which he has inherited from a remote past. The achievement of this, so far as can be seen, is an immediate purpose in his further evolution. 



\section{AUTHORITIES CONSULTED}

\section{ABBREVIATIONS}

A.A.A.S. American Association for Advancement of Science.

A.B. Annals of Botany.

A.M.N.H. American Museum of Natural History (publications).

A.N. American Naturalist.

A.N.H. Annals and Magazine of Natural History.

B.A. British Association for Advancement of Science.

B.G. Botanical Gazette.

B.M. British Museum.

C.M. Century Magazine.

C.N.H. Cambridge Natural History.

E.B. Encyclopædia Britannica.

G.A. Geological Association.

G.M. Geological Magazine.

I.M. International Monthly.

J.L.S. Journal Linnean Society.

L.T.Z. Sir E. Ray Lankester's " Treatise on Zoology."

N. Nature.

N.P. New Phytologist.

N.S. Natural Science.

P. Palæontographica.

P.L.S. Proceedings Linnean Society.

P.M.S. Proceedings Malacological Society.

P.S.M. Popular Science Monthly.

P.T.R.S. Philosophical Transactions of the Royal Society.

Q.J.G.S. Quarterly Journal of the Geological Society.

R.M.S. Royal Microscopical Society. 
R.P.S. Reports Palæontographical Society.

S.T.Z. Sedgwick's “Text Book of Zoology."

T.R.S.E. Transactions Royal Society, Edinburgh.

T.Z.S. Transactions Zoological Society.

U.S.G.S. United States Geological Survey (publications).

Z.T.P. Zittel's “Text-book of Palæontology."

Abbot, Miss. P.T. I895.

Ameghino, F. Mamiferos de la Republica Argentina. I889.

Amalitzky, W. (Warsaw). See page 62.

Andrews, C. W. Catalogue of Tertiary Vertebrata of the Fayûm, Egypt. B.M. Igo6.

Systematic Position of Mœritherium. N. September 9, Igog.

Evolution of the Proboscidea. P.T.R.S. Ig03.

A Descriptive Catalogue of the Marine Reptiles of the Oxford Clay (Part I). B.M. Igro.

Arber, E. A. Newell. Origin of Angiosperms. J.L.S. July, I907.

Fossil Plants, 6o photographs of Flora of Coal Measures. Igog. Avebury, Lord. Prehistoric Times. Igoo.

Balfour, Francis M., and Foster, M. Elements of Embryology. I902. Bateson, W. Materials for the Study of Variation. I894.

Mendel's Principles of Heredity. I909.

Bather, F. A. The Echinoderma. L.T.Z. Igoo.

British Fossil Crinoids. A.N.H. I890-92.

Baur, G. The Stegocephali. Anat. Anzeiger. I896.

Beadnell, H. J. L. See pp. I24, I29.

Beddard, F. E. Mammalia. C.N.H. Ig02.

Structure and Classification of Birds. 1898 .

Beecher, C. E. Collaborator, Trilobites. Z.T.P. Igoo.

Bonney, T. G. The Story of our Planet. New edition, I898.

Boulenger, G. A. Fishes (Teleostei). C.N.H. I904.

Bourne, G. C. Anthozoa, and Ctenophora. L.T.Z. Igoo.

Bower, F. O. Origin of a Land Flora. I908.

Brongniart, C. Recherches pour servir à l'histoire des insectes fossiles. I894.

Calman, W. T. Crustacea. L.T.Z. Igog. 
Campbell, Douglas. Evolution of Plants. I902.

Carpenter, P. H. Catalogue of Blastoidea. B.M. $I 886$ (pars.).

Morphology of Cystidea. J.L.S. I894.

Case, E. C. Revision of the Pelycosauria of North America. I907.

A Great Permian Delta. P.S.M. December, Igo8.

Revision of Amphibia. Z.T.P. Ig02.

Chamberlin, T. C. (University of Chicago), and Salisbury, R. D. (University of Chicago). Geology. Igo6.

Clarke, J. M. Part-collaborator, Crustacea. Z.T.P. Igoo.

Claus, C. Text-book of Zoology, trans. by Adam Sedgwick. Vol. I, $4^{\text {th }}$ ed., I892. Vol. II, I897.

Cooke, A. H. Molluscs. C.N.H. I895.

Cope, E. D. Primary Factors of Organic Evolution. I896.

Condylarthra, Amblypoda, Creodonta. A.N. I884.

Vertebrata of the Tertiary Formations of the West. U.S.G.S. I884.

Crick, G. C. Belemnites. P.M.S. I896, I907.

Dall, W. H. Collaborator, Pelecypoda. Z.T.P. Igoo.

Dana, J. D. Manual of Geology. 4th ed., I895.

Darwin, Charles. Origin of Species (first published I859).

Descent of Man (first published I87I).

Davidson, T. British Fossil Brachiopoda. R.P.S. I85I-86.

Recent Brachiopoda. J.L.S. I886-8.

Dawkins, W. Boyd. Early Man in Britain. I880. Cave-Hunting. I874.

Dawson, Sir J. W. Geological History of Plants. I888.

Dendy, A. Origin of Vertebrates. P.L.S. October, I9Io.

Depéret, C. Transformations of the Animal World. Igog.

de Vries, Hugo. Die Mutationstheorie. Leipzig. I902.

Species and Varieties. Their Origin by Mutation. I895.

Dubois, E. Pithecanthropus erectus. Batavia. I894.

Duckworth, W. L. H. Morphology and Anthropology. I904.

Eastman, Charles R. (Harvard College, U.S.A.). Translator and Editor Zittel's Text-book of Palæontology (Vol. I, Invertebrates, Igoo. Vol. II, Fishes, Amphibians, Reptiles, Birds, I902. Vol. III not yet published). 
Elles, G. L. British Graptolites. R.P.S. IgOI-8.

Etheridge, R. Catalogue of Blastoidea. B.M. I886 (pars.).

Ettingshausen, C. B. British Eocene Flora. R.P.S. I879, I880, I882.

Evans, A. H. Birds. C.N.H. Igoo.

Ewart, J. Cosser. Possible Ancestors of Horses living under Domestication. G.M. August, Igog.

The Celtic Type of Horse. N. I903, p. 239.

Falconer, H. Palæontological Memoirs. I868.

Farmer, J. B. Part-collaborator, Protozoa. L.T.Z. I903.

Flower, W. H., and Lydekker, R. Mammals Living and Extinct. I89I.

Foster, M., and Balfour, F. M. Elements of Embryology. Igo2.

Physiology, General View. E.B.

Fowler, G. H. The Hydromedusæ, and Scyphomedusæ. L.T.Z. I900.

Fraas, E. Die Meer-Crocodilier. P. I902.

Gadow, Hans. Amphibia and Reptiles. C.N.H. Igor.

Gamble, F. W. Part-collaborator, Protozoa. L.T.Z. Igor.

Gardiner, Stanley. P.L.S. October, Igro.

Gardner, J. S. British Eocene Flora. R.P.S. I879, I880, I883, I884, I886.

Gaskell, W. H. Origin of Vertebrates (Igo8), and discussions thereon at meetings of the Linnean Society. P.L.S. October, I9Io.

Gaudry, Albert. Les Enchainements du Monde Animal. I878-9o.

Gegenbaur, Carl. Vergleichende Anatomie der Wirbelthiere. I898.

Geikie, Sir A. Text-book of Geology. 4th ed., I903.

Geikie, J. The Great Ice Age. 4th ed., I903.

Prehistoric Europe. I88r.

Goodrich, E. S. Cyclostomes and Fishes. L.T.Z. I909.

Origin of Vertebrates. P.L.S. October, Igro.

Gregory, J. W. British Palæogene Bryozoa. T.Z.S. I893.

Catalogue of Fossil Bryozoa. B.M. I896, I899.

Palæozoic Ophiuroidea. P.Z.S. I8g6.

Günther, A. Study of Fishes. I88o.

Haeckel, Ernst. History of Creation. Trans. by Ray Lankester. $4^{\text {th }}$ ed., I899. 
Evolution of Man. r883.

The Last Link. 2nd ed., I899.

Harmer, S. F. Joint-Editor Cambridge Natural History. I895-I909.

Polyzoa. C.N.H. Igor. Hemichordata. C.N.H. I904.

Hartog, M. Protozoa. C.N.H. Igo6.

Hatcher, J. B. Part-collaborator, Reptiles. Z.T.P. I902.

Hay, O. P. (American Museum of Natural History, New York.)

Part-collaborator, Reptiles. Z.T.P. I902.

Heer, O. Primeval World of Switzerland. Ed. by J. Heywood. I876. Heilprin, A. The Distribution of Animals. 2nd ed., I894.

Herdman, W. A. Phylogenetic Classification of Animals. I885.

Ascidians and Amphioxus. C.N.H. I904.

Hickson, S. J. Cœlenterata and Ctenophora. C.N.H. Igo6.

Part-collaborator, Protozoa. L.T.Z. I903.

Hinde, G. J. Catalogue of Sponges. B.M. I883.

British Fossil Sponges. I887-93.

Collaborator, Vermes. Z.T.P. I900.

Holland, W. J., Director of the Carnegie Museum, Pittsburg, U.S.A. Carnegie Museum publications.

Hutchinson, Rev. N. Extinct Monsters and Creatures of Other Days.

New and enlarged edition, I9Io.

Huxley, P. H. Man's Place in Nature, I860-63.

Hyatt, A. Collaborator, Cephalopoda. Z.T.P. I90o.

Ingersoll, E. Life of Mammals. Igo6.

Johnston, Sir Harry. See page I7o.

Joly, N. Man Before Metals. 5th ed., I892.

Jukes-Browne, A. J. Stratigraphical Geology. I902.

Kayser, E. Text-book of Comparative Geology. Translated and edited by P. Lake. 2nd ed., I895.

Keane, A. H. Man Past and Present. I90o. Ethnology. Igor.

Kellogg, V. L. Darwinism To-day. I907.

Kingsley, J. S. Part-collaborator, Crustaceans. Z.T.P. Igoo.

Lake, P. See Kayser.

Lang, W. D., see Preface.

Lankester, Sir E. Ray. Editor of Treatise on Zoology (in course of publication). 
Extinct Animals. Ist ed., I905.

Zoology. E.B.

Origin of Vertebrates. P.L.S. October, Igro.

Lapworth, C. British Graptolites. R.P.S. IgoI-8.

Lister, J. J. Foraminifera. L.T.Z. Igo3.

The Arthropods. S.T.Z. Igog.

Lock, R. H. Variation, Heredity, and Evolution. I906.

Lucas, F. A. (Washington Museum). Revision of Aves. Z.T.P. Ig02. Animals of the Past. Igor.

Lydekker, R. Catalogue of Fossil Mammalia. B.M. I885-7.

Catalogue of Fossil Reptilia and Amphibia. B.M. I888-90.

Catalogue of Fossil Birds. B.M. r8gr.

Mostly Mammals. I903.

Geographical Distribution of Mammals. 1896 .

Editor of The Royal Natural History. I894-6.

Extinct Edentates and Ungulates of Argentina. I894.

(With Nicholson) Manual of Palæontology. 3rd ed., I889.

(With Flower) Mammals Living and Extinct. I89I.

Lyell, Sir C. Principles of Geology. I2th ed., I875.

Antiquity of Man. 4th ed., I873.

MacBride, E. W. Echinodermata. C.N.H. Igo6.

Origin of Vertebrates. P.L.S. October, IgIo.

Marsh, O. C. The Dinocerata. I884.

Introduction and Succession of Vertebrate Life in America. A.A.A.S. $\quad 1878$.

The Dinosaurs of North America. U.S.G.S. 1896.

Matthew, W. D. Fossil Mammals in Tertiary of Colorado. A.M.N.H. Igor.

Puerco Fauna. Bull. A.M.N.H. 1897.

Mendel, G. J., referred to, page 4 .

Milne-Edwards, A. Oiseaux Fossiles. Paris. I867-7I.

Minchin, E. A. Sponges; and collaborator, Protozoa. L.T.Z.

Mitchell, P. Chalmers. Origin of Vertebrates. P.L.S. October, Igro.

Morgan, C. Lloyd. The Interpretation of Nature. I905.

Moodie, Roy L. (Kansas University, U.S.A.) The Microsauria. G.M. May, Igog.

Neumayr, M. “Erdegeschichte." (New impression, I897.) 
Newton, R. B. See Preface.

Nicholson, H. A. (with Lydekker). Manual of Palæontology. I889. O'Harra, Cleophas C. Badland Formations of the Black Hills Region. South Dakota School of Mines. Bulletin, November, Igro. Oliver, F. W. Pteridosperms and Angiosperms. N.P. Igo6. Osborn, H. Fairfield, Professor Columbia University, Curator of Vertebrate Palæontology, American Museum of Natural History. Rise of the Mammalia in North America. A.A.A.S. I893. The Ancylopoda. A.N. I893.

The Evolution of the Horse in America. C.M. November, I904. Hunting the Ancestral Elephant. C.M. October, I907.

Ichthyosaurs. C.M. I905.

The Dinosaurs of the Bone-Cabin Quarry. C.M. September, I904.

Collaborator on Reptiles. Z.T.P. I902.

The Age of Mammals. IgIo.

Owen, R. Palæontology. 2nd ed., I86I.

Parker, T. Jefferey. Elementary Biology. 3rd ed. reprinted I9oo.

Parkin, John. Origin of Angiosperms. J.L.S. July, I907.

Pelseneer, P. Mollusca. L.T.Z. Igo6.

Pilsbry, H.A. Collaborator, Gastropoda. Z.T.P. Igoo.

Poulton, E. B. Essays on Evolution. I908.

Pycraft, W. P. Archæopteryx. N.S. October, I893. March and April, I894. December, I895.

Story of Reptile Life. I895.

A History of Birds. IgIo.

Reed, F. R. C. Brachiopods (Fossil). C.N.H. I895.

Ridgeway, W. Origin and Influence of the Thoroughbred Horse. I905.

Salisbury, R. D. (University of Chicago), with T. C. Chamberlin. Geology. Igo6.

Salter, J. W. British Trilobites. R.P.S. I864-83. Saporta, Le Comte. Le Monde des Plantes. I879.

(And A. F. Marion) L'Evolution du Règne végétal. I885. Sargant, Miss Ethel. Early History of Angiosperms. B.G. I905. Scharff, R. F. History of the European Fauna. I899. 
Schlosser, Max. See page I27.

Schmidt, O. Mammalia. 1886.

Schoetensack, Otto, Der Unterkiefer des Homo Heidelbergensis. Leipzig. I908.

Schubert, C. Collaborator, Brachiopoda. Z.T.P. 1900.

Schwann, Theodor. Microscopic Investigations in the Structure of Plants and Animals. I839. English trans., I847.

Scott, Dukinfield H. Studies in Fossil Botany. 2nd ed., I909.

"What were the Carboniferous Ferns ?" Address R.M.S. I905.

The Flowering Plants of the Mesozoic Age. Address R.M.S. I907. Scott, William B. Introduction to Geology. 2nd ed., Igog.

Evolution of the Mammalia. I.M. Igor.

Editor of Reports Princeton Expeditions to Patagonia. IgoI-II. Scudder, S. H. Fossil Insects of the World. U.S.G.S. I89I.

Fossil Insects of North America. 1890.

Sedgwick, Adam. Text-book of Zoology. r898-rgog.

Seeley, H. G. Ornithosauria. I870.

Seward, A. C. Fossil Plants. Vol. I, r898. Vol. II, I9ro.

Catalogue of Mesozoic Plants. B.M. I895.

Sharp, D. Insects. C.N.H.

Shipley, A. E. Joint Editor Cambridge Natural History. I895I909. Brachiopods (Recent). C.N.H.

Insecta and Arachnida. S.T.Z. Igog.

Sinclair, F. G. Myriapods. C.N.H. IgoI.

Sladen, W. P. Collaborator, Asterozoa, Echinozoa. Z.T.B. 1900.

Smith, Geoffrey. Crustacea. C.N.H. Igog.

Sollas, I. B. J. Porifera. C.N.H. I906.

Sollas, W. J. Silurian Echinoidea and Ophiuroidea. Q.J.G.S. I899. Spencer, Herbert. Principles of Biology (first published I864-7).

Starling, E. H. P.L.S. October, Igro.

Stebbing, Rev. T. R. R. Amphipoda (Challenger Report). I888.

Crustacea (Int. Sc. Series, Vol. LXXIV).

Essays on Darwinism. I87I.

Sternberg, C. H. Life of a Fossil Hunter. New York, I909.

Stopes, Miss M. C. Ancient Plants. Igro.

Suess, Eduard. Das Antlitz der Erde. Trans. (I904-8) by Hertha Sollas. 
Thomson, J. Arthur. Outlines of Zoology. New edition, Igro.

Heredity. I908. See also Weismann.

Traquair, R. H. Fossil Fishes. T.R.S.E. I88I.

Extinct Vertebrata of Moray Firth Area. I896.

Ulrich, E. O. Collaborator, Bryozoa, Ostracoda. Z.T.P. Igoo.

Wachsmuth, C. Collaborator, Crinoidea, Blastoidea. Z.T.P. I900.

Walcott, C. D. Fossil Medusæ. U.S.G.S. 1898.

Wallace, A. Russel. Darwinism. 1889.

Speech Darwin-Wallace Celebration Lin. Soc. Ig08.

Walther, J. Geschichte der Erde und des Lebens. I908.

Weismann, August. The Evolution Theory. Trans. by J. Arthur

Thompson and Margaret R. Thompson. I904.

Weldon, W. F. R. Crustacea (pars.). C.N.H. Igog.

Wiedersheim, R. Structure of Man. Trans. by H. and M. Bernard. I895.

Wieland, G. R. American Fossil Cycads. Igo6.

Williston, S. W. (Kansas University, U.S.A.). Part-collaborator, Reptiles. Z.T.P. I902.

Wood, E. M. R. British Graptolites. R.P.S. IgoI-8.

Woods, Henry. Palæontology (Invertebrate). 4th ed., I909.

Trilobites and Eurypterids. C.N.H. Igog.

Woodward, Arthur Smith. Vertebrate Palæontology. I898.

Catalogue of Fossil Fishes. B.M. I889-I90I.

Modern Methods in the Study of Fossils. Pres. Ad. G.A. I905.

Relations of Palæontology to Biology. Ad. Int. Con. St. Louis, U.S.A., September, rgo4.

Evolution of Fins. N.S. I892.

Revision of Fishes. Z.T.P. I902.

Study of Fossil Fishes. Pres. Ad. G.A. February, I906.

Address to Geological Section B.A. Igog.

Origin of Vertebrates. P.L.S. October, Igro.

Woodward, Henry. Catalogue British Fossil Crustacea. B.M. I877. Crustacea. E.B.

Some Coal-Measure Crustaceans and Modern Representatives. G.M. December, I908.

Some Ideas on Life. Pres. Ad. R.M.S. January, I903.

Q 
Evolution of Vertebrate Animals in Time. Pres. Ad. R.M.S. January, I904.

Further Notes on Arthropoda of Coal-Measures. G.M. December, 1907.

The Merostomata. R.P.S. I866-78.

Wright, G. F. Man and the Glacial Period. 2nd ed., I893. Zittel, K. A. von. Handbuch der Palæontologie. I876-93. English Edition. See Eastman. 


\section{GENERAL INDEX}

\section{A}

Aard-varks, I4I

Abdominal ribs, 6r

Acentrophorus, 64

Actinopterygian Ganoids-

Devonian, 4I

Carboniferous, $5^{8}$

Permian, 64

Triassic, 75

Jurassic, 87

Cretaceous, I05

Eocene, I36

Africa, II9, 208

Agriculture, 212, 213

Albatross, I3I

Alcyonarians, 2I, Iro

Algæ, 8, I5, 20

Alligators, Ior, I34

Almond trees, I54

Alps, I38, I68

Alticamelus, ${ }_{5} 8$

Amber, ${ }_{52}$

Amblypods, II7, 122

America, North, passim-

Pliocene, Earlier, I80

- Later, I84

Pleistocene, I9I, I92, 201

America, South-

Miocene, I6I

Pliocene, I8I, I85

Pleistocene, 202

Amia, 76

Ammonites, 44, 67

(See also Ammonoids)

Ammonoids-

Devonian, 43

Carboniferous, 56

Permian, 67

Triassic, 74

\author{
Ammonoids (cont.) - \\ Jurassic, 85 \\ Cretaceous, 107 \\ Eocene, I37 \\ Amphibians- \\ Carboniferous, $5^{8}$ \\ Permian, 6r \\ Triassic, 76 \\ Jurassic, 89 \\ Eocene, I35 \\ Oligocene, I $_{40}$ \\ Miocene, 167 \\ Ancestry of, 59
}

Amphicyon, 146, 156

Amphineura. See Chitons

Amphioxus. See Lancelets

Amphipods, 35

Anaspides, 57

Anchisaurus, 78

Anchitherium, 159

Ancylopods, I40, I7 I

Angiosperms, 89, II2

Annelids, I4

Anomodonts. See Theromorphs

Anoplotheres, I28, I44, I 57

Ant-eaters, I85

- Scaly, I4I

Antelope-

Miocene, $\mathrm{I}_{5} 8$

Pliocene, I69, I78, I83

Elands, I69, I78

Gazelle, r69

Harnessed, 169

Hartebeest, ${ }^{178} 8$

Kudus, I69, I78

Nilgai, 178

Oryx, 169

Sable, I69, I78

Saiga, I94

Waterbuck, 178

Anthozoa. See Corals 
Anthracosaurus, 59

Anthrocotheres, 128, 144, 176

Anthropoids. See Apes and generic names

Ants, 89

Anura. See Frogs, Toads

Apes-

Eocene, 127

Oligocene, 149

Miocene, 154,164

Pliocene, I72, I79, I 84

Present, 215

Baboons, I 55, 179

Chimpanzee, 155, 179

Dryopithecus, I 55

Gibbon, I 55

Gorilla, I 55, 179

"Holy," I 72, I79, I 84

" Howler," I64

Langur. See "Holy"

Macaques, I 72, I79, I 84

Mesopithecus, 172

Orangs, 179

Pliopithecus, 155

Propliopithecus, 127

Semnopithecus, 172

Apus, 19

Arachnida. See Scorpions, Spiders

Araucaria, 68, 70, 88

Archæopteryx, 2, 96

Ark-shells, 18, 55, 66, 73

Armadillos-

Eocene, 124

Miocene, 162

Pliocene, I8I, I 85

Pleistocene, 204

Arsinoitherium, 129

Art, 200, 21 I

Arthrodirans, 39

Arthropods. See Crustaceans, Insects, King-crabs, Myriapods, Scorpions, Sea-scorpions, Spiders, Trilobites Ancestral, 3

Aryans, 213

Asaphus, 26

Asia, Glaciation, 190

Aspidorhynchus, 88

Asses, wild, 215

Asteroids. See Starfishes

Astrapotheres, 163,185

Atlantosaurus, 90,98

Auks, I 66
Australia, 165, 186, 206

- aborigines of, 208

- arrival of man in, 207

\section{B}

Baboons. See under Apes

Bactrites, 43, 56

Baculites, 107

Badgers, 174, 194

Balanoglossus, 3

Barnacles-

Cambrian, 19

Ordovician, 26

Jurassic, 86

Cretaceous, 107

Basques, 2 I 3

Bats, I 26

Beach-fleas. See Amphipods

Bears-

Oligocene, 146

Miocene, I 56

Pliocene, Earlier, I73, 174

- Later, 184

Pleistocene, 190, 192, 194

Cave, I90, I94

Polar, I92

Sloth, I74

Beavers, $\mathbf{I}_{48}, \mathbf{I} 55$

Beaver-squirrels, 156,180

Bees, 89 , I 52

Beetles, 7I, 89, I52

Belemnites-

Triassic, 74

Jurassic, 86

Cretaceous, 107

Eocene, I 37

Ancestry, 74

Belodon, 77

Bennettiteæ, 7 I, 89, I I 3

Berycoids, 106

Birds-

Jurassic, 96

Cretaceous, III

Eocene, I3I

Oligocene, 150

Miocene, I66

Ancestry, 2, 96

(See also under various names.)

Birkenia, 36

Bison, $\mathbf{1 7 8 ,} 200$ 
Bivalves. See Pelecypods

Blastoids,

Silurian, 30

Devonian, 46

Carboniferous, 54

Blastosphere, Io

Bone, 36, 64

Bony pike, 88

Bot-flies, $\mathrm{I}_{52}$

Bovidæ. See Antelope, Bison, Goats, Oxen, Sheep

Brachiopods-

Cambrian, 18

Ordovician, 23

Silurian, 3 I

Devonian, 45

Carboniferous, 54

Permian, 66

Triassic, 72

Jurassic, 84

Cretaceous, 109

Eocene, 137

Ancestry, I4

Zenith, 32

Bream, ro6

Britain, separation of, $2 \mathrm{I} 3$

Brittle-stars-

Ordovician, 23

Silurian, 3r

Devonian, 45

Carboniferous, 54

Permian, 66

Jurassic, 83

Brontops, I4I

Brontosaurus, 90

Bronze, 2I 4

Brute life, decline of, 214

Bryozoans. See Polyzoans

Bumble bees, $\mathrm{r}_{52}$

Burial, rgo, 2 I 3

Bustards, I $5 \mathrm{I}$

Butterflies, I 52

Buzzards, I $32, I_{5}{ }^{-}$

C

Calamaries, 86

Calamites. See Equisetales

Calymene, 26

Cambrian Period, I6
Camels-

Eocene, 129

Oligocene, $\mathrm{I}_{45}$

Miocene, $\mathbf{1}_{58}$

Pliocene, I 77

Canidæ. See Dog family

Capercaillie, $\mathbf{I} 32$

Carboniferous Period, 50

Carnivores-

Eocene, 118, 127

Oligocene, $\mathbf{I}_{4} 6$

Miocene, I 56, I64

Pliocene, I72, I73, I 83

Pleistocene, 194, 206, 210

(See also under various names.)

Carp, 168

Carpathian Mountains, I38, r68

Cat-dogs, 146, ${ }_{5} 6$

Cat family-

Oligocene, $\mathbf{I}_{4} 6$

Miocene, 156

Pliocene, Earlier, I72, I73

- Later, r 83

Pleistocene, 194, 206, 210

(See also under Machærodonts, and various names.)

Caucasian Group, 208, 209, 21 3

Cave-men, 199, 2 II

Cavy, $\mathbf{I}_{4} 8$

Cephalaspis, 36, 38

Cephalopods-

Cambrian, 18

Ordovician, 25

Silurian, 33

Devonian, 43

Carboniferous, 56

Permian, 66

Triassic, 73

Jurassic, 85

Cretaceous, 107

Eocene, I 37

(See also Ammonites, Ammonoids,

Belemnites, Goniatites, Nauti-

loids, Nautilus, Octopus.)

Ceratodus, 76

Ceratosaurus, 92

Ceraurus, 26

Cervidæ. See Deer

Cetacea. See Dolphins, Whales, Zeuglodonts

Cetiosaurus, 90

Chalicotheriidæ, I40, I7I 
Chalk formations, III

Chameleon, 135

Cheetahs, 173

Cheirolepis, $4 \mathrm{I}$

Cheiroptera. See Bats

Chelonians-

Permian, 64

Triassic, 79

Jurassic, 94

Cretaceous, ro2

Eocene, I 34

Miocene, 166

Pliocene, 180

Criptodira, 79, 94

Pleurodira, 79, 94, I 34

Chevrotains-

Eocene, 129

Oligocene, $\mathrm{I}_{44}$

Pliocene, 179

Water, 179

Chimæra, 40, 87

Chimpanzee, I55, 179, 215

Chirocentrus, 106

Chitons, 24, I 37

Chonetes, 32

Cirripedes. See Barnacles

Civets, 127, 147, I73

Cladophora, 17

Cladoselache, 39

Clams, 85, r 37

Clematis, ${ } 54$

Club-moss. See Lycopods

Coal, $5^{I}$

Cobra, 167

Coccosteus, 39

Cockles, 73

Cockroaches, 52

Cœlacanthidæ, 58, 87, 105

Cœlentera, I2

(See also Cladophora, Corals, Graptolites, Jellyfish.)

Coleoptera. See Beetles

Compsognathus, 92

Condylarthra, II 7, II9

Coney. See Hyrax

Conifers, 68, 70, 88, I I 2, I32, I53, I 54

Corals-

Cambrian, 17

Ordovician, 2 I

Silurian, 28

Devonian, 47

Carboniferous, 53
Corals (cont.) -

Permian, 66

Triassic, 72

Jurassic, 82

Cretaceous, I Io

Eocene, 138

Oligocene, I40

Red, r ro

Reef-building, 28

Cordaites, 49, 50, 71

Cormorants, II2, I5O

Coryphodonts, 122

Cowries, 85, 137

Crabs-

Jurassic, 86

Cretaceous, 106

Eocene, 137

Cranes, I3I, ${ }_{5}$ I

Craniidæ, 23, 109

Crawfish, 106

Creodonts-

Eocene, 118, 127

Oligocene, 146

Miocene, 156

Pliocene, I73

Cretaceous Period, 98

Crickets, 89

Crinoids-

Cambrian, $\mathbf{1} 7$

Ordovician, 22

Silurian, 29

Devonian, 46

Carboniferous, 53

Permian, 66

Triassic, 72

Jurassic, 82

Cretaceous, I ro

Eocene, 138

Emancipation, 53, 82, 1 ro

Sanitary modifications, $30,46,53,66$

Crocodiles-

Triassic, 77

Jurassic, 93

Cretaceous, IOC

Eocene, I34

Miocene, I66

Pliocene, 179

- backbone, 93, roo

- breathing modification, 93, 100

- sea-roving, 94, ror

(See also Gavials.)

Cromagnon, 199 
Crossbills, I5I

Crossopterygian Ganoids-

Devonian, $4^{\circ}$

Carboniferous, 57

Permian, 65

Triassic, 75

Jurassic, 87

Cretaceous, I05

Crows, I $_{5} \mathrm{I}$

Crustaceans-

Cambrian, I9

Ordovician, 25

Silurian, 34

Devonian, 42

Carboniferous, 56

Permian, 67

Triassic, 75

Jurassic, 86

Cretaceous, 106

Eocene, I37

(See also under various names.)

Cryptoclidus, 95

Cryptogams, 3

(See also under various plantnames.)

Curlew, I66

Cushion-stars, 83

Cuttle-fishes, I37

Cyathaspis, 36

Cycad-conifers. See Cordaites

Cycad-ferns (Cycadofilices), 48, 50, 68, $7 \mathrm{I}$

Cycads, 68, 7I, 88, II 3

Cyclostomata, 39

Cynodictis, 128, 146

Cypress, 68, 70

Cystids-

Cambrian, 17

Ordovician, 22

Silurian, 29

Devonian, 47

Carboniferous, 53

Permian, 66

\section{D}

Dædicurus, I85, 204

Dasyurus, 187

Date-shells, 55

Decapods. See Crabs, Lobsters, Prawns, Shrimps
Deer family-

Oligocene, I45

Miocene, ${ }_{57}$

Pliocene, Earlier, I7I, I79

- Later, 183

Pleistocene, 194

Domesticated, 213

Irish, Great, 194

Mule, I58, 20I

Muntjac, $157,172,183$

Musk, I45, I79

Red, I83

Reindeer, I94, 199

Roe, 183

Sedgwick's, 183

Spotted, I72

Swamp, I79

Deiphon, 34

Denmark shell-mounds, 2 II

" Devils," Tasmanian, 207

Devonian Period, 38

Diadectes, 64

Dichograptus, 22

Dimetrodon, 63

Dinoceras, I 23

Dinornis, 207

Dinosaurs-

Triassic, 77

Jurassic, 90

Cretaceous, 98

(See also under various generic names.)

Reproduction, 92

Dinotheres, I6I, I7I, I74, I82

Diphycercal tail, 42

Diplodocus, 90, 98

Dipnoans, 4I, 57, 65, 76, 105

Diprotodon, 187, 206

Divers, III, I50

Dog-bears, I46, I56, I73, I74

Dog family-

Eocene, 128

Oligocene, 146

Miocene, 156

Pliocene, Earlier, I73

- Later, I83

Domesticated, 2II, 212, 213

(See also Fox, Jackal, Wolf.)

Dog-fishes, 87

Dolichosaurs, I0I

Dolichosoma, 59

Dolphins, 165 
Dorab, 106

Dormice, 124, 148

Dragon-flies, 52, 89

Drepanaspis, 38

Dryopithecus, 155

Ducks, I5I

Dugongs, I30

Dunlins, II2, I32

\section{$\mathrm{E}$}

Eagle, 132, I51

Eagle-rays, 105, 136

Earwigs, 89

Echinoderms, I3

(See also Blastoids, Brittle-stars, Crinoids, Cystids, Holothurians, Sea-urchins, Starfishes.)

Echinoids. See Sea-urchins

Echinosphæra, 22

Edaphosaurus, 63

Edentates, II8, I24, I4I, I6I, I8I, I85, 203

(See also Armadillos, Ganodonts, Sloths.)

Eels, 106

Egypt, 209, 214

Elands, I69, I78

Elasmobranchs. See Dog-fishes, Rays, Sharks

Elasmosaurus, 103

Elasmotherium, I9I

Elephants-

Eocene, 124

Miocene, 160

Pliocene, I7I, I74, I82

Pleistocene, I89, I91, I93, 202

Present, 214

(See also Dinotheres, Mammoths, Mastodon, Mœritherium, Palæomastodon, Stegodon, Tetrabelodon.)

Elk, 189, 194

Elotherium, 143, I60

Embryology, 2

Engis, human remains, 199

Eocene Period, II6

Eoliths, 188

Eosiren, I30

Equidæ. See Horses

\author{
Equisetales- \\ Cambrian, 20 \\ Ordovician, 27 \\ Devonian, 48 \\ Carboniferous, 50 \\ Permian, 67 \\ Triassic, 70 \\ Jurassic, 88 \\ Cretaceous, 113 \\ Equisetum, 70 \\ Eucalyptus, II4 \\ Europe, Glaciation, I90, I9I \\ - Inter-glacial Epoch, 192 \\ - Re-Glaciation, 196
}

Eurypterids. See Sea-scorpions

Evolution, doctrine of, I et seq.

\section{F}

Falcons, 132

Favosites, 29, 47, 53

Felidæ. See Cat family

Ferns-

Silurian, 28

Devonian, 48

Carboniferous, 50

Permian, 68

Triassic, 70

Jurassic, 89

Adder's Tongue, 70

Bracken, 89

Eusporangiates, 70

Glossopteris, 68

Hart's Tongue, 89

Leptosporangiates, 70,89

Male, 89

Marattiaceæ, 50

Polypod, 70

Royal, 70, 89

Fig trees, II 3

File-shells, 55, 85

Finches, I5I

Fins, 40

Fishes, 2, 3-

Silurian, 35

Devonian, 38

Carboniferous, 57

Permian, 64

Triassic, 75

Jurassic, 86

Cretaceous, I04 
Fishes (cont.) -

Eocene, 135

Miocene, 167

Ancestry, I4

Bony. See Teleosteans

Fins, 40

Flying, 106

Freshwater, I68

Spiny-finned, 106

Tails, $41,58,64,76,88$

(See also Actinopterygian, Crossopterygian, Dipnoans, Ganoids, Teleosteans, and various names.)

Fish-lizards. See Ichthyosaurs

Flamingoes, I12, I3I, I 50

Flowers, first known, 49

Flying Lizards. See Pterosaurs

Foraminifers-

Cambrian, 16

Permian, 66

Cretaceous, I ro

Eocene, 138

Foxes, 156, 194

Frescoes, 200

Fringe-finned ganoids. See Crossopterygian

Frogs-

Eocene, I35

Oligocene, 140

Miocene, 167

Fungi, 8, 15, 20

\section{G}

Gad-flies, $I_{52}$

Gall-flies, I 52

Gannet-like birds, I31, I33

Gannets, I 50

Ganodonts, II8, I4I

Ganoids-

Devonian, 40

Carboniferous, 57

Permian, 64

Triassic, 75

Jurassic, 87

Cretaceous, 105

Eocene, 136

(See also Actinopterygian, Crossopterygian.)

Gastornis, I3I
Gastropods, 14

Cambrian, 18

Ordovician, 24

Silurian, 32

Devonian, 44

Carboniferous, 52, 55

Permian, 66

Triassic, 73

Jurassic, 85

Cretaceous, 108

Eocene, I 37

Oligocene, 140

Land, 52

Respiration, 73

( $\mathrm{See}$ also under various names.)

Gastrula, 12

Gavials, 77, 93, I66, I80

Gazelles, I29, I44, I69

Geese, I3I

Geosaurus, 94

Gibbons, 155,215

Gingko tree, 68, 7o, 89

Giraffes-

Pliocene, I69, I77, I83

Present, 215

Giraffe-camel, ${ }_{5} 8$

Glaciation-

Permian, 67

Pleistocene, I9o et seq.

America, N., I9I, I92, 201

America, S., 202

Asia, I90

Europe, 190, I9I, 196

Gluttons, I89, I94

Glyptocrinus, 22

Glyptodonts, 162, 185, 204

Gnats, 89

Goat, I69, I77

- domesticated, 212, 2I3

Goat-oxen, I 78

Godwits, I32

Gomphoceras, 33

Goniatites-

Devonian, 44

Carboniferous, $5^{6}$

Permian, 67

Gorillas, 155, I79

Graptolites-

Ordovician, 2I

Silurian, 29

Grasses, 89, II4

Grasshoppers, 52 
Great Britain separated, 213

Grebes, III, I50

Greenland, I54

Ground-sloths. See Sloths

Grouse, Sand, I5I

- Willow, 200

Guillemots, 166

Gulls, 150, 166

Gymnosperms. See Cycads, Conifers, and various names

\section{$\mathrm{H}$}

Hadrosaurus, 100

Hag-fishes, 35

Halitherium, 150

Halysites, 29, 47

Hares, ${ }_{4} 8$

Hartebeest, 178

Hatteria. See Sphenodon

Heart-urchins, Io9

Hedgehogs, 148

Helicotoma, 24

Helladotherium, I70

Hemiaspis, 34

Hemipters, 27

Hermit-crabs, 137

Heron, I31, I66

Herring, 76, I05

Hesperornis, I 12

Heterocercal tail, 42

Himalayas, 138

Hipparion, 170, 175, 182

Hippidium, 203

Hippopotamus, 177, I82, I89, 193

Hippurites, 108

Hoatzin, 3

Holoptychius, 4 I

Holothurians, I3, I7, 54

Homo. See Man

Homocercal tail, 4I, 58, 64, 76, 88 ,

Hoopoes, I5I

Hoplopteryx, 106

Hornbills, 132

Hornets, 152

Horse-mackerel, I06

Horses-

Eocene, 120

Oligocene, I43

Miocene, 159

Pliocene, Earlier, 170, 175, 180
Horses (cont.) -

Pliocene, Later, 182, 185

Pleistocene, 189, 193, 203

Domesticated, 213

Keltic type, 182

South American, 203

Thoroughbred, I7 6

"Horsetails." See Equisetales

Hyæna, I73, 184

Hyænodon, 128, 146, I56, 173

Hydra, 12

Hydrozoa. See Cladophora, Graptolites

Hymenocaris, 19

Hyopotamus, 144

Hyracodon, 142

Hyracotherium, I2I

Hyrax, 129

\section{I}

Ibis, 131, 150

Ich thyornis, II2

Ichthyosaurs-

Triassic, 79

Jurassic, 95

Cretaceous, 102

Iguanodon, 98

Implements-

Eolithic, 188

Palæolithic, 195, 198, 199209

Neolithic, 212, 213

Bronze, 214

India, Early Pliocene, 173

Inostransevia, 63, 77

Insectivores-

Jurassic, 97

Eocene, II 8

Oligocene, 148

Miocene, I 55

(See also Hedgehogs, Moles, Shrews.)

Insects-

Ordovician, 27

Devonian, 47

Carboniferous, 52

Triassic, $7 \mathrm{I}$

Jurassic, 89

Cretaceous, II 4

Oligocene, $\mathrm{I}_{5} \mathrm{~s}$

(See also various names.)

Inter-glacial Epoch-

Europe, 192 
Inter-glacial Epoch (cont.)Hunters, 195

Iris, I 54

Irish deer, the Great, 194

Isopods, 43

\section{J}

Jackals, 173

Jaguars, 173, 206

Jellyfish, I2, I7

Jungle-cats, 2 Io

Jurassic Period, 82

\section{K}

Kangaroos, I 86, 206

Kelts, 214

King-crabs-

Cambrian, I9

Ordovician, 26

Silurian, 34

Triassic, 75

Kingfisher, 132

Kites, I 5 I

Kudus, I69, I78

\section{L}

Labyrinthodonts-

Carboniferous, 59

Permian, 6r

Triassic, 76

Lacertilia. See Lizards

Lake-dwellings, 2 I 2

Lama, I 58, 180, 203

Lamellibranchs. See Pelecypods

Lampreys, 39

Lampshells. See Brachiopods

Lanarkia, 36

Lancelets, 3

Lapworthura, 3I

Lariosaurus, 78

Larks, I 32

Lasanius, 36

Leaf-insects, 52

Lemurs-

Eocene, I 19, 126

Oligocene, I49

Miocene, I 54
Leopards, Hunting, 173

Lepadocrinus, 29

Lepidaster, $3 \mathrm{I}$

Lepidodendron. See Lycopods

Lepidoptera. See Butterflies, Moths

Life, appearance of, 7

Limestone, Miolitic, ${ }_{1} 8$

- Nummulitic, 138

Limpets, 18

Lions, I84, 194 pouched, 187,207

Listriodon, I 59

Litopterns-

Miocene, 163

Pliocene, 186

Pleistocene, 205

Liverworts, I 5, 20

Lizards-

Jurassic, 93

Eocene, I35

Miocene, 167

Flying. See Pterosaurs

Llama. See Lama

Loach, I68

Lobsters, 86, 106

Locusts, 52

Lophiodonts, I20, I40, I 57

Loxomma, 59

Lung-fishes. See Dipnoans

Lycopods-

Cambrian, 20

Ordovician, 27

Silurian, 28

Devonian, 48

Carboniferous, 50

Permian, 67

Triassic, $7 \mathrm{c}$

Jurassic, 88

Lynx, 184

\section{M}

Macaques. See Apes

Machærodonts-

Oligocene, 147

Miocene, ${ }_{5} 6$

Pliocene, Earlier, 172, 173

- Later, 183

Pleistocene, 206

Macrauchenia, 205

Magnolia, II 3 
Maidenhair tree. See Gingko

Mammals, appearance of, 80

- decline of, 214

- origin of, 80

- placental, II7

(See also under various names.)

Mammoths, I91, 193, I97, 200, 20r, Man202,210

America, 202, 209

Aryan, 213

Aurignacensis, 198

Caucasian, 208, 209, 213

Cave, 199, 2 II

Cradle-land, 208, 209

Cromagnon, 199

Descent, 127, 187

Dispersal, 208

Engis, 199

Eolithic, 188

Galley Hill, 198

Heidelbergensis, 190

Inter-glacial, 195, 196

Kelts, $2{ }_{4}$

Lake-dwellers, 2 I 2

Mentone, 199

Mollusc-eaters, 2 II

Mongolian, 209

Mousteriensis, 196

Neanderthal, 195

Negroid, 208, 209

Neolithic, 2I 2, 2I 3

Palæolithic, 195, 198, 199, 209

Pithecanthropus, 187

Pliocene, 188

Semitic, 213

Spy, 198

Manatees, 130,150

Marsupials-

Triassic, 80

Jurassic, 97

Cretaceous, $\mathbf{I r}_{4}$

Eocene, Ir 9

Oligocene, 140

Miocene, 164

Pliocene, 186

Pleistocene, 206

(See also under various names.)

Martens, ${ }_{5} 6$

Mastigocrinus, 30

Mastodons-

Pliocene, 174, 180, 182
Mastodons (cont.)-

Pleistocene, 202

Mayflies-

Devonian, 47

Carboniferous, 52

Jurassic, 89

Medusæ. See Jellyfish

Megalohyrax, I29

Megalosaurus, 92, 99

Megatherium, 185, 204

Melaniidæ, 33

Menes, King, 214

Merostomata. See Sea-scorpions, King-crabs

Mesohippus, $\mathbf{I}_{43}$

Mesonyx, I28

Mesopithecus, 172

Metamynodon, $\mathrm{I}_{42}$

Metriorhynchus, 94 , I0I

Microlestes, 80

Millepedes, 47, 52

Miocene Period, 154

Miolitic limestone, $\mathrm{I}_{3} 8$

Mitre-shells, 137

Moa, 207

Mœritherium, I 24

Moles, 97, $\mathbf{I}_{48}$

Molluscoida. See Brachiopods, 'Polyzoans

Molluscs, 14

(See also Cephalopods, Chitons, Gastropods, Pelecypods, Pteropods, Scaphopods, and various names.)

Mongolian races, 208, 209

Monkeys. See Apes

Monotremes, 3, 80

Morality, progress of, $8 \mathrm{I}$

Morula stage, ro

Mosasaurs, I0I

Mosquitoes, 89

Moths, II $4, I_{52}$

Muntjacs. See Deer

Musk-oxen, 189, 194

Mussels, 18, 32, 44, 55, 73, I 37

- River, 44

Mustelidæ. See Badger, Marten Glutton, Polecat, Weasel

Mutations, 4

Mylodon, 185, 204

Myriapods, 47, 52 
$\mathrm{N}$

Natural Selection, 5

Nautiloids-

Cambrian, 18

Ordovician, 25

Silurian, 33

Devonian, 43

Carboniferous, 56

Permian, 66

Triassic, 74

Jurassic, 86

Nautilus-

Carboniferous, 56

Permian, 66

Triassic, 74

Jurassic, 86

Cretaceous, 108

Eocene, 137

Neander human remains, 195

Nebalia, 5, 19

Nebular Hypothesis, 7

Necrolemur, 149

Negroids, 208, 209

Neolithic. See Implements

Nesodon, 163

Newts, 58

Nilgai, 178

Nummulites, 138, 140

Nuthatches, 132

\section{$\mathrm{O}$}

Oaks, II 3

Oceans, formation of, 7

Ocelots, 206

Octopus, 108

Odontopteryx, I3I

Okapi, 170

Olenellus, 19

Oligocene Period, $\mathrm{I}_{40}$

Olive-shells, 137

Onchus, 36

Ophidia. See Snakes, Cobra, Python, Rattle-snake

Ophiuroids. See Brittle-stars

Opossum, 97, II9, 140, 165, I85

Opossum-rat, 165

Orang, 179, 215

Ordovician Period, 2 r

Oreopithecus, 155
Orohippus, I 21

Orthoceras annulatum, 33

Osprey, I32

Ostracoderms, 35, 38

Ostracods-

Cambrian, 19

Ordovician, 26

Silurian, 35

Devonian, 43

Ostriches, 179

Otters, $147,1_{5} 6$

Oudenodon, 63

Ovibos. See Musk-oxen

Owls, I $32, I_{5}$ I

Oxen, 178,183

- domesticated, 212, 213

Oysters-

Devonian, 44

Carboniferous, 55

Triassic, 73

Jurassic, 84

Cretaceous, 108

Edible, 55, 85

Pearl, 32, 55, 66, 85

Saddle, 44

Thorny, 73, 84

Palæohatteria, 62

Palæolithic. See Implements

Palæomastodon, 125

Palæostraca. See King-crabs Seascorpions, Trilobites

Palæotheres, 122, I40, 157

Palms, II4

Panama, Isthmus of, I8I

Paradoxides, 19

Pareiasaurus, 62, 77

Parrots, 151

Partridges, I32, I 5 I

Patriofelis, 128

Pearl-oysters. See Oysters

Peccaries, I43, I59, 180

Pelecypods-

Cambrian, I 8

Ordovician, 24

Silurian, 32

Devonian, 44

Carboniferous, 55

Permian, 66

Triassic, 72

Jurassic, 84 
Pelecypods (cont.) Cretaceous, 108 Eocene, 137 Miocene, I68 (See also under various names.)

Pelicans, 150

Pelycosaurians, 63, 77

Penguins, I 32

Pentamerus, 32

Perch, freshwater, 168

- sea, 106

Periechocrinus, 29

Periwinkles, 18

Permian Period, 6I

Phacops, 34

Phalangers, 187, 207

Phanerogams, 3

(See also under various plantMinames.)

Pheasants, I 5 I

Phenacodus, 2, 120, I40

Phyllopods, I9

Pigeons, I 5 I

Pigs. See Swine

Pike, 168

- bony, 88

Pineapple plants, 154

Pinks, I 54

Pithecanthropus, I87

Placentals, II 7

Plantain-eaters, 166

Plants. See Vegetation

Platystrophia, 23

Pleistocene Period, I 89

Plesiosaurians-

Triassic, 78

Jurassic, 94

Cretaceous, 103

Ancestry, 78

Pleuracanthus, 57, 76

Pliocene Period-

Earlier Epoch, 169

Later Epoch, 182

Pliopithecus, 155

Pliosaurus, 95

Plovers, I 5 I, I66

Plum trees, I 54

Pod-shrimps, I9, 26, 42, 56

Poëbrotherium, I45

Polacanthus, 98

Polecats, 156

Polypterus, 105
Polyzoans-

Ordovician, 25

Silurian, 32

Devonian, 44

Carboniferous, 55

Permian, 66

Triassic, 72

Jurassic, 84

Cretaceous, 109

Eocene, I 38

Poplars, II 3

Poppies, 154

Porcupines, 148, I55

Porifera. See Sponges

Portheus, I05

Pottery, 212, 213

Prawns, 75, 86, 106

Praying insects, 152

Present Period, 2 II

Primates-

Eocene, I I9, I26

Oligocene, 149

Miocene, I54, 164

Pliocene, I 72, I79, I84, I87

(See also Apes, Lemurs.)

Procamelus, 158

Procyonidæ. See Raccoons

Productus, 54, 66

Propliopithecus, 127

Proterotherium, I63, I86

Protoceras, 144

Protohippus, 159

Protospongia, 16, 21

Protozoans-8

Cambrian, 16

Cretaceous, Iro

Eocene, 138

(See also Foraminifers, Nummulites, Radiolarians.)

Ptarmigan, 200

Pteranodon, 104

Pterichthys, 38

Pteropods, 18,24

Pterosaurs, 95, 104

- wings of, 95

Puma, 206

Pycnodonts, 136

Pyrenees, 138

Pyrotherium, 164, 186

Python, 135 
Q

Quagga, 215

Quail, I32

\section{$\mathbf{R}$}

Rabbits, ${ }^{4} 8$

Raccoons, I5?

Radiolarians, I6, I 10

Rails, II2, I3I

Rats, 148

Rattle-snakes, 167

Ray-finned ganoids. See Actinopterygian

Rays, 57,87

- Eagle, ro5, r36

- Electric, 136

Razor-shells, 44

Redshanks, I 5 I

Reindeer, 194, 199

Reptiles, 6I (See also under various names: Crocodiles, Dinosaurs, etc.)

Rhinoceroses-

Eocene, I2I

Oligocene, I42

Miocene, 157

Pliocene, Earlier, I7I, I76, I8o

- Later, 182

Pleistocene, I9I, I93

Present, 2I4

Woolly, I9I, 197, 200, 210

(See also Hyracodon, Metamynodon, Elasmotherium.)

Rodents, 97

Eocene, 123

Oligocene, $\mathbf{I}_{4} 8$

Miocene, I 55

Horned, I56, 180

(See also Beavers, Hares, Squirrels, etc.)

Ruminants-

Eocene, 128

Oligocene, I44

Miocene, 157

(See also Camels, Deer, Oxen, etc.)

S

" Sabre-tooths." See Machærodonts

Salamanders, 58,167
Salmon-shaped fishes, 88

Samotherium, I70

Sandgrouse, I5I

Sandhoppers. See Amphipods

Sarcophiles, 207

Sassafras, II 3

Saw-fishes, ro4

Saw-flies, 152

Scallops, 32, 55

Scaphopods, 24, 33

Scelidosaurus, 9I

Scelidotherium, 185

Scorpions, $35,5^{2}$

Sea-anemones, 12

Sea-bream, ro6

Sea-cows. See Sirenians

Sea-cucumbers. See Holothurians

Sea-fans, 2I, IIo

Sea-firs, 17

Sea-lilies.- See Crinoids

Seals, I66

Sea-perch, 106

Sea-scorpions (Eurypterids)-

Cambrian, I9

Ordovician, 26

Silurian, 34

Devonian, 42

Carboniferous, 56

Permian, 67

Sea-urchins-

Ordovician, 23

Silurian, 3I

Devonian, 45

Carboniferous, 54

Permian, 66

Triassic, 72

Jurassic, 83

Cretaceous, rog

Eocene, 138

Seaweeds, I5, 2 I

Seeds, 48

Selachii. See Sharks, Rays

Semnopithecus, I 72

Sequoia firs, 68, 70, II 2

Serpulites, 3 I

Sertularians, I7

Sewing, 200

Sharks-

Silurian, 36

Devonian, 39

Carboniferous, 57

Permian, 65 
Sharks (cont.)-

Triassic, 75

Jurassic, 87

Cretaceous, 104

Eocene, I35

Miocene, 167

Angel, 87

Blue, I35

Comb-toothed, 87

Cow, 39

Hammer-headed, 167

Porbeagle, 104

Port Jackson, 36, 57, 87

Thresher, 167

Shearwaters, 150

Sheep, I 58 , 189

Shell-mounds, Danish, 2 II

Ship-worms, 85

Shrews, II 8, I49

Shrikes, I5I

Shrimps-

Cambrian, 19

Ordovician, 26

Devonian, 42

Carboniferous, 56

Triassic, 75

Jurassic, 86

Cretaceous, 106

Siberia, 190, 194, 197

Sigillaria, 50, 67, 70, 89

Silures, 213

Silurian Period, 28

Sirenians, 130, I50

Sivatherium, 177

Siwalik formation, $\mathbf{1 7 3}$

Skates. See Rays

Sloths, Ground-

Miocene, I6I

Pliocene, 185

Pleistocene, 204

Ancestry, I62

Snails. See Gastropods, Pteropods

- Land, 44, 52

Snake-flies, 52

Snakes, 135, 167

Sparassodonts, 164

Speech, 190, 198

Sphærexochus, 34

Sphenodon, 62

Sphenophyllum, 27, 47, 50, 70

Spiders, 52, 152

Spinning, 212
Spirifer, 32, 45, 55, 66, 84

Spitzbergen, 89, I54

Sponges-

Cambrian, 16

Ordovician, 21

Silurian, 28

Devonian, 47

Carboniferous, 52

Permian, 66

Triassic, 7 I

Jurassic, 82

Cretaceous, I ro

Calcareous, $47,7 \mathrm{I}$

Spores, $7,4^{8}$

Sprats, 88

Spring-tails, 52

Spruces, 68, 70, 189

Spy human remains, 198

Squalodon, 150, 165

Squids, 86

Squirrels, 124, 148

Starfishes-

Cambrian, 17

Ordovician, 23

Silurian, 30

Devonian, 46

Carboniferous, 54

Permian, 66

Jurassic, 83

Starlings, 132

Staurocephalus, 34

Stegocephs, 58, 6I, 76

- ancestry, 59

Stegodons, 175

Stegosaurus, 91, 98

Stick-insects, 52

Stilts, I 5 I

Storks, I12, 131, x66

Streptelasma, 2 I

Sturgeon, 88, 105, 136

Sun-stars, 83

Survival of the Fittest, 5

Swifts, 132

Swine-

Eocene, 125

Oligocene, 143

Miocene, 159

Pliocene, Earlier, I72, I76

- Later, 183

Syndyoceras, 157

Synxiphosura. See King-crabs

Systemodon, I2I 


\section{$\mathrm{T}$}

Tapirs, I2r, I70

Tarpon family, ro6

Tasmania, aborigines of, 208

Teleosaurs, 93

Teleosteans, 88, 105, I 36

Tellens, 85

Tench, I68

Terataspis, 42

Termites, 89

Terrapins, 166

Tetrabelodon, I6o, I7I, I74, I80, 182

Thelodus, $36,3^{8}$,

Theridonts, 63,80

Theromorphs, 62

Thrips, 152

Thrushes, I5I

Thylacine, 207

Thylacoleo, 187, 207

Tigers, 173

- Sabre-toothed. See Machærodonts

Tillodonts, 123

Tinoceras. See Dinoceras

Titanotheres, I2I, I4I

Toads, I40

Tortoises-

Permian, 64

Triassic, 79

Jurassic, 94

Cretaceous, I02

Eocene, I34

Miocene, I66

Pliocene, Earlier, 180

Toxodonts, I62, I85, 204

Tremataspis, 36

Triassic Period, 70

Triceratops, 99, II6

Trilobites, I4

Cambrian, 19

Ordovician, 25

Silurian, 34

Devonian, 42

Carboniferous, 56

Permian, 67

Trinucleus, 26

Trogons, I5I

Tuatera. See Sphenodon

Turkeys, I5I I66

Turtles, 94, 102, I35, I66

R
Turtles (cont.) -

Edible, 102

Leathery, I 35

Loggerhead, I02

Tortoiseshell, 166

Typotheres, $163,186,205$

U

Uintatherium. See Dinoceras

Univalves. See Gastropods

Ursidæ. See Bears

\section{V}

Variations, 4

Vegetation, 8, I5

Cambrian, 20

Ordovician, 21, 27

Silurian, 28

Devonian, 47

Carboniferous, 50

Permian, 67

Triassic, 70

Jurassic, 88

Cretaceous, II 2

Eocene, I32

Oligocene, 152

Miocene, I 54

(See also various names.)

Venus-shells, 85

Viverridæ. See Civets

Volvox, 3

Vultures, Secretary, I 5 I

W

Walchia, 68

Warblers, I32

Wart-hog, I 76

Wasps, ${ }^{5} 5$

Waterbuck, 178

Weasels, I47

Whales-

Eocene, I 30

Oligocene, 149

Miocene, 165

Bottle-nose, 165

Hump-back, 165 
Whales (cont.) -

Sperm, 165

Whalebone, 165

White, 165

Zeuglodont, I3I, I49, I65

Whelks, 85,137

Wild boar, 183

Willows, 113

Wingshells, 24, 32, 55

Wolverines, I89, I94

Wolves, I27, I46, I56, I73, I83, I89

- pouched, 207

Wombats, 186, 206

Woodpeckers, I32, I 5 I

Worms, I3, I8, 23, 3I
$\mathrm{X}$

Xiphodonts, 129, 144

Y

Yellow races. See Mongolian

Yews, 68, 70

\section{Z}

Zafrentis, 28

Zamia, 7I

Zebra, 182, I89, 193, 215

Zeuglodonts, I3I, I49, I65 

STAMPED BELOW. 
UC SOUTHERN REGIONAL LIBRARY FACUUTY

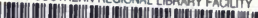

A 0009775123 
